GIUSEPPE PINTAÚDE

\title{
Análise dos Regimes Moderado e Severo de Desgaste Abrasivo utilizando Ensaios Instrumentados de Dureza
}

Tese apresentada à

Escola Politécnica da Universidade de São Paulo para obtenção do título de Doutor em Engenharia

São Paulo

2002 


\section{GIUSEPPE PINTAÚDE}

\section{Análise dos Regimes Moderado e Severo de Desgaste Abrasivo utilizando Ensaios Instrumentados de Dureza}

Tese apresentada à Escola Politécnica da Universidade de São Paulo para obtenção do título de Doutor em Engenharia

Área de Concentração: Engenharia Mecânica

Orientador: Amilton Sinatora

São Paulo

2002 


\section{AGRADECIMENTOS}

À FAPESP, pelo financiamento deste trabalho por meio dos seguintes projetos: 97/12621-5 (Bolsa de doutorado), 00/10115-0 (Auxílio à pesquisa) e 00/03372-6 (Auxílio à pesquisa);

Ao orientador Amilton Sinatora, pela confiança incondicional neste trabalho;

Aos professores Deniol Tanaka e Roberto Martins, pela amizade;

À Divisão de Metalurgia do IPT, na figura do Dr. Eduardo Albertin, pelo apoio experimental e pelo fôlego incansável para as discussões;

Ao Departamento de Metalurgia e de Materiais da EPUSP, na figura do Dr. André Tschiptschin, pela ajuda e disponibilização do uso do microscópio eletrônico de varredura e pelas contribuições para a discussão;

Aos colegas Leonardo Villabón e Bertrand Petitfrere, pela mão na massa;

Ao colega Adonias Franco, pela disponibilização e execução da rotina de cálculo para o módulo elástico;

A Mahle Metal Leve, na figura do Dr. Eduardo Tomanik, pela disponibilização para a execução dos ensaios de rugosidade;

Ao Laboratório de Tribologia e Materiais da UFU, na figura do Dr. José Daniel de Mello, pela ajuda e disponibilização para a execução dos ensaios de interferometria laser;

A Saint-Gobain Abrasivos, na figura do Luis Marcelo Cattini, pela ajuda na caracterização das lixas abrasivas;

Aos colegas do Laboratório de Fenômenos de Superfície, pelo companheirismo durante este período;

Às pessoas com as quais desenvolvi trabalhos conjuntos ao longo deste período: Márcia Daronch, Vanderlei Ferreira, Nilson Cruz, Elidiane Rangel, Lena Adachi, Júnia Cristina Baptista e; 
Para o Luigi que, além de filho, tem carisma. 
Ouça-me bem amor

Preste atenção, o mundo é um moinho Vai triturar teus sonhos tão mesquinhos Vai reduzir as ilusões à pó 


\section{FICHA CATALOGRÁFICA}

(C) Reprodução autorizada pelo autor desde que citada a fonte

\section{Pintaúde, Giuseppe}

Análise dos regimes moderado e severo de desgaste abrasivo utilizando ensaios instrumentados de dureza. São Paulo, 2002.

$200 \mathrm{p}$.

Tese (Doutorado) - Escola Politécnica da Universidade de São Paulo. Departamento de Engenharia Mecânica.

1. Tribologia 2. Desgaste de materiais 3. Dureza de materiais I. Universidade de São Paulo. Escola Politécnica. Departamento de Engenharia Mecânica II.t 


\section{SUMÁRIO}

Tópico

Página

\section{INTRODUÇÃO}

2 REVISÃO DA LITERATURA

2.1 DEFINIÇÃO, CLASSIFICAÇÃO E MECANISMOS DE DESGASTE ABRASIVO

2.2 DUREZA DOS MATERIAIS

2.2.1 Introdução

2.2.2 O conceito de zona plástica

2.2.3 Modelos e comportamento dos materiais sob aplicação de força em ensaios de dureza Vickers

2.2.4 Recuperação elástica dos materiais

2.3 RELAÇÃO ENTRE DESGASTE ABRASIVO E DUREZA

2.3.1 Modelo rígido-plástico (clássico)

2.3.2 Modelo elasto-plástico

2.4 CONCLUSÕES DA REVISÃO BIBLIOGRÁFICA

3 OBJETIVOS DA TESE

4 MATERIAIS E MÉTODOS

4.1 MATERIAIS

4.2 MÉTODOS

4.2.1 Caracterização dos materiais metálicos

4.2.2 Ensaios de desgaste abrasivo

4.2.3 Análise das superfícies desgastadas por rugosidade

4.2.4 Microscopia das superfícies desgastadas

4.2.5 Ensaios instrumentados de dureza 
5.1 CARACTERIZAÇÃO DOS MATERIAIS

5.1.1 Aço AISI 1006

92

5.1.2 Aço AISI 52100

92

5.1.3 Ferro fundido branco de alto cromo 95

5.1.4 Resumo da caracterização dos materiais $\quad 97$

5.2 ENSAIOS DE DESGASTE ABRASIVO 98

5.2.1 Taxas de desgaste $\quad 98$

5.2.1.1 Evolução das taxas de desgaste com o tempo de ensaio 98

5.2.1.2 Valores médios de taxas de desgaste - Efeito de microestrutura $\quad 102$

5.2.1.3 Valores médios das taxas de desgaste dos aços AISI 1006 e AISI 52100

5.2.1.4 Análise dos mecanismos de desgaste dos aços AISI 1006 e AISI 52100

5.2.2 Coeficiente de atrito

5.2.2.1 Evolução do coeficiente de atrito com o tempo de ensaio

5.2.2.2 Valores médios de coeficiente de atrito

5.2.2.3 Comportamento dos materiais quanto ao coeficiente de atrito

5.3 RUGOSIDADE DAS SUPERFÍCIES DESGASTADAS

5.4.1 Força de penetração

5.4.2 Propriedades mecânicas dos materiais metálicos

5.4.2.1 Fator $\alpha$ (morfologia de impressão de dureza) e dureza

5.4.2.2 Rigidez de contato e módulo elástico reduzido

5.4.3 Propriedades mecânicas do abrasivo (vidro)

5.4.4 Implicação dos resultados de dureza na análise dos regimes de desgaste abrasivo 
5.4.4.2 Ensaios com lixa de vidro grana \#240

6 CONCLUSÕES

7 SUGESTÕES PARA TRABALHOS FUTUROS

ANEXO A - Caracterização das lixas abrasivas

ANEXO B - Resultados individuais de perda de massa

ANEXO C - Curvas dos valores médios de coeficiente de atrito 


\section{LISTA DE TABELAS}

Tabela

Página

Tabela 1.1 - Taxas de desgaste $\left[\mathrm{mg} / \mathrm{h} . \mathrm{mm}^{2}\right]$ de revestimento depositado por aspersão térmica e de ferro fundido branco eutético em ensaio de abrasão a três corpos (BOZZI e colaboradores, 1998).

Tabela 2.1 - Variação do tamanho médio de grão dos abrasivos após ensaios de desgaste a três corpos de revestimentos WC-12\%Co (BOZZI; DE MELLO, 1999).

Tabela 2.2 - Variação da dureza da matriz do ferro fundido branco 3,33C-16Cr em ensaios de britador de mandíbulas (SARE; ARNOLD, 1989).

Tabela 2.3 - Valores de dureza Vickers convencional $\left(\mathrm{HV}_{0,1}\right)$ e razões entre $\mathrm{HV}_{0,1}$ e a dureza sob carregamento (HM $)$ (FRÖLICH e colaboradores, 1977). C1,C2 e C3: materiais cerâmicos.

Tabela 2.4 - Valores de dureza Vickers convencional $\left(\mathrm{HV}_{0,1}\right)$ e razões entre $\mathrm{HV}_{0,1}$ e a dureza Martens (HM) (FRÖLICH e colaboradores, 1977).

C1, C2 e C3: materiais cerâmicos.

Tabela 2.5 - Definição de parâmetro para a previsão da ocorrência das morfologias de impressão de dureza, segundo ZENG e colaboradores (1996), GIANNAKOPOULOS; SURESH (1999) e ALCALÁ e colaboradores (2000).

Tabela 2.6 - Parâmetros propostos por FINKIN (1974) como indicativos de resistência ao desgaste abrasivo e seus significados físicos.

Tabela 4.1 - Composição química dos materiais estudados.

Tabela 4.2 - Tratamentos térmicos empregados aos corpos-de-prova.

Tabela 4.3 - Resumo das operações envolvidas para execução dos ensaios de desgaste e aquisição do sinal de força de atrito.

Tabela 5.1 - Dureza de engenharia [MPa] do aço AISI 52100 em diferentes condições metalúrgicas.

Tabela 5.2 - Dureza de engenharia [MPa] de aço AISI 52100 de peças industriais.

Tabela 5.3 - Análise quantitativa do ferro fundido branco de alto cromo bruto de fundição.

Tabela 5.4 - Dureza Martens HM [MPa] do aço AISI 52100 trefilado e das fases constituintes do ferro fundido branco de alto cromo.

Tabela 5.5 - Taxas de desgaste $[\mathrm{mg} / \mathrm{m}$ ] do aço AISI 52100 trefilado e do ferro fundido branco de alto cromo. Abrasivos: vidro grana \#80 e alumina grana \#220. 
Tabela 5.6 - Fatores de desgaste $\left(\times 10^{-6}\right.$ ) de aço matriz e ferro fundido branco eutético, ambos martensíticos, em ensaios pino contra lixa. Abrasivos: $\mathrm{SiC}$ grana \#80 e alumina grana \#400

(ALBERTIN; SINATORA, 2001).

Tabela 5.7 - Taxas de desgaste [mg/m] do aço AISI 52100 nas condições bruto de têmpera, com e sem tratamento sub-zero. Abrasivo: alumina grana \#220.

Tabela 5.8 - Fatores de desgaste de ferro fundido branco com $30 \%$ de carbonetos $\mathrm{M}_{7} \mathrm{C}_{3}$ em ensaios pino contra lixa, utilizando 9,8 N. Abrasivo: alumina grana \#400 (ALBERTIN; SINATORA, 2001).

Tabela 5.9 - Taxas de desgaste [mg/m] do aço AISI 52100 na condição bruto de têmpera com tratamento sub-zero e do ferro fundido branco de alto cromo. Abrasivo: alumina grana \#220.

Tabela 5.10 - Taxas de desgaste [mg/m] dos aços AISI 1006 e AISI 52100. Abrasivo: vidro.

Tabela 5.11 - Resistência ao desgaste relativa e dureza de engenharia do aço AISI 52100 [MPa]. Abrasivo: vidro.

Tabela 5.12 - Valores médios de coeficiente de atrito. Abrasivo: vidro.

Tabela 5.13 - Variação na dureza Vickers [MPa] de aços martensíticos após ensaios de desgaste empregando técnicas de determinação diferentes.

Tabela 5.14 - Dureza $\mathrm{H}_{\mathrm{IT}}$ ("indentation hardness") [MPa] dos aços AISI 1006 e AISI 52100 bruto de têmpera, após diferentes etapas de ensaio de desgaste.

Tabela 5.15 - Dureza $\mathrm{H}_{\mathrm{IT}}$ dos aços [MPa] AISI 1006 e AISI 52100 bruto de têmpera, após ensaio com lixa de vidro grana \#80 e dureza Vickers HV [MPa] de materiais de classes equivalentes, após ensaio de trepanação (RICHARDSON, 1967).

Tabela 5.16 - Valores em micrometros dos parâmetros de rugosidade Ra, Rz e Sm das superfícies desgastadas.

Tabela 5.17 - Valores de profundidade máxima $[\mu \mathrm{m}]$ de compósito cobre-prata (MOORE, 1980).

Tabela 5.18 - Força de penetração $\mathrm{F}_{\text {máx }}[\mathrm{N}]$, profundidades máxima de penetração $\mathrm{h}_{\max }[\mu \mathrm{m}]$ e $\mathrm{Rz}[\mu \mathrm{m}]$ das condições de ensaio de desgaste nas quais se observaram perdas de massa.

Tabela 5.19 - Dureza Martens HM [MPa] dos materiais estudados, sob as condições nas quais se observou perda de massa. 
Tabela 5.20 - Fator $\alpha$ e razão $h_{P} / h_{\text {máx }}$ dos materiais estudados, sob as condições nas quais se observou perda de massa.

Tabela 5.21 - Dureza Vickers convencional HV [MPa] e dureza verdadeira $\mathrm{H}_{\mathrm{IP}}$ [MPa] dos materiais estudados, sob as condições nas quais se observou perda de massa.

Tabela 5.22 - Rigidez de contato $\mathrm{S}$ [MN/m] e módulo elástico reduzido $\mathrm{E}_{\mathrm{r}}$ [GPa] dos materiais estudados, sob as condições nas quais se observou perda de massa.

Tabela 5.23 - Dureza Martens [MPa], dureza sob carregamento [MPa], dureza Vickers convencional [MPa], "indentation hardness" [MPa], dureza verdadeira $[\mathrm{MPa}]$, fator $\alpha$ e módulo elástico reduzido [GPa] obtidos para o vidro.

Tabela 5.24 - Razões entre a dureza do abrasivo (vidro, $\mathrm{H}_{\mathrm{A}}$ ) e a dureza do material ensaiado (H, aço AISI 52100 temperado e revenido $\left.500^{\circ} \mathrm{C} / 90 \mathrm{~min}\right)$, considerando as durezas: Martens $(\mathrm{HM})$, sob carregamento $\left(\mathrm{HM}_{\mathrm{S}}\right)$, Vickers convencional $(\mathrm{HV})$, "indentation hardness" ( $\left.\mathrm{H}_{\mathrm{IT}}\right)$ e verdadeira $\left(\mathrm{H}_{\mathrm{IP}}\right)$.

Tabela 5.25 - Módulo elástico reduzido de desgaste $\left(\mathrm{E}_{\mathrm{rd}}\right)$ [GPa] para a condição de ensaio relativa à lixa grana \#80.

Tabela 5.26 - Razões entre a dureza do abrasivo (vidro, $\mathrm{H}_{\mathrm{A}}$ ) e a dureza do material ensaiado (H, aço AISI 52100 temperado e revenido $500^{\circ} \mathrm{C} / 24 \mathrm{~h}$ ), considerando as durezas Vickers convencional $(\mathrm{HV})$ e verdadeira $\left(\mathrm{H}_{\mathrm{IP}}\right)$.

Tabela A.1 - Aplicação dos critérios da Norma NBR 11094 (ABNT, 1990) à lixa abrasiva de vidro grana \#80.

Tabela A.2 - Exemplos de composição química usuais de vidros comerciais (VAN VLACK, 1973).

Tabela B.1 - Valores de perda de massa individuais [mg] para o aço AISI 1006, em ensaios utilizando vidro como material abrasivo.

Tabela B.2 - Valores de perda de massa individuais [mg] para o aço AISI 52100 recozido, em ensaios utilizando vidro como material abrasivo.

Tabela B.3 - Valores de perda de massa individuais [mg] para o aço AISI 52100 trefilado, em ensaios utilizando vidro como material abrasivo.

Tabela B.4 - Valores de perda de massa individuais [mg] para o aço AISI 52100 trefilado, em ensaios utilizando alumina como material abrasivo.

Tabela B.5 - Valores de perda de massa individuais [mg] para o aço AISI 52100 temperado e revenido $500{ }^{\circ} \mathrm{C} / 24 \mathrm{~h}$, em ensaios utilizando vidro como material abrasivo. 
Tabela B.6 - Valores de perda de massa individuais [mg] para o aço AISI 52100 temperado e revenido $500{ }^{\circ} \mathrm{C} / 90 \mathrm{~min}$, em ensaios utilizando vidro como material abrasivo.

Tabela B.7 - Valores de perda de massa individuais [mg] para o ferro fundido branco de alto cromo, em ensaios utilizando vidro como material abrasivo.

Tabela B.8 - Valores de perda de massa individuais [mg] para o ferro fundido branco de alto cromo, em ensaios utilizando alumina como material abrasivo.

Tabela B.9 - Valores de perda de massa individuais [mg] para o aço AISI 52100 bruto de têmpera, em ensaios utilizando alumina como material abrasivo.

Tabela B.10 - Valores de perda de massa individuais [mg] para o aço AISI 52100 bruto de têmpera seguido de tratamento sub-zero, em ensaios utilizando alumina como material abrasivo. 


\section{LISTA DE FIGURAS}

Figura

Página

Figura 1.1. Relação entre número de Mohs e dureza Vickers [kgf $\left./ \mathrm{mm}^{2}\right]$ (TABOR, 1956).

Figura 1.2. Relação esquemática entre taxa de desgaste e razão entre dureza do abrasivo $\left(\mathrm{H}_{\mathrm{A}}\right)$ e dureza do material desgastado (H) (KRUSCHOV, 1957). $\mathrm{K}_{1}$ : ponto que delimita o início da região de transição; $\mathrm{K}_{2}$ : ponto que delimita o final da região de transição.

Figura 1.3. Variação do volume desgastado $\left[\mathrm{mm}^{3}\right]$ com a razão $\mathrm{H}_{\mathrm{A}} / \mathrm{H}$ em função das durezas do corpo e do contra-corpo (XUAN e colaboradores, 1989).

Figura 1.4. Variação da razão entre a dureza de matrizes metálicas de compósitos e da sílica $\left(\mathrm{H}_{\mathrm{MM}} / \mathrm{H}_{\mathrm{flint}}\right)$ em função da temperatura $\left({ }^{\circ} \mathrm{C}\right)$. HSS: aço rápido. (BERNS; FRANCO, 1997).

Figura 1.5. Variação do fator de desgaste de bolas de aço AISI 1090 forjadas em função da razão $\mathrm{H}_{\mathrm{A}} / \mathrm{H}$, após moagem de minérios de cobre e de ferro (MOROZ, 1982).

Figura 2.1. Variação das taxas de desgaste $\left[\mathrm{mm}^{3} / \mathrm{m} \times 10^{-2}\right]$ de aço AISI 1020 em função da força aplicada [kgf] e da configuração do sistema. Abrasivo: SiC $250 \mu \mathrm{m}$ (MISRA; FINNIE, 1980).

Figura 2.2. (a) Formação de cavaco (A) de aço doce (B) pela ação de um grão abrasivo (C) (VAN VLACK, 1973). (b) Micrografia em microscopia eletrônica de varredura, mostrando o mecanismo de microcorte causado por penetrador de aço ferramenta em aço inoxidável AISI 304 (KAYABA e colaboradores, 1986).

Figura 2.3. Variáveis utilizadas para a definição do parâmetro Dp $(=\mathrm{h} / \mathrm{r})$ (HOKKIRIGAWA e colaboradores, 1987).

Figura 2.4. Variação dos micromecanismos de abrasão controlados por deformação plástica com os parâmetros Dp e $f$ (tensão de cisalhamento do contato/tensão de cisalhamento do material desgastado) (HOKKIRIGAWA e colaboradores, 1987).

Figura 2.5. Micrografia em microscopia eletrônica de varredura, mostrando o mecanismo de microssulcamento causado por penetrador de aço ferramenta em aço inoxidável AISI 304 (KAYABA e colaboradores, 1986). 
Figura 2.6. Micrografias em microscopia eletrônica de varredura, mostrando mecanismos de abrasão em aço ferramenta $(780 \pm 10 \mathrm{HV})$ em ensaios de micro-abrasão com $0,25 \mathrm{~N}$ : (A) microcorte, ensaio com diamante $3 \mu \mathrm{m}$ em concentração de $0,003 \mathrm{~g} / \mathrm{cm}^{3}$ e (B) microimpressões, ensaio com SiC $4 \mu \mathrm{m}$ em concentração de $1,0 \mathrm{~g} / \mathrm{cm}^{3}$ (TREZONA e colaboradores, 1999).

Figura 2.7. Micrografias em estereoscópio óptico, mostrando mecanismos de desgaste em mandíbulas de aço fundido temperado (770 $\left.\pm 30 \mathrm{HV}_{0,1}\right)$ : (A) microcorte, verificado nas mandíbulas fixas e (B) microimpressões, verificado nas mandíbulas móveis (PINTAÚDE; SINATORA, 1998).

Figura 2.8. Efeito da força aplicada no mecanismo de abrasão: (A) força $<\mathrm{p}_{\text {crit }}$

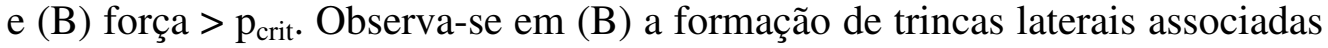
à deformação plástica (JACOBSSON e colaboradores, 1992).

Figura 2.9. Variação da resistência ao desgaste abrasivo com a tenacidade à fratura (ZUM GAHR, 1987).

Figura 2.10. Variação do comportamento mecânico de um material em contato com um penetrador esférico de raio $\mathrm{R}$, segundo modelo proposto por EVANS; WILSHAW (1976). Kc: valores de tenacidade à fratura, sendo $\mathrm{Kc}_{3}>\mathrm{Kc}_{2}>\mathrm{Kc}_{1}$.

Figura 2.11. Impressão de dureza Vickers em MnS (VAN VLACK, 1973). SL: linhas de escorregamento; C: trinca; GB: defeitos cristalinos.

Figura 2.12. Riscos em superfície de vidro (MARSH, 1964).

Figura 2.13. Deformação plástica de carbonetos $\mathrm{M}_{7} \mathrm{C}_{3}$ de ferros fundidos brancos de alto cromo com matriz predominantemente martensítica: (A) desgastado em ensaio de moagem (65 HRC) (ALBERTIN; SINATORA, 2001) e (B) desgastado em britador cônico industrial (63 HRC) (AVERY, 1974).

Figura 2.14. (a) Deformação plástica dos carbonetos causado pelo movimento das partículas abrasivas. (b) Zonas de tração (T) e compressão (C) em região contendo carbonetos sujeitos a esforços simultâneos de cisalhamento e de compressão. LN: linha neutra. (SARE; ARNOLD, 1989).

Figura 2.15. Microtrincamento subsuperficial de carbonetos $\mathrm{M}_{7} \mathrm{C}_{3}$ de ferros fundidos brancos de alto cromo com matriz predominantemente austenítica: (A) desgastado em ensaios em moinho de bolas (47 HRC) (ALBERTIN; SINATORA, 2001) e (B) desgastado em ensaios em britador de mandíbulas (52 HRC) (SARE; ARNOLD, 1989).

Figura 2.16. Variação da tenacidade à fratura de carbonetos $\mathrm{M}_{7} \mathrm{C}_{3}\left[\mathrm{MPa} \cdot \mathrm{m}^{1 / 2}\right.$ ] de ferro fundido branco de alto cromo com a dureza da matriz $\left(\mathrm{HV}_{0,05}\right)$ [kgf/mm²] (FRANCO; SINATORA, 1994). 
Figura 2.17. (A) Ilustração esquemática da sucessão de eventos que resultam no microtrincamento do carboneto $\mathrm{M}_{7} \mathrm{C}_{3}$ em ensaio de moagem. (B) Ferro fundido branco de alto cromo riscado por um grão de quartzo (ALBERTIN; SINATORA, 2001).

Figura 2.18. (A) Superfície inicial do revestimento WC-12\%Co $\left(1.200 \pm 200 \mathrm{HV}_{30}\right)$. (B) Revestimento desgastado por quartzo $190 \mu \mathrm{m} \mathrm{em}$ ensaio a três corpos com tensão nominal de 0,58 MPa. Notam-se microimpressões. (C) Mesmo material desgastado nas mesmas condições de ensaio por alumina $260 \mu \mathrm{m}$. Nota-se microssulcamento. (BOZZI; DE MELLO, 1999).

Figura 2.19. Variação da taxa de desgaste relativa em ensaios pino contra lixa com a razão $\mathrm{H}_{\mathrm{A}} / \mathrm{H}$ (MOORE; KING, 1980).

Figura 2.20. (A) Geometria e impressão Vickers. (B) Geometria e impressão Knoop (TABOR, 1956).

Figura 2.21. Diagrama de blocos que mostra as principais contribuições para a interpretação dos ensaios de dureza.

Figura 2.22. Curva esquemática de tensão-deformação de um material com comportamento rígido-plástico (MEYERS; CHAWLA, 1999). $\sigma$ : tensão verdadeira [MPa]; Y: limite de escoamento [MPa]; $\in$ : deformação $[\mathrm{mm} / \mathrm{mm}]$.

Figura 2.23. Curva esquemática de tensão-deformação de um material com comportamento elasto-plástico ideal (MEYERS, CHAWLA, 1999). E: módulo elástico [GPa].

Figura 2.24. (A) Indicação da zona plástica formada devido ao contato de um penetrador de dureza com a superfície ensaiada. $c$ : raio da zona plástica; $a$ : raio de ação do penetrador (BISHOP; HILL; MOTT, 1945). (B) Observação direta da zona plástica em ensaio de dureza com $250 \mathrm{~N}$ em vidro (LAWN; SWAIN, 1975).

Figura 2.25. Variação da razão H/Y em chumbo com o ângulo do penetrador cônico (HIRST; HOWSE, 1969).

Figura 2.26. Variação da área de contato em função da profundidade de contato para penetrador Vickers e cônico de $70,3^{\circ}$. Curvas de ajuste de pontos experimentais (CSM Instruments, 2002).

Figura 2.27. Variação da extensão da zona plástica, c/a, com a razão E/H, obtida para penetrador Vickers (LAWN e colaboradores, 1980). 
Figura 2.28. Curva de aplicação da força de ensaios instrumentados de dureza (ISO/FDIS 14577-1; ISO, 2002). $\mathrm{h}_{\text {máx }}$ : profundidade máxima de penetração $[\mu \mathrm{m}] ; \mathrm{F}_{\text {máx }}$ : força máxima $[\mathrm{N}] ; \mathrm{W}_{\mathrm{T}}$ : trabalho total realizado $[\mathrm{N} . \mathrm{m}]$.

Figura 2.29. Efeito da força aplicada na dureza Vickers $\left[\mathrm{kgf} / \mathrm{mm}^{2}\right]$, em ensaios conduzidos com e sem lubrificação. (A) Cobre encruado (B) Cobre recozido (LI e colaboradores, 1993).

Figura 2.30. Impressão de dureza Vickers com formação de bordas: (A) esquema da seção transversal e (B) esquema da vista superior. (C) Imagem tridimensional de superfície de cobre encruado após ensaio de dureza Vickers com 160 N (ALCALÁ e colaboradores, 2000).

Figura 2.31. Impressão de dureza Vickers com retração: (A) esquema da seção transversal e (B) esquema da vista superior. (C) Imagem tridimensional de superfície de cobre recozido após ensaio de dureza Vickers com $100 \mathrm{~N}$ (ALCALÁ e colaboradores, 2000).

Figura 2.32. Variação da área de contato com a profundidade de vidro durante a aplicação da força em ensaio de dureza Vickers com $40 \mathrm{~N}$ (COOK; PHARR, 1990).

Figura 2.33. Indicação da profundidade de contato, $\mathrm{h}_{\mathrm{C}}$, em relação à extensão da zona plástica, em um caso de retração (ISO/FDIS 14577-1; ISO, 2002).

Figura 2.34. Extensão da zona plástica em caso de formação de bordas, com indicação da profundidade de contato $\mathrm{h}_{\mathrm{C}}$ (CSM Instruments, 2002).

Figura 2.35. Indicação esquemática dos tipos de escoamento plástico em um ensaio de dureza, segundo STELMASHENKO e colaboradores (1993).

Figura 2.36. Indicação da recuperação elástica em ensaio de dureza. $\mathrm{h}_{\mathrm{e}}$ : recuperação elástica; $\mathrm{h}_{\mathrm{P}}$ : profundidade final; $\mathrm{h}_{\mathrm{S}}$ : profundidade defletida. (STILWELL; TABOR, 1961).

Figura 2.37. Variação da razão entre as diagonais de impressão Knoop com a razão $H_{K} / E$ (MARSHALL e colaboradores, 1982).

Figura 2.38. Indicação esquemática das profundidades de penetração em ensaio convencional. (WEILER, 1989). Curva 1: profundidade real após remoção da força; Curva 2: profundidade hipotética, proporcional à recuperação das diagonais; e Curva 3: profundidade sob aplicação da força.

Figura 2.39. Curva típica de ensaios instrumentados de dureza (ISO/FDIS 14577-1; ISO, 2002) com indicação da profundidade máxima de penetração $\left(h_{\text {máx }}\right)$, da profundidade final $\left(h_{P}\right)$ e da parcela de trabalho elástico We [N.m]. 
Figura 2.40. Curva típica de ensaios instrumentados de dureza (ISO/FDIS 14577-1; ISO, 2002), com indicação de $\mathrm{h}_{\mathrm{r}}$ (interseção com o eixo das abcissas) e da rigidez de contato $\mathrm{S}[\mathrm{N} / \mathrm{mm}]$.

Figura 2.41. Variação da resistência à abrasão $\mathrm{W}^{-1}(=1 / \mathrm{W})$ com a dureza [MPa] de metais puros e minerais da escala Mohs, em ensaios pino contra lixa (KRUSCHOV, 1957).

Figura 2.42. Variação da resistência à abrasão $\mathrm{W}^{-1}(=1 / \mathrm{W})$ com a dureza de aços tratados termicamente, em ensaios pino contra lixa (KRUSCHOV, 1957).

Figura 2.43. Variação da resistência à abrasão $\mathrm{W}^{-1}(=1 / \mathrm{W})$ com a dureza [kgf $\left./ \mathrm{mm}^{2}\right]$ de metais puros e do aço AISI 1020 recozido, em ensaios pino contra lixa (MISRA; FINNIE, 1981).

Figura 2.44. (A) Perfil típico de seção transversal em liga fundida de cobalto após ensaio de esclerometria Vickers com 19,6 N. h': profundidade relativa à formação de bordas laterais. (B) Ilustração das seções transversais de aço 0,99\% C temperado e revenido com diferentes durezas após os ensaios de esclerometria: A 263 HV, B 315 HV, C 441 HV, D 598 HV, E 710 HV, F 890 HV (BUTTERY; ARCHARD, 1970/71).

Figura 2.45. (A) Parâmetros necessários para definição da proporção de material removido (equação 2.28). (B) Variação do fator $\varphi$ com a dureza Vickers do aço 0,99\% C temperado e revenido (A - F) e de uma liga de cobalto fundida (Stellite) (BUTTERY; ARCHARD, 1970/71).

Figura 2.46. Gráfico esquemático mostrando os mecanismos de desgaste abrasivo associados com as variações características da resistência à abrasão $\mathrm{W}^{-1}(=1 / \mathrm{W})$ com a dureza H (MURRAY; MUTTON; WATSON, 1982).

Figura 2.47. Variação da profundidade da região deformada $[\mu \mathrm{m}]$ de cobre, ferro e aços com o parâmetro $(\mathrm{E} / \mathrm{Y})^{1 / 3}(\mathrm{~L} / \mathrm{H})^{1 / 2}[\mu \mathrm{m}]$, em ensaios pino contra lixa de SiC, granas \#60 e \#180 (MOORE, 1980).

Figura 3.1. Diagrama de bloco mostrando a seqüência de atividades realizadas para atingir os objetivos da Tese.

Figura 4.1. Fotografia das peças de ferro fundido branco em estado bruto de fundição, ilustrando a geometria dos modelos utilizados.

Figura 4.2. Curva de solidificação obtida após vazamento de amostra coquilhada.

Figura 4.3. Diagrama de bloco das atividades relativas aos tratamentos térmicos empregados para o aço AISI 52100. 
Figura 4.4. Exemplo da rotina de cálculos utilizada para obtenção dos parâmetros de rugosidade.

Figura 4.5. Indicação dos segmentos utilizados para o cálculo dos parâmetros de rugosidade.

Figura 5.1. Microestrutura do aço AISI 1006 (ferrita + inclusões).

Figura 5.2. Microestruturas do aço AISI 52100: (A) recozido (matriz ferrítica + carbonetos $\mathrm{M}_{3} \mathrm{C}$ ) e (B) bruto de têmpera (matriz martensítica + carbonetos $\left.\mathrm{M}_{3} \mathrm{C}\right)$.

Figura 5.3. Microestrutura bruta de fundição do ferro fundido branco de alto cromo: (A) seção "ponta" (matriz austenítica + perlita + carbonetos eutéticos $\mathrm{M}_{7} \mathrm{C}_{3}$ ) e (B) seção "meio" (matriz austenítica + perlita + carbonetos eutéticos $\mathrm{M}_{7} \mathrm{C}_{3}$ ).

Figura 5.4. Microestrutura após tratamento térmico a $700{ }^{\circ} \mathrm{C}$ por $8 \mathrm{~h}$ do ferro fundido branco de alto cromo (perlita + carbonetos eutéticos $\mathrm{M}_{7} \mathrm{C}_{3}$ ).

Figura 5.5. Evolução da perda de massa com o tempo de ensaio para o par aço AISI 52100 trefilado/lixa grana \#240.

Figura 5.6. Evolução da perda de massa com o tempo de ensaio para o par aço AISI 52100 temperado e revenido $500{ }^{\circ} \mathrm{C}$-24h/lixa grana \#80.

Figura 5.7. Evolução da perda de massa com o tempo de ensaio para aço AISI 1074 com $650 \mathrm{HV}$ ensaiado contra lixa de vidro grana \#30 (RICHARDSON, 1968).

Figura 5.8. Evolução da perda de massa com o tempo de ensaio de uma mandíbula fixa de britador de aço $1,5 \mathrm{Si}-2 \mathrm{Cr}-0,5 \mathrm{Mo}$ 101 (PINTAÚDE; SINATORA, 1998).

Figura 5.9. Superfície polida do aço AISI 52100 trefilado riscada manualmente com fragmento de vidro, observada em microscopia eletrônica de varredura. Nota-se a impressão de dureza Vickers.

Figura 5.10. Superfície polida de ferro fundido branco de alto cromo riscada manualmente com fragmento de vidro, observada em microscopia eletrônica de varredura.

Figura 5.11. Variação da resistência ao desgaste relativa (AISI $1006=1$ ) com a dureza de engenharia $[\mathrm{MPa}]$. 
Figura 5.12. Superfície desgastada de aço AISI 52100 temperado e revenido a $500{ }^{\circ} \mathrm{C}$ por $24 \mathrm{~h}$, observada em microscopia eletrônica de varredura, após ensaio com a lixa de vidro grana \#80: (A) microssulcamento e (B) vazio deixado por partícula abrasiva.

Figura 5.13. Superfície desgastada de aço AISI 52100 temperado e revenido a $500{ }^{\circ} \mathrm{C}$ por 90 min observada em microscopia eletrônica de varredura ensaiado com lixa grana $\# 80$.

Figura 5.14. Superfície desgastada de aço AISI 52100 temperado e revenido observada em microscopia eletrônica de varredura após 4,4 megaciclos em ensaio disco-contra-disco com pressão máxima de contato de 2,41 $\mathrm{GPa}$ (MEDEIROS, 2002).

Figura 5.15. Superfície desgastada de aço AISI 52100 temperado e revenido a $500{ }^{\circ} \mathrm{C}$ por $24 \mathrm{~h}$, observada em microscopia eletrônica de varredura, após ensaio com a lixa de vidro grana \#240: (A) microssulcamento e (B) vazio deixado por partícula abrasiva.

Figura 5.16. (A) Superfície desgastada de aço AISI 52100 temperado e revenido a $500{ }^{\circ} \mathrm{C}$ por $24 \mathrm{~h}$ observada em microscopia eletrônica de varredura ensaiado com lixa grana \#240. (B) Mesma superfície observada em microscopia óptica. Nota-se uma trinca ao lado de uma impressão de dureza.

Figura 5.17. Superfície desgastada de cobre 99,96\% de pureza, após ensaios de desgaste por deslizamento em dispositivo cilindro contra cilindro (JAHANMIR e colaboradores, 1974).

Figura 5.18. Variação da resistência ao desgaste relativa $(\mathrm{Fe}=1)$ com a dureza dos materiais. Abrasivo: vidro (RICHARDSON, 1968).

Figura 5.19. Evolução do coeficiente de atrito com o tempo de ensaio [s] para o aço AISI 1006.

Figura 5.20. Evolução do coeficiente de atrito com o tempo de ensaio [s] para o aço AISI 52100 bruto de têmpera.

Figura 5.21. Variação do coeficiente de atrito médio com a dureza de engenharia dos materiais [MPa].

Figura 5.22. Condição da superfície desgastada do aço AISI 1006, após nivelamento com lixa de alumina grana \#600, ilustrando as medidas de dureza.

Figura 5.23. (A) Impressões de dureza Vickers em aço carbono $\mathrm{Cr}-\mathrm{Si}$ temperado após ensaio em britador de mandíbulas (PINTAÚDE; SINATORA, 1998). (B) Impressões de dureza Vickers em Mo puro após ensaio pino contra lixa de SiC grana \#180 (RICHARDSON, 1967). 
Figura 5.24. Imagem em microscopia óptica da superfície desgastada do aço AISI 1006, após ensaios com a lixa de vidro grana \#80. Nota-se a intensa deformação plástica.

Figura 5.25. Relação entre razão $\mathrm{H}_{S} / \mathrm{H}_{0}$ (equação 5.1) e coeficiente de atrito para os ensaios com os aços AISI 1006 e AISI 52100 bruto de têmpera.

Figura 5.26. Imagem em microscopia óptica da superfície desgastada do aço AISI 52100 bruto de têmpera após ensaio com lixa de vidro grana \#80. Notase uma impressão de dureza com $0,25 \mathrm{~N}$.

Figura 5.27. Superfície da lixa de vidro grana \#240 observada em microscopia eletrônica de varredura, após ensaio com o aço AISI 1006.

Figura 5.28. Superfície da lixa de "waffers" de silício após desgastarem pinos de chumbo (GAHLIN; JACOBSON, 1999).

Figura 5.29. Superfície da lixa de vidro grana \#80 observada em microscopia eletrônica de varredura, após ensaio com o aço AISI 1006.

Figura 5.30. Superfície da lixa de vidro grana \#240 após ensaio com o aço AISI 52100 bruto de têmpera.

Figura 5.31. Variação do coeficiente de atrito com a razão w/r (largura do sulco/raio do abrasivo), segundo modelo de SIN e colaboradores (1979) para abrasivos cônicos com ponta esférica.

Figura 5.32. (A) Aparato experimental utilizado por TABOR (1954). (B) Variação da força tangencial [kgf] com três ângulos $\alpha$, utilizando ferramenta de dureza $940 \mathrm{kgf} / \mathrm{mm}^{2}$, força normal de $4,2 \mathrm{kgf}$ e ângulo $\beta$ de $75^{\circ}$.

Figura 5.33. Variação do parâmetro Sm dos aços AISI 1006 e AISI 52100 bruto de têmpera com as diferentes etapas de ensaio.

Figura 5.34. Definição de Rz. Legenda: $1_{\mathrm{m}}=$ segmento de cálculo (cut-off); $\mathrm{l}_{\mathrm{e}}=$ segmento de medida $\left(=\mathrm{l}_{\mathrm{m}} / 5\right) ; \mathrm{Zn}=$ valores unitários para cálculo de $\mathrm{Rz}$ e $\mathrm{R}_{\max }=$ máximo valor unitário de $\mathrm{Rz}$.

Figura 5.35. (a) Exemplo de perfil real de liga de cobalto (Stellite) após ensaio de esclerometria linear e (b) Esquema ilustrativo de referência para indicação da profundidade máxima $h_{\text {máx }}$ (BUTTERY; ARCHARD, 1970/71).

Figura 5.36. Frequiência observada nos valores de profundidade máxima de sulcos $[\mu \mathrm{m}]$ produzidos por lixa de SiC grana \#220 em aço baixo carbono (MULHEARN; SAMUELS, 1962). 
Figura 5.37. Variação da força de penetração [N] com a dureza Martens HM [MPa] dos aços AISI 1006, AISI 52100 recozido, AISI 52100 trefilado e AISI 52100 temperado e revenido a $500{ }^{\circ} \mathrm{C}$ por $24 \mathrm{~h}$, nas condições relativas aos ensaios com as lixas grana \#80 e \#240.

Figura 5.38. Variação da força de penetração [N] com a dureza Martens [MPa] dos materiais estudados na condição relativa ao ensaio com a lixa grana \#80.

Figura 5.39. (A) Imagem em microscopia eletrônica de varredura da superfície desgastada do ferro fundido branco de alto cromo após ensaio com lixa de vidro grana \#80. Nota-se uma grande incidência de incrustação de abrasivos na superfície desgastada. (B) Análise química por espectrometria de energia dispersiva (EDS) da região indicada com seta vermelha da imagem A.

Figura 5.40. Impressões de dureza com profundidade máxima de penetração de 3,0 $\mu \mathrm{m}$ em aço AISI 52100 trefilado: (A) e (B) imagens em microscopia óptica; (C) e (D) imagens em interferometria laser. Nota-se a formação de bordas.

Figura 5.41. Valores de dureza HM, HV e $\mathrm{H}_{\mathrm{IP}}$ [MPa] dos aços AISI 1006 e AISI 52100 e do ferro fundido branco de alto cromo (FFBAC), para a condição de ensaio relativa à lixa grana \#80.

Figura 5.42. Valores de dureza HM, HV e $\mathrm{H}_{\mathrm{IP}}$ [MPa] dos aços AISI 1006 e AISI 52100, para a condição de ensaio relativa à lixa grana \#240.

Figura 5.43. Aspecto dos grãos de vidro grana \#36 embutidos em resina a frio para ensaios de dureza.

Figura 5.44. Valores de dureza HM, HV e $\mathrm{H}_{\mathrm{IP}}[\mathrm{MPa}]$ do vidro.

Figura 5.45. Variação da razão $\mathrm{H}_{\mathrm{A}} / \mathrm{H}$, calculada segundo a dureza $\mathrm{H}_{\mathrm{IT}}$, com a força de ensaio de dureza (PINTAÚDE e colaboradores, 2001).

Figura 6.1. Quadro resumo das conclusões da Tese, considerando os regimes moderado e severo de desgaste abrasivo, segundo o modelo de KRUSCHOV (1957).

Figura A.1. \% do material passante acumulado em função do tamanho de grão da lixa grana \#80.

Figura A.2. Costado da lixa de grana \#80 utilizada nos ensaios de desgaste abrasivo, indicando grana segundo fabricante.

Figura A.3. Etiqueta de embalagem do importador da lixa GlassPaper Premium para lixa de grana \#80. 
Figura A.4. \% do material passante acumulado em função do tamanho de grão da lixa grana \#240.

Figura A.5. Costado da lixa de grana \#240 utilizada nos ensaios de desgaste abrasivo, indicando grana segundo fabricante.

Figura A.6. Etiqueta de embalagem do importador da lixa GlassPaper Premium para lixa de grana \#240.

Figura A.7. Análise do tamanho de grão do vidro de grana \#80 com relação a malhas de peneiras padronizadas.

Figura A.8. Espectro de EDS dos grãos de vidro.

Figura C.1. Evolução do coeficiente de atrito com o tempo de ensaio [s] para o aço AISI 52100 recozido.

Figura C.2. Evolução do coeficiente de atrito com o tempo de ensaio [s] para o aço AISI 52100 trefilado.

Figura C.3. Evolução do coeficiente de atrito com o tempo de ensaio [s] para o aço AISI 52100 temperado e revenido $500{ }^{\circ} \mathrm{C} / 24 \mathrm{~h}$.

Figura C.4. Evolução do coeficiente de atrito com o tempo de ensaio [s] para o aço AISI 52100 temperado e revenido $500^{\circ} \mathrm{C} / 90 \mathrm{~min}$.

Figura C.5. Evolução do coeficiente de atrito com o tempo de ensaio [s] para o ferro fundido branco de alto cromo. 


\section{LISTA DE SIGLAS E ABREVIATURAS}

ABNT: Associação Brasileira de Normas Técnicas

AISI: American Iron and Steel Institute

ASTM: American Society for Testing and Materials

C: trinca

CVD: Chemical Vapor Deposition

EDS: espectrometria de energia dispersiva (Energy-dispersive spectrometer)

FAPESP: Fundação de Apoio à Pesquisa do Estado de São Paulo

FDIS: Final Draft International Standard

FEPA: Federation of European Producers of Abrasives

FFBAC: ferro fundido branco de alto cromo

GB: defeitos cristalinos

GEPSI: Grupo de Estudos de Propriedades de Superfícies e Interfaces

HSS: aço rápido

IPT: Instituto de Pesquisas Tecnológicas do Estado de São Paulo S/A

ISO: International Organization for Standardization

LEM: método de extrapolação linear

LFS: Laboratório de Fenômenos de Superfície

LN: linha neutra

NBR: Norma Brasileira

PEAD: polietileno de alta densidade

PLM: método da lei potencial

PUC-RS: Pontifícia Universidade Católica do Estado do Rio Grande do Sul

PVD: Physical Vapor Deposition

SL: linhas de escorregamento

UFGM: Universidade Federal de Minas Gerais

UFPR: Universidade Federal do Paraná

UFU: Universidade Federal de Uberlândia

UNESP: Universidade Estadual Paulista

USP: Universidade de São Paulo 


\section{LISTA DE SÍMBOLOS}

$\alpha$ : parâmetro para a previsão da morfologia de impressão de dureza

$\beta$ : fator geométrico para cálculo do módulo reduzido $\mathrm{E}_{\mathrm{r}}$

$\varepsilon$ : fator geométrico para cálculo da profundidade de contato $\mathrm{h}_{\mathrm{C}}$

$\gamma$ : tensão superficial $\left[\mathrm{J} / \mathrm{m}^{2}\right]$

$\pi: 3,14$

$\rho:$ severidade da formação de bordas

v: coeficiente de Poisson

$v_{\mathrm{i}}$ : coeficiente de Poisson do penetrador de diamante

$\in:$ deformação $[\mathrm{mm} / \mathrm{mm}]$

$\varphi$ : proporção de material removido em um ensaio de desgaste abrasivo

$\theta$ : semi-ângulo de um cone

$\theta_{\mathrm{C}}$ : ângulo de ataque crítico de uma partícula abrasiva

$\sigma:$ tensão verdadeira $[\mathrm{MPa}]$

$\mu:$ coeficiente de atrito

$\mu_{\mathrm{A}}$ : parcela do coeficiente de atrito por adesão

$\mu_{\mathrm{D}}$ : parcela do coeficiente de atrito por deformação

â: diagonal de impressão de dureza Vickers $[\mu \mathrm{m}]$ dividida por $2^{1 / 2}$. л

a': menor diagonal de impressão Knoop $[\mu \mathrm{m}]$

a: raio de ação de um penetrador em um ensaio de dureza $[\mu \mathrm{m}]$

$\mathrm{A}_{1}, \mathrm{~A}_{2}$ : áreas relativas às bordas após ensaio de desgaste abrasivo $\left[\mu \mathrm{m}^{2}\right]$

$\mathrm{a}_{1}$ : constante que descreve a etapa de carregamento em um ensaio de dureza $[\mathrm{N} / \mathrm{m}]$

$\mathrm{a}_{2}$ : constante que descreve a etapa de carregamento em um ensaio de dureza [MPa]

$\mathrm{A}_{\mathrm{P}}$ : área projetada de uma impressão de dureza $\left[\mu \mathrm{m}^{2}\right]$

$\mathrm{A}_{s}$ : área superficial de uma impressão de dureza $\left[\mu \mathrm{m}^{2}\right]$ 
$\mathrm{A}_{\mathrm{V}}$ : área do sulco formado por uma partícula abrasiva $\left[\mu \mathrm{m}^{2}\right]$

b': maior diagonal de impressão Knoop [ $\mu \mathrm{m}]$

$\mathrm{C}$ : constante que relaciona a força aplicada com a área em um ensaio de dureza [MPa]

$\mathrm{C}^{\prime}$ : constante que relaciona a força aplicada com $\mathrm{h}^{2}$ durante a etapa de carregamento $[\mathrm{MPa}]$

c: raio da zona plástica formada subsuperficialmente em um ensaio de dureza $[\mu \mathrm{m}]$

$\mathrm{C}_{\mathrm{UL}}$ : constante que relaciona a força aplicada com a profundidade durante a etapa de descarregamento [MPa]

d: diagonal de impressão de dureza [mm]

$\mathrm{d}_{50}$ : tamanho relativo que corresponde a $50 \%$ do total do material passante $[\mu \mathrm{m}]$

Dp**: valor crítico para a transição entre mecanismos de desgaste abrasivo controlados por deformação plástica

Dp*: valor crítico para a transição entre mecanismos de desgaste abrasivo controlados por deformação plástica

Dp: valor para a transição entre mecanismos de desgaste abrasivo controlados por deformação plástica

E: módulo elástico $[\mathrm{GPa}]$

$\mathrm{E}_{\mathrm{i}}$ : módulo elástico do penetrador de diamante [GPa]

$\mathrm{E}_{\mathrm{IT}}$ : "indentation modulus" [GPa]

$\mathrm{E}_{\mathrm{r}}$ : módulo elástico reduzido $[\mathrm{GPa}]$

$\mathrm{E}_{\mathrm{rd}}$ : módulo elástico do sistema de desgaste [GPa]

$\mathrm{F}$ : força em um ensaio de dureza $[\mathrm{N}]$

$f$ : parâmetro adimensional relacionado com a resistência ao cisalhamento do contato entre abrasivo e superfície desgastada

$\mathrm{F}_{\text {máx }}$ : força máxima em um ensaio de dureza $[\mathrm{N}]$

h': altura da borda formada $[\mu \mathrm{m}]$

$\mathrm{H}$ : dureza $[\mathrm{MPa}]$

$\mathrm{H}_{0}$ : constante $[\mathrm{MPa}]$

$\mathrm{H}_{\mathrm{A}}$ : dureza do abrasivo [MPa] 
$\mathrm{h}_{\mathrm{C}}$ : profundidade de contato $[\mu \mathrm{m}]$

$h_{e}$ : quantidade de recuperação elástica $[\mu \mathrm{m}]$

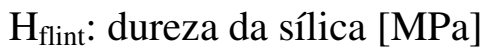

$\mathrm{H}_{\mathrm{IP}}$ : dureza verdadeira [MPa]

$\mathrm{H}_{\mathrm{IT}}$ : "indentation hardness" [MPa]

$\mathrm{H}_{\mathrm{K}}$ : dureza Knoop [MPa]

HM: dureza Martens [MPa]

$\mathrm{H}_{\max }$ : máxima dureza da superfície desgastada [MPa]

$\mathrm{h}_{\text {máx}}$ : profundidade máxima de penetração $[\mu \mathrm{m}]$

$\mathrm{H}_{\mathrm{MM}}$ : dureza de compósito de matriz metálica [MPa]

$\mathrm{HM}_{\mathrm{S}}$ (ou HVL): dureza Vickers sob carregamento [MPa]

$h_{P}$ : profundidade final após remoção da força $[\mu \mathrm{m}]$

HRC: dureza Rockwell escala C

$\mathrm{h}_{\mathrm{S}}:$ profundidade defletida $[\mu \mathrm{m}]$

HU: dureza universal [MPa]

HV: dureza Vickers convencional [MPa]

$\mathrm{HV}_{0,05}$ : dureza Vickers convencional determinada com $0,49 \mathrm{~N}[\mathrm{MPa}]$

$\mathrm{HV}_{0,1}$ : dureza Vickers convencional determinada com 0,98 $\mathrm{N}$ [MPa]

$\mathrm{HV}_{1}$ : dureza Vickers convencional determinada com 9,8 N [MPa]

$\mathrm{HV}_{5}$ : dureza Vickers convencional determinada com $49 \mathrm{~N}$ [MPa]

$\mathrm{HV}_{30}$ : dureza Vickers convencional determinada com $294 \mathrm{~N}[\mathrm{MPa}]$

K: coeficiente de desgaste

k: fator geométrico para definição da área superficial de uma impressão de dureza

$\mathrm{k}_{1}$ : razão entre a dureza Vickers de cada mineral subseqüente da escala Mohs

$\mathrm{K}_{1}$ : valor da razão $\mathrm{H}_{\mathrm{A}} / \mathrm{H}$ que define a região de transição entre os regimes moderado e severo de desgaste abrasivo 
$\mathrm{K}_{2}$ : valor da razão $\mathrm{H}_{\mathrm{A}} / \mathrm{H}$ que define a região de transição entre os regimes moderado e severo de desgaste abrasivo

Kc: tenacidade à fratura $\left[\mathrm{MPa} . \mathrm{m}^{1 / 2}\right]$

lm: comprimento amostral em medida de rugosidade $[\mu \mathrm{m}]$

le: segmento de medida de rugosidade $(=\mathrm{lm} / 5)[\mu \mathrm{m}]$

L: força aplicada em um ensaio de desgaste $[\mathrm{N}]$

m: índice de Meyer

M: número Mohs

$\mathrm{m}_{\mathrm{UL}}$ : expoente que descreve a etapa de carregamento

$\mathrm{n}$ : coeficiente de encruamento

p: extensão da região deformada devido ao processo de desgaste abrasivo [ $\mu \mathrm{m}]$

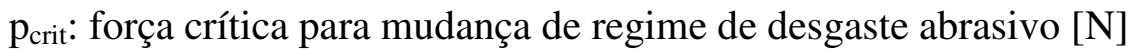

r: raio de contato entre abrasivo e superfície desgastada $[\mu \mathrm{m}]$

$\mathrm{R}$ : raio de um penetrador esferico $[\mu \mathrm{m}]$

Ra: parâmetro de rugosidade $[\mu \mathrm{m}]$

Rmax: parâmetro de rugosidade que expressa a altura máxima entre um pico de aspereza e um vale $[\mu \mathrm{m}]$

Rz: parâmetro de rugosidade que expressa a altura média entre um pico de aspereza e um vale $[\mu \mathrm{m}]$

$\mathrm{S}$ : rigidez de contato $[\mathrm{N} / \mathrm{mm}]$

Sm: parâmetro de rugosidade $[\mu \mathrm{m}]$

U: módulo de resiliência [MPa]

w: largura do sulco causado por um abrasivo $[\mu \mathrm{m}]$

$\mathrm{W}:$ taxa de desgaste $=$ perda volumétrica por distância percorrida $\left[\mathrm{mm}^{3} / \mathrm{m}\right]$

$\mathrm{W}^{-1}$ : resistência ao desgaste $(=1 / \mathrm{W})\left[\mathrm{m} / \mathrm{mm}^{3}\right]$

We: parcela de trabalho elástico em um ensaio de dureza [N.m]

$\mathrm{W}_{\mathrm{T}}$ : trabalho total realizado em um ensaio de dureza [N.m]

$\mathrm{Y}$ : limite de escoamento [MPa] 


\section{RESUMO}

Este trabalho apresenta uma metodologia experimental para investigar a relação entre taxas de desgaste abrasivo e dureza. Investigam-se os regimes moderado e severo de desgaste abrasivo em função da razão entre a dureza do abrasivo $\left(\mathrm{H}_{\mathrm{A}}\right)$ e a dureza do material desgastado $(\mathrm{H})$. Foram realizados ensaios pino contra lixa, utilizando vidro como abrasivo em dois tamanhos, grana \#80 e grana \#240, e pinos com $3 \mathrm{~mm}$ de diâmetro sob força de $20 \mathrm{~N}$. Os materiais ensaiados foram os aços AISI 1006 e AISI 52100, este último em diferentes condições metalúrgicas, e um ferro fundido branco de alto cromo, de composição eutética e matriz perlítica. Três tipos de resposta do sistema tribológico foram utilizadas para avaliar os regimes de desgaste: perda de massa, coeficiente de atrito e força de penetração do abrasivo. Determinaram-se as perdas de massa ao longo dos ensaios; o coeficiente de atrito medido por meio de célula de carga e a força de penetração com o uso de ensaios instrumentados de dureza, estimando-se a profundidade máxima de penetração com base no parâmetro Rz. A partir das medidas de dureza, foi utilizado um parâmetro para incorporar os efeitos do comportamento elasto-plástico dos materiais, que considera a morfologia de impressão de dureza. Com este parâmetro, foi possível obter uma dureza denominada "verdadeira", que incorpora os efeitos de formação de bordas ou retração dos materiais. Verificou-se que os valores de resistência ao desgaste relativa não dependem do tamanho do abrasivo, mas que os valores de coeficiente de atrito dependem, sob regime severo de desgaste. Por sua vez, no regime moderado, os valores de coeficiente de atrito são independentes do tamanho do abrasivo. 


\section{ABSTRACT}

This work presents an experimental methodology to investigate the relationship between abrasive wear rates and hardness. The mild and severe abrasive wear regimes are investigated in relation to the abrasive hardness-to-worn material hardness ratio $\left(\mathrm{H}_{\mathrm{A}} / \mathrm{H}\right)$. Pin-against-paper tests were performed, using glass as abrasive material in two grain sizes, grit \#80 and grit \#240, and 3-mm diameter pins under $20 \mathrm{~N}$ of applied load. The tested materials were AISI 1006 e AISI 52100 steels, the last one in different metallurgical conditions, and a high-chromium white cast iron, with eutetic composition and pearlitic matrix. Three kinds of tribological system responses were used to evaluate the wear regimes: mass loss, friction coefficient and load of penetration of abrasive. Mass losses were determined along testing time; friction coefficient was determined by means of load cell and the load of penetration using instrumented hardness test, selecting the maximum depth penetration based on the Rz roughness parameter. From hardness measurements, a parameter was used to incorporate the elastic-plastic behavior of materials, which consider the indentation hardness morphology. Using this parameter, it was possible to obtain a kind of hardness called "true", which incorporate the pilling-up and sinking-in effects. It has been demonstrated that the relative abrasive resistance is not dependent of the abrasive particle size, but the friction coefficient values change, under severe wear regime. On the other hand, under mild regime, the friction coefficient values are independent of the abrasive particle size. 


\title{
1 INTRODUÇÃO
}

\begin{abstract}
"De tanto andar a porca já não anda, de tanto usada a faca já não corta, como é difícil, pai, abrir a porta, esta palavra presa na garganta." (Cálice, Chico Buarque \& Gilberto Gil, 1978)
\end{abstract}

A seleção de materiais resistentes ao desgaste abrasivo pode ser resumida como a maximização da dureza sem prejuízos à tenacidade à fratura. O melhor compromisso entre essas propriedades é ditado em grande parte pela severidade do sistema de desgaste em questão (MOORE, 1980).

$\mathrm{Na}$ seleção de materiais, procuram-se materiais ou fases constituintes com dureza maior que a do quartzo, o abrasivo mais abundante na superfície terrestre. A dureza do quartzo, 11,8 GPa, (BLAU, 1992), é maior do que a dos aços, $10 \mathrm{GPa}$ (OHMURA e colaboradores, 2001), mesmo aqueles com alto teor de carbono e tratados termicamente. A presença de grandes frações volumétricas de carbonetos eutéticos $\mathrm{M}_{7} \mathrm{C}_{3}$, mais duro que o quartzo, explica o desempenho satisfatório de ferros fundidos brancos de alto cromo em mineração e movimentação de terra (GUNDLACH; PARKS, 1977).

Os aços Hadfield exemplificam bem o caso em que é necessário priorizar uma elevada tenacidade em aplicações de desgaste (BORIK; SCHOLZ, 1971). Nas operações de britagem é necessário combinar tenacidades elevadas com valores de dureza suficientes para propiciar resistência ao desgaste em níveis satisfatórios. 
Uma outra vertente da engenharia de materiais visando maior resistência ao desgaste abrasivo é o desenvolvimento de revestimentos, que podem substituir famílias tradicionais de materiais resistentes ao desgaste, tais como os ferros fundidos brancos, com ganho de custo-benefício considerável. A Tabela 1.1 mostra os resultados de taxas de desgaste obtidos por BOZZI e colaboradores (1998) em ensaio de abrasão a três corpos.

Tabela 1.1 - Taxas de desgaste $\left[\mathrm{mg} / \mathrm{h} . \mathrm{mm}^{2}\right]$ de revestimento depositado por aspersão térmica e de ferro fundido branco eutético em ensaio de abrasão a três corpos (BOZZI e colaboradores, 1998).

\begin{tabular}{|c|c|c|}
\hline \multirow{2}{*}{ Material } & \multicolumn{2}{|c|}{ Taxa de desgaste $\left[\mathrm{mg} / \mathrm{h} . \mathrm{mm}^{2}\right]$} \\
\cline { 2 - 3 } & Alumina & Carbeto de silício \\
\hline Revestimento WC-12\% Co sobre aço AISI 1020 & 0,99 & 12,25 \\
\hline Ferro fundido branco de alto cromo eutético & 1,70 & 2,00 \\
\hline
\end{tabular}

A Tabela 1.1 mostra que o melhor desempenho de um ou outro material depende da severidade do sistema. O revestimento WC-12\%Co apresentou desempenho superior ao do ferro fundido branco apenas no sistema menos severo (ensaio com alumina).

A demanda para materiais resistentes ao desgaste não se limita apenas às aplicações em mineração e movimentação de terra. Componentes para usinagem, que precisam ter suas propriedades mecânicas estáveis em altas temperaturas, vêm apresentando solicitações crescentes de desgaste, em função da necessidade do aumento da produção e trabalho com ferramentas de durezas cada vez maiores, como em usinagem de moldes para injeção de plásticos (SINATORA; BOCCALINI Jr, 1999 e 2000). Neste caso, superfícies revestidas, por deposição PVD (physical vapor deposition) e CVD (chemical vapor deposition), e compósitos com fase de reforço cerâmica são cada vez mais empregadas. Tanto com os compósitos de matriz metálica 
(BERNS, 2001) como com os de matriz cerâmica (FERREIRA e colaboradores, 2001) é possível obter um ganho conjunto em dureza e em tenacidade.

Para a inovação de materiais resistentes ao desgaste se faz necessário o conhecimento aprofundado de variáveis de processamento e das interações possíveis entre abrasivo e superfície desgastada. BERNS; WEWERS (2001) desenvolveram um

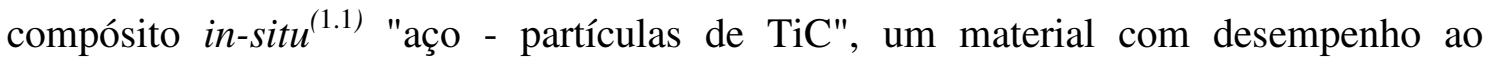
desgaste abrasivo semelhante e custo mais baixo do que outros compósitos de matriz metálica, tais como os reforçados com partículas de $\mathrm{NbC}$ e de $\mathrm{CrB}_{2}$. MATSUBARA e colaboradores (1994) desenvolveram uma família de materiais para cilindros de laminação a quente por meio da adição de elementos de liga $(\mathrm{Cr}, \mathrm{V}, \mathrm{Mo}, \mathrm{W}$ e Co) em teores diferentes das composições básicas de aços ferramentas, além de maiores teores de C. Estas adições promovem a formação de carbonetos com as mais variadas morfologias, o que confere um desempenho adequado em relação às diferentes solicitações de desgaste que estão envolvidas neste tipo de componente.

Percebeu-se que os equipamentos tradicionais de dureza, em função da faixa de força aplicada e da sua resolução óptica, não eram capazes de medir com precisão a dureza de revestimentos sem interferência das propriedades do substrato, ou das fases de reforço cerâmicas de compósitos sem interferência das propriedades da matriz. Segundo BHATTACHARYA; NIX (1988), a profundidade de penetração permitida para que uma medida de dureza de um revestimento não sofra influência das

\footnotetext{
${ }^{1.1}$ In situ significa "no mesmo lugar", ou seja, partículas de Fe-Ti se transformam em partículas de TiC sem mudança de posição, tamanho e forma. O carbono necessário para a reação $\mathrm{M}+\mathrm{C}=\mathrm{MC}$ é disponibilizado pela adição de pó de grafite ou por um pó de ferro com alto teor de C (BERNS; WEWERS, 2001).
} 
propriedades do substrato é de no máximo $20 \%$ da espessura do revestimento. Nos processos de deposição por PVD e por CVD, as espessuras usuais dos revestimentos são de 1 a $10 \mu \mathrm{m}$ (HUTCHINGS, 1992) e os equipamentos convencionais não possuem resolução suficiente para profundidades de penetração relativas a $20 \%$ destes valores.

Devido em grande parte a estas limitações é que na década de 70 foi desenvolvida a técnica de medida de dureza instrumentada (FRÖLICH e colaboradores, 1977). Esta técnica aliou duas características inexistentes nos equipamentos convencionais: força menor que $1 \mathrm{gf}$ (alguns equipamentos possuem resolução de $0,5 \mu \mathrm{N}$ e para profundidade de penetração de $3 \mathrm{~nm}$ ) e o acompanhamento contínuo da profundidade de penetração ao longo do ensaio.

Além de dispensar o uso de meio ópticos para medir a dureza (o que associa erros ligados ao operador), os equipamentos instrumentados possibilitaram obter informações sobre as propriedades mecânicas dos materiais, tais como módulo elástico, trabalho realizado durante a penetração e parcelas elástica e plástica ${ }^{(1.2)}$. A aplicação destas propriedades para a análise do comportamento tribológico de revestimentos já foi defendida na literatura (LEYLAND; MATTHEWS, 2000).

A metodologia de análise dos resultados obtidos em ensaios instrumentados de dureza está sendo discutida atualmente visando a confecção de uma Norma ISO. Esta Tese adota a nomenclatura definida na ISO/FDIS ${ }^{(1.3)}$ 14577-1:2002 - "Instrumented

\footnotetext{
1.2 Além de permitir a caracterização de fases microestruturais de pequenos tamanhos, com os equipamentos de dureza instrumentados é possível caracterizar a resistência de ligação da interface 'matriz-reforço' em materiais compósitos (vide, por ex., CHAWLA, 1993).

${ }^{1.3}$ FDIS: Final Draft International Standard.
} 
indentation test for hardness and material parameters" (ISO, 2002) para os parâmetros e as propriedades mecânicas obtidas com este ensaio.

No Brasil, os departamentos ligados à área de Física Aplicada foram os primeiros que mostraram a preocupação em determinar propriedades mecânicas de superfícies revestidas ou modificadas. Em 1996 foi criado o Laboratório de Propriedades Nanomecânicas no Departamento de Física da UFPR - Universidade Federal do Paraná, com a aquisição do equipamento NANOINDENTER IIs, fabricado pela Nano Instruments, Inc, uma empresa norte-americana.

Na mesma época, por meio de um Projeto Temático junto à FAPESP - Fundação de Apoio à Pesquisa do Estado de São Paulo, o LFS - Laboratório de Fenômenos de Superfície, no Departamento de Engenharia da Escola Politécnica da USP, adquiriu um equipamento instumentado, FISCHERSCOPE H100V, da empresa alemã FISCHER.

Mais recentemente outros dois departamentos ligados à área de Física Aplicada adquiriram equipamentos de dureza instrumentados, contabilizando um total de quatro existentes no Brasil: um no Laboratório de Plasmas e Aplicações do Departamento de Física e Química da UNESP, em Guaratinguetá, produzido pela HYSITRON, norteamericana; e outro no GEPSI - Grupo de Estudos de Propriedades de Superfícies e Interfaces da Faculdade de Física da PUC-RS, produzido pela FISCHER, alemã.

Além desses grupos de pesquisa, o Laboratório de Tribologia e Materiais da UFU - Universidade Federal de Uberlândia, vem desenvolvendo no próprio laboratório equipamentos de dureza instrumentados (ABRAHÃO e colaboradores, 1998), sendo pioneiros na determinação deste tipo de propriedade para temperaturas elevadas (FRANCO e colaboradores, 2001). 
Estes grupos de pesquisa vêm mantendo uma interatividade com os grupos que investigam o processamento de materiais, ou seja, há uma massa crítica no País que está executando ensaios de dureza instrumentada e discutindo a linguagem para a interpretação e a discussão dos resultados. Como exemplo desta interatividade, o Departamento de Engenharia Metalúrgica e de Materiais da UFGM - Universidade Federal de Minas Gerais, produziu revestimentos pelo processo PVD em aços AISI H13 temperados e revenidos, com espessuras de 2,2 a $2,5 \mu \mathrm{m}$ (BATISTA e colaboradores, 2002). As medidas de dureza foram feitas no LFS, utilizando $15 \mathrm{mN}$, que gerou uma profundidade de penetração de $0,02 \mu \mathrm{m}$, valor de $10 \%$ da espessura do revestimento, garantindo que as medidas estivessem livres do efeito do substrato.

A idéia de relação entre resistência ao desgaste abrasivo e dureza é intuitiva. Por exemplo, um conceito clássico e bem difundido é a escala Mohs de dureza. A dureza Mohs é um número entre 1 e 10 dado a um material após o mesmo ser submetido ao riscamento por uma série de minerais que correspondem aos valores da escala, sendo talco o número 1 e o diamante o número 10. Logo, a dureza Mohs situa-se entre a do mineral que deixa de riscar e a do mineral que risca e que, portanto, que desgasta o material ensaiado, dentre os 10 minerais da escala de dureza ${ }^{(1.4)}$.

TABOR (1956) investigou a possibilidade de que a escala Mohs fosse arbitrária. Este pesquisador reuniu medidas de dureza Vickers dos minerais selecionados por Mohs, correlacionando os valores na forma apresentada na Figura 1.1.

\footnotetext{
${ }^{1.4}$ A escala Mohs é utilizada ainda hoje para avaliar a dureza de componentes estruturais, como pisos cerâmicos, vide, por exemplo, a Norma NBR 13818 (ABNT, 1997).
} 


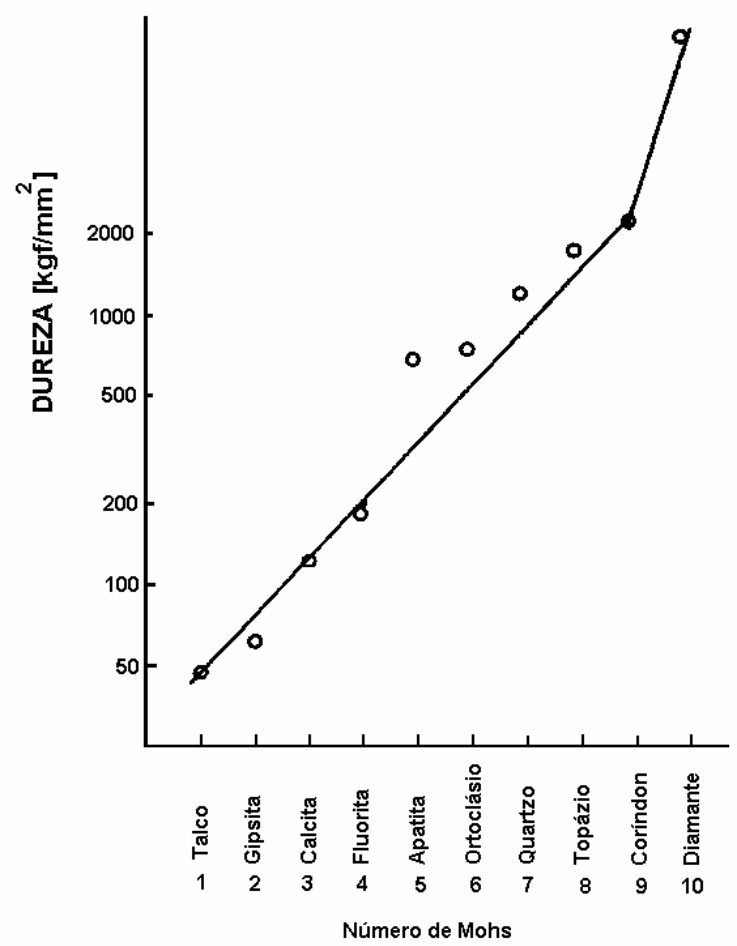

Figura 1.1. Relação entre número de Mohs e dureza Vickers $\left[\mathrm{kgf} / \mathrm{mm}^{2}\right]$ (TABOR, 1956).

A Figura 1.1 mostra que é possível estabelecer uma relação como a equação 1.1:

$\log \left(\mathrm{H} / \mathrm{H}_{0}\right)=\log \mathrm{k}_{1} \cdot \mathrm{M}$

Equação 1.1

onde;

H é a dureza $\left[\mathrm{N} / \mathrm{mm}^{2}\right]$;

$\mathrm{H}_{0}$ é uma constante $\left[\mathrm{N} / \mathrm{mm}^{2}\right]$ e;

M é o número Mohs.

Na equação 1.1 o parâmetro $k_{1}$ corresponde à razão entre a dureza Vickers de cada mineral subseqüente da escala Mohs. Com base nos resultados da Figura 1.1, podese calcular esta razão, que é de aproximadamente 1,6. Esta regularidade sugere que Mohs não escolheu simplesmente dez minerais em ordem crescente de dureza, mas selecionou uma série capaz de satisfazer a "igualdade nos intervalos". Resultados $\begin{array}{lllllll}\text { semelhantes } & \text { aos } & \text { da } & \text { Figura } & 1.1 & \text { foram } & \text { obtidos }\end{array}$ 
GONÇALVES e colaboradores (2000), que determinaram a dureza dinâmica Vickers dos minerais da escala Mohs em ensaios de esclerometria linear ${ }^{(1.5)}$. Neste caso, o parâmetro $\mathrm{k}_{1}$ foi de aproximadamente 1,8 .

A regularidade nas diferenças de dureza entre os minerais da escala Mohs corresponde razoavelmente ao parâmetro freqüentemente utilizado para prever o regime de desgaste abrasivo, moderado ou severo: a razão entre dureza do abrasivo e dureza do material desgastado, $\mathrm{H}_{\mathrm{A}} / \mathrm{H}$. A variação das taxas de desgaste em função desta razão resulta em uma curva característica de transição com dois níveis de taxas de desgaste, como mostra a Figura 1.2 (KRUSCHOV, 1957).

Na Figura $1.2 \mathrm{~K}_{1}$ e $\mathrm{K}_{2}$ são os valores que definem a região de transição dos regimes moderado e severo. Segundo KRUSCHOV, estes valores são de 0,7 a 1,1 para $\mathrm{K}_{1}$ e 1,3 a 1,7 para $\mathrm{K}_{2}$, sendo que esta faixa para $\mathrm{K}_{2}$ compreende o valor encontrado por TABOR (1956) de 1,6 para os minerais constituintes da escala Mohs de dureza. A proposta de KRUSCHOV para $\mathrm{K}_{1}$ e $\mathrm{K}_{2}$ considerou a dureza dos materiais determinada previamente aos ensaios de desgaste. LARSEN-BASSE (1966) mostrou que a dureza determinada após o processo de abrasão apresenta melhor relação com a resistência ao desgaste do que a dureza inicial. Considerando medidas de dureza da superfície encruada, $H_{\max }$, RICHARDSON (1968) apresentou valores da razão $\mathrm{H}_{\mathrm{A}} / \mathrm{H}_{\max }$ para definir a região de transição: 0,8 para o início e 1,2 para o final.

\footnotetext{
${ }^{1.5}$ A dureza dinâmica obtida em esclerometria linear é calculada em relação à projeção da área de contato. Para um penetrador do tipo Vickers esta área é equivalente a $4 . \mathrm{L}^{2}$, onde $\mathrm{L}$ é a largura do sulco formado.
} 


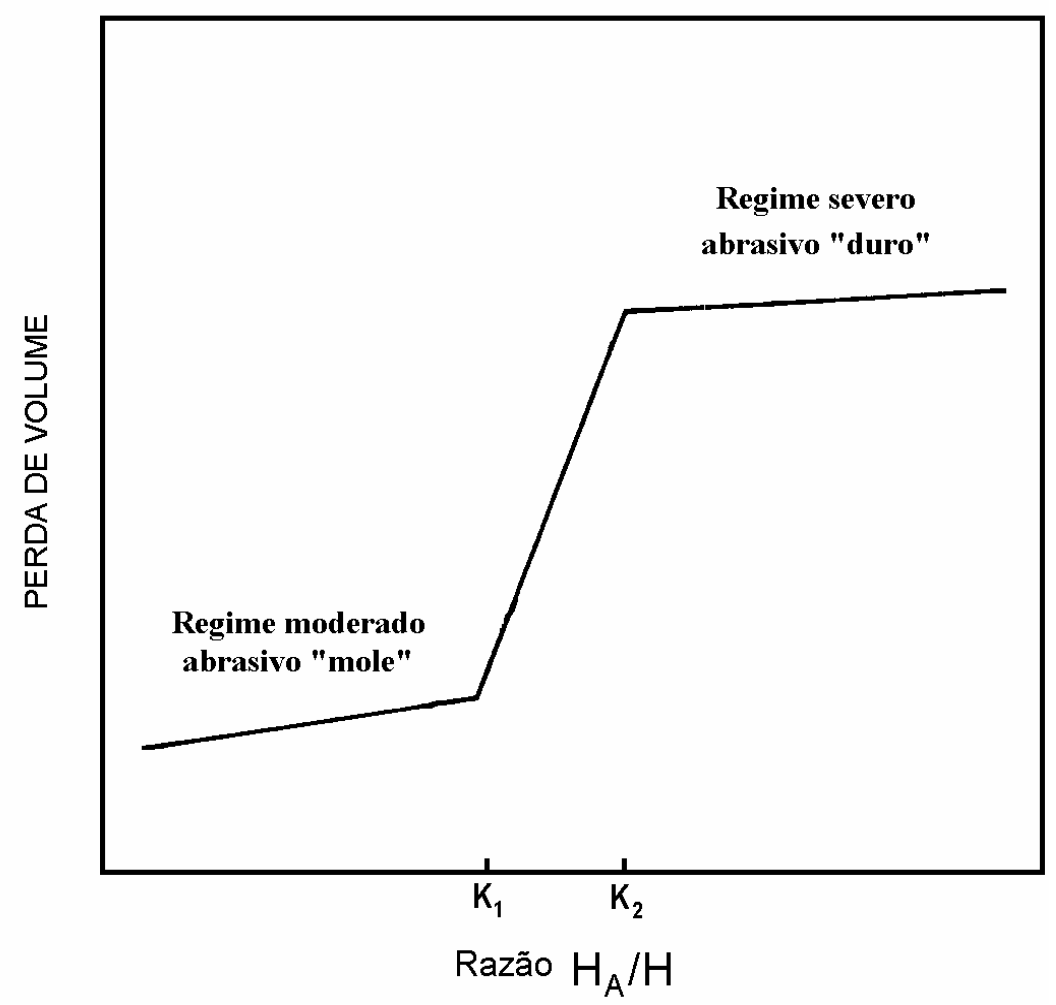

Figura 1.2. Relação esquemática entre taxa de desgaste e razão entre dureza do abrasivo $\left(H_{\mathrm{A}}\right)$ e dureza do material desgastado (H) (KRUSCHOV, 1957). $\mathrm{K}_{1}$ : ponto que delimita o início da região de transição; $K_{2}$ : ponto que delimita o final da região de transição.

Os valores $\mathrm{H}_{\mathrm{A}} / \mathrm{H}$ propostos por KRUSCHOV (1957) e por RICHARDSON (1968) para prever os regimes de desgaste abrasivo consideraram apenas materiais monofásicos. Resultados interessantes foram obtidos por LARSEN BASSE; PREMARATNE (1983) para materiais polifásicos. Estes pesquisadores mostraram que a região de transição ficou compreendida entre valores $\mathrm{H}_{\mathrm{A}} / \mathrm{H}$ de 1 a 1,2 considerando durezas $\mathrm{HV}_{0,05}$ determinadas previamente aos ensaios.

De qualquer forma, a razão $\mathrm{H}_{\mathrm{A}} / \mathrm{H}$ passou a ser bastante utilizada pela literatura. As propostas de KRUSCHOV e de RICHARDSON motivaram outros pesquisadores, como ZUM GAHR (1987), a definirem como um abrasivo "duro" aquele que possui dureza $20 \%$ maior do que a dureza da superfície desgastada ou $50 \%$ maior do que a dureza prévia ao processo de desgaste. 
Além da razão $\mathrm{H}_{\mathrm{A}} / \mathrm{H}$, é preciso considerar as características do tribossistema e o tipo de dureza para prever o regime de desgaste operante. A seguir serão apresentados alguns exemplos de sistemas nos quais outros parâmetros necessariamente precisam ser acrescentados.

A Figura 1.3 apresenta resultados de XUAN e colaboradores (1989), que determinaram as perdas volumétricas de materiais metálicos em um sistema a três corpos lubrificado.

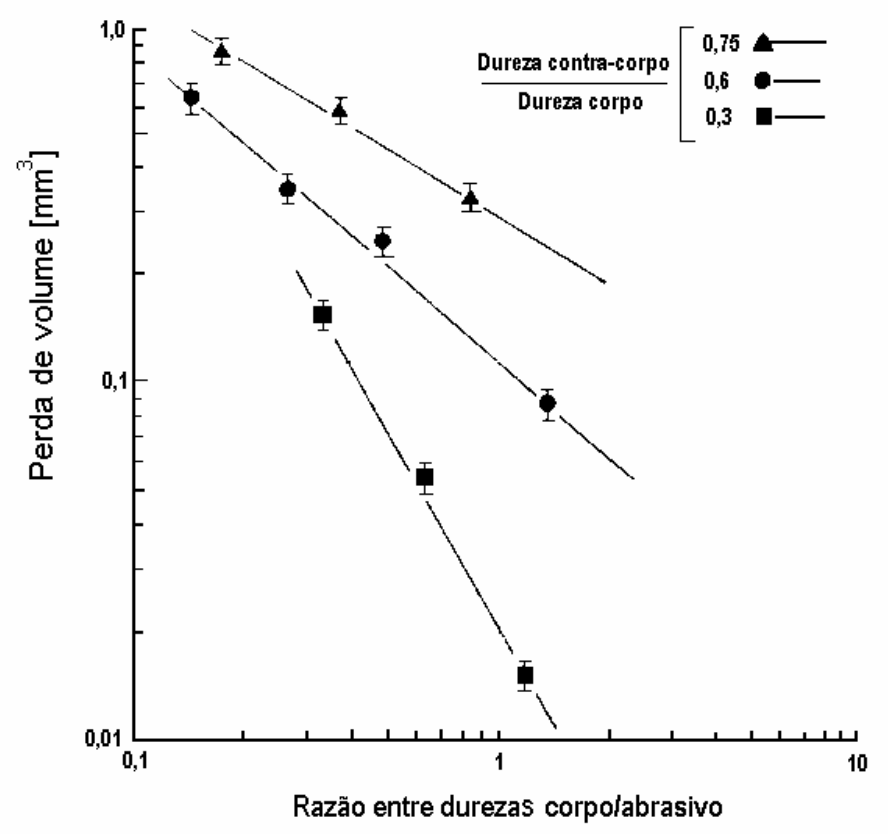

Figura 1.3. Variação do volume desgastado $\left[\mathrm{mm}^{3}\right]$ com a razão $H_{A} / H$ em função das durezas do corpo e do contra-corpo (XUAN e colaboradores, 1989).

Os resultados da Figura 1.3 mostram que, para uma mesma razão $\mathrm{H}_{\mathrm{A}} / \mathrm{H}$, há perdas volumétricas diferentes em função das razões entre durezas do corpo e do contracorpo.

A Figura 1.4 apresenta a variação da razão entre a dureza da sílica $\left(\mathrm{H}_{\text {flint }}\right)$ e a dureza de diferentes matrizes metálicas de compósitos $\left(\mathrm{H}_{\mathrm{MM}}\right)$, em função da temperatura (BERNS; FRANCO, 1997). 


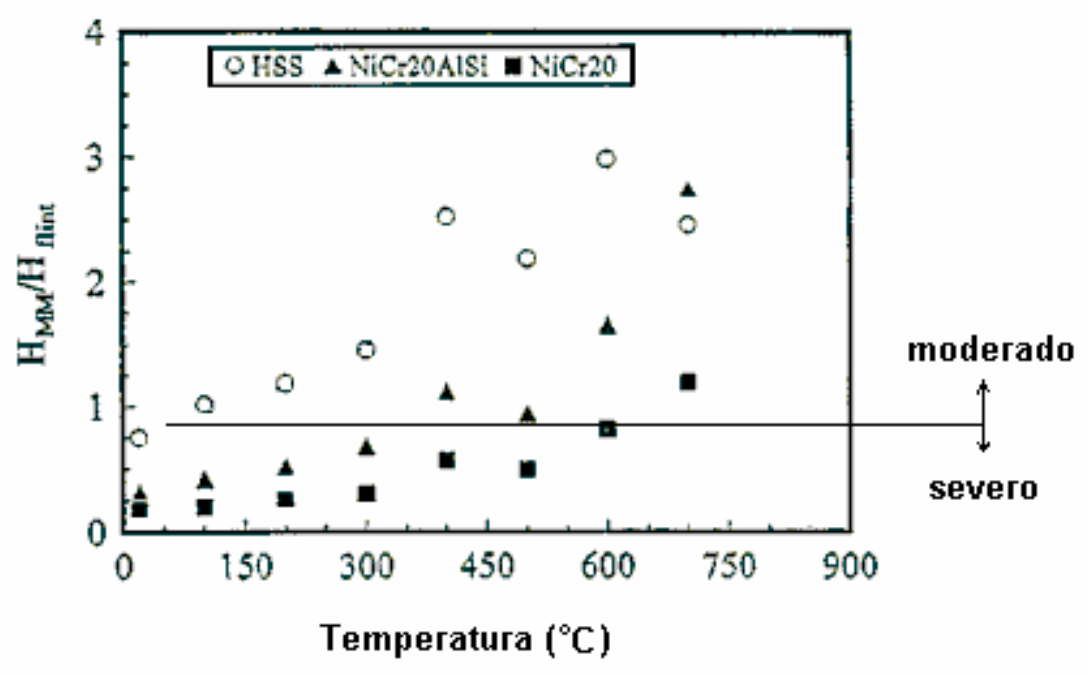

Figura 1.4. Variação da razão entre a dureza de matrizes metálicas de compósitos e da sílica $\left(\mathrm{H}_{\mathrm{MM}} / \mathrm{H}_{\text {flint }}\right)$ em função da temperatura $\left({ }^{\circ} \mathrm{C}\right)$. HSS: aço rápido. (BERNS; FRANCO, 1997).

A Figura 1.4 mostra diferentes razões $\mathrm{H}_{\mathrm{A}} / \mathrm{H}$, sendo possível prever uma transição de regime de desgaste operante, moderado para severo, com a variação da temperatura.

A razão $\mathrm{H}_{\mathrm{A}} / \mathrm{H}$ como critério para previsão dos regimes de desgaste abrasivo pode ser limitada também nos casos em que os abrasivos são heterogêneos, como minérios processados para fins metalúrgicos. A fração volumétrica dos componentes minerais pode ser mais decisiva para o desgaste de um corpo moedor do que uma dureza média do minério (PINTAÚDE e colaboradores, 2001). A Figura 1.5 apresenta resultados obtidos por MOROZ (1982) para fatores de desgaste de bolas de aço AISI 1090 forjado após moagem de minérios de ferro e de cobre. 


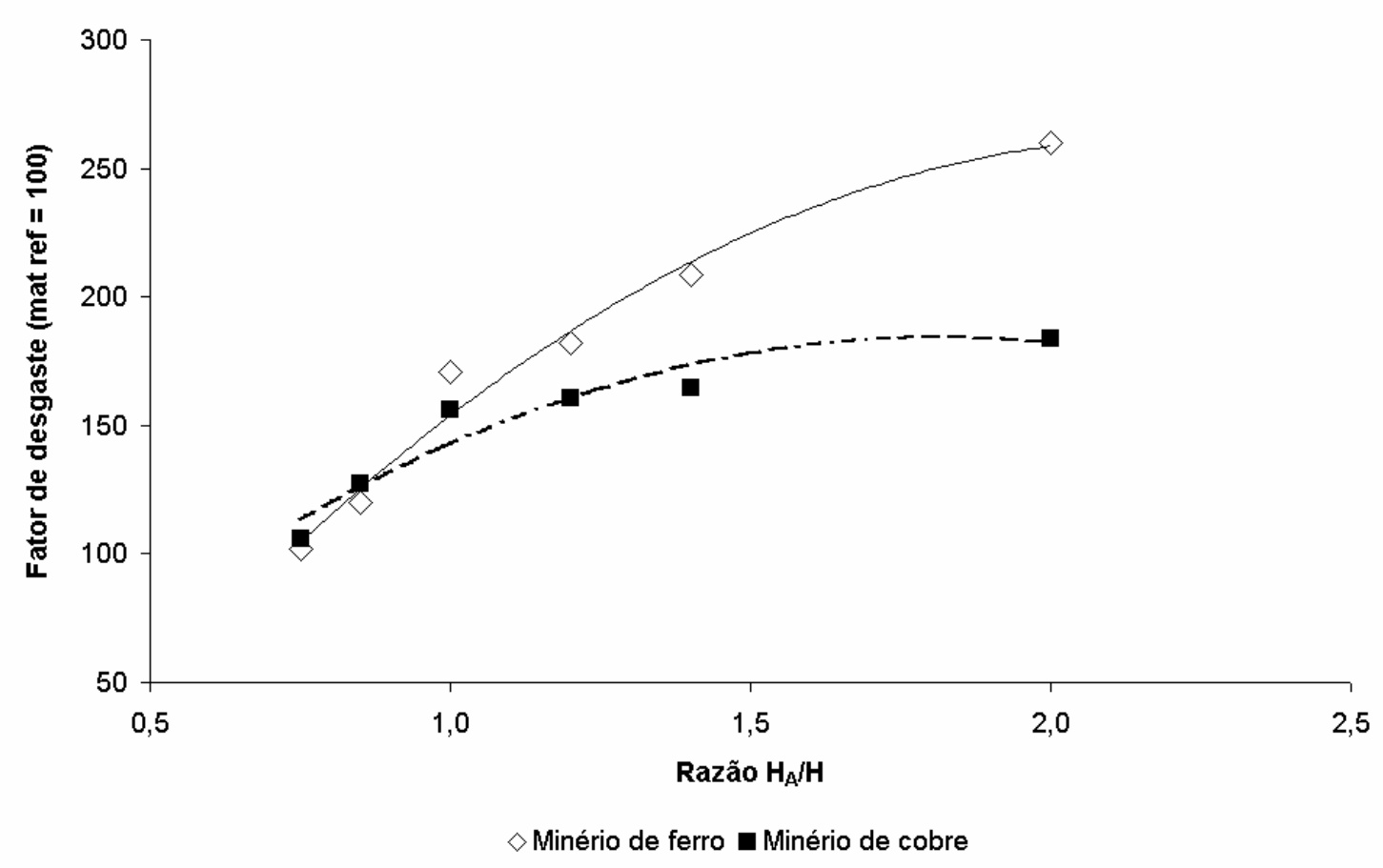

Figura 1.5. Variação do fator de desgaste de bolas de aço AISI 1090 forjadas com a razão $H_{A} / H$, após moagem de minérios de cobre e de ferro (MOROZ, 1982).

A Figura 1.5 mostra dois comportamentos diferentes. A moagem de minério de cobre resultou em um comportamento como previsto na Figura 1.2: a partir de um valor $\mathrm{H}_{\mathrm{A}} / \mathrm{H}$ maior que aproximadamente 1,2 as taxas de desgaste praticamente não se modificam com o aumento desta razão. Por outro lado, a moagem de minério de ferro resultou em fatores de desgaste cada vez maiores para valores $\mathrm{H}_{\mathrm{A}} / \mathrm{H}$ maiores que 1,2. Tal variação pode ser resultado de uma alteração significativa da microestrutura dos materiais de menor dureza ou devido à influência de componentes mineralógicos sobre a taxa de desgaste, como o quartzo, não considerada pelo trabalho de MOROZ (1982).

Na revisão da literatura a seguir, aprofundam-se as discussões sobre a dureza dos materiais e sobre os fatores que afetam os regimes de desgaste abrasivo. 


\section{REVISÃO DA LITERATURA}

\subsection{DEFINIÇÃO, CLASSIFICAÇÃO E MECANISMOS DE DESGASTE ABRASIVO}

A ASTM G40-01 (ASTM, 2001) define o desgaste abrasivo como "a perda de massa resultante da interação entre partículas ou asperezas duras que são forçadas contra uma superfície, ao longo da qual se movem".

DA SILVA e colaboradores (1999) verificaram mecanismos de abrasão em pinos de polietileno de alta densidade (PEAD), após ensaios de deslizamento contra discos de aço galvanizado. Neste caso, as asperezas do disco de aço são "duras" em relação às do PEAD. O conceito de abrasão causado aplica-se também para os sistemas em que se verifica uma alteração do tipo de desgaste em função do tempo em que o contato entre as superfícies é mantido. FARIAS; SINATORA (1999) verificaram mecanismos de abrasão no ensaio por deslizamento metal-metal do tipo pino-sobredisco, em corpos-de-prova de aço inoxidável AISI 304. Os possíveis resíduos de desgaste, gerados pelas asperezas em contato, podem ser óxidos de ferro, austenita encruada e martensita induzida por deformação; todos com dureza maior do que a austenita, e, no caso desses resíduos permanecerem entre as superfícies, o sistema passa a ser do tipo abrasivo.

O contato entre abrasivo e corpo é classificado tradicionalmente em dois tipos: abrasão a dois corpos e a três corpos. Nas situações onde a velocidade em que o abrasivo atinge a superfície desgastada é uma variável importante o desgaste é 
classificado como abrasão por erosão (MISRA; FINNIE, 1980). A interpretação usual define a abrasão a dois corpos como o sistema no qual as partículas ou as asperezas estão rigidamente fixas no segundo corpo, fazendo com que penetrem e causem riscos no primeiro corpo. Por sua vez, a abrasão a três corpos é o sistema no qual os abrasivos estão livres para rolarem. Como conseqüência disso, ensaios a dois corpos podem gerar taxas de desgaste uma ordem de grandeza maior que as observadas em ensaios a três corpos, como mostra a Figura 2.1.

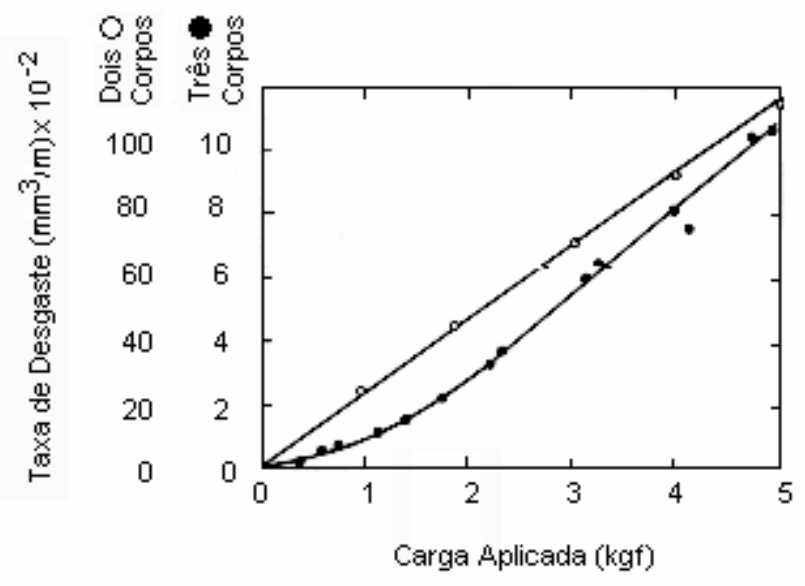

Figura 2.1. Variação das taxas de desgaste $\left[\mathrm{mm}^{3} / \mathrm{m} \times 10^{-2}\right]$ de aço AISI $1020 \mathrm{em}$ função da força aplicada [kgf] e da configuração do sistema. Abrasivo: SiC $250 \mu \mathrm{m}$ (MISRA; FINNIE, 1980).

GATES (1998) discutiu dois exemplos de conflitos existentes com o uso de tal classificação. O ensaio da roda-de-borracha, padronizado pela ASTM G65-00e1 (ASTM, 2001), que é usualmente classificado como um sistema a três-corpos, pode adquirir a configuração a dois corpos, devido à possibilidade dos abrasivos ficarem incrustados na borracha, após penetrarem na interface entre o corpo-de-prova e a roda. Outro caso que mostra a problemática de tal classificação refere-se a abrasivos livres, como em uma calha transportadora de minérios. Este sistema pode ser classificado como abrasão a dois corpos (calha e minérios), entretanto, os abrasivos estão livres para rolar, o que é característico de um sistema a três-corpos, segundo a classificação usual. 
A questão relativa ao ensaio roda-de-borracha pode ser considerada como problema de concepção do ensaio, face às diversas propostas de ensaios alternativos, concebidos com o cuidado de evitar a transição de dois para três corpos (MISRA; FINNIE, 1980 e STEVENSON; HUTCHINGS, 1996). Em contrapartida, pode-se afirmar a favor da classificação em dois ou três corpos que, com esta classificação, é possível prever a variação das taxas de desgaste em ordens de grandeza e, além disso, sintetizar os efeitos da angulosidade do abrasivo.

GATES (1998) sugeriu que a abrasão seja classificada em três regimes: moderado, severo e extremo. As variáveis que definiriam a classificação seriam: tamanho, angulosidade e restrição ao movimento dos abrasivos e os níveis de tensão aplicada. Diferentes combinações de valores destas variáveis definiriam diferentes níveis de severidade. Por sua vez, TREZONA e colaboradores (1999) sugeriram que a nomenclatura da classificação em dois ou três-corpos seja trocada, por outra que remeta ao tipo de morfologia observada nas superfícies desgastadas: abrasão por riscamento (grooving wear), quando o desgaste é promovido por partículas fixas; e abrasão por rolamento (rolling wear), quando o desgaste é gerado por partículas em movimento.

HUTCHINGS (1992) distingue os mecanismos de desgaste abrasivo em dois tipos: os que são controlados por deformação plástica e aqueles controlados por fratura frágil.

O microcorte é o mecanismo mais efetivo para a remoção de material, em um processo abrasivo controlado por deformação plástica. Neste mecanismo, o abrasivo atua como uma ferramenta de corte, e o material é removido na forma de cavacos, como mostra a Figura 2.2. 


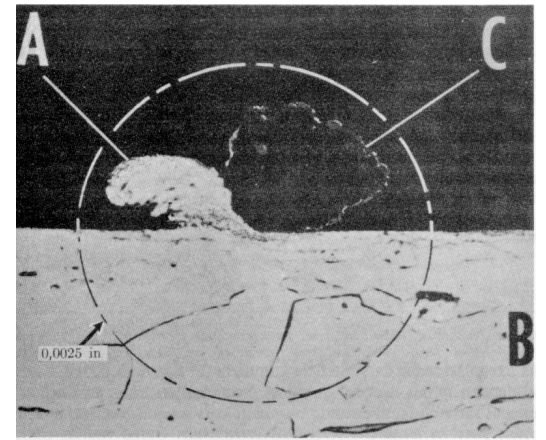

(a)

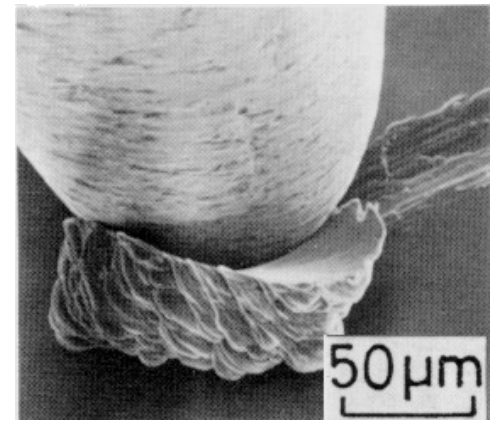

(b)

Figura 2.2. (a) Formação de cavaco (A) de aço doce (B) pela ação de um grão abrasivo (C) (VAN VLACK, 1973). (b) Micrografia em microscopia eletrônica de varredura, mostrando o mecanismo de microcorte causado por penetrador de aço ferramenta em aço inoxidável AISI 304 (KAYABA e colaboradores, 1986).

A predominância dos mecanismos controlados por deformação plástica foi analisada por HOKKIRIGAWA e colaboradores (1987) com base no parâmetro Dp. Este parâmetro é definido pela razão entre a profundidade de penetração (h) e o raio de contato (r) para uma partícula esférica de raio R, como mostra a Figura 2.3. HOKKIRIGAWA e colaboradores procuraram expressar o parâmetro Dp por meio de variáveis importantes de um tribossistema, tais como força aplicada, dureza do material desgastado e angulosidade do abrasivo.

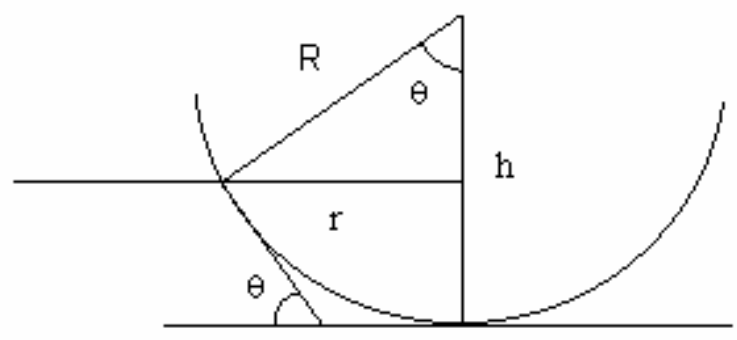

Figura 2.3. Variáveis utilizadas para a definição do parâmetro Dp $(=\mathbf{h} / \mathbf{r})$ (HOKKIRIGAWA e colaboradores, 1987).

A Figura 2.4 mostra como o parâmetro Dp pode ser utilizado para definir a predominância de um determinado micromecanismo de abrasão, em conjunto com o parâmetro $f$, relacionado com a resistência ao cisalhamento do contato. 


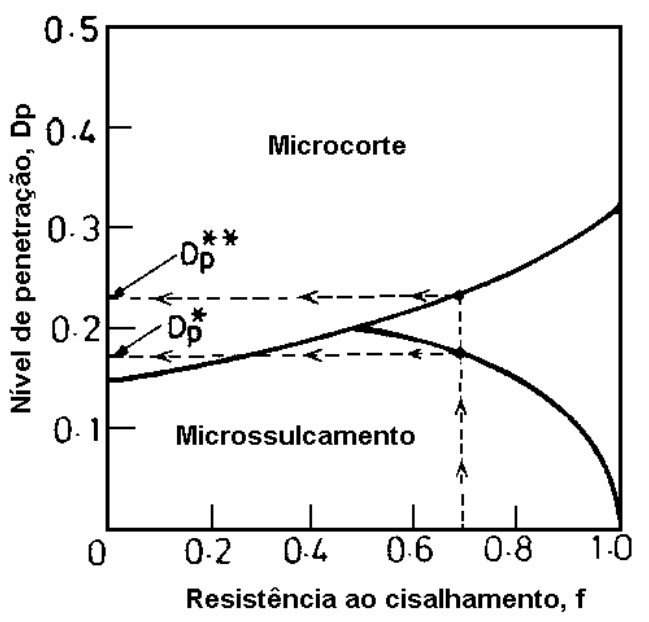

Figura 2.4. Variação dos micromecanismos de abrasão controlados por deformação plástica com os parâmetros Dp e $f$ (tensão de cisalhamento do contato/tensão de cisalhamento do material desgastado) (HOKKIRIGAWA e colaboradores, 1987).

Segundo HOKKIRIGAWA e colaboradores (1987), um valor usual para $f$ de aços em contatos não-lubrificados é 0,7 . Neste caso, o microcorte passa a predominar quando Dp é maior que um valor crítico $\mathrm{Dp} \mathrm{p}^{* *}$ de 0,23 . Por outro lado, nos casos em que Dp é menor que $\mathrm{Dp}^{*}, 0,17$, o mecanismo de microssulcamento passa a ser predominante, verificando-se apenas o deslocamento de material do sulco formado para as bordas laterais, não implicando perda de massa, como mostra a Figura 2.5.

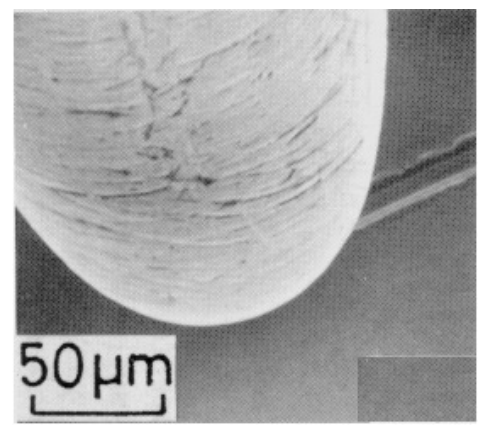

Figura 2.5. Micrografia em microscopia eletrônica de varredura, mostrando o mecanismo de microssulcamento causado por penetrador de aço ferramenta em aço inoxidável AISI 304 (KAYABA e colaboradores, 1986).

A sucessão de interações posteriores sob ação do mecanismo de microssulcamento pode resultar em perda de massa como conseqüência de um processo 
de fadiga de baixo ciclo, ou seja, um acúmulo sucessivo de danos no material, até que seja atingida uma deformação plástica suficiente para a geração de cavacos. Há evidências de que a característica das superfícies neste caso possui similaridade à observada no desgaste por delaminação, que ocorre por uma combinação de efeitos de fadiga subsuperficial, nucleação e propagação de trincas (MURRAY; MUTTON; WATSON, 1982 e LARSEN-BASSE, 1983).

A Figura 2.6 mostra os mecanismos de desgaste observados por TREZONA e colaboradores (1999) em aço-ferramenta temperado e revenido $(780 \pm 10 \mathrm{HV})$, após ensaios de micro-abrasão ${ }^{(2.6)}$.

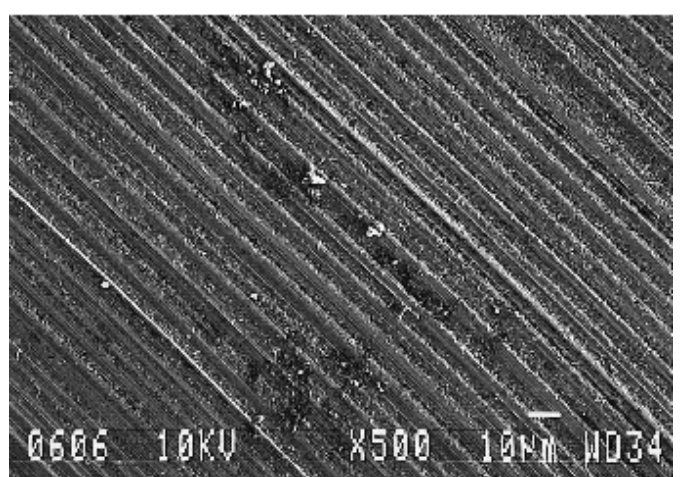

(A)

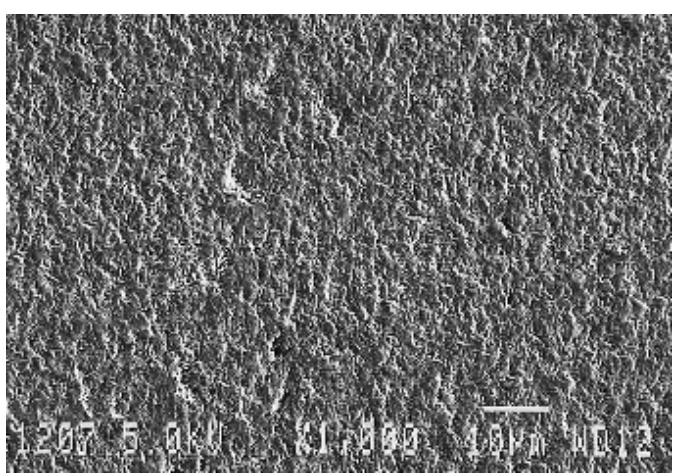

(B)

Figura 2.6. Micrografias em microscopia eletrônica de varredura, mostrando mecanismos de abrasão em aço ferramenta (780 $\pm 10 \mathrm{HV})$ em ensaios de microabrasão com $0,25 \mathrm{~N}$ : (A) microcorte, ensaio com diamante $3 \mu \mathrm{m}$ em concentração de $0,003 \mathrm{~g} / \mathrm{cm}^{3}$ e (B) microimpressões ${ }^{(2.7)}$, ensaio com $\mathrm{SiC} 4 \mu \mathrm{m}$ em concentração de $1,0 \mathrm{~g} / \mathrm{cm}^{3}$ (TREZONA e colaboradores, 1999).

\footnotetext{
2.6 Detalhes sobre este método de ensaio podem ser encontrados em RUTHERFORD; HUTCHINGS (1997).
}

2.7 Esta nomenclatura deve-se à tradução do inglês multiple indentation (TREZONA e colaboradores, 1999). 
A Figura 2.6 mostra dois mecanismos de desgaste bastante diferentes: no primeiro caso observa-se microcorte, e no outro, microimpressões. Segundo TREZONA e colaboradores (1999), as variáveis que explicam a ocorrência da transição entre estes mecanismos são a concentração do abrasivo $\left[\mathrm{g} / \mathrm{cm}^{3}\right]$ e a força aplicada $[\mathrm{N}]$, embora nos casos da Figura 2.6 a força tenha sido a mesma em ambas situações. O microcorte passou a ser predominante nos casos de incrustação dos abrasivos na superfície do contra-corpo (bola de aço 1\%C, $990 \pm 40 \mathrm{HV}$ ), o que foi verificado nos ensaios com altas forças e baixas concentrações de abrasivo na lama.

A variação dos mecanismos observados por TREZONA e colaboradores (1999) em um mesmo tipo de ensaio foi também descrita por PINTAÚDE; SINATORA (1998), em britador de mandíbulas (ASTM G81-97a, ASTM, 2001). O abrasivo utilizado por PINTAÚDE; SINATORA, granito, possuía um tamanho médio de $25 \mathrm{~mm}$. A Figura 2.7 mostra os mecanismos de desgaste verificados em mandíbulas de aço fundido temperado $\left(770 \pm 30 \mathrm{HV}_{0,1}\right)$.

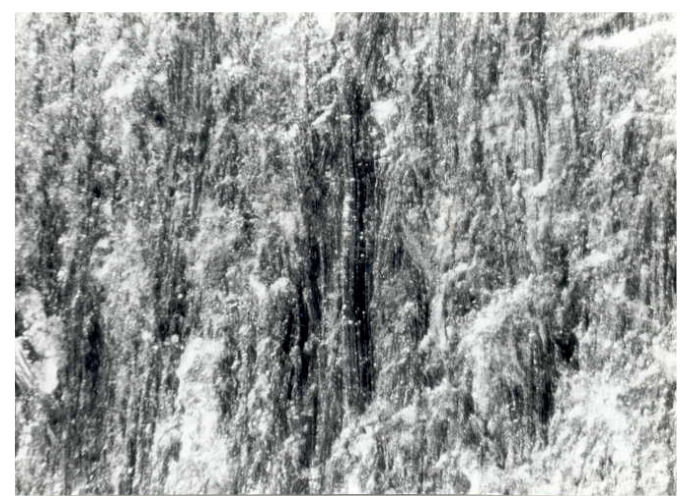

(A)

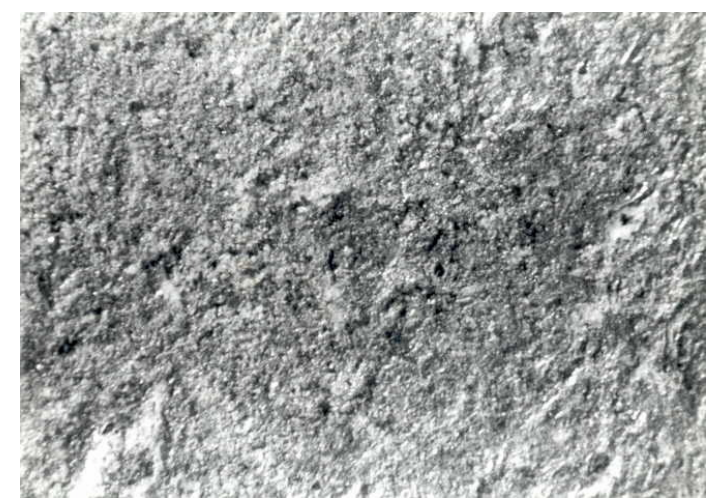

(B)

Figura 2.7. Micrografias em estereoscópio óptico, mostrando mecanismos de desgaste em mandíbulas de aço fundido temperado $\left(770 \pm 30 \quad \mathrm{HV}_{0,1}\right)$ : (A) microcorte, verificado nas mandíbulas fixas e (B) microimpressões, verificado nas mandíbulas móveis (PINTAÚDE; SINATORA, 1998). 
As diferenças nas taxas de desgaste entre mandíbulas fixas e móveis refletiram os mecanismos de desgaste observados: as mandíbulas fixas desgastaram quatro vezes mais do que as móveis. PINTAÚDE; SINATORA (1998), da mesma forma que SARE; ARNOLD (1989), atribuíram este resultado ao tipo de movimento relativo entre as mandíbulas.

Verifica-se nos ensaios de desgaste apresentados (micro-abrasão e britador de mandíbulas) a ocorrência dos mesmos mecanismos de desgaste, embora exista uma disparidade entre os sistemas quanto ao tamanho dos abrasivos.

Pode-se resumir, da análise da literatura sobre mecanismos de desgaste controlados por deformação plástica que, a associação entre micromecanismos e as taxas de desgaste, conforme varia a razão $\mathrm{H}_{\mathrm{A}} / \mathrm{H}$ (dureza do abrasivo e a dureza do material desgastado), foi apresentada por LARSEN-BASSE (1983). Segundo este pesquisador, os mecanismos associados à fadiga de baixo ciclo, como microimpressões, estão relacionados com baixas razões $\mathrm{H}_{\mathrm{A}} / \mathrm{H}$, caracterizando o regime de desgaste moderado, enquanto que o microcorte pode ser associado com o regime severo e com altas razões $H_{A} / H$. Usualmente a literatura utiliza a razão $H_{A} / H$ para a previsão dos regimes de desgaste apenas para as situações nas quais são verificados mecanismos controlados por deformação plástica.

Adicionalmente, uma observação feita por RICHARDSON (1968) deve ser considerada. Este pesquisador propôs que, quando a dureza da superfície desgastada atingisse valores semelhantes à dureza do abrasivo, ocorre a redução do poder de corte das arestas do abrasivo. A proposição de RICHARDSON é corroborada pelos resultados da Tabela 2.1, que mostra o nível de fragmentação dos abrasivos, determinado por 
BOZZI; DE MELLO (1999), após os ensaios de desgaste de revestimentos WC-12\%Co depositados por aspersão térmica.

Tabela 2.1 - Variação do tamanho médio de grão dos abrasivos após ensaios de desgaste a três corpos de revestimentos WC-12\% Co (BOZZI; DE MELLO, 1999).

\begin{tabular}{ccccc}
\hline Abrasivo & $\begin{array}{c}\text { Tempo para o } \\
\text { regime } \\
\text { permanente }(m i n)\end{array}$ & $\begin{array}{c}\text { Tamanho médio } \\
\text { inicial }(\mu \mathrm{m})\end{array}$ & $\begin{array}{c}\text { Tamanho médio } \\
\text { após ensaio }(\mu \mathrm{m})\end{array}$ & Variação (\%) \\
\hline $\mathrm{SiO}_{2}$ & 330 & $190 \pm 60$ & $120 \pm 40$ & 36,8 \\
$\mathrm{Al}_{2} \mathrm{O}_{3}$ & 26 & $260 \pm 50$ & $220 \pm 60$ & 15,4 \\
$\mathrm{SiC}$ & 5 & $250 \pm 40$ & $240 \pm 40$ & 4,0 \\
\hline
\end{tabular}

A Tabela 2.1 mostra que, além do nível de fragmentação ter sido maior nos ensaios com sílica, o tempo necessário de ensaio para que fosse atingido o regime permanente de desgaste foi maior, o que evidencia a dificuldade deste abrasivo em promover alterações na superfície desgastada do revestimento WC-12\%Co.

Além da fragmentação dos abrasivos, um outro efeito relatado pela literatura, decorrente da interação entre corpos em abrasão, é a queda nos valores de resistência mecânica dos materiais abrasivos. EVANS; BUDD (1994) propuseram um modelo no qual a resistência mecânica do vidro após desgaste é inversamente proporcional à raiz quadrada da dureza do material metálico que está em contato com vidro.

Em materiais e em microconstituintes com plasticidade limitada, a possibilidade de ocorrer microcorte é pequena. Segundo LAWN; MARSHALL (1979), o microtrincamento passa a ser predominante quando a profundidade do sulco formado ultrapassa uma profundidade crítica. Esta profundidade seria proporcional ao quadrado da razão entre a tenacidade à fratura e a dureza do material desgastado, $(\mathrm{Kc} / \mathrm{H})^{2}$, parâmetro que possui dimensões de comprimento. Pode-se prever também a ocorrência 
do microtrincamento com o conceito de força crítica, $\mathrm{p}_{\text {crit }}$, que é proporcional à razão $\mathrm{Kc}^{4} / \mathrm{H}^{3}$ : a fratura frágil passa a ser efetiva quando a força aplicada pelo abrasivo excede $\mathrm{p}_{\text {crit }}$, como pode ser visto na Figura 2.8 (JACOBSSON e colaboradores, 1992).

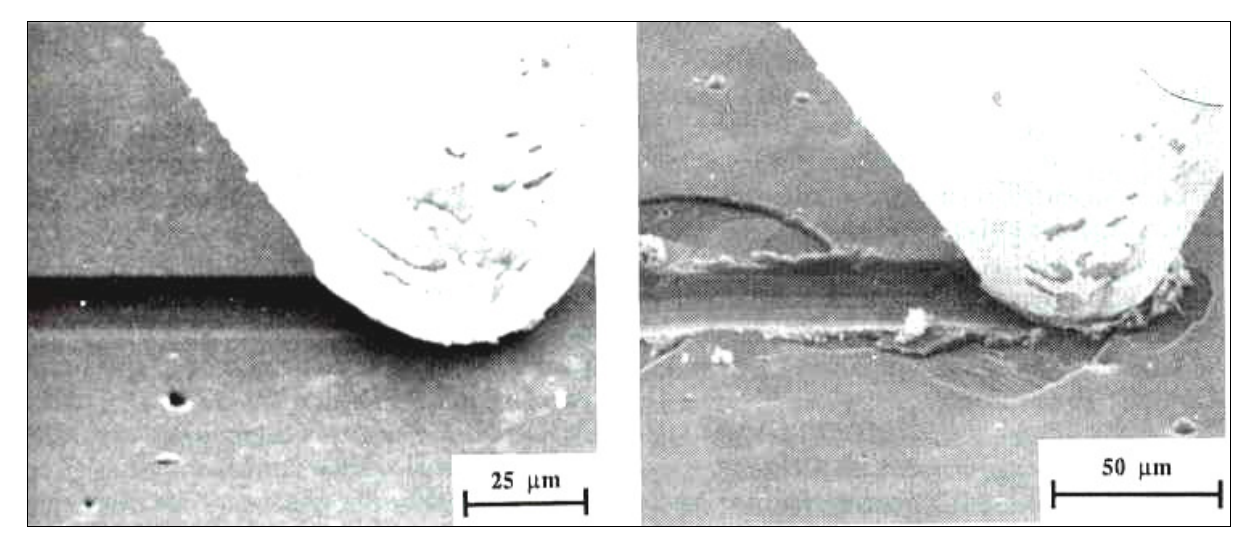

(A)

(B)

Figura 2.8. Efeito da força aplicada no mecanismo de abrasão de filme depositado por PVD: (A) força < p crit e (B) força > pcrit. Observa-se em (B) a formação de trincas laterais associadas à deformação plástica (JACOBSSON e colaboradores, 1992).

A Figura 2.9 ilustra de forma esquemática a variação da resistência ao desgaste abrasivo com a tenacidade à fratura (ZUM GAHR, 1987).

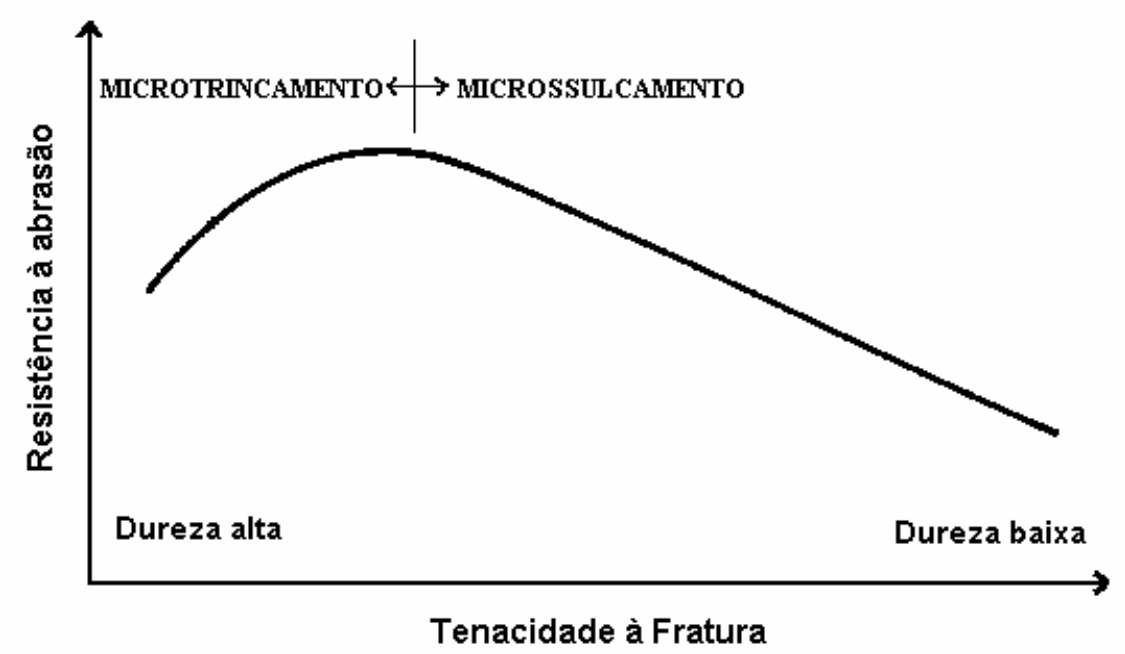

Figura 2.9. Variação da resistência ao desgaste abrasivo com a tenacidade à fratura (ZUM GAHR, 1987). 
A Figura 2.9 mostra que há uma combinação entre dureza e tenacidade à fratura na qual se atinge um "ponto ótimo" para a resistência à abrasão. A partir deste ponto, reduções na tenacidade farão com que o material sofra microtrincamento.

EVANS; WILSHAW (1976) propuseram um modelo para previsão do comportamento mecânico de materiais frágeis, apresentado na Figura 2.10. Este modelo contempla o efeito do tamanho do abrasivo, supondo que este possa ser representado por um penetrador esférico de raio $\mathrm{R}$.

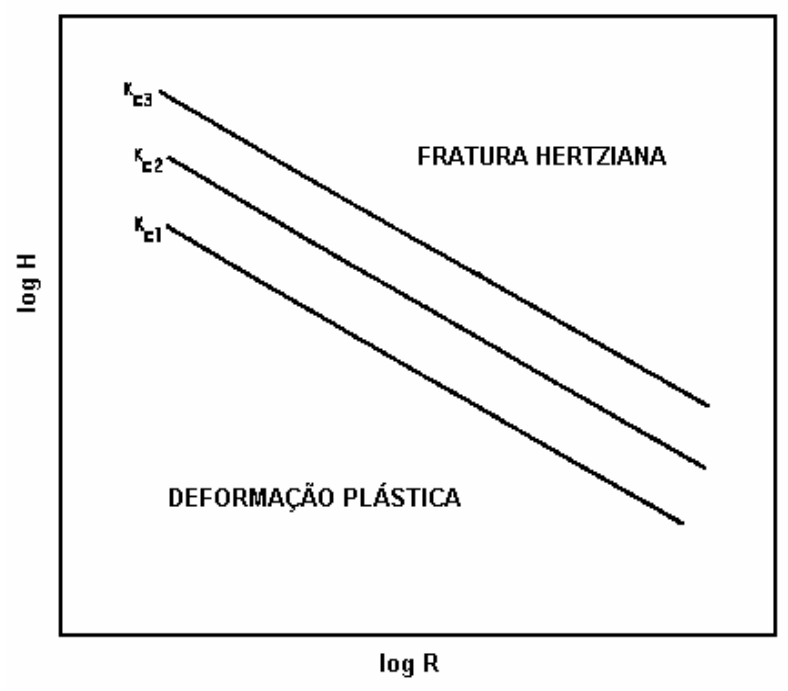

Figura 2.10. Variação do comportamento mecânico de um material em contato com um penetrador esférico de raio $R$, segundo modelo proposto por EVANS; WILSHAW (1976). Kc: valores de tenacidade à fratura, sendo $\mathrm{Kc}_{3}>\mathrm{Kc}_{2}>\mathrm{Kc}_{1}$.

A Figura 2.10 mostra que para penetradores com raios pequenos é possível maximizar a dureza do material desgastado sem que este experimente o regime de fratura Hertziana. Por outro lado, penetradores maiores podem levar o material ao regime de fratura mesmo que a dureza não seja elevada.

TABOR (1956) mostrou que $2 / 3$ da pressão de contato em compressão é hidrostática, que não contribui para o escoamento e a pressão hidrostática associada a um estado de compressão inibe a ocorrência de fratura frágil. Este é o principal motivo 
para que sejam observados em materiais e em microconstituintes frágeis mecanismos de deformação plástica, como mostram as Figuras 2.11, 2.12 e 2.13.

A Figura 2.11 apresenta linhas de escorregamento em MnS após ensaios de dureza Vickers (VAN VLACK, 1973).

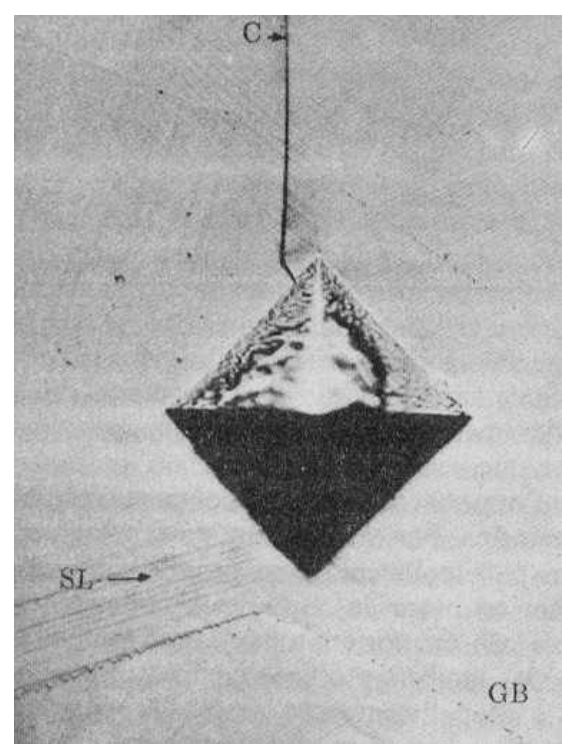

Figura 2.11. Impressão de dureza Vickers em MnS (VAN VLACK, 1973). SL: linhas de escorregamento; C: trinca; GB: defeitos cristalinos.

A Figura 2.12 mostra riscos em superfície de vidro, evidenciando a ocorrência de deformação plástica neste material (MARSH, 1964).

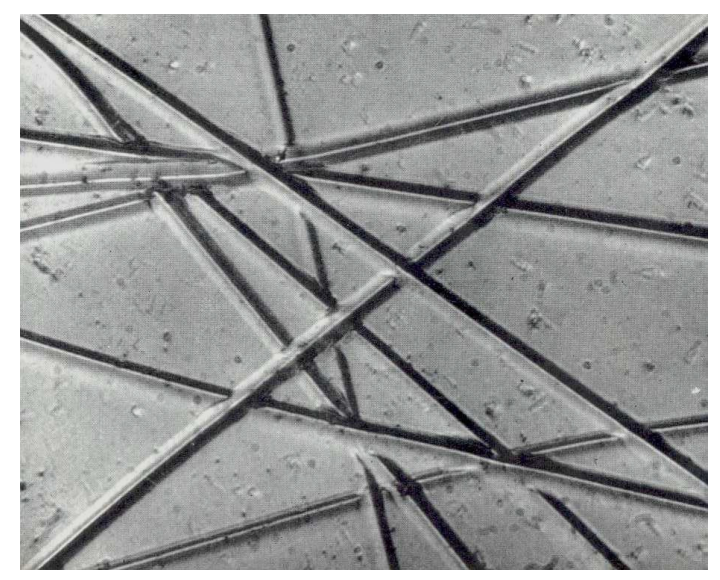

Figura 2.12. Riscos em superfície de vidro (MARSH, 1964). 
A Figura 2.13 mostra os mecanismos de desgaste observados em ferros fundidos brancos de alto cromo, submetidos a ensaios de moagem (ALBERTIN: SINATORA, 2001) e de britagem (AVERY, 1974).

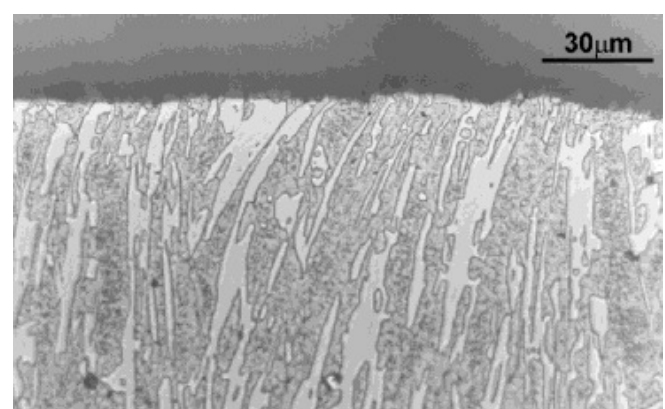

(A)

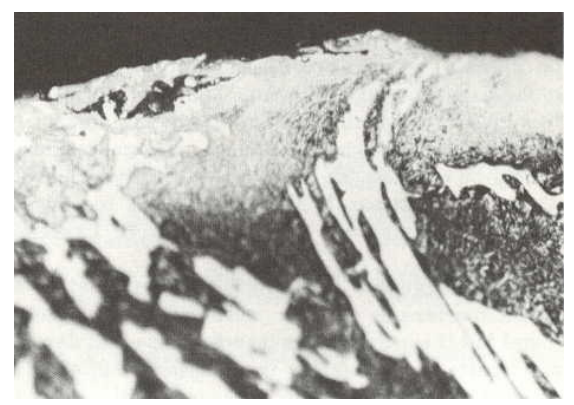

(B)

Figura 2.13. Deformação plástica de carbonetos $M_{7} C_{3}$ de ferros fundidos brancos de alto cromo com matriz predominantemente martensítica: (A) desgastado em ensaio de moagem (65 HRC) (ALBERTIN; SINATORA, 2001) e (B) desgastado em britador cônico industrial (63 HRC) (AVERY, 1974).

Uma possível explicação para resultados da Figura 2.12 foi proposta por SARE; ARNOLD (1989), com o modelo físico da Figura 2.14.

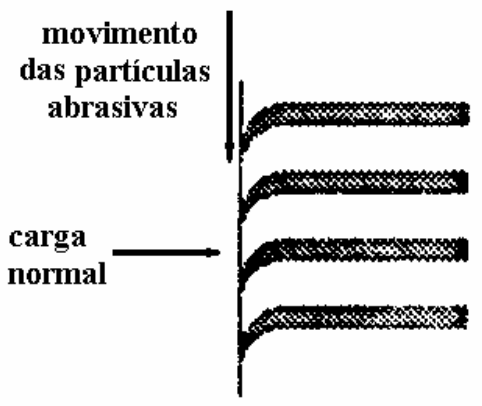

(a)

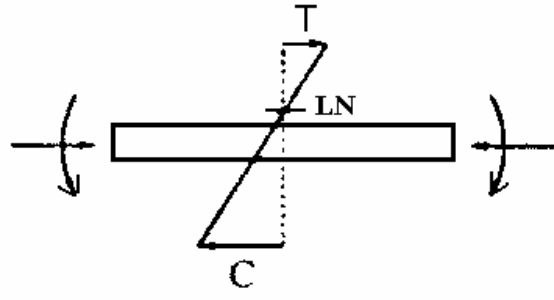

(b)

Figura 2.14. (a) Deformação plástica dos carbonetos causado pelo movimento das partículas abrasivas. (b) Zonas de tração (T) e compressão (C) em região contendo carbonetos sujeitos a esforços simultâneos de cisalhamento e de compressão. LN: linha neutra. (SARE; ARNOLD, 1989).

Considerando os carbonetos eutéticos como vigas em balanço, a Figura 2.14 mostra que a linha neutra (LN) está fora dos carbonetos sob esforços simultâneos de cisalhamento e de compressão, o que faz com que os carbonetos experimentem apenas tensões de compressão. SARE; ARNOLD consideraram o efeito que o tamanho médio 
dos carbonetos exerce sobre a posição da linha neutra: quanto maior o tamanho, maior é a dificuldade da região dos carbonetos experimentar apenas tensões de compressão.

Adicionalmente, SARE; ARNOLD (1989) mostraram que, além do tamanho médio dos carbonetos, a deformação dos carbonetos foi dependente da quantidade de deformação da matriz, não considerada no modelo da Figura 2.14. Nas situações em que foram observadas grandes deformações da matriz, os carbonetos trincaram subsuperficialmente, como mostra a Figura 2.15.

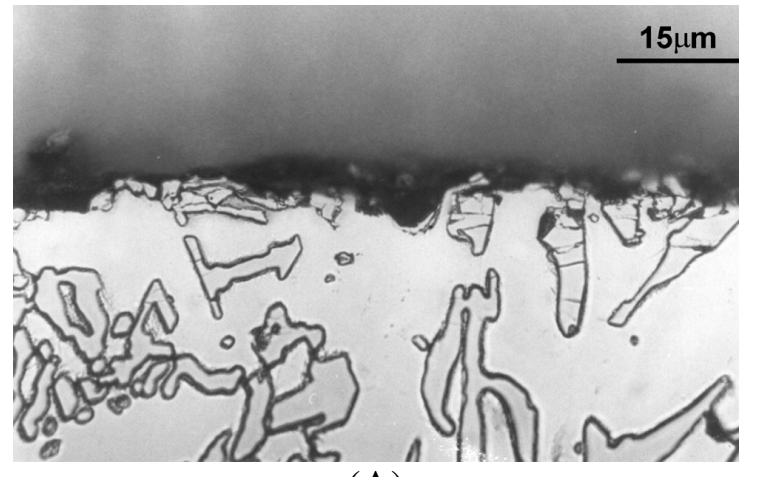

(A)

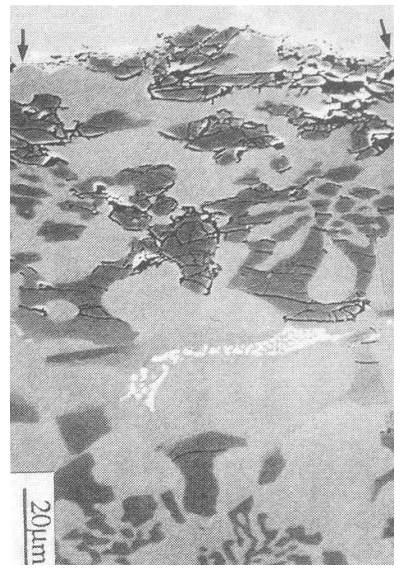

(B)

Figura 2.15. Microtrincamento subsuperficial de carbonetos $M_{7} C_{3}$ de ferros fundidos brancos de alto cromo com matriz predominantemente austenítica: (A) desgastado em ensaios em moinho de bolas (47 HRC) (ALBERTIN; SINATORA, 2001) e (B) desgastado em ensaios em britador de mandíbulas (52 HRC) (SARE; ARNOLD, 1989).

A Tabela 2.2 apresenta medidas de dureza Vickers realizadas por SARE; ARNOLD para o caso da Figura 2.15 (B), as quais podem ser utilizadas para avaliar o grau de deformação plástica da matriz.

Tabela 2.2 - Variação da dureza da matriz do ferro fundido branco 3,33C-16Cr em ensaios de britador de mandíbulas (SARE; ARNOLD, 1989).

\begin{tabular}{cccc}
\hline Matriz & $\mathrm{HV}_{30}$ (inicial) & $\mathrm{HV}_{5}$ (após desgaste) & Variação (\%) \\
\hline Austenítica & $550 \pm 10$ & $770 \pm 20$ & 40 \\
Martensítica & $870 \pm 20$ & $1.010 \pm 30$ & 16 \\
\hline
\end{tabular}


A Tabela 2.2 mostra que o encruamento da matriz predominantemente austenítica é bem maior do que o verificado para a matriz predominantemente martensítica. Este resultado possui relação com os obtidos por FRANCO; SINATORA (1994), apresentados na Figura 2.16, que mostram que a dureza da matriz afeta os resultados de tenacidade à fratura dos carbonetos $\mathrm{M}_{7} \mathrm{C}_{3}$, determinados em equipamento de dureza Vickers.

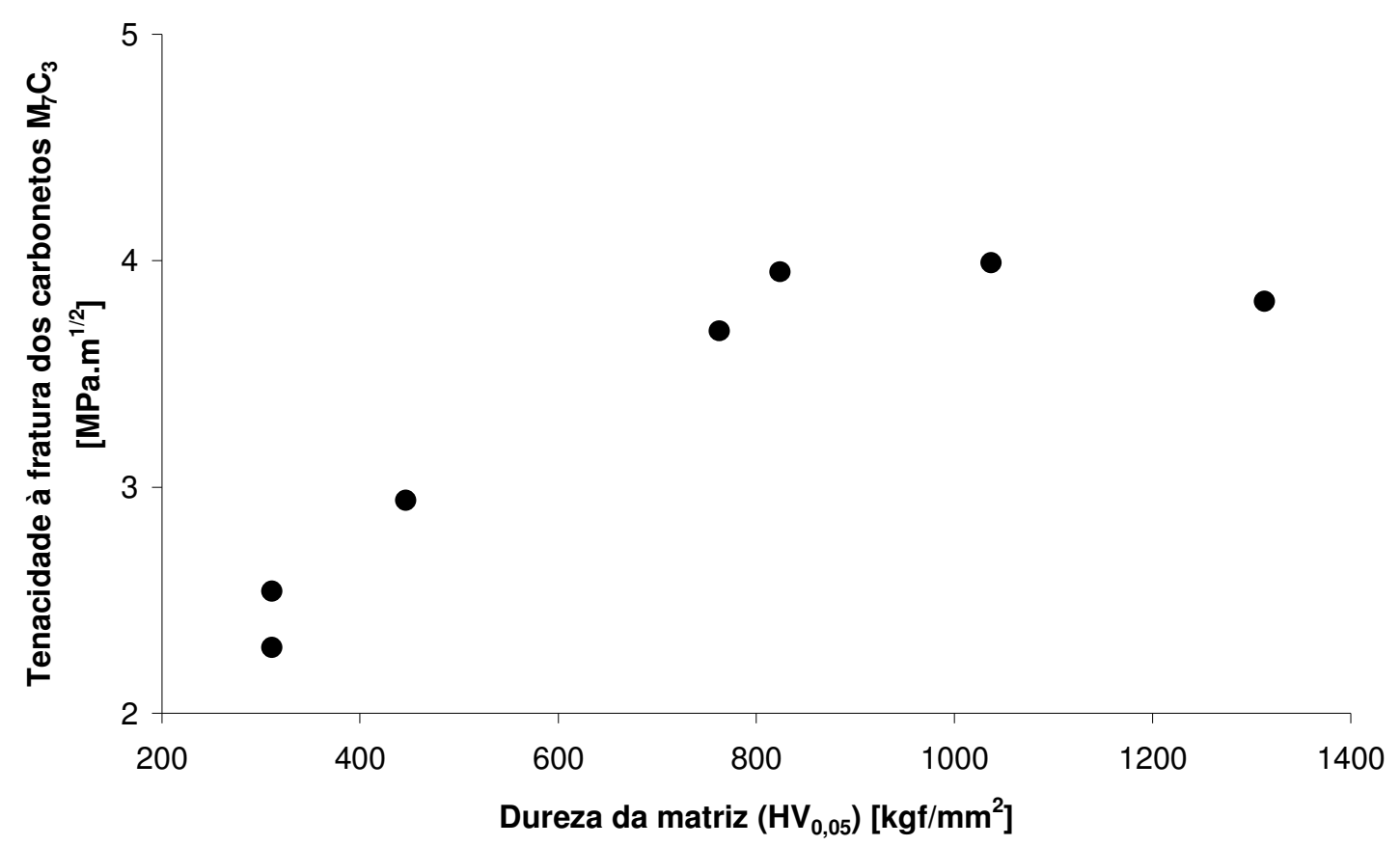

Figura 2.16. Variação da tenacidade à fratura de carbonetos $M_{7} C_{3}\left[M P a . m^{1 / 2}\right]$ de ferro fundido branco de alto cromo com a dureza da matriz $\left(\mathrm{HV}_{0,05}\right)\left[\mathrm{kgf} / \mathrm{mm}^{2}\right]$ (FRANCO; SINATORA, 1994).

A Figura 2.16 mostra que os valores de tenacidade à fratura aumentaram com a dureza da matriz. Para as matrizes mais duras, a tenacidade assumiu valores aproximadamente constantes, ou seja, acima de um certo valor de dureza o efeito da matriz diminui. Uma explicação para estes resultados é a combinação entre as tensões aplicadas nos carbonetos com o grau de deformação na matriz, que é maior à medida que a dureza diminui. Portanto, nos resultados da Figura 2.15, como esta combinação 
possibilitou uma grande deformação plástica da matriz, ocorreu o microtrincamento dos carbonetos.

A contribuição de uma fase de reforço, dura e frágil, para o aumento da resistência à abrasão depende da relação entre a dureza do abrasivo $\left(\mathrm{H}_{\mathrm{A}}\right)$ e a dureza da matriz metálica $\left(\mathrm{H}_{\mathrm{M}}\right)$ (ALBERTIN; SINATORA, 2001).

A Figura 2.17 (A) mostra o mecanismo de desgaste envolvendo o microtrincamento, sugerido por ALBERTIN; SINATORA em um ferro fundido branco de alto cromo martensítico, durante a moagem de quartzo. A Figura 2.17 (B) o microtrincamento do carboneto $\mathrm{M}_{7} \mathrm{C}_{3}$ devido ao riscamento por um grão de quartzo.

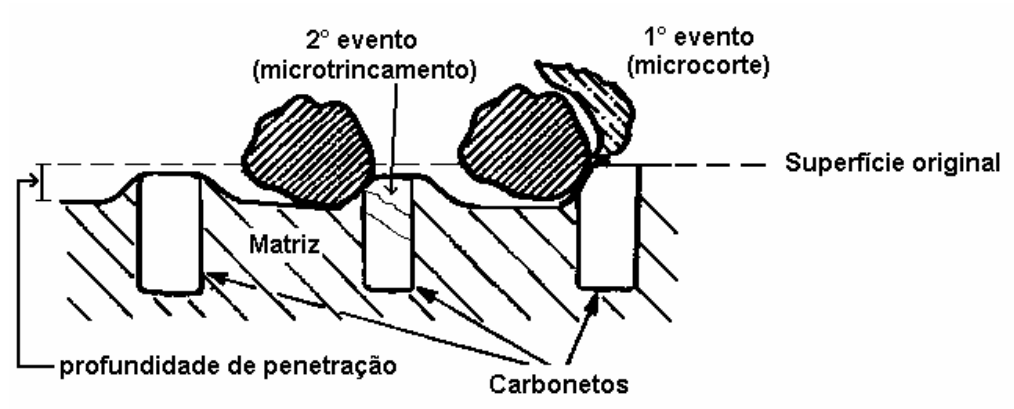

(A)

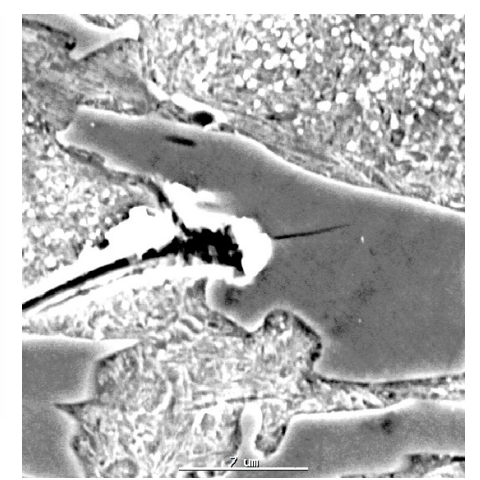

(B)

Figura 2.17. (A) Ilustração esquemática da sucessão de eventos que resultam no microtrincamento do carboneto $M_{7} C_{3}$ em ensaio de moagem. (B) Ferro fundido branco de alto cromo riscado por um grão de quartzo (ALBERTIN; SINATORA, 2001).

A Figura 2.17 mostra que o microtrincamento dos carbonetos ocorre pela falta de sustentação por parte da matriz metálica, desgastada pelo quartzo. Esta mesma explicação foi utilizada por LARSEN-BASSE; KOYANAGI (1979) para explicar o desgaste de metal duro (WC-Co) causado por este mesmo abrasivo.

Entretanto, há uma diferença fundamental entre as duas situações, devido à fração volumétrica de carbonetos WC em um metal duro ser muito superior à fração de carbonetos $\mathrm{M}_{7} \mathrm{C}_{3}$ em um ferro fundido branco de alto cromo. Nos metais duros, como o 
caminho livre médio na matriz é pequeno, o desgaste, tanto da matriz metálica por deformação plástica como dos carbonetos WC posteriormente por microtrincamento, ocorre somente após sucessivas interações entre o abrasivo e o material desgastado.

Dada esta diferença, provavelmente as taxas de desgaste verificadas por LARSEN-BASSE; KOYANAGI (1979) para metais duros seriam menores do que as taxas de materiais com menores frações volumétricas de carbonetos, quando ensaiados nas mesmas condições. De fato, isto foi verificado por BOZZI e colaboradores (1998) em ensaios de desgaste a três corpos (vide Tabela 1.1) e por PINTAÚDE e colaboradores (2000) em ensaios a dois corpos, ambos utilizando alumina como abrasivo.

BOZZI; DE MELLO (1999), diferentemente do observado por LARSEN BASSE; KOYANAGI (1979) verificaram em revestimentos WC-12\%Co $\left(1.200 \pm 200 \mathrm{HV}_{30}\right)$ a ocorrência de mecanismos controlados por deformação plástica, como mostra a Figura 2.18.

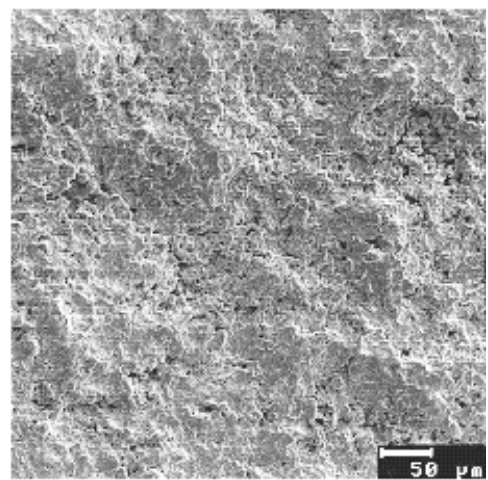

(A)

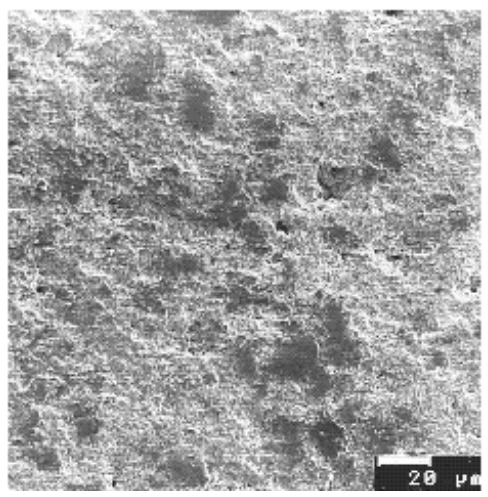

(B)

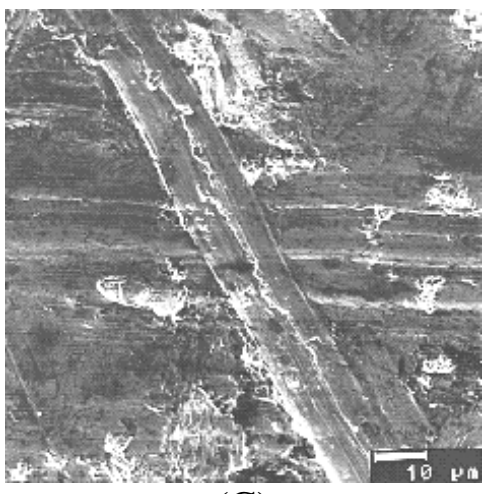

(C)

Figura 2.18. (A) Superfície inicial do revestimento $\mathrm{WC}-12 \%$ Co $\left(1.200 \pm 200 \mathrm{HV}_{30}\right)$. (B) Revestimento desgastado por quartzo $190 \mu \mathrm{m}$ em ensaio a três corpos com tensão nominal de $0,58 \mathrm{MPa}$. Notam-se microimpressões. (C) Mesmo material desgastado por alumina $260 \mu \mathrm{m}$. Nota-se microssulcamento (BOZZI; DE MELLO, 1999). 
A Figura 2.18 mostra que, em função do abrasivo utilizado, os mecanismos de desgaste transitaram de microimpressões para microssulcamento. Na Figura 2.18 (C) está evidente que ocorreu deformação plástica dos carbonetos WC, devido à largura dos sulcos formados. A deformação destes carbonetos em ensaios de dureza Vickers foi verificada por HIBBS; SINCLAIR (1981) em um estudo detalhado com microscopia eletrônica de transmissão. BOZZI; DE MELLO (1999) verificaram a ocorrência de mecanismos de desgaste controlados por fratura frágil nos revestimentos WC-12\%Co somente nos ensaios utilizando SiC como abrasivo.

Usualmente a literatura utiliza a razão $\mathrm{H}_{\mathrm{A}} / \mathrm{H}$ para a previsão dos regimes de desgaste, moderado e severo, apenas para as situações nas quais são verificados mecanismos controlados por deformação plástica, como realizado por BOZZI; DE MELLO (1999) em relação aos resultados da Figura 2.18.

A razão $\mathrm{H}_{\mathrm{A}} / \mathrm{H}$ foi utilizada para estimar os regimes de desgaste abrasivo de materiais frágeis por MOORE; KING (1980). Os resultados obtidos por estes pesquisadores em ensaios pino-contra-lixa utilizando $\mathrm{SiC}$ e sílex como abrasivos estão apresentados na Figura 2.19. 


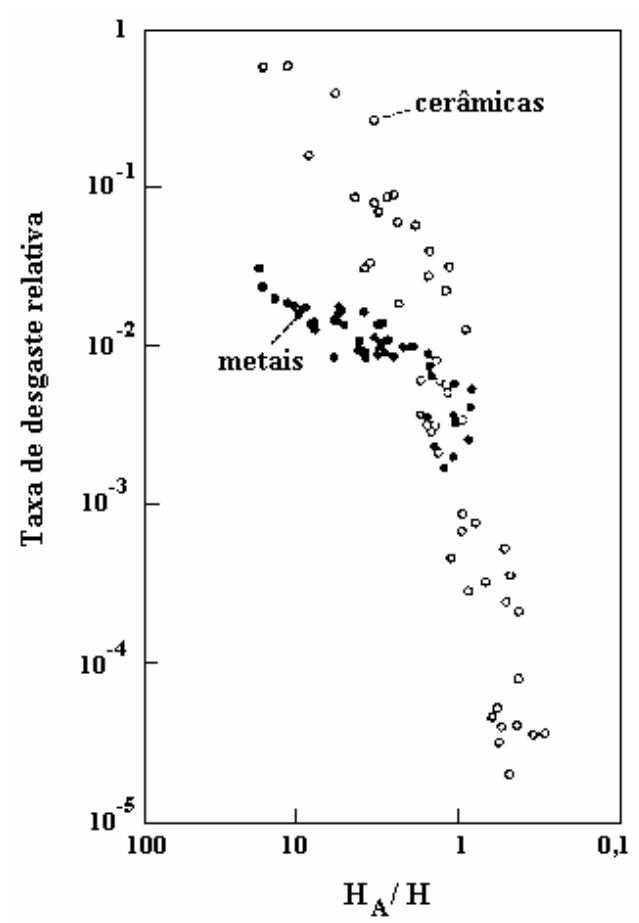

Figura 2.19. Variação da taxa de desgaste relativa em ensaios pino contra lixa com a razão $H_{\mathrm{A}} / \mathrm{H}$ (MOORE; KING, 1980).

A Figura 2.19 mostra que os materiais cerâmicos apresentam regiões com variações diferentes nas taxas de desgaste, sendo que a transição entre estas ocorre em um valor $\mathrm{H}_{\mathrm{A}} / \mathrm{H}$ em torno de 1 , o que coincide com a faixa de valores proposta para a transição em metais (KRUSCHOV, 1957 e RICHARDSON, 1968). Para valores $\mathrm{H}_{\mathrm{A}} / \mathrm{H}$ maiores que 1 , as cerâmicas apresentam taxas de desgaste bem superiores às dos metais e uma variação mais acentuada das mesmas. Além disso, MOORE; KING (1980) verificaram que a mudança na taxa de desgaste com o aumento do tamanho do abrasivo, para uma mesma razão $\mathrm{H}_{\mathrm{A}} / \mathrm{H}$, também foi mais acentuada nas cerâmicas do que nos metais, o que corrobora o modelo proposto por EVANS; WILSHAW (1976), apresentado na Figura 2.10. Estas variações mais bruscas nas taxas de desgaste abrasivo de cerâmicas em relação aos metais se devem à maior participação e à maior eficiência dos mecanismos de desgaste controlados por fratura frágil. 
Independentemente do tipo de mecanismo de desgaste abrasivo, como postulado por MOORE; KING (1980), "a dureza é certamente o fator mais importante na determinação do regime de desgaste, pois exerce um efeito marcante na deterioração das partículas abrasivas, e, conseqüentemente, na geometria das partículas e no tipo de contato". Isto está evidenciado na Figura 2.19 quando se observam taxas de desgaste semelhantes de metais e de cerâmicas, quando a razão $H_{\mathrm{A}} / \mathrm{H}$ situa-se em valores próximos de 1.

Portanto, parece pertinente o uso da razão $\mathrm{H}_{\mathrm{A}} / \mathrm{H}$ para a previsão dos regimes de desgaste abrasivo de materiais frágeis. Nestes casos, o mecanismo de microtrincamento estaria associado com o regime de desgaste severo e com altas razões $\mathrm{H}_{\mathrm{A}} / \mathrm{H}$. Nos casos de regime moderado de desgaste e de baixas razões $\mathrm{H}_{\mathrm{A}} / \mathrm{H}$, o mecanismo associado é de microssulcamento, controlado por deformação plástica.

Como a previsão dos regimes de desgaste abrasivo por meio da razão $\mathrm{H}_{\mathrm{A}} / \mathrm{H}$ é objeto de estudo desta Tese, é necessário abordar as teorias sobre dureza dos materiais, que são apresentadas a seguir.

\subsection{DUREZA DOS MATERIAIS}

\subsubsection{INTRODUÇÃO}

Dureza é a propriedade do material que exprime a capacidade de resistir à ação de um penetrador duro (TABOR, 1956). Usualmente a dureza é expressa pela relação entre a força de penetração e a área de contato final entre o penetrador e o material ensaiado, o que resulta em dimensões de pressão, tais como $\mathrm{N} / \mathrm{mm}^{2}$. Pode-se afirmar 
que o valor de dureza depende fundamentalmente de 3 variáveis: o material ensaiado, a geometria do penetrador e a força aplicada.

Os ensaios de dureza são classificados em três tipos (DIETER, 1967 e SOUZA, 1982): (a) dureza por riscamento; (b) dureza por choque e (c) dureza por penetração.

A dureza por riscamento tem importância para o estudo do desgaste abrasivo, como apresentado no capítulo 1. Além da dureza Mohs, descrita anteriormente, uma outra escala possui relevância para este trabalho. Em 1890, A. Martens definiu dureza por risco como a força em gramas-força sob a qual um diamante de ângulo de $90^{\circ}$ produziria um risco de $0,01 \mathrm{~mm}$ de largura num material qualquer (SOUZA, 1982). Atualmente, a dureza Martens possui outro conceito (WILDE; WEHRSTEDT, 2001) e pode ser medida por meio de ensaios instrumentados, como definido pela ISO/FDIS 14577-1 (ISO, 2002).

A dureza Shore é o único tipo de dureza por choque utilizada tecnicamente. Este tipo de dureza aplica-se em especial a borrachas e ensaios de campo em componentes metálicos de grande porte, tais com cilindros de laminação (SOUZA, 1982).

Existem diversos tipos de dureza por penetração em função da geometria do penetrador e das condições de aplicação de força. As durezas Brinell, Vickers e Rockwell destacam-se pela grande utilização (DIETER, 1967; ISO 6506-1, 1999; ISO 6507-1, 1997 e ISO 6508-1, 1999). Estes métodos compreendem uma grande gama de tipos de penetradores, que variam em geometria (esféricos, piramidais e cônicos) e que podem ser de diferentes materiais (aço, metal duro e diamante). 
A utilização de ensaios de dureza na escala microscópica permite a caracterização de microconstituintes dos materiais. No que se refere a este tipo de ensaio, a ASTM E384 99e1 (ASTM, 2001) especifica o uso dos penetradores Vickers e Knoop $^{(2.8)}$ com forças de ensaio entre 1 e 1000 gf $(0,098$ e 9,8 N). As geometrias destes penetradores estão indicadas na Figura 2.20. Nos casos em que a área de impressão reflete de forma fidedigna a geometria do penetrador Vickers, a diagonal de impressão corresponde a sete vezes a profundidade máxima de penetração.
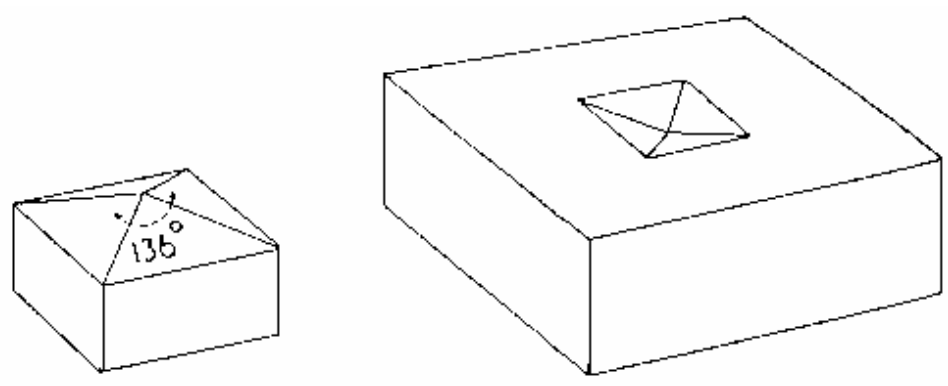

(A)
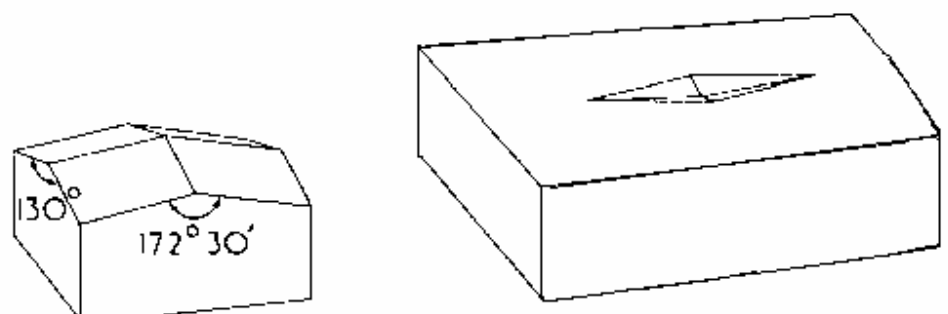

(B)

Figura 2.20. (A) Geometria e impressão Vickers. (B) Geometria e impressão Knoop (TABOR, 1956).

\footnotetext{
${ }^{2.8}$ Mais recentemente, em ensaios instrumentados de dureza, além do penetrador Vickers, tem sido utilizado com freqüência o penetrador Berkovich (ISO/FDIS 14577-1; ISO, 2002). O penetrador Berkovich tem geometria na forma de uma pirâmide triangular com ângulo entre faces de $65,3^{\circ}$. Para um material isotrópico e condições de ensaio semelhantes, os valores de dureza Berkovich e Vickers são os mesmos.
} 


\subsubsection{O CONCEITO DE ZONA PLÁSTICA}

A análise dos resultados de dureza depende do tipo de comportamento mecânico admitido para os materiais. Os comportamentos dos materiais, expressos em curvas de tensão-deformação ideais, são: rígido-plástico, elasto-plástico, elasto-plástico com encruamento linear e elasto-plástico com encruamento parabólico (MEYERS; CHAWLA, 1999). Neste item será apresentado um histórico dos modelos de comportamento mecânico para os materiais quando submetidos a ensaios de dureza. Os principais são:

1) Modelos segundo comportamento rígido-plástico e;

2) Modelos segundo comportamento elasto-plástico.

O diagrama de blocos apresentado na Figura 2.21 mostra, para cada um destes modelos, os pesquisadores que propuseram marcos no entendimento dos fenômenos envolvidos durante um ensaio de dureza.
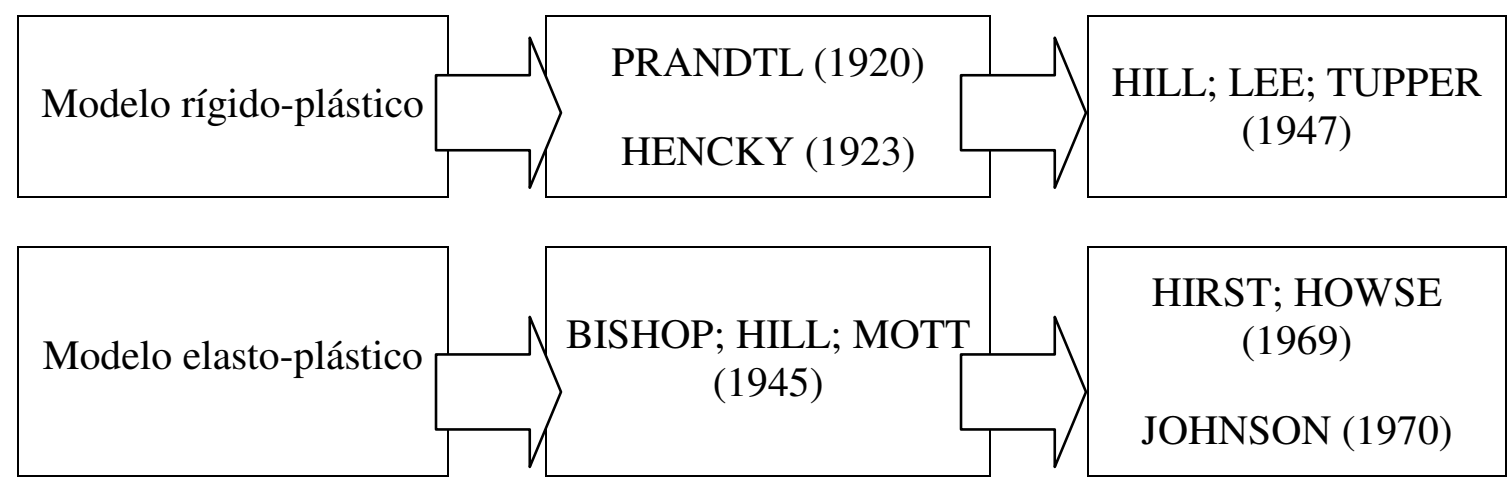

Figura 2.21. Diagrama de blocos que mostra as principais contribuições para a interpretação dos ensaios de dureza.

Em 1920, L. Prandtl, e posteriormente em 1923 H. Hencky (citados por TABOR, 1956), consideraram um material rígido-plástico, com comportamento mecânico expresso na Figura 2.22, e mostraram, com base na teoria dos campos de 
linhas de deslizamento, que a relação entre dureza $(\mathrm{H})$ e limite de escoamento (Y) é a da equação 2.1 para um punção plano ${ }^{(2.9)}$.

$\mathrm{H} / \mathrm{Y} \approx 3$ Equação 2.1

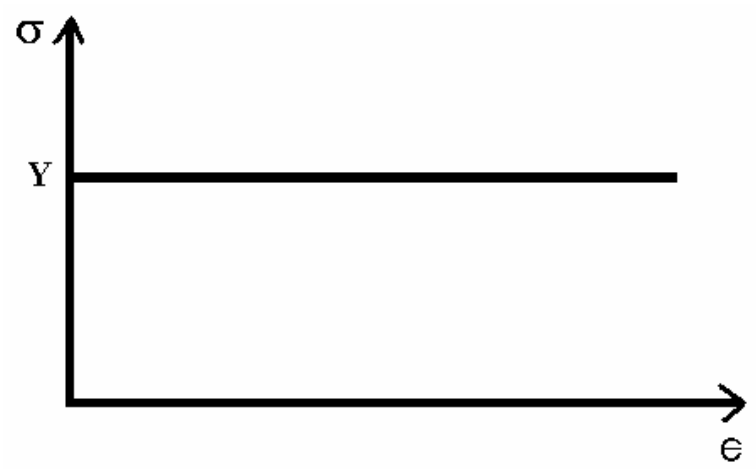

Figura 2.22. Curva esquemática de tensão-deformação de um material com comportamento rígido-plástico (MEYERS; CHAWLA, 1999). $\sigma$ : tensão verdadeira [MPa]; Y: limite de escoamento [MPa]; $\epsilon$ : deformação [mm/mm].

A equação 2.1 se aplica bem para os materiais metálicos e foi muito difundida devido ao trabalho de TABOR (1956), que verificou a relação para alumínio, cobre e aço baixo carbono, tanto para a dureza Brinell como para a dureza Vickers. Este pesquisador sugeriu que a mesma relação pudesse ser aplicada para penetradores cônicos.

Entretanto, HILL; LEE; TUPPER (1947) já haviam demonstrado que, no caso de penetradores cônicos, a relação entre dureza $(\mathrm{H})$ e limite de escoamento $(\mathrm{Y})$ depende do ângulo do cone ${ }^{(2.10)}$. Por exemplo, no caso da geometria da escala Rockwell C (semiângulo $\theta=60^{\circ}$ ) com o modelo proposto por estes pesquisadores, a relação da equação 2.1 passa a ser $\mathrm{H} / \mathrm{Y}=2,5$.

\footnotetext{
${ }^{2.9}$ Exemplos de solução detalhada para este problema podem ser encontrados em DIETER (1967), em McCOLM (1990) e em MEYERS; CHAWLA (1999).
} 
As simplificações sobre o comportamento mecânico dos materiais necessárias para a obtenção da equação 2.1 foram reconsideradas por BISHOP; HILL; MOTT (1945). Estes pesquisadores consideraram que os materiais são elasto-plásticos, como mostra a Figura 2.23, e não mais rígido-plásticos.

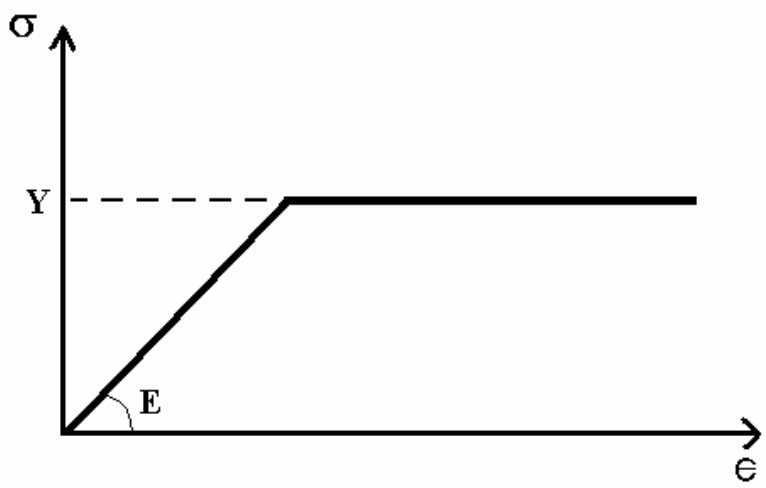

Figura 2.23. Curva esquemática de tensão-deformação de um material com comportamento elasto-plástico ideal (MEYERS, CHAWLA, 1999). E: módulo elástico [GPa].

BISHOP; HILL; MOTT (1945) modelaram o tipo de comportamento apresentado na Figura 2.23 considerando penetradores cônicos, e sugeriram a formação de uma região deformada plasticamente, como mostra a Figura 2.24.

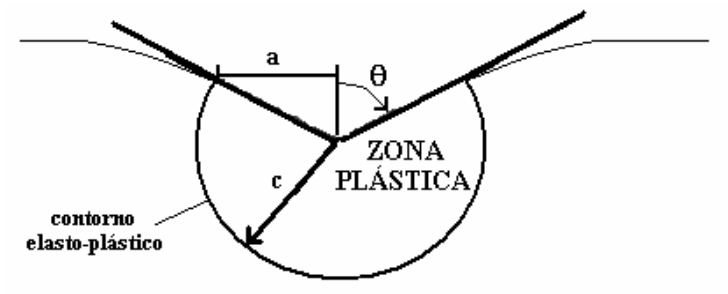

(A)

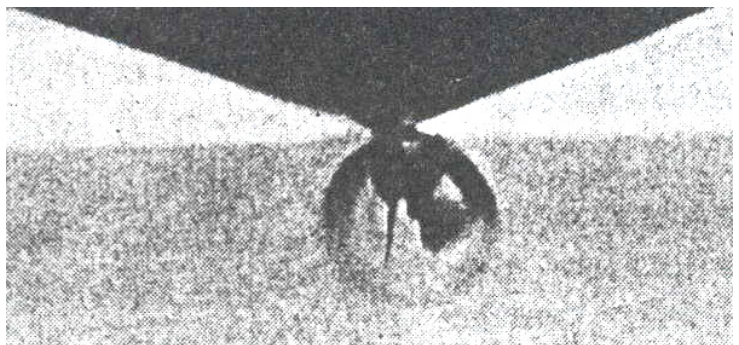

(B)

Figura 2.24. (A) Indicação da zona plástica formada devido ao contato de um penetrador com a superfície ensaiada. $c$ : raio da zona plástica; $a$ : raio de ação do penetrador (BISHOP; HILL; MOTT, 1945). (B) Observação direta da zona plástica em ensaio de dureza com força $250 \mathrm{~N}$ em vidro (LAWN; SWAIN, 1975).

\footnotetext{
${ }^{2.10}$ A modelagem matemática utilizada por HILL; LEE; TUPPER (1947) é bastante complexa (teoria dos campos de linhas de deslizamento) e pode ser verificada com detalhe em JOHNSON e colaboradores (1970).
} 
A geometria da zona plástica foi definida por BISHOP; HILL; MOTT (1945) por meio da equação 2.2:

$\frac{c}{a}=\left[\frac{E}{(1+v) Y}\right]^{\frac{1}{3}}$

Equação 2.2

onde,

$v$ é o coeficiente de Poisson e;

$c$ e $a$ são parâmetros definidos na Figura 2.24 (A).

A relação entre dureza $(\mathrm{H})$ e limite de escoamento $(\mathrm{Y})$ foi modelada por BISHOP; HILL; MOTT (1945), considerando a existência da zona plástica apresentada na Figura 2.24 e a natureza elasto-plástica dos materiais. Esta análise resultou na relação da equação 2.3:

$\frac{H}{Y}=\frac{2}{3}(1+3 \log c / a)$

Equação 2.3

HIRST; HOWSE (1969) analisaram a influência do ângulo de penetradores cônicos na relação entre dureza e limite de escoamento. Os resultados obtidos por estes pesquisadores em ensaios com chumbo estão apresentados na Figura 2.25.

Na Figura 2.25 está incluído o modelo de HILL; LEE; TUPPER (1947), baseado no comportamento rígido-plástico dos materiais. Observa-se na Figura o afastamento dos pontos experimentais com relação ao modelo rígido-plástico e que para os penetradores de maiores ângulos, os valores de H/Y se aproximam das previsões deste modelo. Nota-se ainda a influência da geometria do penetrador para o comportamento elasto-plástico, indicando que ao modelo da equação 2.3 precisa ser incorporado o efeito da geometria do penetrador. 


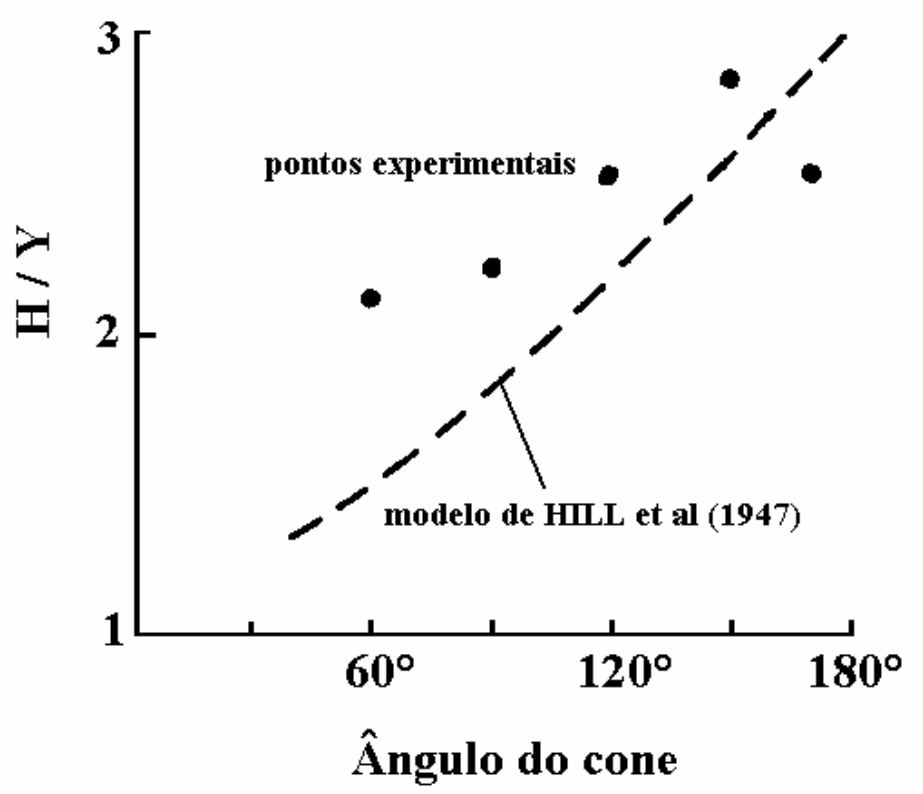

Figura 2.25. Variação da razão $H / Y$ em chumbo com o ângulo do penetrador cônico (HIRST; HOWSE, 1969).

O efeito da geometria do penetrador cônico para o modelo elasto-plástico foi considerado por JOHNSON (1970), ampliando a proposta de BISHOP; HILL; MOTT (1945), como mostra a equação 2.4:

$\frac{c}{a}=\left[\frac{E}{Y} \frac{\operatorname{tg}(\pi / 2-\theta)}{6(1-v)}+\frac{2}{3} \frac{(1-2 v)}{(1-v)}\right]^{\frac{1}{3}}$

Equação 2.4

JOHNSON (1970) propôs que a equação 2.4 fosse aplicada para penetradores Vickers. Neste caso, o ângulo $\theta$ de um cone é aquele que causa a mesma profundidade de penetração feita por um penetrador Vickers, que seria $70,3^{\circ}$. Uma alternativa simplificada à equação 2.4 para um penetrador Vickers é a equação 2.5 (CHIANG e colaboradores, 1982), que relaciona o parâmetro $a$ com a diagonal de impressão Vickers (d): 
$c / a \approx(c / \hat{\mathrm{a}})\left(2^{1 / 2} \pi / \cot \theta\right)^{1 / 3}$

Equação 2.5

onde,

$\hat{\mathrm{a}}=\mathrm{d} /\left(2^{1 / 2}\right.$. л)

A Figura 2.26 apresenta a variação da área de contato com a profundidade de penetração, nas escalas nano e micrométrica, para os penetradores Vickers e cônico de $70,3^{\circ}$.

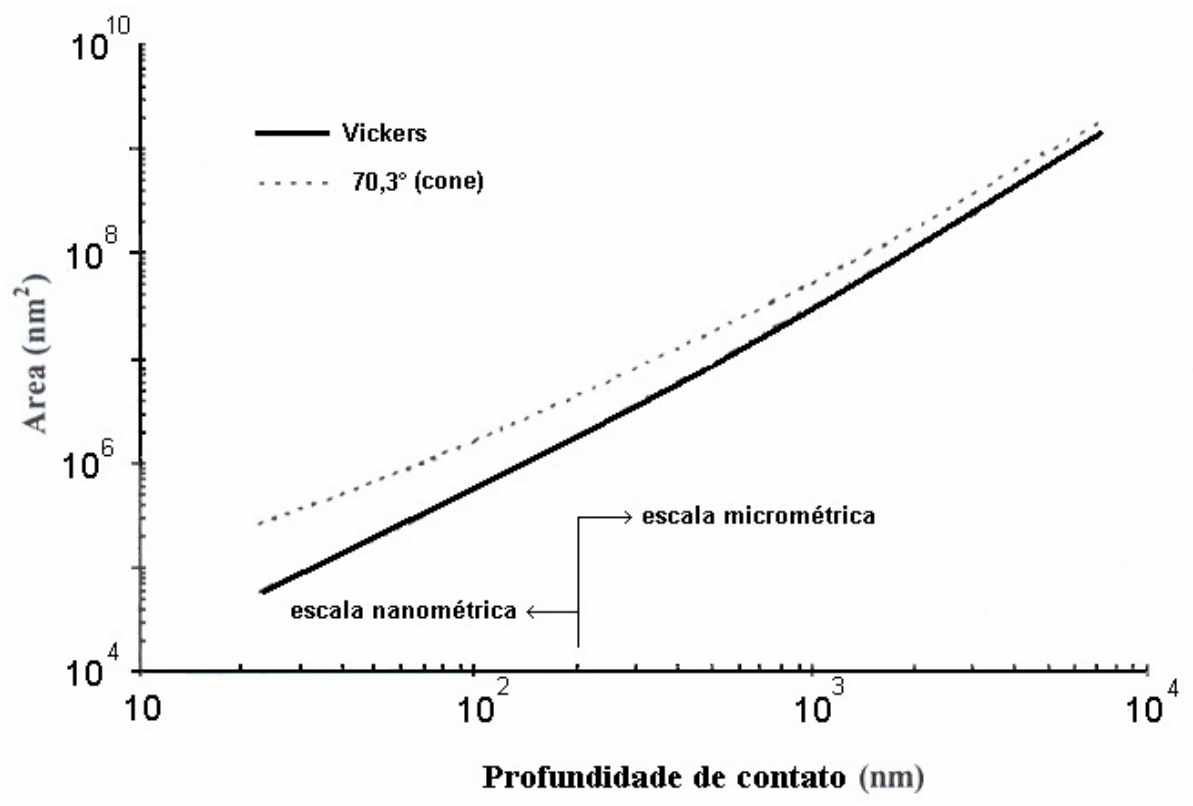

Figura 2.26. Variação da área de contato com a profundidade de contato, para penetradores Vickers e cônico de $70,3^{\circ}$. Curvas de ajuste de pontos experimentais (CSM Instruments, 2002).

Verifica-se na Figura 2.26 que na escala micrométrica (a partir de uma profundidade em torno de $1 \mu \mathrm{m})$ a área de contato correspondente ao penetrador cônico de $70,3^{\circ}$ apresenta pequenos desvios em relação à área correspondente ao penetrador Vickers. Portanto, a hipótese de JOHNSON (1970) sobre o uso da equação 2.4 para penetradores Vickers possui apoio experimental. 
LAWN e colaboradores (1980) propuseram um modelo alternativo ao de JOHNSON (1970) para o cálculo da extensão da zona plástica. O modelo está apresentado na equação 2.6:

$c / a \approx(E / H)^{1 / 2}(\cot \theta)^{1 / 3}$

Equação 2.6

Os resultados obtidos por LAWN e colaboradores (1980) em ensaios de dureza Vickers estão apresentados na Figura 2.27.

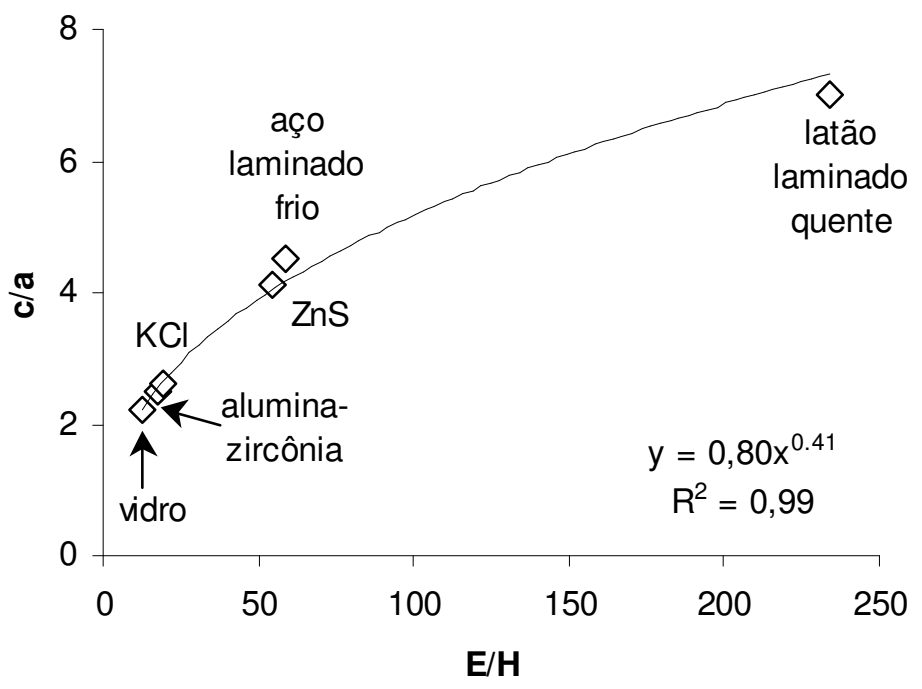

Figura 2.27. Variação da extensão da zona plástica, c/a, com a razão E/H, obtida para penetrador Vickers (LAWN e colaboradores, 1980).

Na Figura 2.27 foi acrescentada uma regressão dos pontos experimentais, na qual o expoente da equação $(0,41)$ está próximo do valor apresentado na equação 2.6 $(0,50)$, e o valor da constante $(0,80)$ é próximo de $\left(\cot 70,3^{\circ}\right)^{1 / 3}$. 
2.2.3 MODELOS E COMPORTAMENTO DOS MATERIAIS SOB APLICAÇÃO DE FORÇA EM ENSAIOS DE DUREZA VICKERS

A ASTM E384-99e1 (ASTM, 2001) define a dureza Vickers segundo a equação 2.7:

$H V=\frac{F}{A_{S}}=\frac{F}{d^{2} / 2 \operatorname{sen}\left(136^{\circ} / 2\right)}=\frac{1,8544 F}{d^{2}}$ Equação 2.7

onde,

HV é a dureza Vickers convencional [MPa];

F é a força aplicada $[\mathrm{N}]$;

$\mathrm{A}_{\mathrm{S}}$ é a área superficial ${ }^{(2.11)}\left[\mathrm{mm}^{2}\right] \mathrm{e}$;

d é a diagonal de impressão [mm].

A escala Vickers apresenta uma vantagem em relação às demais escalas de dureza por se aplicar a praticamente todas as classes de materiais, em uma extensa faixa de forças. Embora a definição da equação 2.7 suponha que a relação entre a área superficial e a força aplicada seja constante para um determinado material, isto não é verificado na prática. Observa-se que os valores de dureza costumam ser maiores à medida que os ensaios são conduzidos com forças menores. Esta variação é denominada efeito do tamanho de impressão ("indentation size effect") ${ }^{(2.12)}$ (SARGENT, 1989).

${ }^{2.11}$ Nomenclatura de acordo com a ISO/FDIS 14577-1 (ISO, 2002).

${ }^{2.12}$ Não há um consenso na literatura para explicar o efeito do tamanho de impressão. Duas teorias bastante citadas devem-se a LI e colaboradores (1993) e a STELMASHENKO e colaboradores (1993). 
BÜCKLE (1959) apresentou uma revisão dos modelos matemáticos utilizados para a dureza Vickers, no sentido de quantificar a variação da relação entre a força e a área de contato. O primeiro modelo utilizado para tanto foi uma extensão da relação entre a força aplicada e a área de contato, aplicada para a dureza Brinell, conhecida como lei de Meyer (TABOR, 1951), como mostra a equação 2.8:

$\mathrm{F}=\mathrm{Cd}^{\mathrm{m}}$

Equação 2.8

onde,

C é uma constante que depende do material ensaiado [MPa] e;

m é o índice de Meyer (TABOR, 1951), relacionado de forma direta com o coeficiente de encruamento, $n$, por meio da relação $m=n+2$, apenas no caso de penetradores esféricos.

Segundo BÜCKLE, a equação 2.8 pode ser aplicada no caso de penetradores piramidais como Vickers somente a partir de 29,4 N (3 kgf), situação na qual se verifica que o índice de Meyer assume valor constante em torno de 2.

Outro modelo apresentado por BÜCKLE para a dureza Vickers é uma extensão da equação 2.8 e está apresentado na equação 2.9:

$$
\mathrm{F}=\mathrm{a}_{1} d+a_{2} d^{2}
$$

onde,

$\mathrm{a}_{1}$ é o parâmetro com dimensão [N/mm] e;

$\mathrm{a}_{2}$ é o parâmetro com dimensão [MPa].

Segundo FRÖLICH e colaboradores (1977), o termo $\mathrm{a}_{1}$ corresponderia à energia despendida durante a penetração para a criação da impressão de dureza, ou seja, 
relacionado com a energia de superfície ${ }^{(2.13)}$, e o termo $\mathrm{a}_{2}$ corresponderia à energia gasta com a deformação plástica, ou seja, relacionado com a energia do volume. Além disso, estes pesquisadores estudaram o comportamento dos materiais em ensaios de dureza instrumentados, nos quais pode-se obter a curva de força em função da profundidade de penetração, como mostra a Figura 2.28.

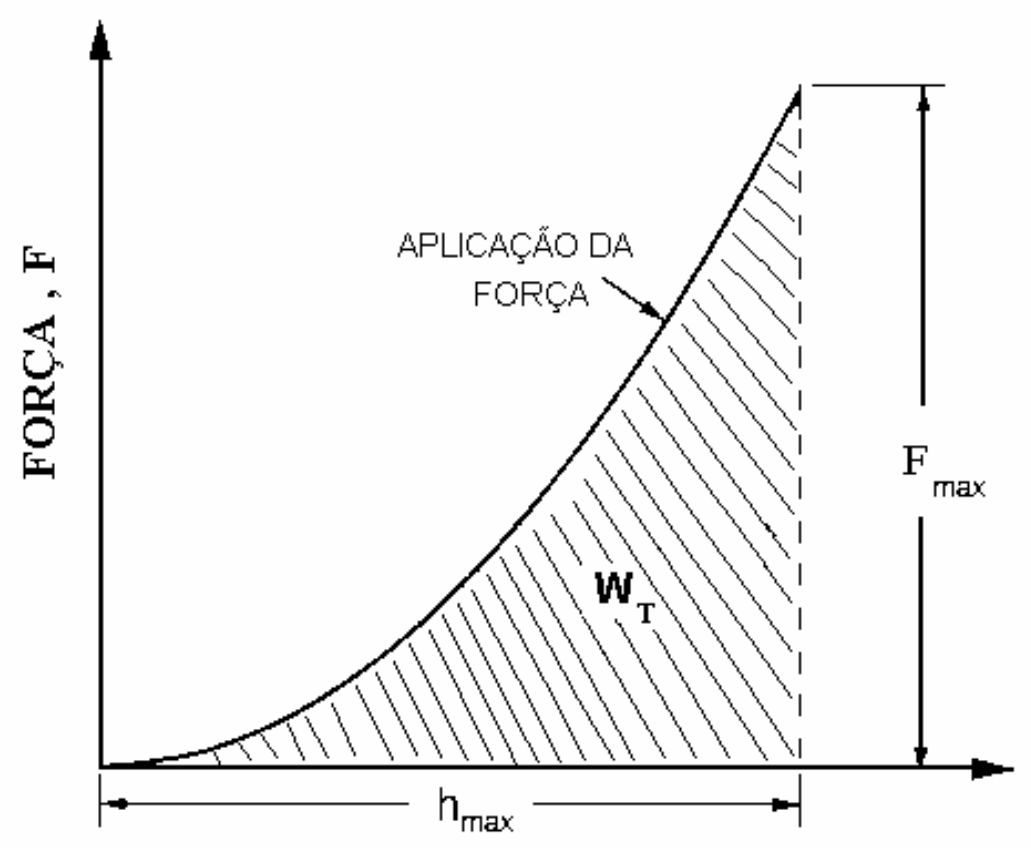

PROFUNDIDADE, $h$

Figura 2.28. Curva de aplicação da força de ensaios instrumentados de dureza (ISO/FDIS 14577-1; ISO, 2002). $h_{\text {máx }}$ profundidade máxima de penetração[ $\left.\mu \mathrm{m}\right]$; $\mathrm{F}_{\text {máx }}$ : força máxima $[\mathrm{N}] ; \mathrm{W}_{\mathrm{T}}$ : trabalho total realizado [N.m].

A partir de curvas como a da Figura 2.28 é possível calcular os parâmetros $m, \mathrm{a}_{1}$ e $\mathrm{a}_{2}$, definidos nas equações 2.8 e 2.9 , utilizando $\mathrm{h}$ ao invés de $\mathrm{d}$. ION e colaboradores (1990) propuseram uma forma de cálculo direta para $m$, como mostra a equação 2.10:

\footnotetext{
${ }^{2.13}$ HIRAO; TOMOZAWA (1987) sugeriram uma possível correlação entre o termo $\mathrm{a}_{1}$ (determinado em ensaios de dureza Knoop) e a tensão superficial $\gamma\left[\mathrm{J} / \mathrm{m}^{2}\right]$ para diversos tipos de vidros.
} 
$\mathrm{m}=\left(F_{\max } \cdot h_{\max } / \mathrm{W}_{\mathrm{T}}\right)-1$

Equação 2.10

FRÖLICH e colaboradores (1977) propuseram a equação 2.11 para calcular a dureza isenta do efeito do tamanho de impressão, $\mathrm{HM}_{\mathrm{S}}{ }^{(2.14)}$ :

$\mathrm{HM}_{\mathrm{S}}=\mathrm{a}_{2} \cdot \mathrm{k}$

Equação 2.11

onde,

k é um fator geométrico $(=26,43$ para penetrador Vickers).

Os valores da dureza $\mathrm{HM}_{\mathrm{S}}$ devem ser semelhantes aos determinados com forças superiores a 9,8 N (1 kgf), considerando-se que o efeito do tamanho de impressão deixa de ocorrer aproximadamente a partir deste valor, como mostra, por exemplo, a Figura 2.29 (LI e colaboradores, 1993).
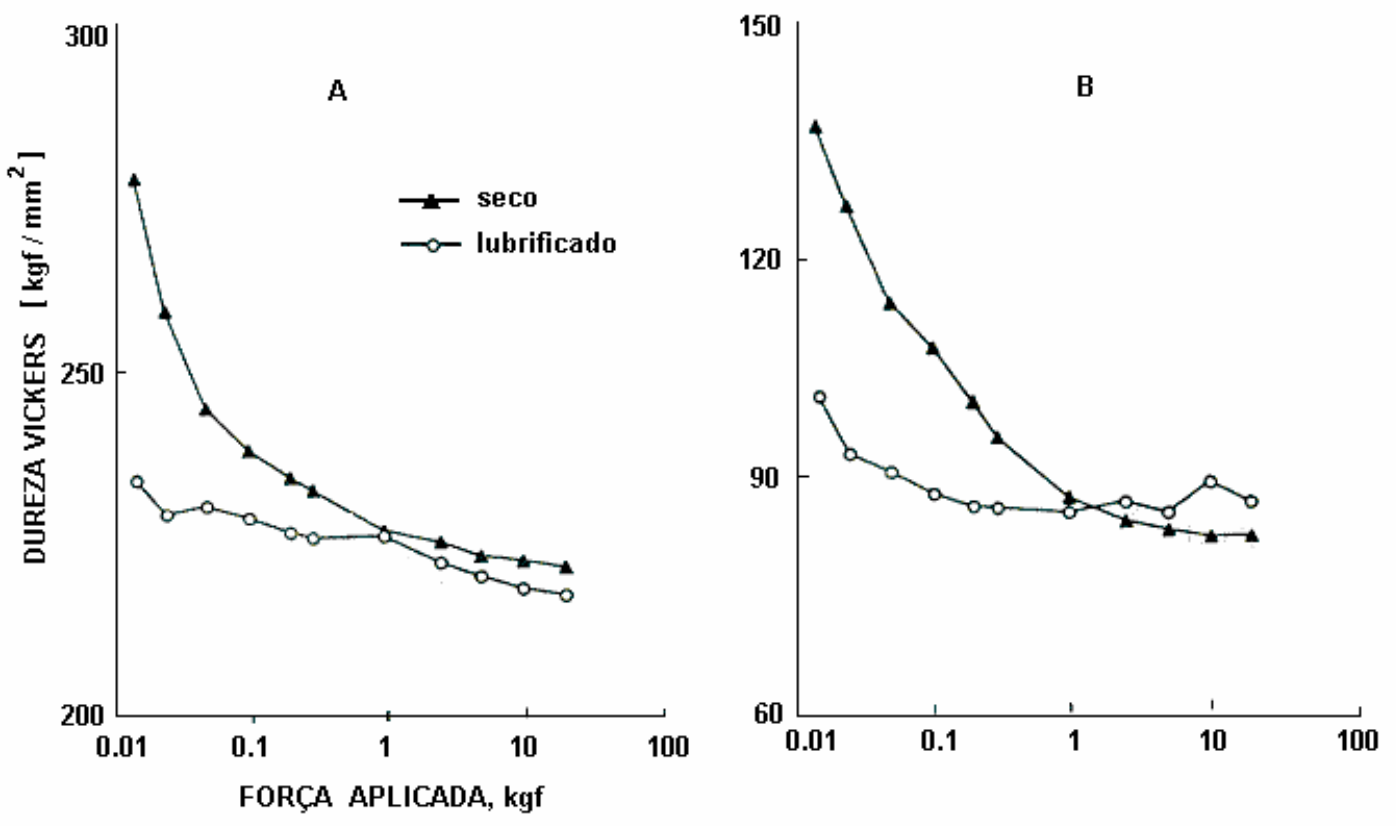

Figura 2.29. Efeito da força aplicada na dureza Vickers $\left[\mathrm{kgf} / \mathrm{mm}^{2}\right]$, em ensaios conduzidos com e sem lubrificação. (A) Cobre encruado (B) Cobre recozido (LI e colaboradores, 1993).

2.14 Nomenclatura adotada pela ISO/FDIS 14577-1 (ISO, 2002). FRÖLICH e colaboradores (1977) designaram este tipo de dureza por HVL. 
A Figura 2.29 mostra que a dureza tem valores aproximadamente constantes para forças maiores que 9,8 N, contrariamente do que afirmou BÜCKLE (1959), que esta estabilização ocorreria a partir de 29,4 N. Adicionalmente, observa-se nesta Figura que nos ensaios sem lubrificação, a partir de aproximadamente 9,8 $\mathrm{N}$, os valores de dureza passam a ter menores variações que nos ensaios com forças menores e, quando o ensaio é realizado com lubrificação, a faixa na qual a variação é reduzida se amplia.

A Tabela 2.3 mostra os resultados comparativos, obtidos por FRÖLICH e colaboradores (1977), entre a dureza Vickers HV, determinada de forma convencional com $0,98 \mathrm{~N}\left(\mathrm{HV}_{0,1}\right)$, e a dureza $\mathrm{HM}_{\mathrm{S}}$, obtida a partir das curvas de aplicação de força, isenta da variação devido à força aplicada.

Tabela 2.3 - Valores de dureza Vickers convencional $\left(H V_{0,1}\right)$ e razões entre $H V_{0,1}$ e a dureza sob carregamento $\left(\right.$ HM $\left._{S}\right)$ (FRÖLICH e colaboradores, 1977).

C1, C2 e C3: materiais cerâmicos.

\begin{tabular}{|c|cc|cccc|}
\cline { 2 - 7 } \multicolumn{1}{c|}{} & \multicolumn{3}{c|}{ GRUPO 1 } & \multicolumn{4}{c|}{ GRUPO 2 } \\
\cline { 2 - 7 } \multicolumn{1}{c|}{} & Latão & Aço baixo C & Vidro & $\mathrm{C} 1$ & $\mathrm{C} 2$ & $\mathrm{C} 3$ \\
\hline $\mathrm{HV}_{0,1}\left[\mathrm{kgf} / \mathrm{mm}^{2}\right]$ & 122 & 252 & 540 & 988 & 1220 & 900 \\
\hline $\mathrm{HV}_{0,1} / \mathrm{HM}_{\mathrm{S}}$ & 1,09 & 1,17 & 2,10 & 2,31 & 2,71 & 2,80 \\
\hline
\end{tabular}

A Tabela 2.3 mostra que os valores $\mathrm{HM}_{\mathrm{S}}$ foram menores que $\mathrm{HV}_{0,1}$ para todos os materiais estudados. Este resultado está de acordo com o conceito que a dureza $\mathrm{HM}_{\mathrm{S}}$ é independente do efeito do tamanho de impressão. Além disso, para os materiais do grupo 1, as razões $\mathrm{HV}_{0,1} / \mathrm{HM}_{\mathrm{S}}$ são próximas de 1 , enquanto que para o grupo 2 estas razões são maiores que 2. Esta diferença pode estar associada com a maior participação da componente elástica na etapa de aplicação de força dos materiais com baixas razões $\mathrm{E} / \mathrm{H}$. 
Com o advento dos ensaios instrumentados de dureza houve a necessidade de novas definições para os valores de dureza medidos. Com base na proposta de nomenclatura feita por WILDE; WEHRSTEDT (2001), a ISO/FDIS 14577-1 (ISO, 2002) definiu a dureza Martens $(H M)^{(2.15)}$, como mostra a equação 2.12:

$$
H M=\frac{F_{\text {máx }}}{A_{S}}=\frac{F_{\text {máx }}}{k h_{\text {máx }}^{2}}
$$

onde,

k é um fator geométrico, definido na equação 2.11 .

FRÖLICH e colaboradores (1977) obtiveram resultados comparativos entre a dureza convencional $\left(\mathrm{HV}_{0,1}\right)$ e a dureza Martens (HM), que estão apresentados na Tabela 2.4.

Tabela 2.4 - Valores de dureza Vickers convencional $\left(H_{V_{0,1}}\right)$ e razões entre $H_{0,1}$ e a dureza Martens (HM) (FRÖLICH e colaboradores, 1977). C1, C2 e C3: materiais cerâmicos.

\begin{tabular}{|c|ccc|cccc|}
\cline { 2 - 8 } \multicolumn{1}{c|}{} & \multicolumn{3}{c|}{ GRUPO 1 } & \multicolumn{4}{c|}{ GRUPO 2 } \\
\cline { 2 - 8 } \multicolumn{1}{c|}{} & Latão & Aço baixo C & AlMg5 & Vidro & C1 & C2 & C3 \\
\hline $\mathrm{HV}_{0,1}\left[\mathrm{kgf} / \mathrm{mm}^{2}\right]$ & 122 & 252 & 103 & 540 & 988 & 1220 & 900 \\
\hline $\mathrm{HV}_{0,1} / \mathrm{HM}$ & 0,60 & 0,75 & 0,76 & 1,74 & 1,89 & 2,31 & 2,25 \\
\hline
\end{tabular}

A Tabela 2.4 mostra que para os materiais do grupo 1, que podem ser considerados como rígido-plásticos $(\mathrm{H} / \mathrm{Y} \approx 3)$, $\mathrm{HM}$ é maior que $\mathrm{HV}_{0,1}$. Por outro lado, o grupo 2 é caracterizado por materiais com comportamento elasto-plástico ideal e apresentam $\mathrm{HM}$ menor que $\mathrm{HV}_{0,1}$.

${ }^{2.15}$ Inicialmente denominada por dureza Universal (HU) (WEILER, 1989). 
FRÖLICH e colaboradores (1977) não apresentaram uma explicação para os diferentes valores $\mathrm{HV}_{0,1} / \mathrm{HM}$ da Tabela 2.4. Estes pesquisadores sugeriram que as morfologias de impressão de dureza, usualmente denominadas por piling-up e sinkingin $^{(2.16)}$, pudessem ser os fenômenos que determinariam os valores $\mathrm{HV}_{0,1} / \mathrm{HM}$.

Os termos piling-up e sinking-in precisam ser incorporados ao vocabulário técnico da língua portuguesa. SOUZA (1982) apresentou os termos aderência e afundamento, respectivamente. O "Dicionário Metalúrgico" (TAYLOR, 1994) apresenta os termos acumulação e empilhamento para piling-up. Este trabalho considera que os termos mais adequados sejam respectivamente formação de bordas e retração, que serão adotados a partir deste ponto.

A Figura 2.30 apresenta ilustrações da formação de bordas.

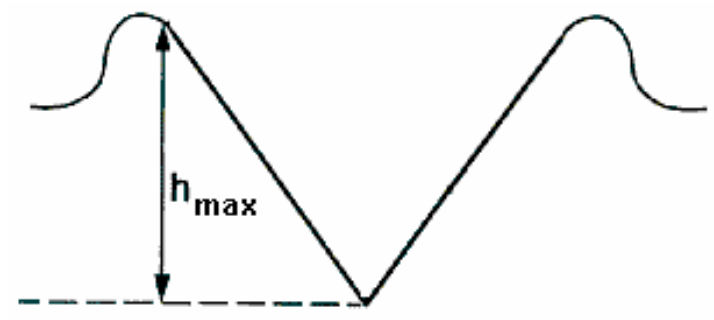

(A)

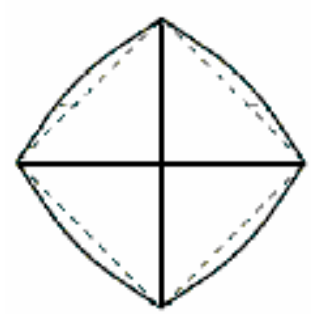

(B)

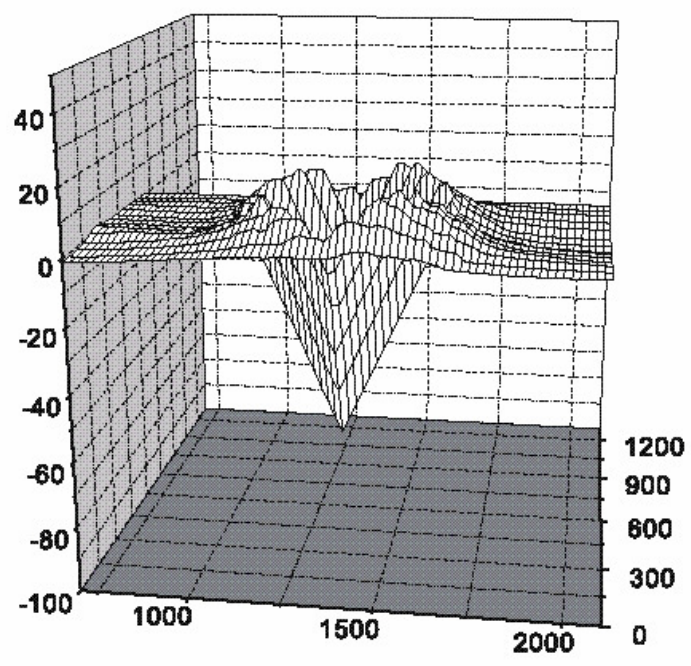

(C)

Figura 2.30. Impressão de dureza Vickers com formação de bordas: (A) esquema da seção transversal e (B) esquema da vista superior. (C) Imagem tridimensional de superfície de cobre encruado após ensaio de dureza Vickers com $160 \mathrm{~N}$ (ALCALÁ e colaboradores, 2000).

2.16 Estas nomenclaturas foram utilizadas em relação à dureza Brinell em 1928 (NORBURY; SAMUEL, 1928). 
CHAUDHRI; WINTER (1988), em ensaios de dureza com cobre encruado e aço baixo carbono encruado utilizando penetradores cônico e Vickers, mostraram que a formação de bordas ocorre durante a etapa de aplicação de força em um ensaio de dureza. Isto permite afirmar que este fenômeno é independente da recuperação elástica dos materiais e é controlado ao mesmo tempo pelas componentes elástica e plástica durante a aplicação de força.

A Figura 2.31 apresenta ilustrações da retração.

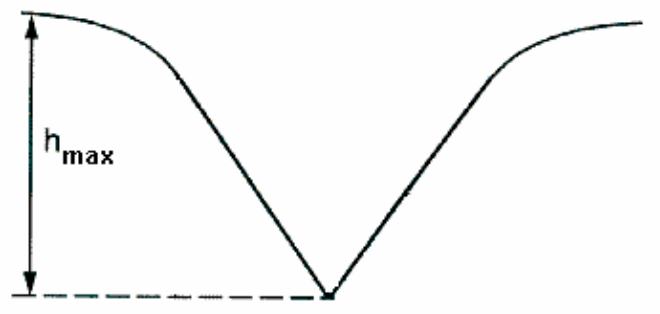

(A)

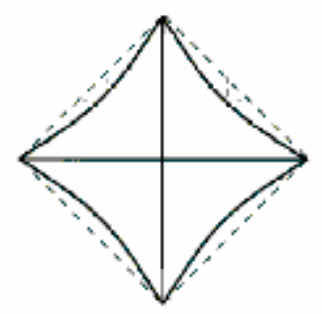

(B)

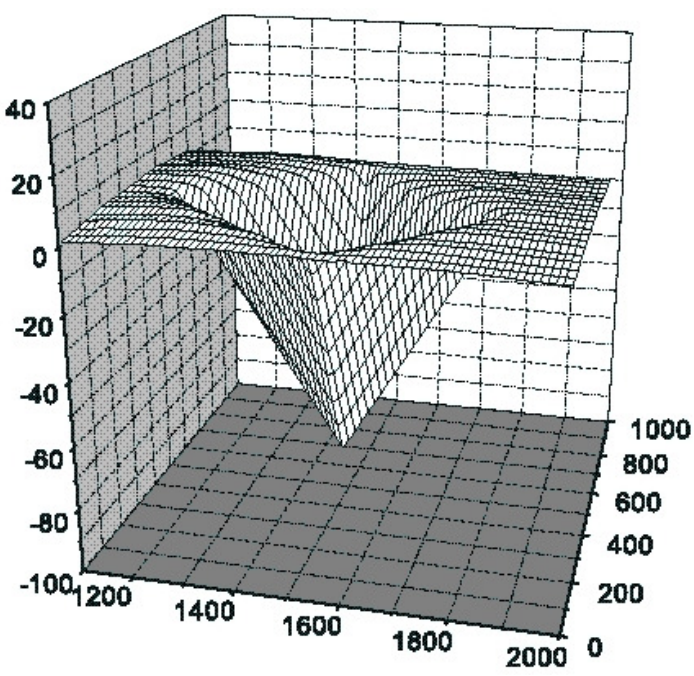

(C)

Figura 2.31. Impressão de dureza Vickers com retração: (A) esquema da seção transversal e (B) esquema da vista superior. (C) Imagem tridimensional de superfície de cobre recozido após ensaio de dureza Vickers com $100 \mathrm{~N}$ (ALCALÁ e colaboradores, 2000).

COOK; PHARR (1990) também observaram que a retração ocorre durante a aplicação de força, como mostra a Figura 2.32. 


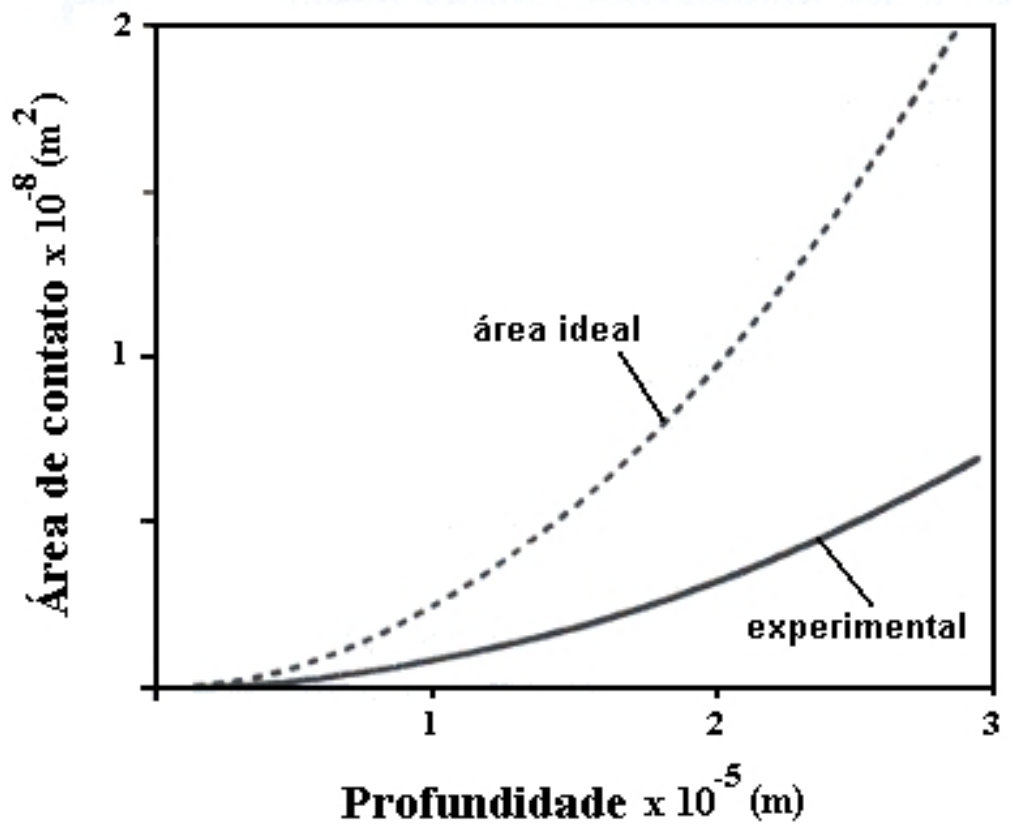

Figura 2.32. Variação da área de contato com a profundidade de vidro durante a aplicação da força em ensaio de dureza Vickers com 40 N (COOK; PHARR, 1990).

A Figura 2.32 mostra que a área de contato entre o vidro e o penetrador Vickers durante a aplicação de força foi aproximadamente 3 vezes menor do que a área ideal, caracterizando a retração do volume da impressão de dureza para o vidro.

Diversos pesquisadores propuseram que fossem calculados parâmetros a partir de curvas como a da Figura 2.32 com o objetivo de prever a morfologia da impressão de dureza (formação de bordas ou retração). A Tabela 2.5 sintetiza estas propostas.

Tabela 2.5 - Definição de parâmetro $(\alpha)$ para a previsão da ocorrência das morfologias de impressão de dureza, segundo ZENG e colaboradores (1996), GIANNAKOPOULOS; SURESH (1999) e ALCALÁ e colaboradores (2000).

\begin{tabular}{|c|ccc|}
\cline { 2 - 4 } \multicolumn{1}{c|}{} & ZENG et al. (1996) & $\begin{array}{c}\text { GIANNAKOPOULOS; } \\
\text { SURESH (1999) }\end{array}$ & $\begin{array}{c}\text { ALCALÁ et al. } \\
(2000)\end{array}$ \\
\hline Definição de $\alpha$ & $\left(24,5 . \mathrm{h}_{\text {máx }}{ }^{2}\right) /\left(0,54 . \mathrm{d}^{2}\right)$ & $\mathrm{h}_{\mathrm{P}} / \mathrm{h}_{\text {máx }}$ & $\left(\mathrm{h}_{\mathrm{C}} / \mathrm{h}_{\mathrm{S}}\right)^{2}$ \\
\hline Bordas & $\alpha<1$ & $\alpha>0,875$ & $\alpha^{1 / 2}-1>0$ \\
\hline Retração & $\alpha>1$ & $\alpha<0,875$ & $\alpha^{1 / 2}-1<0$ \\
\hline
\end{tabular}


ZENG e colaboradores (1996) apresentaram um parâmetro para previsão da ocorrência da formação de bordas ou retração em ensaios de dureza, como na equação 2.13:

$$
\alpha=\frac{24,5 \cdot h_{\max }^{2}}{d^{2} / 1,854}
$$

A equação 2.13 utiliza a área projetada da superfície definida pela profundidade máxima de penetração $\left(24,5 \mathrm{~h}_{\text {máx }}^{2}\right)$ e a área superficial do plano definido pelas diagonais de impressão $\left(\mathrm{d}^{2} / 1,854\right)$, portanto, quando o valor de $\alpha$ é 1 não há ocorrência de nenhuma das morfologias; valores maiores que 1 ocorrem nos casos em que se observa a retração e menores que 1 correspondem à formação de bordas.

A análise da proposta de ZENG e colaboradores (1996) mostra que os resultados comparativos entre dureza convencional HV e Martens HM obtidos por FRÖLICH e colaboradores (1977), apresentados na Tabela 2.4, não são fortuitos. De fato, FRÖLICH e colaboradores indicaram que a morfologia de impressão poderia explicar a diferença nos valores de $\mathrm{HV}_{0,1} / \mathrm{HM}$ entre dois grupos de materiais estudados. É importante ressaltar que a definição da dureza HM difere por uma constante da definição de ZENG e colaboradores (1996), 26,43 para 24,5. No caso dos resultados da Tabela 2.4, esta constante não afeta a análise da previsão da morfologia de impressão (formação de bordas para o grupo 1 de materiais e retração para o grupo 2).

Posteriormente à proposta de ZENG e colaboradores (1996), duas outras surgiram para a definição do parâmetro $\alpha$. Uma destas deve-se a GIANNAKOPOULOS; SURESH (1999). Para estes pesquisadores a formação de bordas ou retração pode ser avaliada com a razão $\left(h_{P} / h_{\text {máx }}\right)$, ou seja, a profundidade final após a remoção da força e a profundidade máxima de penetração. 
Resultados obtidos por STRANGE; VARSHNEYA (2001) para liga de alumínio 6061-T6, utilizando 4,6 N, mostraram que a altura das bordas correspondeu a $20 \%$ da profundidade final $h_{P}$. A razão $\left(h_{P} / h_{\text {máx }}\right)$ observada por estes pesquisadores foi $0,90 \pm 0,01$, o que corrobora a proposta de GIANNAKOPOULOS; SURESH (1999) para a previsão da morfologia de impressão (Tabela 2.5).

Uma outra proposta para a previsão de formação de bordas ou retração, apresentada na equação 2.14, deve-se a ALCALÁ e colaboradores (2000):

$\alpha=\left(\mathrm{h}_{\mathrm{C}} / \mathrm{h}_{\mathrm{S}}\right)^{2}$

Equação 2.14

onde,

$\mathrm{h}_{\mathrm{C}}$ é a profundidade de contato (definido na Figura 2.33) e;

$\mathrm{h}_{\mathrm{S}}$ é a profundidade defletida $\left(=\mathrm{h}_{\text {máx }}-\mathrm{h}_{\mathrm{C}}\right)$.

A Figura 2.33 mostra a definição da profundidade de contato e sua relação com a extensão da zona plástica, para um caso no qual está caracterizada a retração.

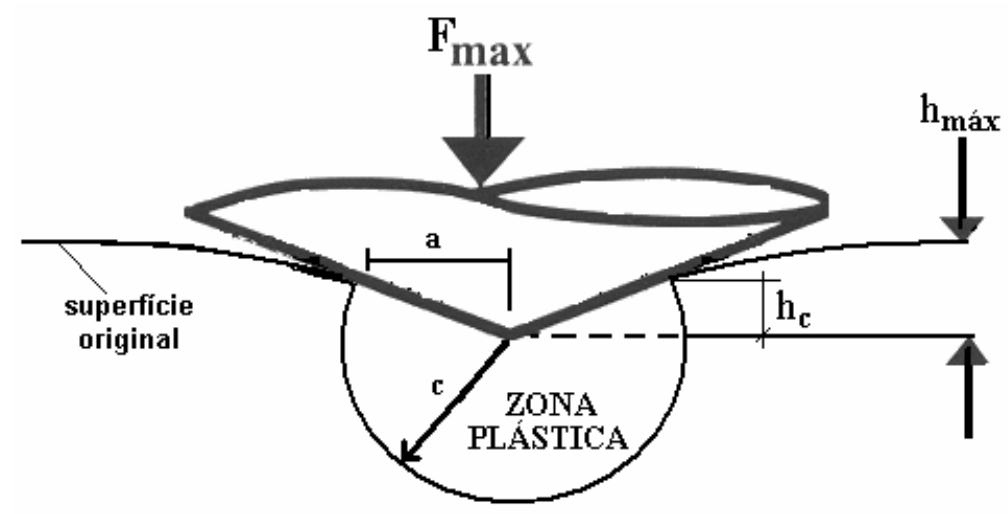

Figura 2.33. Indicação da profundidade de contato, $\mathrm{h}_{\mathrm{C}}$, em relação à extensão da zona plástica, em um caso de retração (ISO/FDIS 14577-1; ISO, 2002).

A extensão da zona plástica é afetada quando ocorre a formação de bordas. A Figura 2.34 mostra, de forma esquemática, a extensão da zona plástica neste caso (CSM Instruments, 2002). 


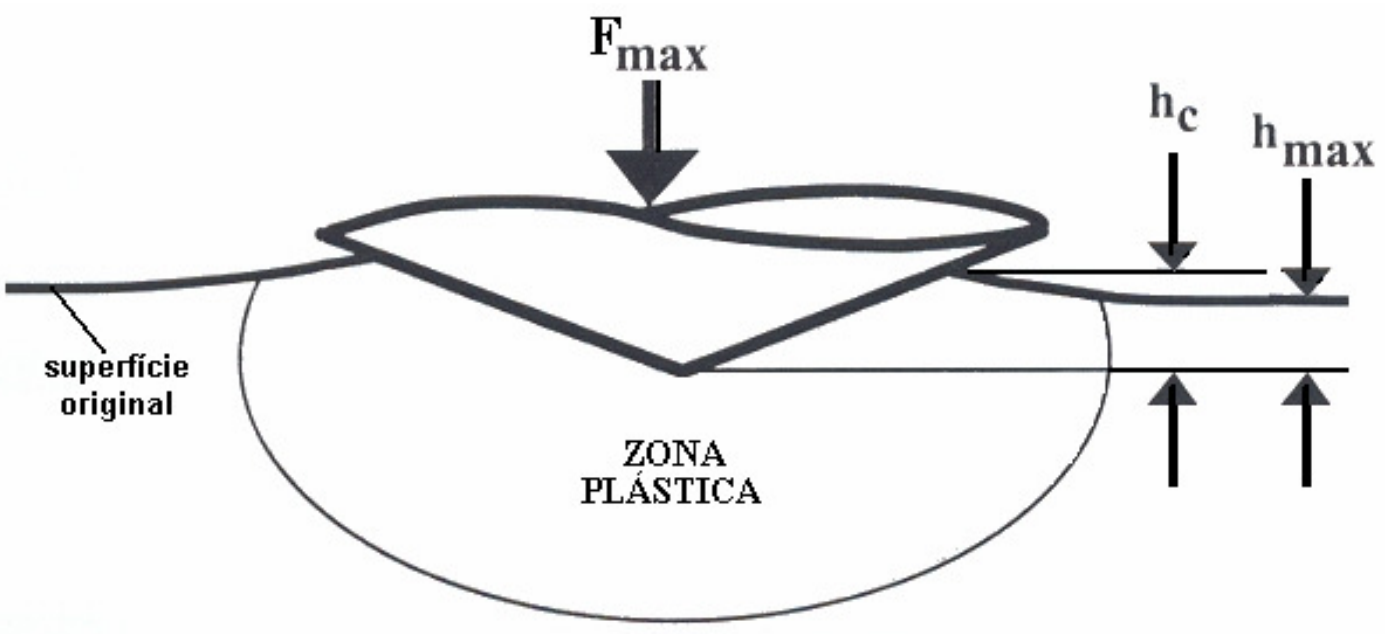

Figura 2.34. Extensão da zona plástica em caso de formação de bordas, com indicação da profundidade de contato $h_{C}$ (CSM Instruments, 2002).

A Figura 2.34 mostra que a extensão da zona plástica passa a ser maior nos casos em que há formação de bordas do que naqueles onde ocorre a retração (Figura 2.33). Além disso, a profundidade de contato é maior do que a profundidade máxima de penetração. Neste caso, a utilização da dureza Martens HM é mais adequada para a estimativa da área relativa à zona plástica, pois a dureza Vickers convencional, determinada pelo tamanho das diagonais de impressão, despreza a formação de bordas.

STELMASHENKO e colaboradores (1993) apresentaram um modelo para o escoamento de material durante um ensaio de dureza. Segundo estes pesquisadores, o escoamento ocorre preferencialmente em duas direções, como mostra a Figura 2.35.

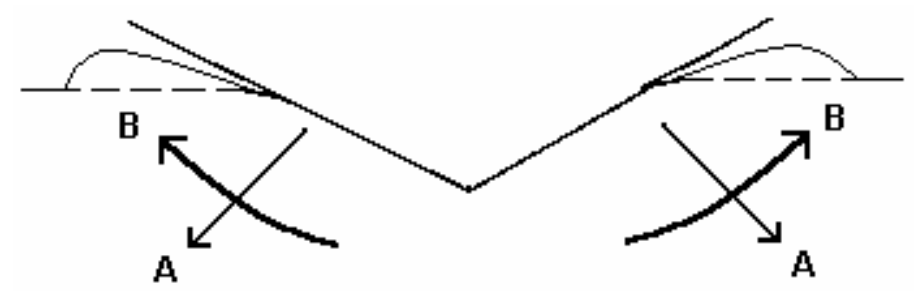

Figura 2.35. Indicação esquemática dos tipos de escoamento plástico em um ensaio de dureza, segundo STELMASHENKO e colaboradores (1993). 
Para STELMASHENKO e colaboradores (1993) o campo de deslocamento segundo a direção A gera um armazenamento local de material no volume, causando tensões compressivas elásticas, que são compensadas por tensões de tração para fora do deste campo. A recuperação elástica da profundidade de penetração após a remoção da força é uma medida da quantidade de escoamento do tipo A. Por outro lado, em caso de um escoamento exclusivamente do tipo B todo o volume de material seria deslocado para as bordas e a recuperação elástica nula.

\subsubsection{RECUPERAÇÃO ELÁSTICA DOS MATERIAIS}

O cálculo do módulo elástico a partir de ensaios de dureza está associado com a recuperação elástica dos materiais. Um trabalho pioneiro foi de STILWELL; TABOR (1961), no qual foi apresentada uma equação que relaciona o módulo elástico com a quantidade de recuperação elástica, $h_{e}$ (indicada na Figura 2.36), considerando-se um penetrador cônico:

$h_{e}=h_{\text {máx }}-h_{P}=\frac{(F \cdot H \cdot \pi)^{0,5}}{E_{r}}$

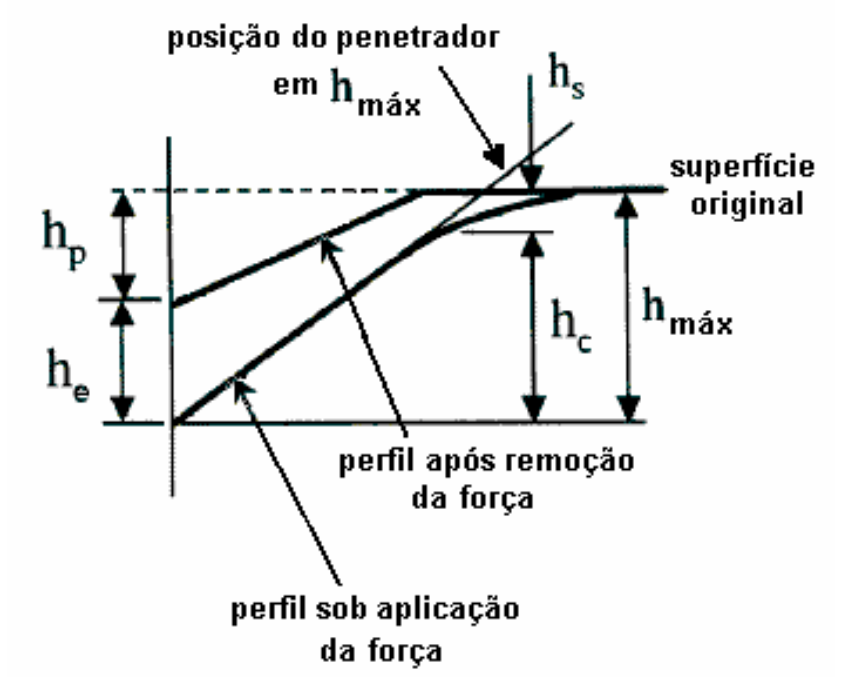

Figura 2.36. Indicação da recuperação elástica em ensaio de dureza. $h_{\mathrm{e}}$ : recuperação elástica; $h_{\mathrm{P}}$ : profundidade final; $h_{S}$ : profundidade defletida. (STILWELL; TABOR, 1961). 
$\mathrm{Na}$ equação 2.15 o termo $\mathrm{E}_{\mathrm{r}}$ é o módulo elástico reduzido, definido pela equação 2.16:

$\frac{1}{E_{r}}=\frac{1-v_{i}^{2}}{E_{i}}+\frac{1-v^{2}}{E}$

onde,

$\mathrm{E}_{\mathrm{r}}$ é o módulo elástico reduzido $[\mathrm{GPa}]$;

$\mathrm{E}_{\mathrm{i}}$ é o módulo elástico do penetrador $\left(1.140 \mathrm{GPa}^{2.17}\right)$;

$v_{\mathrm{i}}$ é o coeficiente de Poisson do penetrador $\left(0,07^{2.12}\right)$;

E é o módulo elástico do material ensaiado ${ }^{(2.18)}[\mathrm{GPa}] \mathrm{e}$;

$v$ é o coeficiente de Poisson do material ensaiado.

MARSHALL e colaboradores (1982) apresentaram uma proposta para cálculo do módulo elástico (equação 2.17) a partir de um ensaio de dureza convencional Knoop, considerando a hipótese de que a recuperação elástica na menor diagonal de impressão Knoop (b') é significativamente maior do que a observada na maior diagonal (a').

$b^{\prime} / a^{\prime}=1 / 7-0,45\left(H_{K} / E\right)$

Equação 2.17

onde,

$\mathrm{H}_{\mathrm{K}}$ é a dureza Knoop [MPa].

A equação 2.17 permite determinar o módulo elástico e a Figura 2.37 mostra a relação entre $\left(b^{\prime} / a^{\prime}\right)$ e $\quad\left(\mathrm{H}_{\mathrm{K}} / \mathrm{E}\right)$ verificada experimentalmente por MARSHALL e colaboradores (1982).

\footnotetext{
${ }^{2.17}$ Valores adotados pela ISO/FDIS 14577-1 (ISO, 2002).

${ }^{2.18} \mathrm{O}$ termo E/(1- $\left.v^{2}\right)$ foi denominado pela ISO/FDIS 14577-1 (ISO, 2002) por "indentation modulus" com a simbologia $\mathrm{E}_{\mathrm{IT}}$.
} 


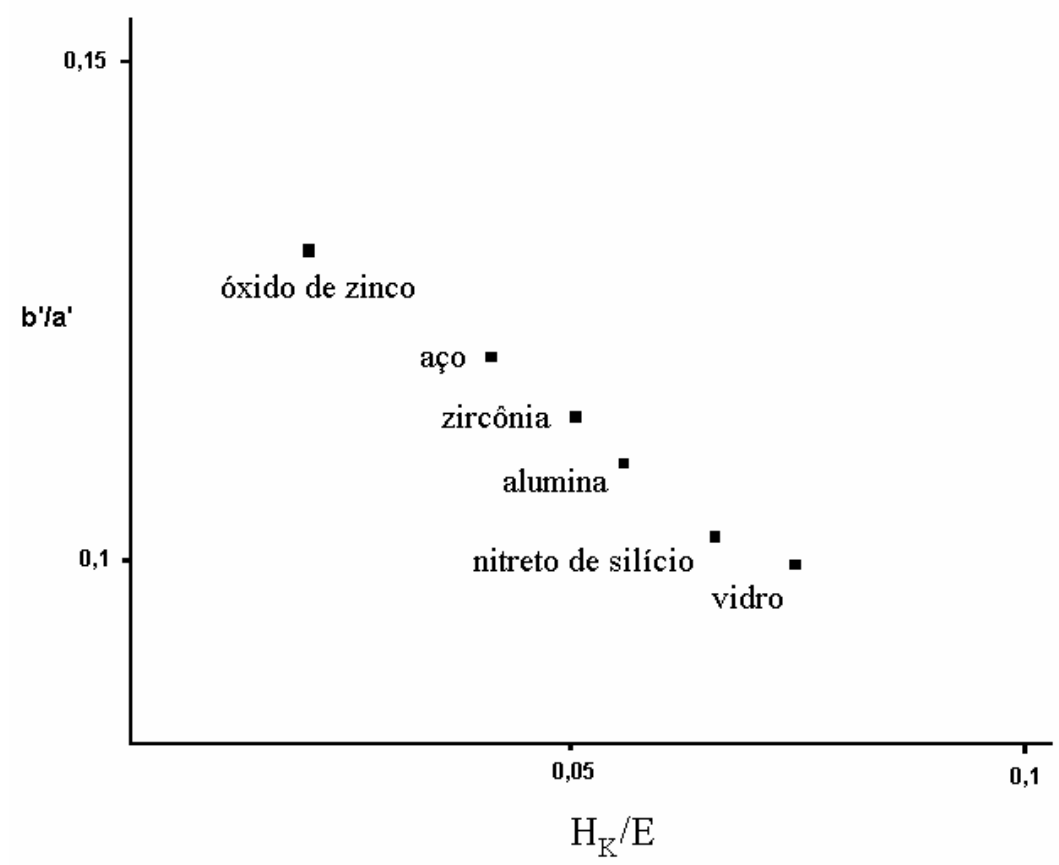

Figura 2.37. Variação da razão entre as diagonais de impressão Knoop com a razão $H_{K} / E$ (MARSHALL e colaboradores, 1982).

A equação 2.17 não pode ser aplicada para impressões Vickers, porque a recuperação elástica entre as diagonais Vickers (se existente) não deve apresentar diferença, como mostra de maneira esquemática a Figura 2.38 (WEILER, 1989).

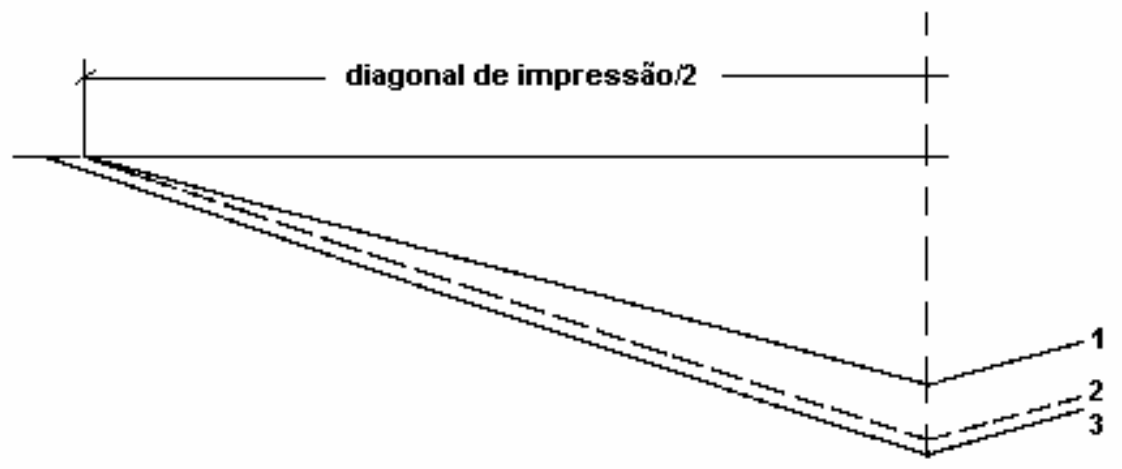

Figura 2.38. Indicação esquemática das profundidades de penetração em ensaio convencional. (WEILER, 1989). Curva 1: profundidade real após remoção da força; Curva 2: profundidade hipotética, proporcional à recuperação das diagonais; e Curva 3: profundidade sob aplicação da força.

A Figura 2.38 mostra que a profundidade de penetração após a recuperação elástica (curva 1) não possui correspondência geométrica com a diagonal de impressão, 
devido à recuperação elástica nas diagonais ser pequena ou até nula. TATE (1945) mostrou que a variação dos valores de dureza com a força aplicada (efeito do tamanho de impressão) foi maior para a dureza Knoop do que para a dureza Vickers e creditou esta diferença à maior recuperação elástica que ocorre em ensaios Knoop.

A avaliação da recuperação elástica e, portanto, do módulo elástico, ganhou impulso com o desenvolvimento dos ensaios instrumentados de dureza. Uma definição para a quantidade de recuperação elástica, $h_{e}$, a partir de uma curva típica resultante deste tipo de ensaio (Figura 2.39) é apresentada na equação 2.18.

$\mathrm{h}_{\mathrm{e}}=\mathrm{h}_{\text {máx }}-\mathrm{h}_{\mathrm{P}}=2 \mathrm{We} / \mathrm{F}_{\text {máx }}$

Equação 2.18

onde,

We é o trabalho elástico [N.m] (definido na Figura 2.39).

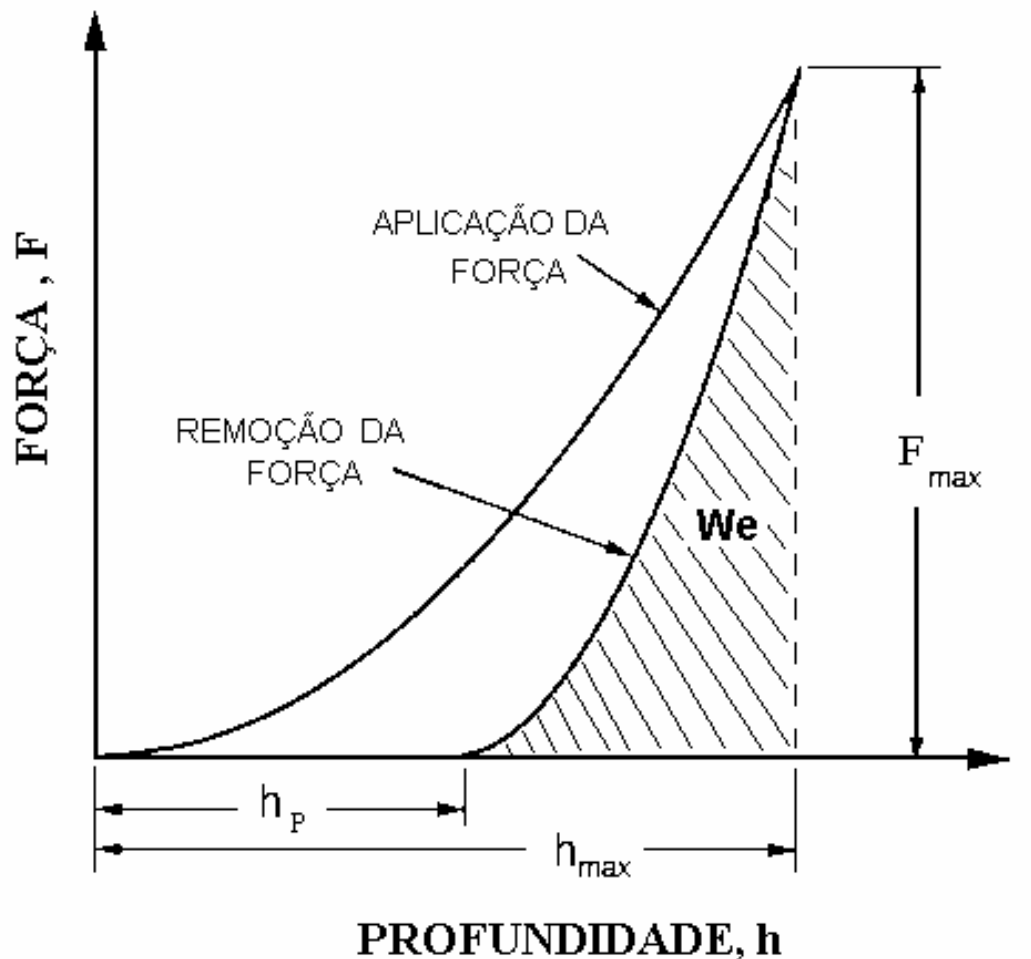

Figura 2.39. Curva típica de ensaios instrumentados de dureza (ISO/FDIS 145771; ISO, 2002) com indicação da profundidade máxima de penetração $\left(h_{\text {máx }}\right)$, da profundidade final $\left(h_{P}\right)$ e da parcela de trabalho elástico We [N.m]. 
Uma expressão para o cálculo do módulo elástico reduzido $\mathrm{E}_{\mathrm{r}}$ (equação 2.16) está apresentada na equação 2.19:

$E_{r}=\frac{S}{\beta \sqrt{A_{P}}}$

Equação 2.19

onde,

$\mathrm{A}_{\mathrm{P}}$ é a área projetada $\left[\mathrm{mm}^{2}\right]\left(=24,5 \cdot \mathrm{h}_{\mathrm{C}}^{2}\right.$ para penetrador Vickers $) ;$

$\beta$ é um fator geométrico (= 1,142 para penetrador Vickers: KING, 1987) e;

S é a rigidez de contato [N/mm] (definida na Figura 2.40).

A Figura 2.40 apresenta como a rigidez S pode ser calculada.

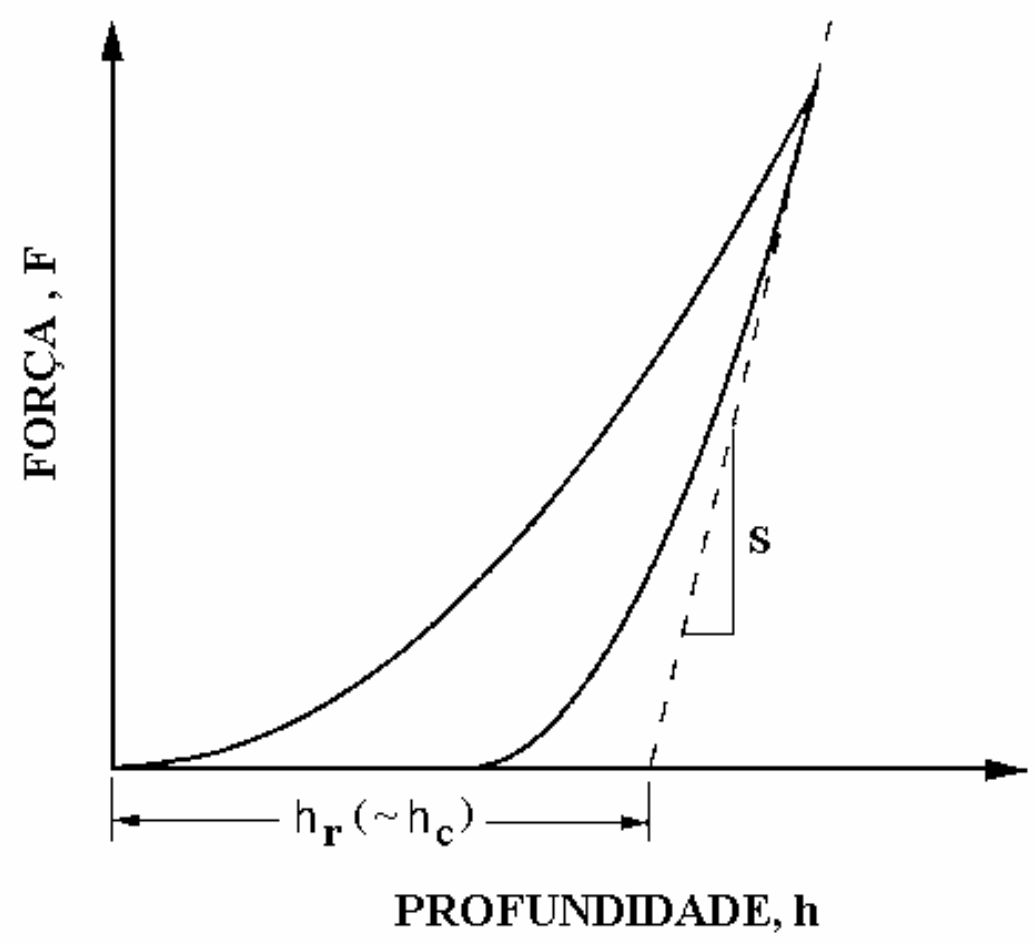

Figura 2.40. Curva típica de ensaios instrumentados de dureza (ISO/FDIS 145771; ISO, 2002), com indicação de $h_{r}$ (interseção com o eixo das abcissas) e da rigidez de contato $S[\mathrm{~N} / \mathrm{mm}]$.

Duas metodologias para o cálculo da rigidez por meio da tangente à curva de remoção da força são bastante difundidas. A primeira deve-se a 
DOERNER; NIX (1986), que propuseram o método de extrapolação linear (LEM), o qual admite que a primeira terça parte da curva de remoção da força é linear e utilizando estes pontos calcula uma curva de regressão.

A segunda metodologia foi proposta por OLIVER; PHARR (1992), conhecida como método da lei potencial (PLM), e considera que a primeira parte da curva não é linear e pode ser descrita por uma equação do tipo potencial, como mostra a equação 2.20:

$$
\mathrm{F}=\mathrm{C}_{\mathrm{UL}}\left(h-h_{P}\right)^{\mathrm{m}_{\mathrm{UL}}}
$$

onde,

$\mathrm{C}_{\mathrm{UL}}, \mathrm{m}_{\mathrm{UL}}$ são constantes que dependem do material ensaiado.

$\mathrm{O}$ cálculo da rigidez de contato $\mathrm{S}$ resulta da derivação da equação $2.20 \mathrm{em}$ função da profundidade $\mathrm{h}(\mathrm{dF} / \mathrm{dh})$, como mostra a equação 2.21 :

$$
\mathrm{S}=\mathrm{C}_{\mathrm{UL}} m_{U L}\left(h_{\text {máx }}-h_{P}\right)^{\mathrm{m}_{\mathrm{UL}}-1}
$$

Equação 2.21

Adicionalmente, OLIVER; PHARR (1992) propuseram que a interseção da tangente no eixo das abcissas, que determina o valor de $h_{r}$, pode ser utilizada para definir a profundidade de contato, $\mathrm{h}_{\mathrm{C}}$, como mostra a equação 2.22 :

$$
\mathrm{h}_{\mathrm{C}}=h_{\text {máx }}-\varepsilon\left(h_{\text {máx }}-h_{r}\right)
$$

Equação 2.22

onde,

$\varepsilon$ é um fator geométrico (= 0,75 para penetrador Vickers: OLIVER; PHARR, 1992).

A partir do valor de $h_{C}$ é possível calcular a dureza denominada pela ISO/FDIS 14577-1 (ISO, 2002) como "indentation hardness", $\mathrm{H}_{\mathrm{IT}}$, segundo a equação 2.23: 


$$
\mathrm{H}_{\mathrm{IT}}=F_{\text {máx }} / A_{P}=F_{\text {máx }} / 24,5 \cdot \mathrm{h}_{\mathrm{C}}{ }^{2}
$$

A determinação da profundidade $h_{C}$ permite calcular a área projetada, $A_{P}$, necessária para o cálculo do módulo elástico reduzido (equação 2.19).

A proposta de OLIVER; PHARR (1992) vem sendo contestada por outros pesquisadores (ZENG e colaboradores, 1996; GIANNAKOPOULOS; SURESH, 1999; ALCALÁ e colaboradores, 2000 e STRANGE; VARSHNEYA, 2001), pois define a profundidade $h_{C}$ a partir da curva de remoção de força, enquanto que fisicamente esta profundidade é definida durante a aplicação de força. Isto faz com que, nos casos em que há formação de bordas, os valores de $\mathrm{H}_{\mathrm{IT}}$ e de $\mathrm{E}_{\mathrm{r}}$ sejam inadequados, pois $\mathrm{h}_{\mathrm{C}}$ será maior do que $\mathrm{h}_{\text {máx }}$, como apresentado na Figura 2.33.

ZENG e colaboradores (1996) propuseram a equação 2.13 para calcular a profundidade de contato $\mathrm{h}_{\mathrm{C}}$ :

$\mathrm{h}_{\mathrm{c}}=\mathrm{h}_{\text {máx }} / \alpha^{1 / 2}$

A equação 2.24 contempla os efeitos decorrentes da morfologia de impressão (formação de bordas ou retração), incorporados ao cálculo de $\mathrm{h}_{\mathrm{C}}$ por meio de $\alpha$.

ZENG e colaboradores (1996) compararam, para uma série de materiais cerâmicos, os valores $h_{C}$ calculados pela equação 2.24 com os calculados pelos métodos LEM (DOERNER; NIX, 1986) e PLM (OLIVER; PHARR, 1992) e as diferenças chegaram até $20 \%$.

Utilizando a equação 2.24, ZENG e colaboradores propuseram que o módulo elástico reduzido fosse determinado utilizando a área projetada calculada com a profundidade $\mathrm{h}_{\text {máx }}$, ao invés da profundidade $\mathrm{h}_{\mathrm{C}}$. STRANGE; VARSHNEYA (2001) 
aplicaram este conceito para ensaios de dureza com liga de alumínio 6061-T6, para os quais foi observada a formação de bordas, resultando em um valor de módulo elástico reduzido $20 \%$ menor em relação ao calculado segundo o método de OLIVER; PHARR (1992).

JOSLIN; OLIVER (1990) apresentaram uma equação para o cálculo do módulo elástico reduzido, o qual combina as equações 2.19 e 2.23:

$H / E_{r}^{2}=F_{\text {máx }} /(\beta . S)^{2}$

Equação 2.25

JOSLIN; OLIVER definiram o termo $\mathrm{H} / \mathrm{E}_{\mathrm{r}}^{2}$ como sendo a resistência do material à penetração plástica, conceito que pode ser utilizado para avaliação da resistência ao desgaste abrasivo e de interesse deste trabalho.

\subsection{RELAÇÃO ENTRE DESGASTE ABRASIVO E DUREZA}

\subsubsection{MODELO RÍGIDO-PLÁSTICO (CLÁSSICO)}

A maioria dos modelos matemáticos para previsão das taxas de desgaste abrasivo, controladas por deformação plástica e em alguns casos por fratura frágil, apresenta como ponto de partida a equação de Archard (PINTAÚDE e colaboradores, 1997), originalmente desenvolvida para o desgaste por deslizamento:

$\mathrm{W}=\mathrm{K} \frac{\mathrm{L}}{\mathrm{H}}$

Equação 2.26

onde, 
$\mathrm{W}$ é a taxa de desgaste $=$ perda volumétrica por distância percorrida $\left[\mathrm{mm}^{3} / \mathrm{m}\right]$;

Lé a força aplicada $[\mathrm{N}] \mathrm{e}$;

K é o coeficiente de desgaste ${ }^{(2.19)}$.

A adequação da equação 2.26 para o desgaste abrasivo deve-se a RABINOWICZ e colaboradores (1961). As hipóteses utilizadas por estes pesquisadores foram:

a) $\mathrm{O}$ abrasivo penetra na superfície desgastada em uma profundidade que é proporcional à razão entre dureza e força aplicada (material rígido-plástico);

b) O abrasivo e suas propriedades não são afetados pelo processo e;

c) O volume do sulco formado é totalmente removido (o microcorte é o único mecanismo operante).

Estas hipóteses implicam que o coeficiente de desgaste $\mathrm{K}$ (equação 2.26) dependa apenas da geometria do abrasivo $(K=\cot \theta / \pi$, para um abrasivo cônico de ângulo 20). Este conceito de coeficiente de desgaste foi ampliado com o modelo de MULHEARN; SAMUELS (1962) para a previsão de taxas de desgaste.

MULHEARN; SAMUELS (1962) introduziram o conceito de ângulo de ataque crítico, $\theta_{\mathrm{C}}$ O mecanismo de microcorte passa a ser efetivo com ângulos maiores que $\theta_{\mathrm{C}}$, o que possibilita a previsão da ocorrência do mecanismo de microssulcamento. Com

\footnotetext{
2.19 Alguns trabalhos expressam as taxas de desgaste em função da força aplicada, parâmetro denominado de coeficiente de desgaste dimensional $\left.\left[\mathrm{mm}^{3} \quad \text { (N.m }\right)^{-1}\right]$. (vide, por exemplo, BLICKENSDERFER e colaboradores, 1985).
} 
este modelo, a hipótese (c) utilizada por RABINOWICZ e colaboradores (1961) passou a não ser mais necessária para a determinação das taxas de desgaste.

Além disso, os efeitos decorrentes do tipo de movimento relativo dos abrasivos, ou seja, o fato de sistemas a dois corpos produzirem maiores taxas de desgaste do que os sistemas a três corpos (MISRA; FINNIE, 1980), puderam também ser compreendidos com o conceito de ângulo de ataque crítico. Nos sistemas onde os abrasivos estão livres para rolar, a possibilidade destes disporem de ângulos de ataque maiores que o ângulo crítico é pequena.

A equação 2.26 consolidou a idéia intuitiva de que a resistência ao desgaste abrasivo é dependente da dureza. Este critério, embora tenha limitações do ponto de vista teórico, é extremamente útil no sentido prático, pois para grande parte das aplicações que envolvam abrasão é possível descartar um grande conjunto de materiais em função da dureza, mesmo que esta seja determinada de forma macroscópica (LARSEN-BASSE, 1991).

As hipóteses (a) e (b) utilizadas por RABINOWICZ e colaboradores (1961) são adequadas para os casos em que se observa uma relação linear entre dureza e taxas de desgaste abrasivo, como os resultados obtidos por KRUSCHOV (1957), apresentados na Figura 2.41.

A Figura 2.41 mostra que a resistência ao desgaste de um metal puro é muito superior a de um mineral com dureza semelhante. Este resultado está associado com a elevada dureza do abrasivo em relação à dureza dos materiais ensaiados e o desgaste ocorrer para ambos em regime severo (vide Figura 2.19). 


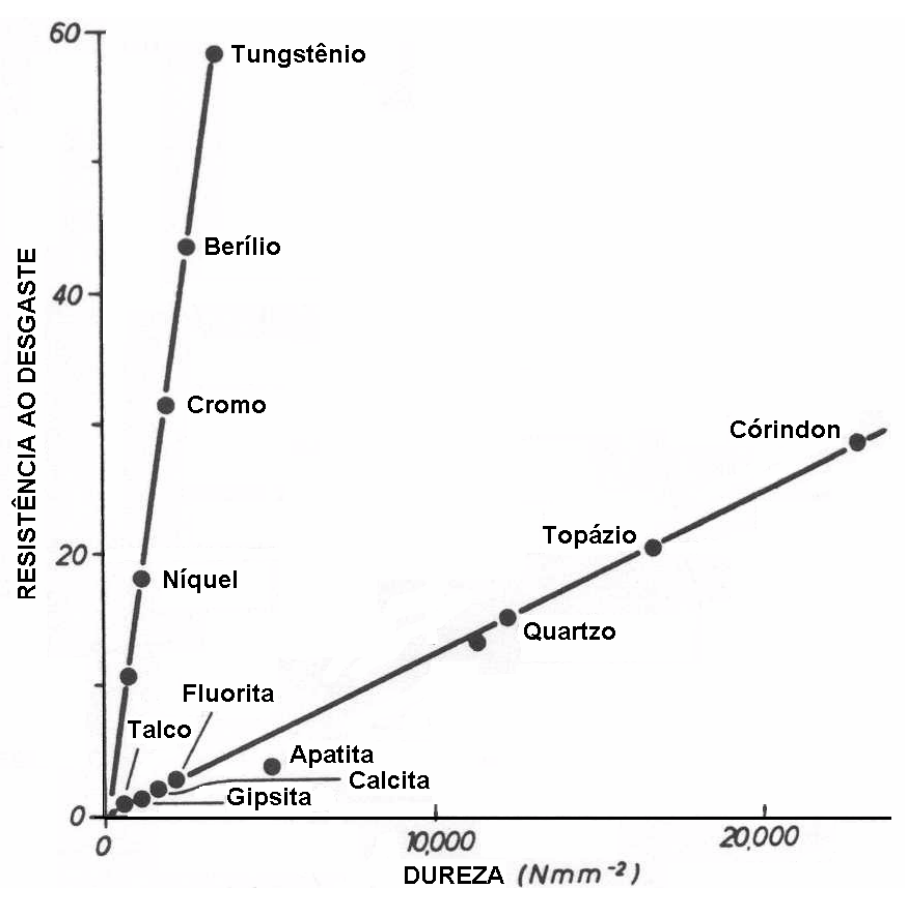

Figura 2.41. Variação da resistência à abrasão $\mathrm{W}^{-1}(=1 / \mathrm{W})$ com a dureza $[\mathrm{MPa}]$ de metais puros e minerais da escala Mohs, em ensaios pino contra lixa (KRUSCHOV, 1957).

A existência da relação linear entre dureza e taxa de desgaste dos metais puros pode ser explicada por duas razões:

1) O comportamento mecânico rígido-plástico é aplicável para esta classe de materiais (o que satisfaz a hipótese a de RABINOWICZ e colaboradores, 1961) e;

2) Os ensaios pino-contra-lixa foram conduzidos com abrasivo de dureza bastante superior às durezas dos metais. Como apresentado na Tabela 2.2, nos sistemas em que a razão $\mathrm{H}_{\mathrm{A}} / \mathrm{H}$ é maior que 1,2 a fragmentação dos abrasivos é muito pequena (o que satisfaz a hipótese $b$ de RABINOWICZ e colaboradores, 1961).

Chega a ser surpreendente, em uma primeira análise, a existência de uma relação linear entre taxa de desgaste e dureza para os minerais da escala Mohs apresentada na 
Figura 2.41. Há duas considerações que podem ser feitas no sentido de explicar a existência desta relação. Uma é que a literatura reporta razões H/Y em torno de 3 para cerâmicas (SUSZYNSKA e colaboradores, 1997), onde Y é determinado em estado de compressão. Este tipo de resultado foi corroborado por JAYARAM e colaboradores (1986), que verificaram os mesmos mecanismos de deformação e fratura do WC-10\%Co em ensaios de compressão e em ensaios de dureza.

Além disso, a escala Mohs de dureza representa a capacidade de corte de um material sobre outro (TABOR, 1956), o que requer a existência de mecanismos de deformação plástica, mesmo que ocorram simultaneamente mecanismos de fratura frágil (vide Figura 2.8). Pode-se ainda considerar o fato de que, para muitos materiais frágeis, a nucleação e propagação das trincas laterais, usualmente associadas com a remoção de material em desgaste (LAWN; SWAIN, 1975) ocorrem muitas vezes na etapa de recuperação elástica (COOK; PHARR, 1990).

\subsubsection{MODELO ELASTO-PLÁSTICO}

KRUSCHOV (1957) verificou para aços tratados termicamente uma relação entre dureza e resistência à abrasão diferente dos resultados da Figura 2.41. Para esta classe de materiais, a resistência ao desgaste não pode ser descrita por uma relação do tipo $\mathrm{W}^{-1}=\mathrm{K} . \mathrm{H}$, como mostra a Figura 2.42 . 


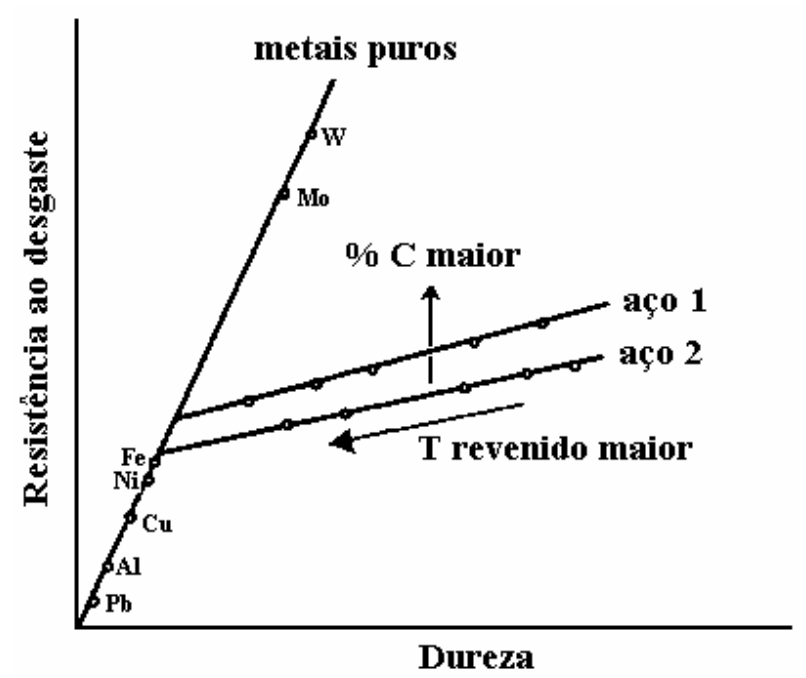

Figura 2.42. Variação da resistência à abrasão $W^{-1}(=1 / \mathrm{W})$ com a dureza de aços tratados termicamente, em ensaios pino contra lixa (KRUSCHOV, 1957).

A Figura 2.42 mostra que a resistência ao desgaste abrasivo de um aço tratado termicamente é menor do que a de um metal puro com dureza semelhante e que aços de diferentes composições tratados para uma mesma dureza não apresentam a mesma resistência ao desgaste. Posteriormente aos resultados de KRUSCHOV (1957), MUTTON; WATSON (1978) verificaram que a resistência ao desgaste de aços tratados termicamente pode não variar de forma linear com a dureza. Estes resultados mostram que a hipótese de RABINOWICZ e colaboradores (1961), a qual admite comportamento rígido-plástico para os materiais, não deve se aplicar para aços tratados termicamente.

MISRA; FINNIE (1981) observaram uma relação surpreendente entre a resistência à abrasão e a dureza de metais puros, ensaiados em pino contra lixa de diferentes granulometrias. Os resultados obtidos por estes pesquisadores estão apresentados na Figura 2.43. 


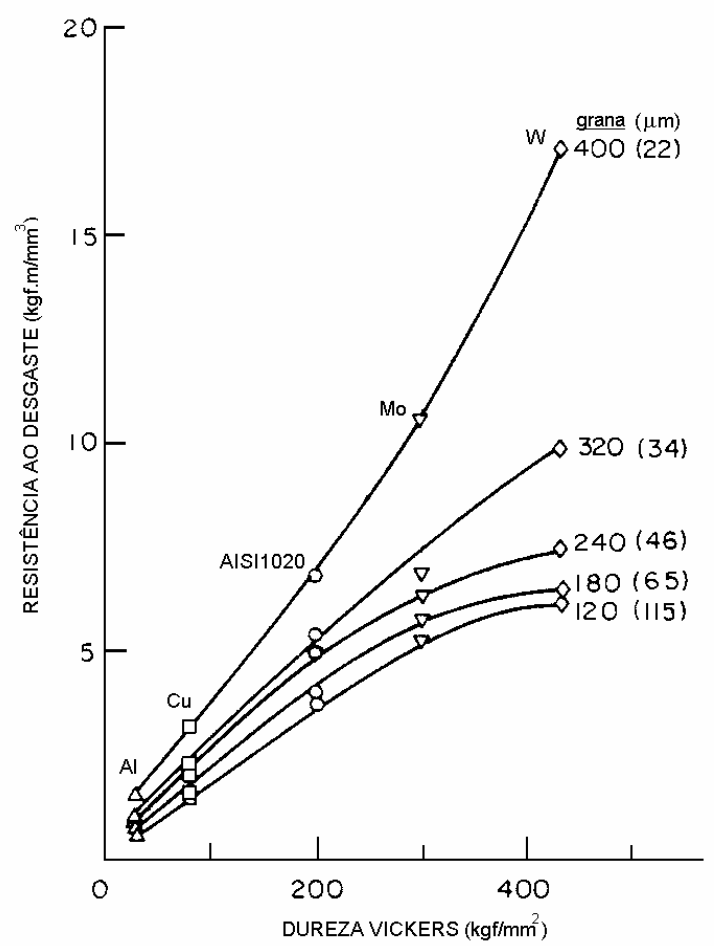

Figura 2.43. Variação da resistência à abrasão $W^{-1}(=1 / W)$ com a dureza [kgf $\left./ \mathrm{mm}^{2}\right]$ de metais puros e do aço AISI 1020 recozido, em ensaios pino contra lixa (MISRA; FINNIE, 1981).

A Figura 2.43 mostra que a resistência à abrasão do tungstênio, o metal de maior dureza estudado por MISRA; FINNIE (1981), apresenta um comportamento não linear entre resistência à abrasão e dureza, com exceção da curva obtida com a lixa grana \#320. Estes resultados sugerem que o comportamento ao desgaste em função do tamanho do abrasivo não pode ser descrito por um modelo rígido-plástico.

BUTTERY; ARCHARD (1970/71) estudaram a variação dos mecanismos de desgaste abrasivo de aços tratados termicamente utilizando ensaios de esclerometria linear, com penetrador Vickers. Os resultados obtidos por estes pesquisadores estão apresentados na Figura 2.44. 


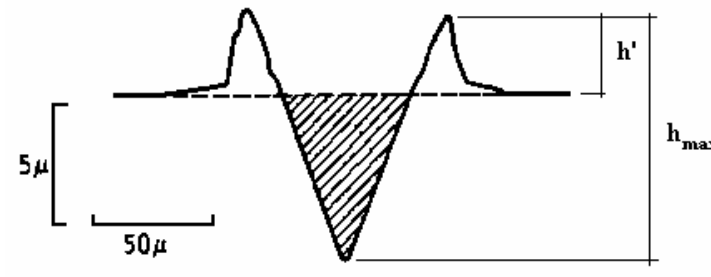

(A)

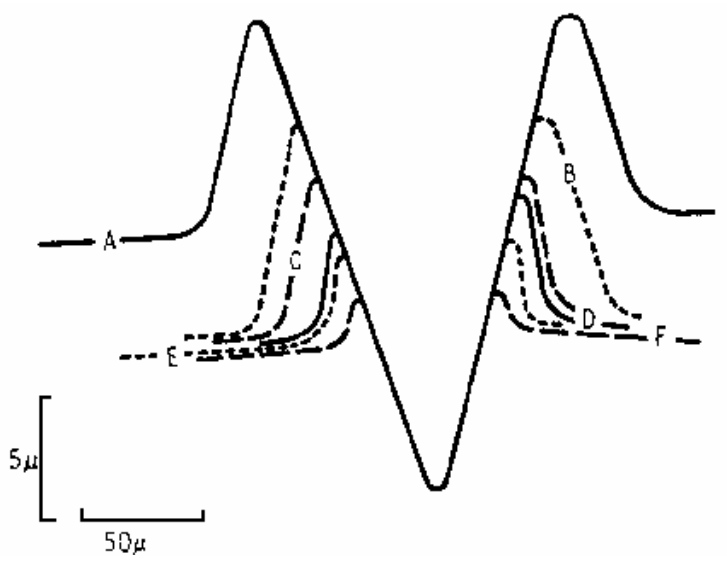

(B)

Figura 2.44. (A) Perfil típico de seção transversal em liga fundida de cobalto após ensaio de esclerometria Vickers com 19,6 N. h': profundidade relativa à formação de bordas laterais. (B) Ilustração das seções transversais de aço $0,99 \% \mathrm{C}$ temperado e revenido com diferentes durezas após os ensaios de esclerometria: A $263 \mathrm{HV}$, B $315 \mathrm{HV}$, C $441 \mathrm{HV}$, D $598 \mathrm{HV}$, E $710 \mathrm{HV}$, F 890 HV (BUTTERY; ARCHARD, 1970/71).

A Figura 2.44 mostra a formação de bordas, fenômeno discutido com detalhe no item 2.2.3. BUTTERY; ARCHARD (1970/71) definiram a severidade da formação de bordas, $\rho$, apresentada na equação 2.27 :

$\rho=h^{\prime} / h_{\max }$

onde,

h' é a altura da borda formada $[\mu \mathrm{m}]$, definida na Figura 2.44 (A).

Na Figura 2.44 (B) estão apresentadas as seções transversais do aço 0,99\% C com diferentes durezas. Pode-se verificar que as maiores formações de borda ocorreram para os materiais com menores durezas, ou seja, durante o desgaste destes materiais uma grande parcela da energia é desprendida para a deformação plástica, ao invés de servir para operar o mecanismo de microcorte. Este resultado pode trazer uma explicação para a não linearidade observada nos resultados da Figura 2.43.

Um conceito que ajuda a compreender este tipo de diferença é proporção de material removido, introduzido por STROUDMAN; WILMAN (1962). A Figura 2.45 
mostra os parâmetros necessários para a definição da proporção de material removido, $\varphi$ (equação 2.28), bem como a variação desta proporção com a dureza, obtida por BUTTERY; ARCHARD (1970/71).

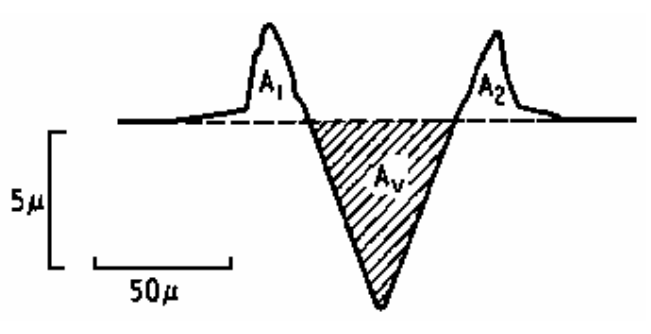

(A)

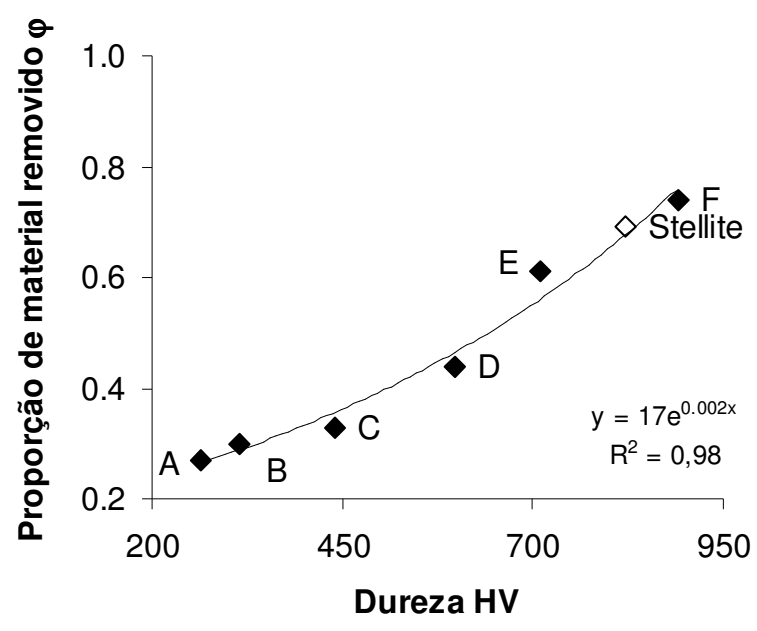

(B)

Figura 2.45. (A) Parâmetros necessários para definição da proporção de material removido (equação 2.28). (B) Variação do fator $\varphi$ com a dureza Vickers do aço $0,99 \% \mathrm{C}$ temperado e revenido $(\mathrm{A}-\mathrm{F})$ e de uma liga de cobalto fundida (Stellite) (BUTTERY; ARCHARD, 1970/71).

$\varphi=\frac{A_{V}-\left(A_{1}+A_{2}\right)}{A_{V}}=1-\frac{\left(A_{1}+A_{2}\right)}{A_{V}}$

Equação 2.28

onde,

$A_{V}$ é a área do sulco formado por uma partícula abrasiva $\left[\mu \mathrm{m}^{2}\right]$ (definida na Figura 2.45 A) e;

$\mathrm{A}_{1}, \mathrm{~A}_{2}$ são as áreas relativas às bordas $\left[\mu^{2}\right]$ (definidas na Figura $2.45 \mathrm{~A}$ ).

A Figura 2.45 (B) mostra que a proporção de material removido não varia de forma linear com a dureza. Isto pode ser devido à mudança na intensidade da formação de bordas quando se eleva a dureza do aço $0,99 \% \mathrm{C}$. 
Muitos pesquisadores consideram que o fator $\varphi$ da equação 2.28 é uma parcela do coeficiente de desgaste K (BUTTERY; ARCHARD, 1970/71; MOORE, 1980; ZUM GAHR, 1987). Os mecanismos de desgaste abrasivo também podem ser expressos por meio deste fator. Em um caso ideal, quando o valor de $\varphi$ fosse igual a 1, significaria que apenas o microcorte estaria operando, enquanto que um valor zero significaria microssulcamento puro. A Figura 2.45 (B) mostra que, quanto maior a dureza dos aços, maior foi a energia gasta em mecanismo de microcorte. Este resultado não tem magnitude suficiente para se contrapor ao fato de que as maiores durezas dos aços tratados termicamente não permitem o aumento da profundidade do sulco formado para a remoção de material por microcorte (MURRAY; MUTTON; WATSON, 1982).

No caso do mecanismo de microcorte, para que o fator $\varphi$ tenha valores próximos de 1 a soma $\left(A_{1}+A_{2}\right)$ deve ser pequena, e necessariamente a severidade na formação das bordas deve ser menor, o que foi verificado na Figura 2.45 (B) para os materiais com maior dureza.

Com base nos resultados das Figuras 2.41, 2.42 e 2.45 (B), MURRAY; MUTTON; WATSON (1982) propuseram uma associação entre o tipo de variação da resistência ao desgaste com a dureza e os micromecanismos de abrasão, como mostra a Figura 2.46. 


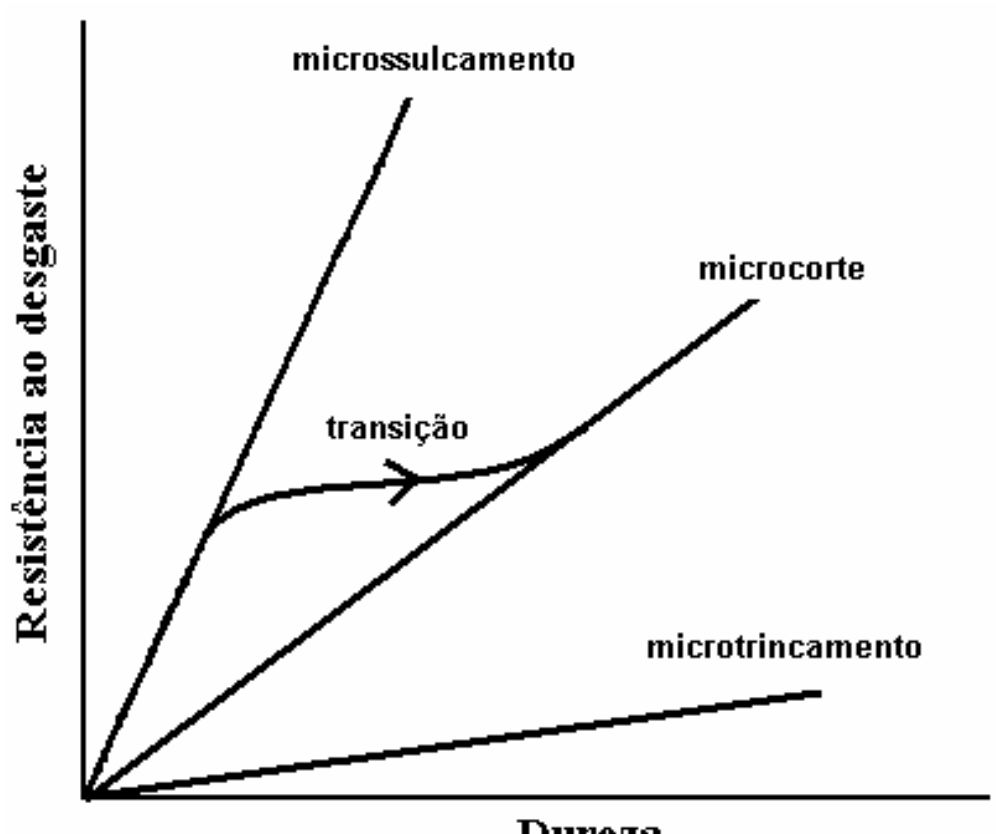

Dureza

Figura 2.46. Gráfico esquemático mostrando os mecanismos de desgaste abrasivo associados com as variações características da resistência à abrasão $W^{-1}(=1 / \mathrm{W})$ com a dureza H (MURRAY; MUTTON; WATSON, 1982).

Na Figura 2.46 está indicada uma curva de transição entre as curvas ideais correspondentes aos mecanismos de microssulcamento e microcorte, correspondente ao comportamento observado para os aços tratados termicamente.

A aplicação do comportamento elasto-plástico ideal para um modelo de previsão de taxas de desgaste requer o conhecimento da extensão da zona plástica, que depende não somente da dureza, mas também de outras propriedades como o módulo elástico. Diferentes tentativas foram realizadas no sentido de expressar a resistência ao desgaste abrasivo dos materiais como uma combinação entre essas propriedades mecânicas (FINKIN, 1974; ATKINS, 1980; TORRANCE, 1980 e MOORE, 1980).

Dentre estas tentativas destaca-se o trabalho de FINKIN (1974). A Tabela 2.6 mostra quais foram os parâmetros avaliados como critérios de resistência à abrasão e o significado físico para cada um destes atribuídos por FINKIN. 
Tabela 2.6 - Parâmetros propostos por FINKIN (1974) como indicativos de resistência ao desgaste abrasivo e seus significados físicos.

\begin{tabular}{cc}
\hline PARÂMETRO & Significado físico (considerando $\mathrm{H} / \mathrm{Y}=$ constante) \\
\hline $\mathrm{H} / \mathrm{E}$ & Deformação relativa ao escoamento \\
$(\mathrm{H} / \mathrm{E})^{2}$ & Transição do tipo de contato - elástico para plástico ${ }^{(2.20)}$ \\
$\mathrm{H}^{2} / 2 \mathrm{E}$ & Módulo de resiliência \\
\hline
\end{tabular}

FINKIN procurou relações entre estes parâmetros e os resultados de taxas de desgaste obtidos por KRUSCHOV (1957) para as ligas de Cu-Ni e de Pb-Sn. Estas taxas não puderam ser relacionadas com nenhum dos parâmetros da Tabela 2.6, da mesma forma como a dureza, o que é surpreendente. O parâmetro de melhor correlação com as taxas de desgaste foi o módulo elástico.

O modelo proposto por MOORE (1980), apresentado na equação 2.29, possui outro significado físico, não explorado por FINKIN (1974), pois toma como referência o trabalho de BISHOP; HILL; MOTT (1945) para a definição da extensão da zona plástica.

$\mathrm{p} \propto(\mathrm{E} / \mathrm{Y})^{1 / 3}(\mathrm{~L} / \mathrm{H})^{1 / 2}$

Equação 2.29

onde,

p é a extensão da região deformada devido ao processo de desgaste abrasivo $[\mu \mathrm{m}]$.

O conceito aplicado por MOORE (1980) foi que a extensão da região deformada devido ao processo de desgaste, p, é proporcional à extensão da zona plástica, c/a, expressa pela razão $(\mathrm{E} / \mathrm{Y})^{1 / 3}$ (componente elasto-plástica), e proporcional à área de contato, expressa pela razão $(\mathrm{L} / \mathrm{H})^{1 / 2}$ (componente rígido-plástica). A Figura 2.47

\footnotetext{
${ }^{2.20}$ Um trabalho pioneiro na definição de um parâmetro para prever o tipo de contato mecânico deve-se a GREENWOOD; WILLIANSON (1966).
} 
mostra a variação da profundidade da região deformada de cobre, ferro e aços; após ensaios com lixas de SiC granas \#60 e \#180.

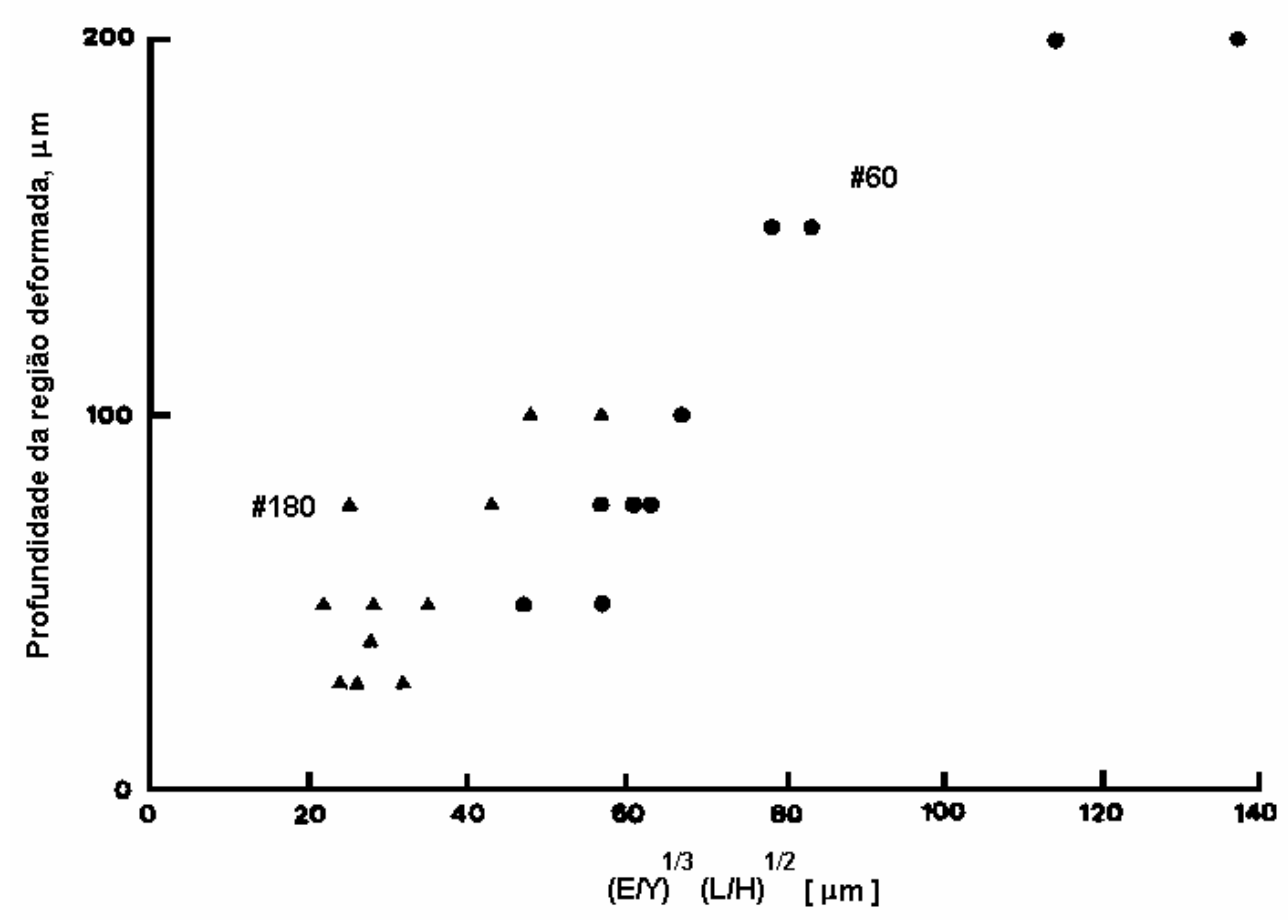

Figura 2.47. Variação da profundidade da região deformada $[\mu \mathrm{m}]$ de cobre, ferro e aços com o parâmetro $(\mathrm{E} / \mathrm{Y})^{1 / 3}(\mathrm{~L} / \mathrm{H})^{1 / 2}[\mu \mathrm{m}]$, em ensaios pino contra lixa de $\mathrm{SiC}$, granas \#60 e \#180 (MOORE, 1980).

A Figura 2.47 mostra que, embora não se possa verificar uma relação clara entre o parâmetro $(\mathrm{E} / \mathrm{Y})^{1 / 3}(\mathrm{~L} / \mathrm{H})^{1 / 2}$ e a profundidade da região deformada; de modo geral para os maiores os valores deste parâmetro, maiores foram as profundidades.

Um parâmetro relevante para a aplicação da equação 2.29 é o limite de escoamento dos materiais, Y, considerando-se o estado de tensões de um processo de desgaste abrasivo, ou ainda, de um ensaio de dureza. Como apresentado no item 2.2.2, a razão c/a depende da geometria do abrasivo ou da geometria do penetrador de dureza, e há diferentes modelos para expressar este parâmetro. Os valores de E e Y podem ser determinados em ensaios instrumentados de dureza, nos quais o estado de tensões é 
mais parecido com o que ocorre em um processo de desgaste, do que o estado de tensões de ensaios mecânicos convencionais, como tração.

Outro fator que pode explicar a dispersão dos resultados apresentados na Figura 2.47 é que MOORE (1980) utilizou para a variável L o valor da força normal de ensaio, ao invés da força aplicada por cada grão abrasivo, a qual depende do tamanho do abrasivo (BULSARA e colaboradores, 1998).

\subsection{RESUMO DA REVISÃO BIBLIOGRÁFICA}

1. A razão $\mathrm{H}_{\mathrm{A}} / \mathrm{H}$ se aplica aos casos em que mecanismos de desgaste são controlados por deformação plástica, indicando a transição entre microssulcamento (microimpressões) e microcorte, e provavelmente também para os casos em que os mecanismos são controlados por fratura frágil, indicando a transição entre microssulcamento e microtrincamento.

2. Durante a etapa de aplicação da força em um ensaio de dureza se define a morfologia de impressão (formação de bordas ou retração) e a profundidade máxima de penetração e de contato.

3. Quando há formação de bordas, a extensão da zona plástica é maior que no caso de retração e a profundidade de contato é maior que a profundidade máxima de penetração. No caso de formação de bordas, a dureza Martens (HM) é o tipo de dureza que mais se aproxima da "dureza verdadeira", ou seja, aquela que considera a área real de contato. 
4. As propostas para cálculo da profundidade de contato e da área projetada de contato por meio de curvas de remoção da força não incorporam o efeito da formação de bordas.

5. O modelo de Archard para desgaste considera os materiais como rígido-plásticos. Isto é uma simplificação para muitos materiais, em especial os aços, para os quais não se observa uma relação entre resistência à abrasão e dureza do tipo $\mathrm{W}^{-1}=\mathrm{K} . \mathrm{H}$. Neste caso, a aplicação de um modelo elasto-plástico pode ser mais adequada.

6. Aços tratados termicamente apresentam menor resistência ao desgaste abrasivo do que um metal puro com dureza semelhante, verificando-se uma maior proporção de material removido para uma mesma dureza.

7. Para que modelos elasto-plásticos sejam aplicados para a previsão das taxas de desgaste é necessário que a dureza, o módulo elástico, o limite de escoamento e a força aplicada por cada grão abrasivo sejam calculados de modo a incorporar este tipo de comportamento. 


\section{OBJETIVOS DA TESE}

Esta Tese de Doutorado apresentará uma metodologia experimental para investigar a relação entre taxas de desgaste abrasivo e dureza. Serão consideradas as propriedades obtidas com a técnica instrumentada de dureza, seguindo a ISO/FDIS 14577-1 (ISO, 2002). Em particular, objetiva-se:

1) Investigar o comportamento dos materiais sob regime severo de desgaste abrasivo.

2) Investigar o comportamento dos materiais sob regime moderado de desgaste abrasivo.

3) Investigar o comportamento dos materiais sob regime de transição de desgaste abrasivo.

4) Investigar o efeito de uma segunda fase dura no comportamento dos materiais quanto ao desgaste abrasivo.

5) Estudar o comportamento mecânico dos materiais quando submetidos a ensaios de dureza, propondo formas de cálculo que incorporem os efeitos dos comportamentos descritos.

6) Aplicar as diferentes formas de cálculo de dureza para previsão da transição entre regimes de desgaste abrasivo.

7) Discutir o efeito do tamanho do abrasivo na transição entre os regimes de desgaste. 
A Figura 3.1 apresenta a seqüência de atividades utilizada de modo para atingir os objetivos propostos.

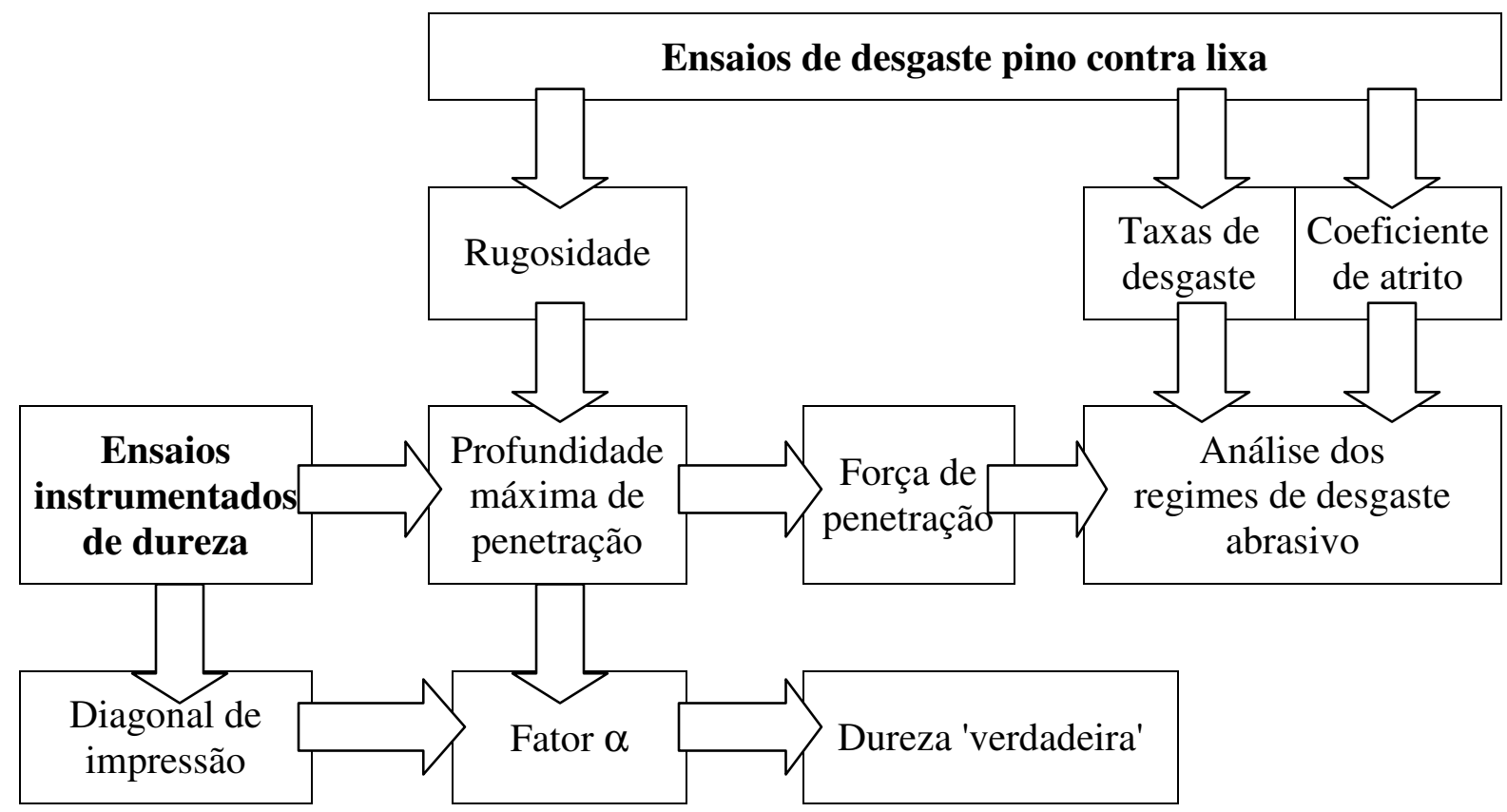

Figura 3.1. Diagrama de bloco mostrando a sequiência de atividades realizadas para atingir os objetivos da Tese. 


\section{MATERIAIS E MÉTODOS}

\subsection{MATERIAIS}

Os materiais utilizados neste trabalho originaram-se de três grupos:

- Aço carbono AISI 1006.

- Aço baixa-liga AISI 52100 trefilado.

- Ferro fundido branco de alto cromo.

O aço AISI 1006 foi utilizado no estado bruto de fundição, como elaborado pelo Laboratório de Fundição do IPT. Este material foi selecionado de modo a se comparar os resultados de desgaste com os obtidos por RICHARDSON (1968), que utilizou como material de referência um ferro comercialmente puro.

O aço AISI 52100 foi adquirido na condição trefilado em arame de $3 \mathrm{~mm}$ de diâmetro. Este material foi selecionado para a produção de microestruturas com matrizes martensíticas, com os menores teores possíveis de austenita retida. Além disso, trabalhou-se com materiais nos estados trefilado e recozido.

$\mathrm{O}$ aço AISI 52100 foi submetido a dois tratamentos térmicos de têmpera semelhantes no que diz respeito a tempo e temperatura de austenitização. Entretanto, em um dos lotes os corpos-de-prova foram submetidos a tratamento sub-zero em nitrogênio líquido, após o tratamento de austenitização. A produção destes lotes visou verificar se os teores de austenita retida seriam modificados com o tratamento sub-zero, com modificação também na dureza e na resistência ao desgaste abrasivo. Os corpos-de- 
prova de aço AISI 52100 submetidos a tratamentos térmicos por tempos de $24 \mathrm{~h}$ e a temperatura de $700{ }^{\circ} \mathrm{C}$ foram encapsulados em quartzo, antes de serem colocados no forno.

O ferro fundido branco de alto cromo foi elaborado no Laboratório de Fundição do IPT. Este material foi selecionado para se estudar o efeito de uma segunda fase dura na resistência ao desgaste abrasivo. Ao mesmo tempo, foi selecionada a composição eutética, em função de ALBERTIN; SINATORA (2001) terem demonstrado que ferros fundidos brancos com esta composição apresentaram um desempenho superior quanto ao desgaste abrasivo.

A fundição do ferro fundido branco foi realizada em forno de indução AJAX com capacidade de $100 \mathrm{~kg}$. Foram utilizados moldes de areia aglomerada com resina de cura a frio. As peças utilizadas podem ser visualizadas pela Figura 4.1.

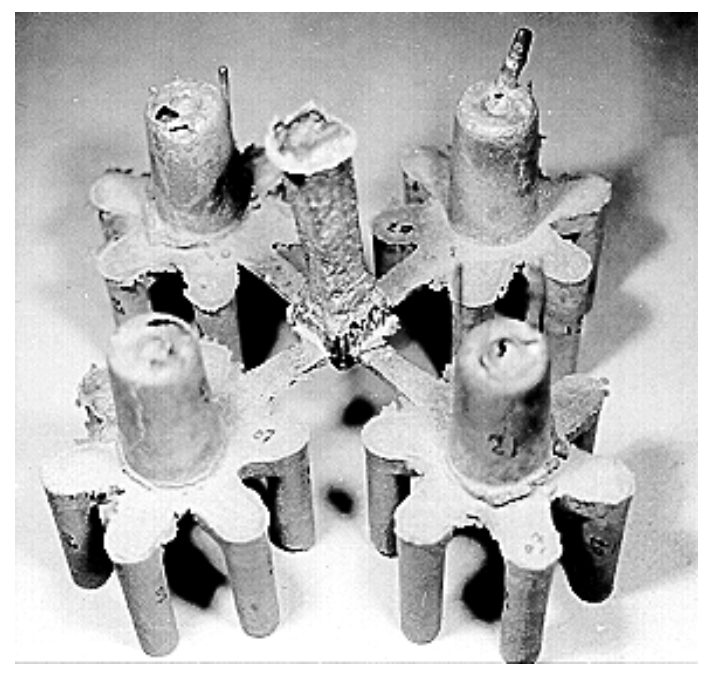

Figura 4.1. Fotografia das peças de ferro fundido branco em estado bruto de fundição, ilustrando a geometria dos modelos utilizados. 
Simultaneamente à fundição dos corpos-de-prova foram vazadas amostras coquilhadas para análises químicas. Estas análises foram realizadas por espectrometria de raios X, com exceção do carbono, analisado por combustão.

Ao longo da corrida, a composição química foi controlada por meio de curvas de resfriamento, para verificar se a solidificação era eutética. Para tanto, amostras foram retiradas do forno, em temperaturas entre 1400 e $1450{ }^{\circ} \mathrm{C}$ e vertidas em pequenos copos instrumentados com termopares. A curva de resfriamento é mostrada na Figura 4.2. A pequena diferença entre os patamares de solidificação (fase primária + eutético) indica uma composição muito próxima da eutética.

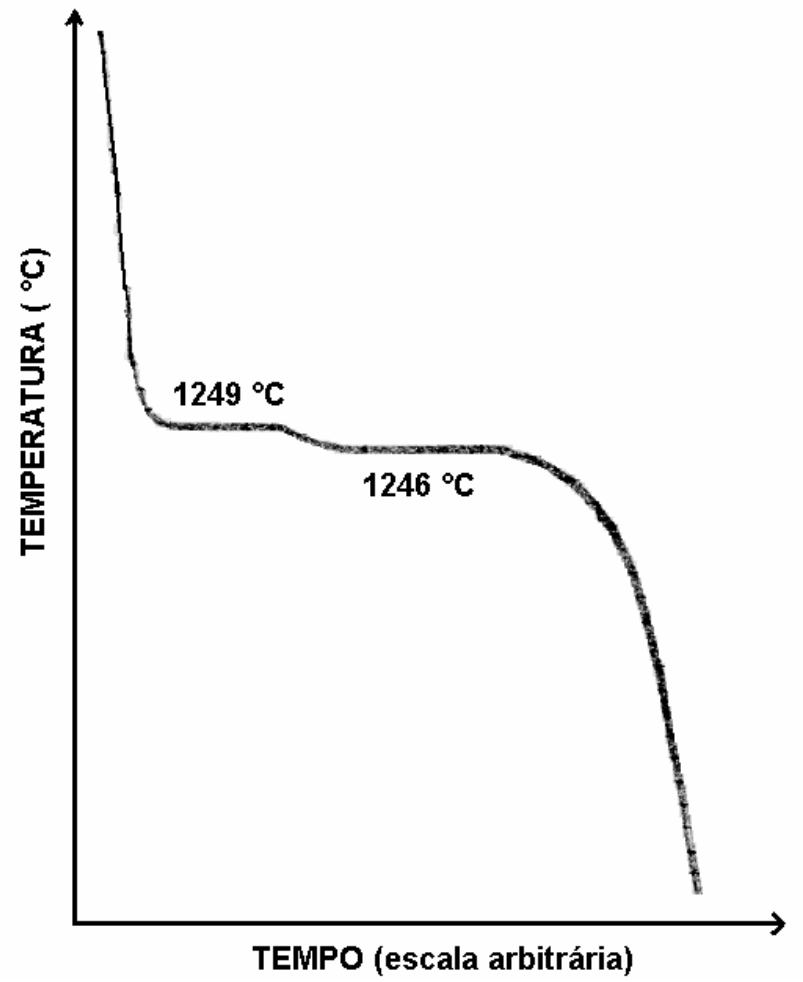

Figura 4.2. Curva de solidificação obtida após vazamento de amostra coquilhada.

A composição química dos materiais está apresentada na Tabela 4.1. 
Tabela 4.1 - Composição química dos materiais estudados.

\begin{tabular}{ccccccccc}
\hline Material & $\mathrm{C}$ & $\mathrm{Mn}$ & $\mathrm{Si}$ & $\mathrm{Cr}$ & $\mathrm{Ni}$ & $\mathrm{Mo}$ & $\mathrm{P}$ & $\mathrm{S}$ \\
\hline AISI 1006 & 0,07 & 0,02 & $<0,01$ & 0,02 & 0,05 & $<0,01$ & $<0,005$ & 0,011 \\
AISI 52100 & 1,03 & 0,39 & 0,29 & 1,49 & 0,14 & 0,05 & 0,018 & 0,008 \\
Ferro fundido & 3,37 & 1,13 & 0,87 & 19,17 & 0,18 & 0,03 & 0,032 & 0,011 \\
\hline
\end{tabular}

O resumo dos tratamentos térmicos e das condições metalúrgicas está apresentado na Tabela 4.2.

Tabela 4.2 - Tratamentos térmicos empregados aos corpos-de-prova.

\begin{tabular}{|c|c|c|}
\hline Material & Tratamentos térmicos & Microestrutura esperada \\
\hline AISI 1006 & Bruto de fundição & Ferrita \\
\hline \multirow{6}{*}{ AISI 52100} & Trefilado (como recebido) & Ferrita + carbonetos $\mathrm{M}_{3} \mathrm{C}$ \\
\hline & Recozido a $700{ }^{\circ} \mathrm{C}$ por $90 \mathrm{~min}$ & Ferrita + carbonetos $\mathrm{M}_{3} \mathrm{C}$ \\
\hline & $\begin{array}{l}\text { Austenitizado a } 850{ }^{\circ} \mathrm{C} \text { por } 60 \text { min (a } \\
\text { partir da condição trefilado), resfriado } \\
\text { em óleo e seguido de tratamento sub- } \\
\text { zero em } \mathrm{N}_{2} \text { líquido. }\end{array}$ & $\begin{array}{l}\text { Martensita + carbonetos } \\
\qquad \mathrm{M}_{3} \mathrm{C}\end{array}$ \\
\hline & $\begin{array}{c}\text { Austenitizado a } 850{ }^{\circ} \mathrm{C} \text { por } 60 \text { min }(\mathrm{a} \\
\text { partir da condição trefilado) e } \\
\text { resfriado em óleo }\end{array}$ & $\begin{array}{l}\text { Martensita + austenita } \\
\text { retida + carbonetos } \mathrm{M}_{3} \mathrm{C}\end{array}$ \\
\hline & $\begin{array}{c}\text { Temperado e revenido a } 500{ }^{\circ} \mathrm{C} \text { por } \\
90 \text { min (a partir da condição de } \\
\text { têmpera seguida de sub-zero) }\end{array}$ & $\begin{array}{l}\text { Martensita revenida }+ \\
\text { carbonetos } \mathrm{M}_{3} \mathrm{C}\end{array}$ \\
\hline & $\begin{array}{l}\text { Temperado e revenido a } 500^{\circ} \mathrm{C} \text { por } \\
24 \text { h (a partir da condição de têmpera } \\
\text { seguida de sub-zero) }\end{array}$ & $\begin{array}{l}\text { Martensita revenida }+ \\
\text { carbonetos } \mathrm{M}_{3} \mathrm{C}\end{array}$ \\
\hline Ferro fundido branco & Recozido a $700{ }^{\circ} \mathrm{C}$ por $8 \mathrm{~h}$ & Perlita + carbonetos $\mathrm{M}_{7} \mathrm{C}_{3}$ \\
\hline
\end{tabular}

A Figura 4.3 mostra de forma esquemática a sequiência de procedimentos para tratamento térmico do aço AISI 52100, no sentido dos materiais originais utilizados. 


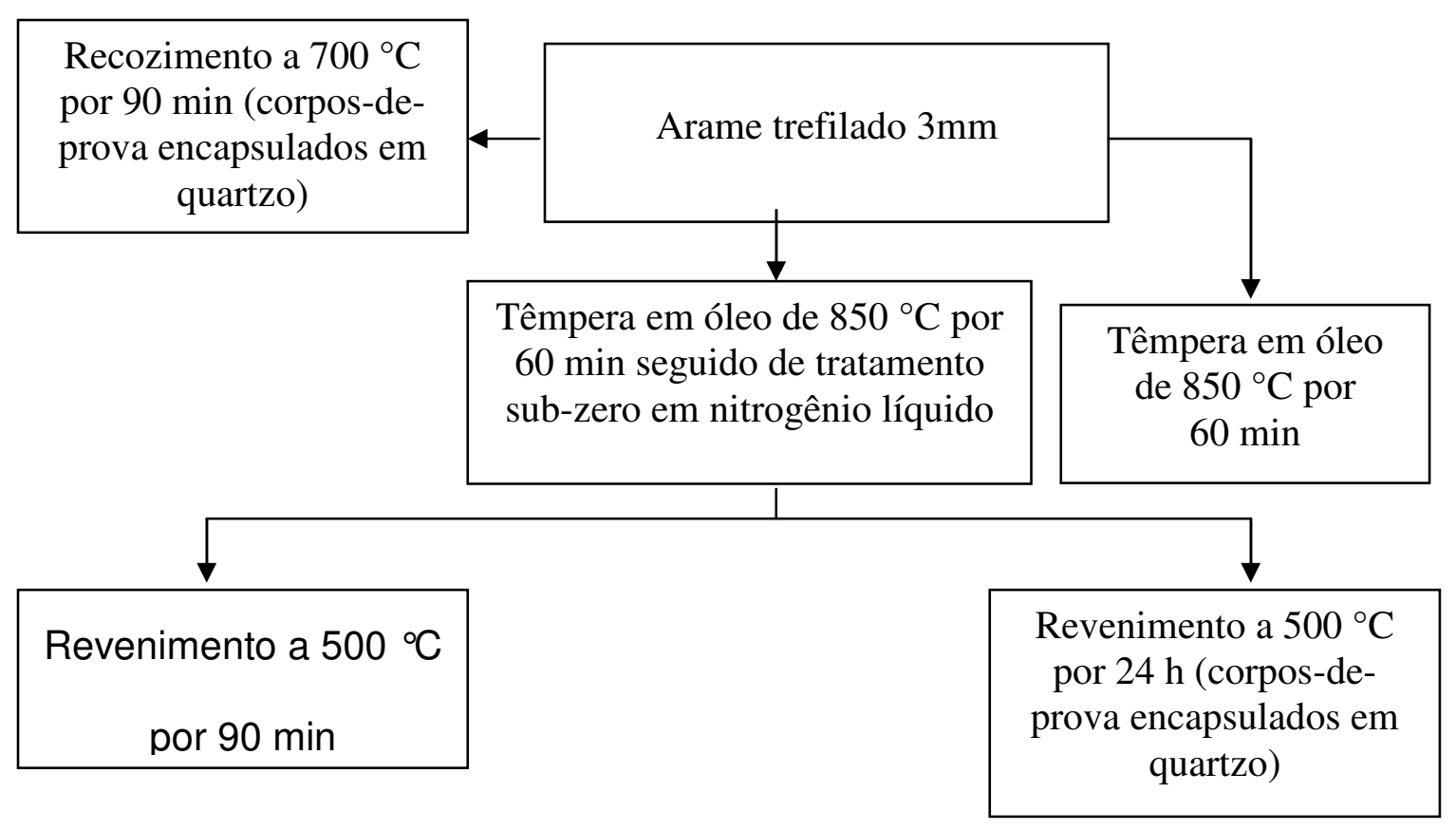

Figura 4.3. Diagrama de bloco das atividades relativas aos tratamentos térmicos empregados para o aço AISI 52100.

\subsection{MÉTODOS}

\subsubsection{Caracterização dos materiais metálicos}

Os materiais foram caracterizados metalograficamente de modo convencional. Para o aço AISI 52100 as microestruturas foram reveladas em microscopia eletrônica de varredura, enquanto que para o aço AISI 1006 e para o ferro fundido branco de alto cromo utilizou-se a microscopia óptica.

Foram realizadas contagens de frações volumétricas de perlita e de carbonetos do ferro fundido branco de alto cromo na condição bruta de fundição, em duas seções do cilindro original, denominadas por "meio" (velocidade de solidificação mais lenta) e "ponta" (velocidade de solidificação mais rápida). As contagens de frações 
volumétricas foram realizadas utilizando-se o programa QWIN do analisador de imagens LEICA, sendo que as médias correspondem a 30 determinações.

De modo a caracterizar a dureza dos materiais, utilizou-se um durômetro convencional Vickers, com forças aplicadas de 9,8 N. Esta dureza será denominada de dureza de engenharia, por existir nesta Tese menções a diferentes tipos e formas de obtenção de dureza. Os valores médios de dureza de engenharia correspondem a uma série de 3 determinações. A dureza dos microconstituintes do ferro fundido branco de alto cromo foram determinadas utilizando-se $0,005 \mathrm{~N}$ no equipamento FISCHERSCOPE H100V, sendo que os valores médios correspondem a uma série de 7 determinações.

\subsubsection{Ensaios de desgaste abrasivo}

Pinos de $3 \mathrm{~mm}$ de diâmetro e $21 \mathrm{~mm}$ de comprimento foram ensaiados no equipamento PLINT\&PARTNERS, modelo TE79, contra lixas. A seleção da metodologia de ensaio seguiu as diretrizes apresentadas nas normas ASTM G99-95a (2000)e1 (ASTM, 2001) e ASTM G132-96 (ASTM, 2001) e no trabalho de MUSCARA; SINNOTT (1972).

Durante a execução dos ensaios controlaram-se as seguintes variáveis: velocidade tangencial e de rotação, número de revoluções, posição do pino em relação ao disco, distância percorrida, forças normal e tangencial, coeficiente de atrito, umidade relativa do ar e temperatura ambiente.

As condições de ensaio utilizadas foram: 
- Velocidade tangencial: $0,08 \mathrm{~m} / \mathrm{s}$;

- Percurso em espiral com raio inicial de $40 \mathrm{~mm}$ e final de $15 \mathrm{~mm}$, resultando numa distância total percorrida de $6,0 \pm 0,1 \mathrm{~m}$ por lixa e numa superposição da pista percorrida pelo pino crescente para os menores raios;

- Abrasivos: lixas de vidro grana \#80 (código NORTON® Premium Glasspaper F2) e grana \#240 (código NORTON® Premium Glasspaper 00) em costado de papel ${ }^{(4.21)}$, substituídas a cada ensaio. Para cada pino, sempre foi realizado um assentamento da sua superfície, utilizando-se lixa de alumina grana \#600 (código NORTON® T223), nas mesmas condições de ensaio utilizadas para as lixas de vidro e;

- Força normal: $20 \mathrm{~N}$.

Adotou-se a seguinte sequiência para os ensaios:

- limpeza em ultra-som, utilizando etanol anidro;

- pesagem;

- assentamento da superfície dos pinos com lixa de alumina grana \#600;

- nova limpeza da amostra e;

- novas pesagens a cada lixa utilizada.

${ }^{4.21}$ Uma descrição detalhada das características físicas e químicas dos grãos abrasivos está apresentada no ANEXO A. 
A resolução da balança analítica utilizada é de $0,1 \mathrm{mg}$. Cada determinação de massa foi realizada levando-se em conta que a diferença entre a massa inicial e final fosse de pelo menos $1 \mathrm{mg}$, de modo a não se utilizar a casa de erro da balança. Caso esta diferença fosse menor, o número de lixas utilizadas entre duas determinações de massa foi aumentado, até um limite máximo de 10 lixas. Nos casos em que seriam necessários mais de 10 lixas para se atingir uma diferença de massa de pelo menos $1 \mathrm{mg}$, a taxa de desgaste foi considerada como nula.

A umidade relativa do ar foi controlada para ficar entre 45 e $55 \%$ durante a execução de todos os ensaios e foi mantida nestes valores por meio de desumidificadores.

Além dos ensaios com lixas de vidro, o aço AISI 52100 nas condições trefilado e bruto de têmpera e o ferro fundido branco de alto cromo foram ensaiados com lixa de alumina grana \#220 (código NORTON® A237).

Durante os ensaios de desgaste foi monitorada a força de atrito, por meio de uma célula de carga. A freqüência de aquisição foi de $1 \mathrm{~Hz}$, o que corresponde para cada lixa um total de 74 pontos. Foram adquiridos dados de 3 ensaios para construção de uma curva média de coeficiente de atrito.

Aplicou-se a metodologia apresentada na Tabela 4.3 para os ensaios de desgaste, com base em experimentos preliminares (PINTAÚDE e colaboradores, 2000).

Os anexos $\mathrm{B}$ e $\mathrm{C}$ apresentam todos os resultados de perda de massa [mg] individuais e as curvas de coeficiente de atrito médio, respectivamente. 
Tabela 4.3- Resumo das operações envolvidas para execução dos ensaios de desgaste e aquisição do sinal de força de atrito.

\begin{tabular}{cccc}
\hline Etapa & Tempo [s] & Ação & Objetivo \\
\hline 1 & Variável & Movimentar a mesa & $\begin{array}{c}\text { Ajustar a posição inicial de ensaio para o } \\
\text { raio de } 40 \mathrm{~mm}\end{array}$ \\
2 & 20 & Movimentar o disco & $\begin{array}{c}\text { Ajustar a velocidade de rotação do disco } \\
\text { para } 0,08 \mathrm{~m} / \mathrm{s} .\end{array}$ \\
3 & 3 & Movimentar o braço & $\begin{array}{c}\text { Promover o contato entre o pino e a lixa } \\
\text { abrasiva. }\end{array}$ \\
4 & 12 & $\begin{array}{c}\text { Movimentar o pino } \\
\text { apenas no raio de 40 mm }\end{array}$ & $\begin{array}{c}\text { Vencer a inércia devido ao contato do pino } \\
\text { com a lixa abrasiva. }\end{array}$ \\
5 & 74 & $\begin{array}{c}\text { Movimentar o pino do } \\
\text { raio 40 para o raio de } \\
15 \text { mm, em espiral. }\end{array}$ & $\begin{array}{c}\text { Período em que os sinais são adquiridos, } \\
\text { correspondentes ao ensaio de desgaste } \\
\text { propriamente dito. }\end{array}$ \\
\hline
\end{tabular}

\subsubsection{Rugosidade das superfícies desgastadas}

Analisou-se a rugosidade dos pinos para cada uma das etapas de ensaio, nivelamento e ensaios com lixa de vidro.

Até o momento das medidas de rugosidade, os pinos foram submersos em pó de grafite numa caixa com sílica-gel, de modo a evitar a sua oxidação. Previamente às medidas de rugosidade, os pinos foram lavados com álcool etílico anidro.

As medidas de rugosidade foram realizadas em um equipamento PERTHOMETER v. 6.2, de fabricação MAHR, situado na empresa MAHLE METAL LEVE S/A. Empregou-se o comprimento de 1,75 mm, sendo que a superfície de desgaste dos pinos foi disposta transversalmente ao penetrador de diamante, iniciando-se a medida a partir de um ponto próximo ao centro do pino. $\mathrm{O}$ rugosímetro utilizado permite adquirir os dados com uma diferença de nivelamento da 
superfície de até $25 \mu \mathrm{m}$, para mais ou para menos em função de uma linha de referência própria do programa.

Os perfis adquiridos foram exportados para o software MATLAB $5^{\circledR}$, versão 5.3 , aonde os dados foram processados para obtenção dos parâmetros de rugosidade $\mathrm{Ra}, \mathrm{Rz}$ e Sm.

Foi criada uma rotina de cálculo, utilizando-se 2 filtros para o sinal adquirido. $\mathrm{O}$ primeiro filtro tinha a função de traçar uma linha de referência do perfil original, de modo que as áreas abaixo e acima desta linha fossem idênticas. Esta linha foi obtida utilizando-se uma equação polinomial de segundo grau. Após isto, um segundo perfil tinha como função fazer com que o perfil obtido ficasse "paralelo" ao eixo horizontal. Um exemplo destas operações está apresentado na Figura 4.4.

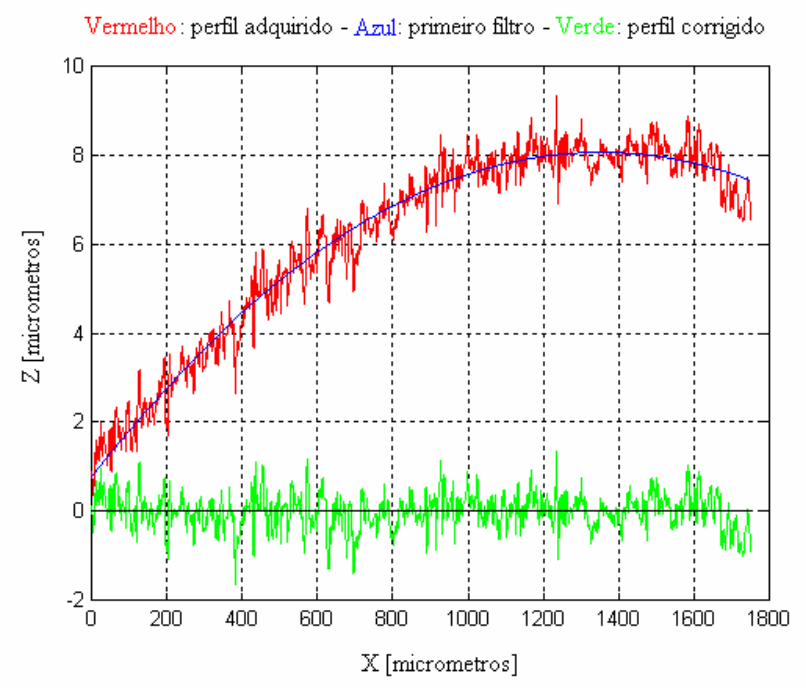

Figura 4.4. Exemplo da rotina de cálculos utilizada para obtenção dos parâmetros de rugosidade.

Com um perfil ajustado, como a linha verde mostrada na Figura 4.4, foram calculados os parâmetros de rugosidade. Foram empregadas 7 divisões para os cálculos 
com comprimento total de $1,75 \mathrm{~mm}$, o que resulta em segmentos de $250 \mu \mathrm{m}$. Para o cálculo dos valores médios de rugosidade, desprezou-se os segmentos iniciais e finais, em função das possíveis diferenças de aceleração do penetrador que podem ocorrer durante as medidas, restando então 5 segmentos para os cálculos de média e desviopadrão. Um esquema do tratamento do perfil para os cálculos dos parâmetros é mostrado na Figura 4.5.

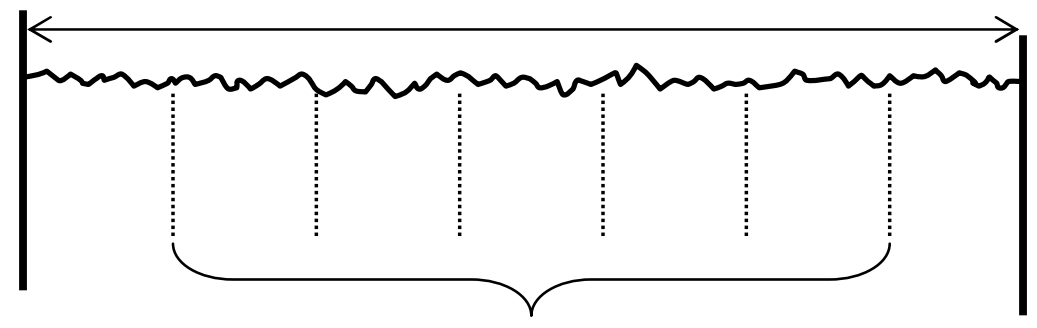

SEGMENTOS UTILIZADOS PARA CÁLCULO

DOS PARÂMETROS Ra, Rz e Sm.

Figura 4.5. Indicação dos segmentos utilizados para o cálculo dos parâmetros de rugosidade.

Esta rotina foi aplicada a um padrão de rugosidade da MAHLE METAL LEVE S/A com os mesmos procedimentos descritos anteriormente. Verificou-se que os valores de $\mathrm{Rz}$ e Sm calculados correspondiam àqueles indicados no padrão.

\subsubsection{Microscopia das superfícies desgastadas}

Após os ensaios de desgaste, a superfície dos pinos desgastados e a superfície das lixas abrasivas utilizadas foram observadas em microscopia eletrônica de varredura, em equipamento do Laboratório de Microscopia e Microanálise do Departamento de Metalurgia e de Materiais da Escola Politécnica da USP. As lixas abrasivas foram 
recobertas com ouro previamente à análise por microscopia eletrônica, enquanto que os pinos foram analisados sem nenhuma preparação na superfície desgastada.

\subsubsection{Ensaios instrumentados de dureza}

Os ensaios instrumentados de dureza (Norma ISO/FDIS 14577-1; ISO, 2002) foram realizados utilizando o equipamento FISCHERSCOPE H100V, que opera com força máxima de $1 \mathrm{~N}$. Este equipamento permite a realização de ensaios por meio da seleção da profundidade máxima de penetração, ao invés da seleção da força a ser aplicada.

Os ensaios obedeceram ao seguinte procedimento:

- seleção da profundidade máxima de penetração, com aplicação da força em até 60 passos de $0,1 \mathrm{~s}$ cada;

- após atingida a força máxima, esta foi mantida por $10 \mathrm{~s} \mathrm{e;}$

- remoção da força em 100 passos de $0,1 \mathrm{~s}$ até $0,4 \mathrm{mN}$.

Para cada um dos materiais foram realizadas 7 impressões de dureza. Os resultados destes ensaios foram analisados de forma numérica por meio de curvas de regressão, tanto para a etapa de carregamento quanto para a de descarregamento. Com os dados da etapa de descarregamento foi calculada a rigidez de contato $\mathrm{S}$, segundo o método proposto por OLIVER; PHARR (1992) que foi adotado pela ISO/FDIS 14577-1 (ISO, 2002), permitindo a avaliação do módulo elástico reduzido $\mathrm{E}_{\mathrm{r}}$.

As impressões de dureza foram analisadas posteriormente no equipamento MICROMET2103, um durômetro que opera entre 1 e 2000 gf e que dispõe de um 
conjunto de lentes que permite aumento de até 1000 vezes. Foram medidas as diagonais de impressão com a régua graduada disponível na lente ocular deste equipamento, para calcular os valores de dureza Vickers convencional.

As morfologias de impressão de dureza foram analisadas em microscopia óptica e também por interferometria laser, em equipamento fabricado pela empresa UBM, pertencente ao Laboratório de Tribologia e Materiais da UFU. Este equipamento é capaz de medir o perfil de uma superfície por meio da varredura de um feixe de laser. A resolução de leitura utilizada foi de uma aquisição a cada $1 \mu \mathrm{m}$. A análise dos dados foi feita no programa UBSoft 1.9 .

A dureza dos grãos de vidro foi determinada utilizando-se o equipamento FISCHERSCOPE H100V, com 1 N. Os grão foram removidos manualmente de uma lixa grana \#36 e então embutidos em resina a frio. Esta granulometria foi selecionada de modo que se obtivesse uma maior área disponível para as impressões de dureza.

No caso da dureza Vickers convencional mediu-se as diagonais de impressão dos grãos de vidro no equipamento MICROMET 2103, com 0,98 N. A diferença entre as diagonais de impressão devido ao uso de dois equipamentos e de duas forças de ensaio foi corrigida, utilizando-se um fator obtido por meio de medidas com um vidro óptico, que é um material de referência do equipamento FISCHERSCOPE H100V.

Foi calculado o fator $\alpha$ apresentado na equação 2.13, proposto por ZENG e colaboradores (1996). Este fator permite a previsão da morfologia de impressão de dureza, que foi analisada por meio de interferometria laser e microscopia óptica. 
Com este fator foi calculada a profundidade de contato, $\mathrm{h}_{\mathrm{C}}$, e a dureza que será denominada dureza verdadeira, $\mathrm{H}_{\mathrm{IP}}$. Ao cálculo desta dureza estão incorporados os efeitos da morfologia de impressão, formação de bordas ou retração. As equações a seguir apresentam a sequiência de cálculos utilizada ${ }^{(4.22)}$.

$$
\begin{aligned}
& H_{I P}=\frac{F_{\text {máx }}}{A_{\text {verdadeira }}}=\frac{F_{\text {máx }}}{C^{\prime} \cdot h_{C}^{2}}=\frac{F_{\text {máx }} \cdot \alpha}{C^{\prime} \cdot h_{\text {máx }}^{2}} \\
& \alpha=\frac{A_{\text {ideal }}}{A_{\text {verdadeira }}}=\frac{24,5 \cdot h_{C}^{2}}{C^{\prime} \cdot h_{C}^{2}}=\frac{24,5}{C^{\prime}} \\
& H_{I P}=\frac{F_{\text {máx }} \cdot \alpha^{2}}{24,5 \cdot h_{\text {máx }}^{2}} \\
& A_{\text {verdadeira }}=24,5\left(h_{\text {máx }} / \alpha\right)^{2}
\end{aligned}
$$

Equação 4.4

onde,

$\mathrm{C}^{\prime}$ é uma constante que relaciona a força aplicada com a profundidade ao quadrado durante a etapa de carregamento [MPa].

O mesmo raciocínio foi utilizado para o cálculo do módulo elástico reduzido. Neste caso, a equação final é dada pela combinação entre a equação 2.20 e a área verdadeira apresentada na equação 4.4. Desta forma, o módulo elástico reduzido é calculado por:

$$
E_{r}=\frac{\alpha \cdot S}{5,65 \cdot h_{\text {máx }}}
$$

\section{Equação 4.5}

${ }^{4.22}$ O valor 24,5 apresentado nas equações 4.2 a 4.4 é válido apenas para as geometrias Vickers e Berkovich. 


\section{RESULTADOS E DISCUSSÃO}

\subsection{CARACTERIZAÇÃO DOS MATERIAIS}

\subsubsection{Aço AISI 1006}

A Figura 5.1 apresenta a microestrutura do aço AISI 1006.

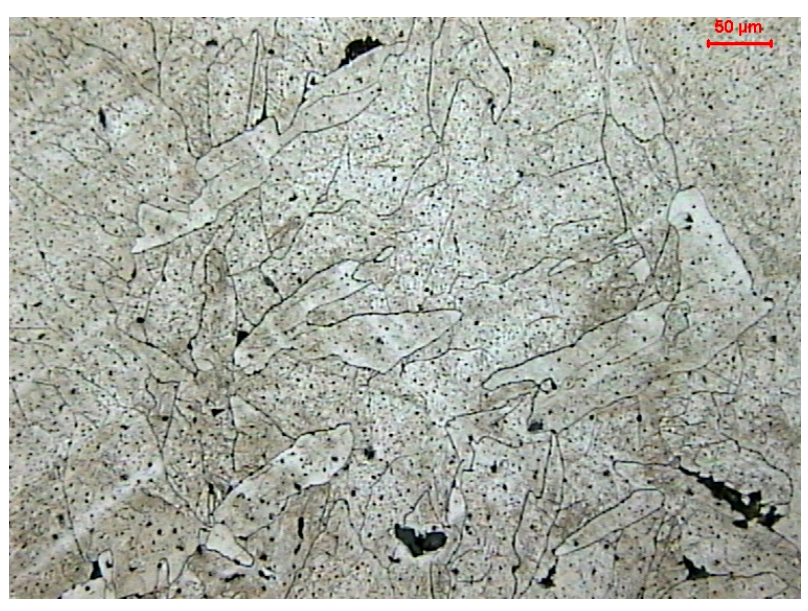

Figura 5.1. Microestrutura do aço AISI 1006 (ferrita + inclusões).

A dureza $\mathrm{HV}_{1}$ do aço AISI 1006 é $(973 \pm 3) \mathrm{MPa}$, valor semelhante ao obtido por RICHARDSON (1968) para o ferro comercialmente puro, que foi $981 \mathrm{MPa}$.

\subsubsection{Aço AISI 52100}

A Figura 5.2 apresenta a microestrutura do aço AISI 52100 nas condições recozido e bruto de têmpera. 


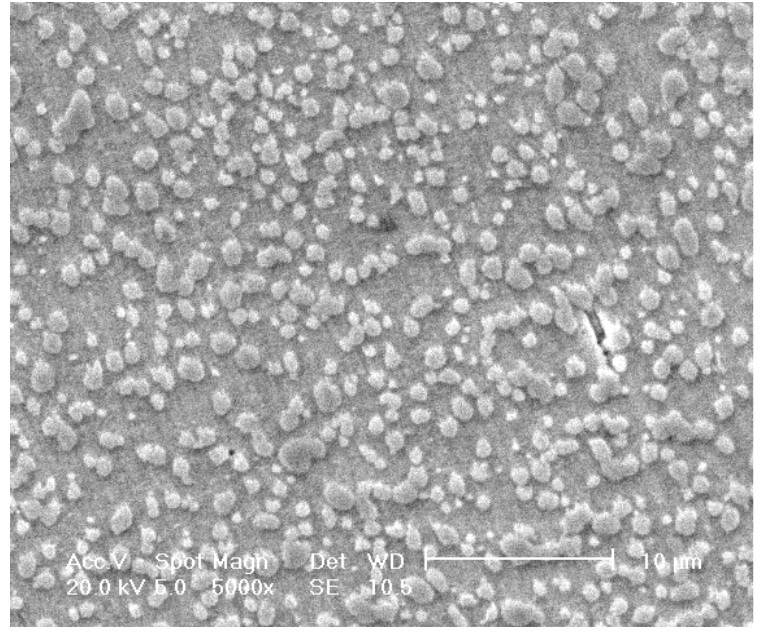

(A)

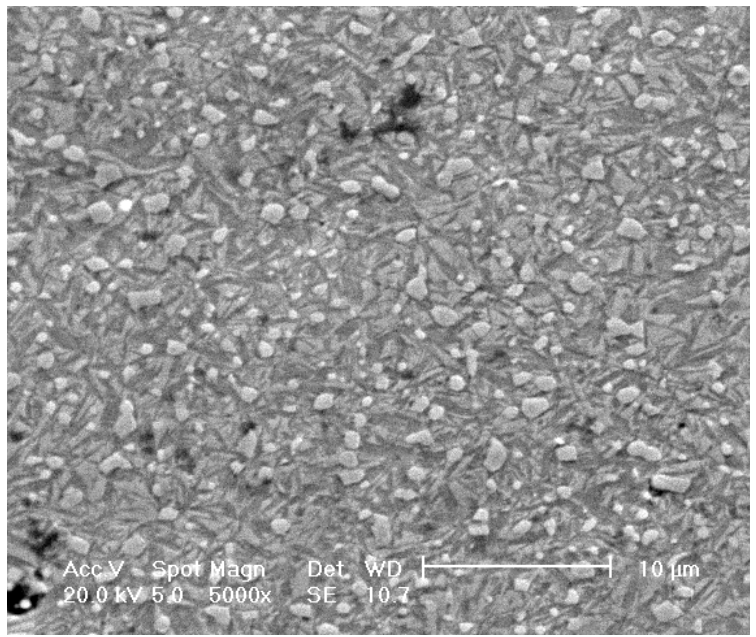

(B)

Figura 5.2. Microestruturas do aço AISI 52100: (A) recozido (ferrita + carbonetos $\mathrm{M}_{3} \mathrm{C}$ ) e (B) bruto de têmpera (martensita + carbonetos $\mathrm{M}_{3} \mathrm{C}$ ).

A Figura 5.2 mostra que o tratamento de austenitização a $850{ }^{\circ} \mathrm{C}$ por $1 \mathrm{~h}$ solubilizou parcialmente os carbonetos $\mathrm{M}_{3} \mathrm{C}$.

A Tabela 5.1 apresenta os valores de dureza Vickers para cada uma das condições metalúrgicas do aço AISI 52100, a serem referidas como dureza de engenharia ao longo deste trabalho.

Tabela 5.1 - Dureza de engenharia [MPa] do aço AISI 52100 em diferentes condições metalúrgicas.

\begin{tabular}{cc}
\hline Condição metalúrgica & $\mathrm{HV}_{1}[\mathrm{MPa}]$ \\
\hline Recozido & $1.930 \pm 10$ \\
Trefilado & $3.160 \pm 90$ \\
Temperado e revenido $500^{\circ} \mathrm{C} / 24 \mathrm{~h}$ & $4.070 \pm 30$ \\
Temperado e revenido $500^{\circ} \mathrm{C} / 90 \mathrm{~min}$ & $4.900 \pm 200$ \\
Bruto de têmpera & $8.400 \pm 200$ \\
Bruto de têmpera seguido de sub-zero & $9.500 \pm 200$ \\
\hline
\end{tabular}


A Tabela 5.1 mostra que há diferença significativa nos valores de dureza entre a amostra bruta de têmpera e a tratada em nitrogênio líquido. Esta diferença mostra que o tratamento sub-zero foi efetivo no sentido de eliminar possíveis frações existentes de austenita retida após a têmpera em óleo.

Segundo resultados obtidos por SILVA e colaboradores (1996), independentemente do tempo de austenitização, para uma temperatura de $850{ }^{\circ} \mathrm{C}$ os teores de austenita retida em aço AISI 52100 bruto de têmpera sem posterior tratamento sub-zero é de aproximadamente $15 \%$, enquanto que nas mesmas condições com posterior tratamento sub-zero, os teores de austenita retida tendem a estar em torno de 3 $\%$, ou seja, dentro do limite de detecção de microconstituintes em uma análise de difração por raios $\mathrm{X}$, o que está em acordo com os resultados apresentados na Tabela 5.1.

A título de comparação, foram caracterizadas as durezas de engenharia de aços AISI 52100 retirados de produção industrial da empresa INA Rolamentos S/A, nos estados trefilado e temperado e revenido, que correspondem a estágios diferentes da fabricação de rolamentos de agulhas, com dimensões semelhantes aos pinos utilizados neste trabalho. A Tabela 5.2 apresenta os valores obtidos.

Tabela 5.2 - Dureza de engenharia [MPa] de aço AISI 52100 de peças industriais.

\begin{tabular}{cc}
\hline Condição metalúrgica & $\mathrm{HV}_{1}[\mathrm{MPa}]$ \\
\hline Trefilado & $2.930 \pm 50$ \\
Temperado e revenido $^{(5.23)}$ & $7.500 \pm 200$ \\
\hline
\end{tabular}

${ }^{5.23} \mathrm{O}$ tratamento térmico industrial de revenido usual para aço AISI 52100 é de $180^{\circ} \mathrm{C}$ por 60 min, conforme mostra o trabalho de SILVA e colaboradores (1996). 
Os resultados da Tabela 5.2 mostram valores da mesma ordem de grandeza em relação às durezas das condições metalúrgicas utilizadas neste trabalho, apresentadas na Tabela 5.1. Este resultado mostra que a metodologia experimental utilizada para a obtenção das condições metalúrgicas desejadas foi satisfatória.

\subsubsection{Ferro fundido branco de alto cromo}

A Figura 5.3 apresenta a microestrutura do ferro fundido branco de alto cromo bruto de fundição, em duas seções diferentes.

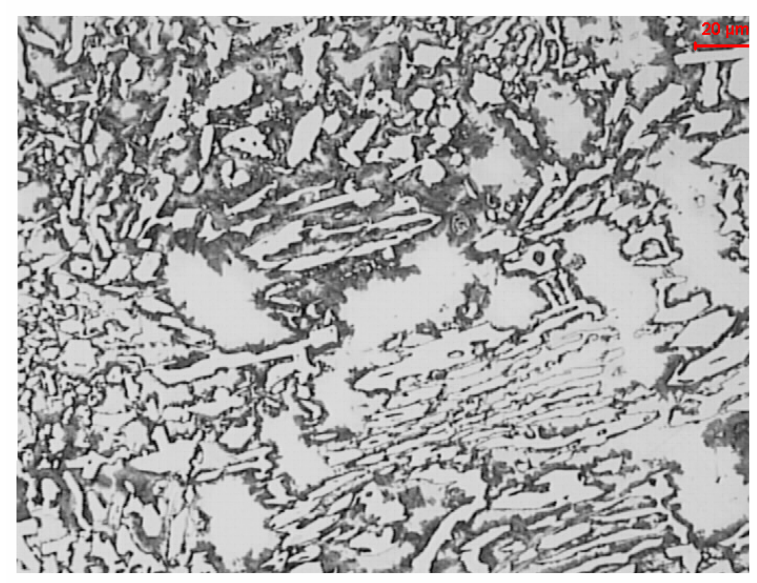

(A)

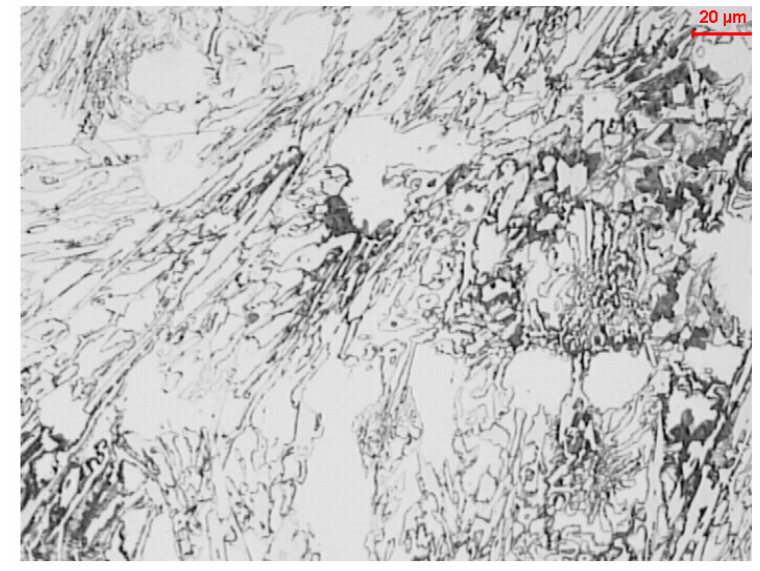

(B)

Figura 5.3. Microestrutura bruta de fundição do ferro fundido branco de alto cromo: (A) seção "ponta" (austenita + perlita + carbonetos eutéticos $\left.M_{7} C_{3}\right)$ e $(B)$ seção "meio" (austenita + perlita + carbonetos eutéticos $\mathrm{M}_{7} \mathrm{C}_{3}$ ).

Os resultados de análise metalográfica quantitativa do ferro fundido branco de alto cromo, relativos às micrografias da Figura 5.3, encontram-se na Tabela 5.3.

\section{Tabela 5.3 - Análise quantitativa do ferro fundido branco de alto cromo bruto de fundição.}

\begin{tabular}{cc}
\hline Fração volumétrica de perlita - ponta & $4,0 \pm 0,6$ \\
Fração volumétrica de perlita - meio & $22,4 \pm 0,5$ \\
Fração volumétrica de carbonetos $\mathrm{M}_{7} \mathrm{C}_{3} *$ & $35 \pm 1$ \\
\hline
\end{tabular}

* Não foi verificada nenhuma diferença significativa na fração volumétrica de carbonetos entre seções diferentes da peça cilíndrica original bruta de fundição. 
A Figura 5.4 apresenta a microestrutura resultante do tratamento isotérmico a $700{ }^{\circ} \mathrm{C}$ por $8 \mathrm{~h}$ do ferro fundido branco de alto cromo.

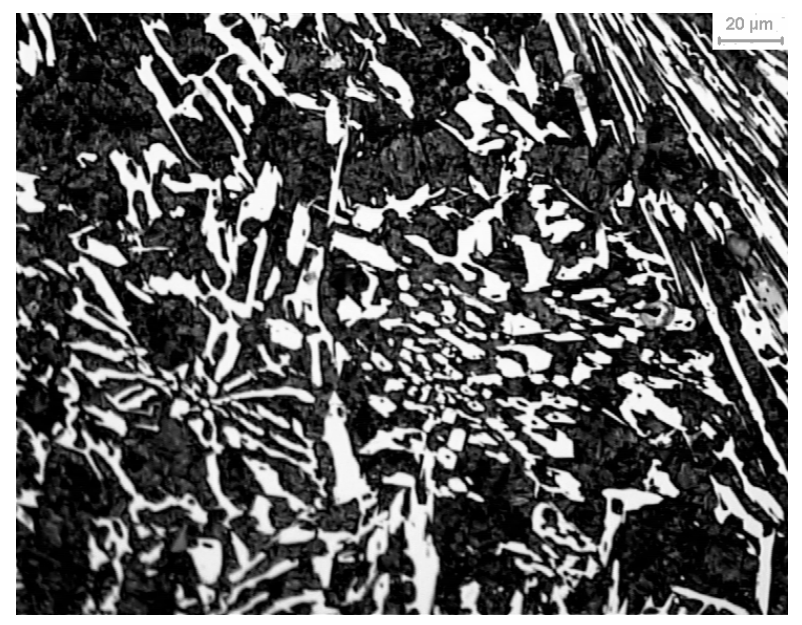

Figura 5.4. Microestrutura após tratamento térmico a $700{ }^{\circ} \mathrm{C}$ por $8 \mathrm{~h}$ do ferro fundido branco de alto cromo (perlita + carbonetos eutéticos $\mathrm{M}_{7} \mathrm{C}_{3}$ ).

A Figura 5.4 mostra que após o tratamento isotérmico a $700{ }^{\circ} \mathrm{C}$ a matriz ficou 100\% perlítica, como desejado. Tratamentos térmicos preliminares foram realizados mostrando que tempos de tratamento de $1 \mathrm{~h}$ já eram suficientes para deixar a matriz totalmente perlítica, indiferentemente da seção da peça bruta de fundição. O tempo de tratamento de $8 \mathrm{~h}$ foi o que forneceu resultados de dureza para a matriz perlítica menores e mais semelhantes à microdureza do aço AISI 52100 trefilado.

A dureza de engenharia do ferro fundido branco de alto cromo após tratamento isotérmico a $700{ }^{\circ} \mathrm{C}$ por $8 \mathrm{~h}$ foi $(4.600 \pm 200) \mathrm{MPa}$.

A Tabela 5.4 apresenta os resultados de dureza das fases, matriz perlítica e carboneto $\mathrm{M}_{7} \mathrm{C}_{3}$, do ferro fundido branco de alto cromo. Para efeito de comparação, apresenta-se a dureza do aço AISI 52100 trefilado, obtida com as mesmas condições de ensaio. 
Tabela 5.4 - Dureza Martens HM [MPa] determinada com 0,005 N do aço AISI 52100 trefilado e das fases constituintes do ferro fundido branco de alto cromo.

\begin{tabular}{cc}
\hline Material - microestrutura & Dureza Martens HM [MPa] \\
\hline Aço AISI 52100 trefilado - ferrita + carboneto $\mathrm{M}_{3} \mathrm{C}$ & $3.250 \pm 90$ \\
Ferro fundido branco de alto cromo - matriz & $3.250 \pm 70$ \\
Ferro fundido branco de alto cromo - carboneto $\mathrm{M}_{7} \mathrm{C}_{3}$ & $10.800 \pm 400$ \\
\hline
\end{tabular}

A Tabela 5.4 mostra que a dureza da matriz perlítica do ferro fundido branco de alto cromo e a do aço AISI 52100 trefilado são idênticas.

\subsubsection{Resumo da caracterização dos materiais}

Este Item teve como principal objetivo mostrar que a metodologia aplicada para a fabricação dos corpos-de-prova conseguiu produzir microestruturas com durezas que permitem o estudo da transição entre regimes de desgaste abrasivo.

O resumo da caracterização dos materiais é:

- Aço AISI 1006: apresenta valor de dureza comparável ao material de referência utilizado por RICHARDSON (1968).

- Aço AISI 52100: apresenta valores de dureza com queda progressiva a partir da condição bruta de têmpera.

- Ferro fundido branco de alto cromo: material com segunda fase dura e com matriz de dureza igual à do aço AISI 52100 trefilado. 


\subsection{ENSAIOS DE DESGASTE ABRASIVO}

\subsubsection{Taxas de desgaste}

\subsubsection{Evolução das taxas de desgaste com o tempo de ensaio}

A evolução da perda de massa com o tempo de ensaio, utilizando-se lixa de vidro grana \#240, para o aço AISI 52100 trefilado está apresentada na Figura 5.5.

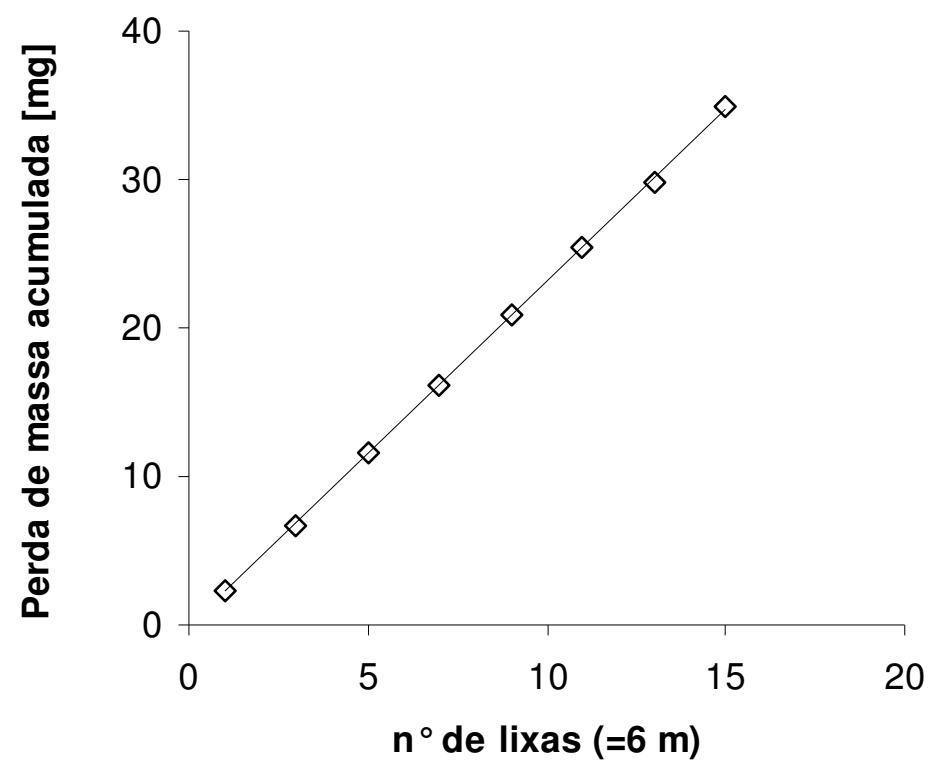

Figura 5.5. Evolução da perda de massa com o tempo de ensaio para o par 'aço AISI 52100 trefilado - lixa de vidro grana \#240'.

Na Figura 5.5 não é possível identificar um período de amaciamento ("runningin"), provavelmente porque este período deve ocorrer para distâncias menores que as equivalentes a uma lixa. Este tipo de curva foi verificado também para os materiais com menor dureza (aço AISI 1006 e aço AISI 52100 recozido), independentemente do tamanho do abrasivo utilizado. 
A evolução da perda de massa com o tempo de ensaio, utilizando-se lixa grana \#80, para o aço AISI 52100 temperado e revenido $500^{\circ} \mathrm{C} / 24 \mathrm{~h}$ está apresentada na Figura 5.6.

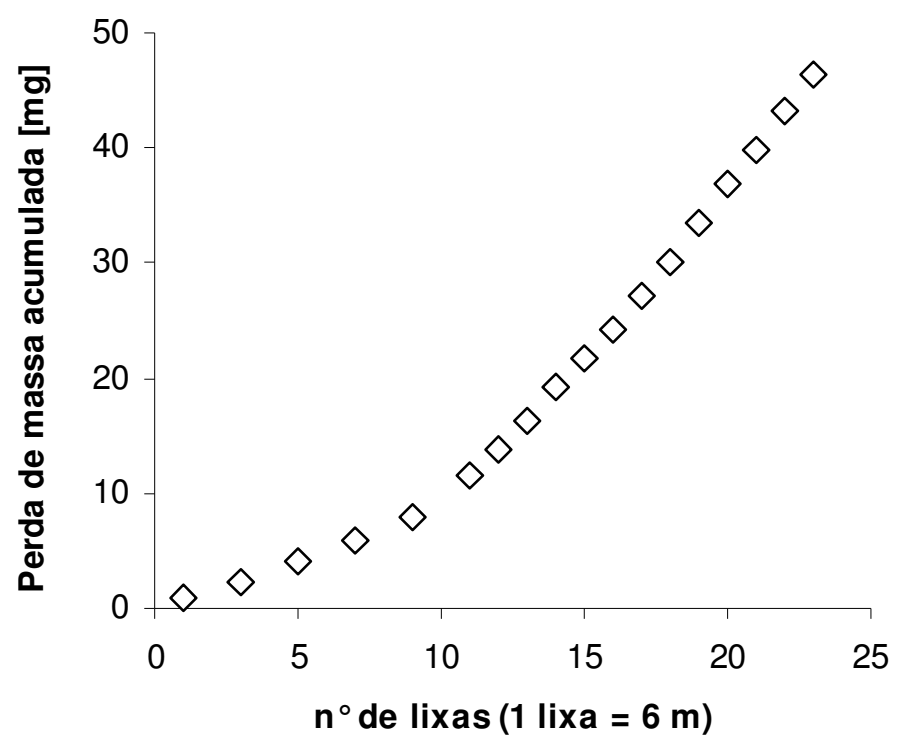

Figura 5.6. Evolução da perda de massa com o tempo de ensaio para o par 'aço AISI 52100 temperado e revenido $500{ }^{\circ} \mathrm{C} / 24 \mathrm{~h}$ - lixa de vidro grana \#80'.

A Figura 5.6 mostra um período de amaciamento pouco usual em desgaste abrasivo, no qual a taxa de desgaste é menor durante este período que a taxa calculada para o regime permanente. Neste caso, foram necessárias 10 lixas, que eqüivalem a uma distância percorrida de $60 \mathrm{~m}$, para que o material atingisse o regime permanente de desgaste. Foram utilizadas 100 lixas nos ensaios com a lixa de vidro grana \#240 para que fosse estabelecido o regime permanente de desgaste, equivalente a uma distância de aproximadamente $600 \mathrm{~m}$.

Os comportamentos apresentados nas Figuras 5.5 e 5.6 foram observados também para os seguintes materiais, independentemente do tamanho do abrasivo, respectivamente: 
- Figura 5.5: aço AISI 1006, aço AISI 52100 nas condições recozido e trefilado;

- Figura 5.6: aço AISI 52100 nas condições 'temperado e revenido' e para o ferro fundido branco de alto cromo.

O tipo de comportamento esperado para a Figura 5.6 seria como o apresentado na Figura 5.7, obtida por RICHARDSON (1968) em ensaios pino contra lixa para um aço AISI 1074 com $650 \mathrm{HV}$, utilizando lixa de vidro grana \#30 e tensão nominal de contato de $1 \mathrm{MPa}$.

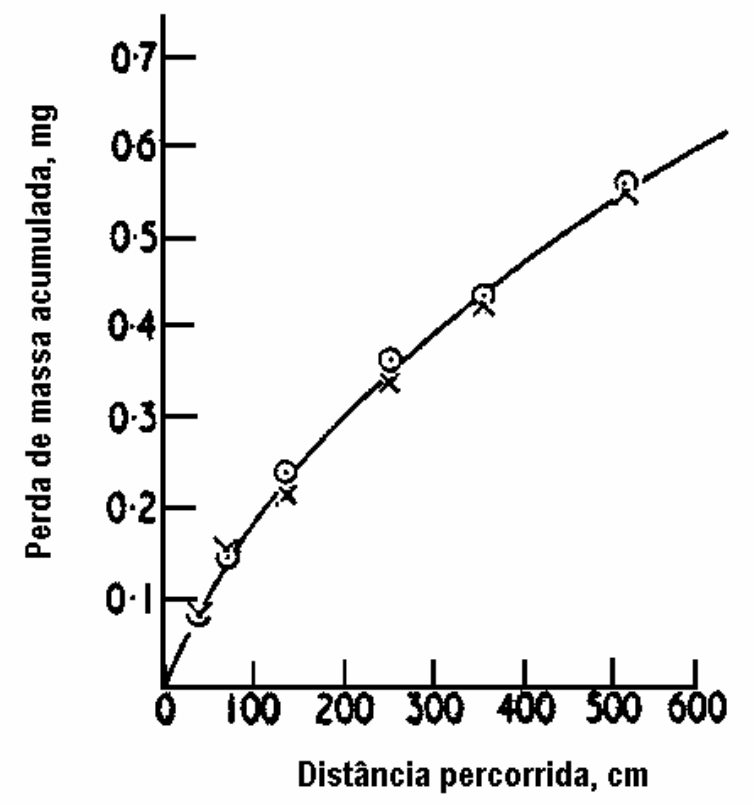

Figura 5.7. Evolução da perda de massa com o tempo de ensaio para o par aço AISI 1074 temperado e revenido / lixa de vidro grana \#30 (RICHARDSON, 1968).

A Figura 5.7 mostra que a taxa de desgaste do período de amaciamento é maior que a do período de regime permanente. Isto se deve ao fato da dureza inicial da superfície ser menor que a dureza atingida após o regime permanente e, portanto, as taxas de desgaste iniciais são maiores, como mostram os resultados obtidos por PINTAÚDE; SINATORA (1998), apresentados na Figura 5.8. 


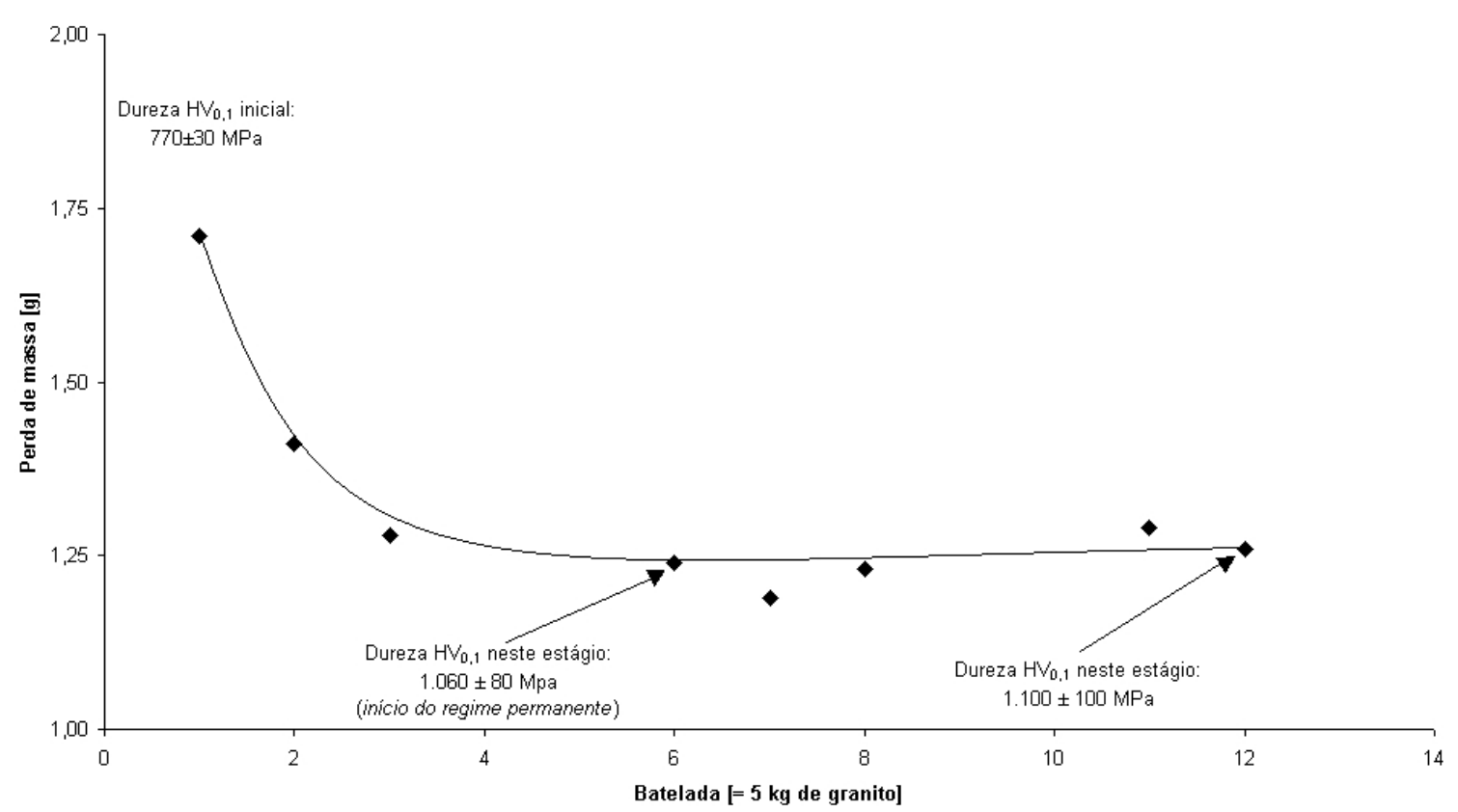

Figura 5.8. Evolução da perda de massa com o tempo de ensaio de uma mandíbula fixa de britador, feita de aço 1,5Si-2Cr-0,5Mo (PINTAÚDE; SINATORA, 1998).

A Figura 5.8 mostra que a estabilização das taxas de desgaste coincide com a estabilização da dureza da superfície desgastada. Uma hipótese para os resultados da Figura 5.6 é que o nível de encruamento inicial, determinado pela lixa de alumina grana \#600, foi elevado o suficiente de tal forma que a lixa de vidro não conseguiu modificá-lo. Sendo assim, se a dureza após a etapa de nivelamento é mais alta do que a dureza devido à deformação imposta pelos grãos de vidro, a taxa de desgaste é crescente com o tempo de ensaio até ser atingida a estabilização.

Um estudo mais detalhado é necessário para compreender a evolução das taxas de desgaste com o tempo de ensaio, apresentada nas Figuras 5.5 e 5.6. Como este tipo de resultado não é objetivo desta Tese, fica como sugestão para trabalhos futuros uma investigação sobre estes resultados, utilizando medidas de dureza na superfície e na 
subsuperfície desgastada, de modo a relacionar a evolução das taxas de desgaste com a evolução do encruamento superficial, como apresentado na Figura 5.8.

\subsubsection{Valores médios de taxas de desgaste - Efeito de microestrutura}

A Tabela 5.5 apresenta os resultados de taxas de desgaste para o aço AISI 52100 trefilado e para o ferro fundido branco, ensaiados com lixas de vidro e de alumina, bem como os valores de dureza prévia ao desgaste destes materiais.

Tabela 5.5 - Taxas de desgaste [mg/m] do aço AISI 52100 trefilado e do ferro fundido branco de alto cromo. Abrasivos: vidro grana \#80 e alumina grana \#220.

\begin{tabular}{ccc}
\cline { 2 - 3 } & Aço AISI 52100 trefilado & Ferro fundido branco \\
\hline Dureza de engenharia [MPa] & 3.160 & 4.600 \\
Dureza HM (matriz) $[\mathrm{MPa}]$ & 3.250 & 3.250 \\
Taxa ensaio vidro $[\mathrm{mg} / \mathrm{m}]$ & $1,13 \pm 0,05$ & $0,037 \pm 0,002$ \\
Taxa ensaio alumina $[\mathrm{mg} / \mathrm{m}]$ & $1,43 \pm 0,03$ & $1,02 \pm 0,03$ \\
\hline
\end{tabular}

Os resultados da Tabela 5.5 mostram que a taxa de desgaste do ferro fundido branco é 30 vezes menor que a do aço AISI 52100 trefilado nos ensaios com lixa de vidro. No caso dos ensaios alumina, a taxa do ferro fundido branco é aproximadamente $40 \%$ menor que a do aço. Considerando o efeito do abrasivo nas taxas de desgaste para um mesmo material, no caso do aço AISI 52100 a taxa obtida com a lixa de vidro é aproximadamente $25 \%$ menor que a obtida com a alumina. Este efeito foi bem mais pronunciado nos ensaios com o ferro fundido branco: a lixa de vidro o desgastou 27 vezes menos que a lixa de alumina. Estas diferenças estão relacionadas com a 
microestrutura dos materiais, em particular com a presença dos carbonetos $M_{7} C_{3}$ do ferro fundido, uma vez que a dureza da matriz destes materiais é semelhante.

De modo a investigar com maior detalhe o efeito da microestrutura, um experimento foi realizado: as superfícies destes materiais, preparadas metalograficamente, foram riscadas com um fragmento de vidro. A Figura 5.9 apresenta a superfície do aço AISI 52100 em microscopia eletrônica de varredura após esta experiência, imagem na qual está evidenciada também uma impressão de dureza Vickers.

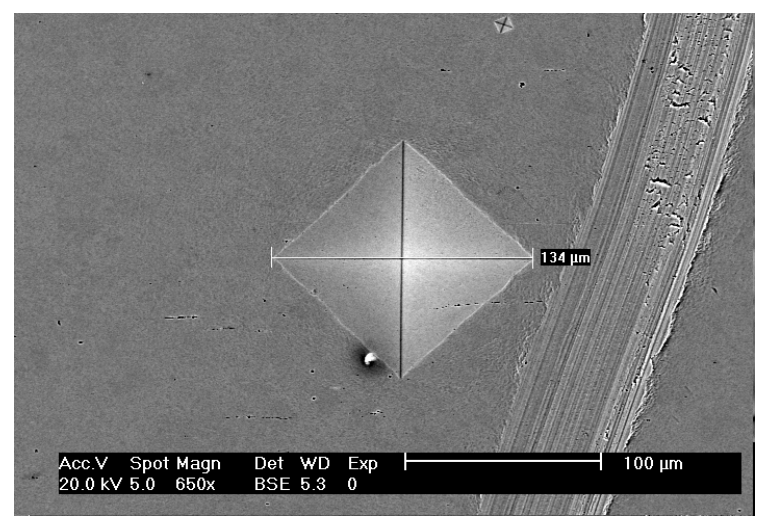

Figura 5.9. Superfície polida do aço AISI 52100 trefilado riscada com fragmento de vidro, observada em microscopia eletrônica de varredura. Nota-se a impressão de dureza Vickers.

A Figura 5.9 mostra que o risco produzido tem uma largura de aproximadamente $50 \mu \mathrm{m}$ e o aspecto deste risco evidencia o mecanismo de microcorte.

A Figura 5.10 apresenta as imagens em microscopia eletrônica de varredura do riscamento da superfície polida do ferro fundido branco de alto cromo. 


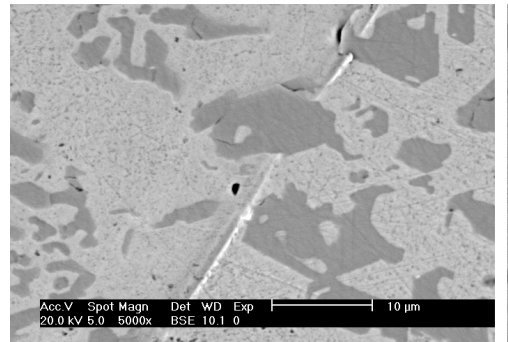

(A)

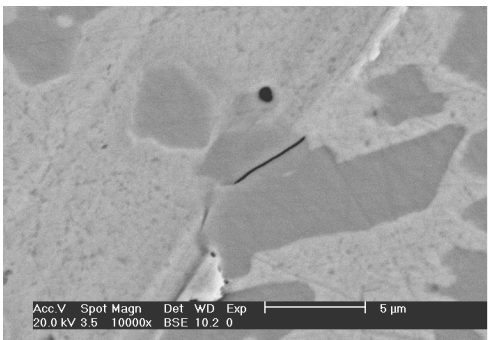

(B)

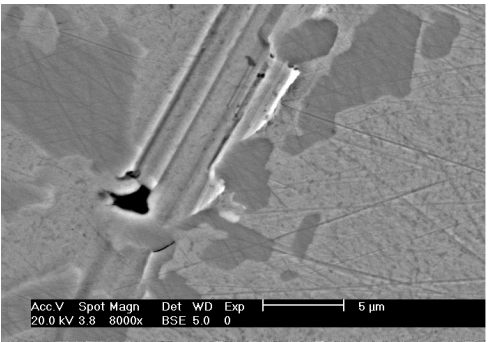

(C)

Figura 5.10. Superfície polida de ferro fundido branco de alto cromo riscada manualmente com fragmento de vidro, observada em microscopia eletrônica de varredura.

A Figura 5.10 (A) mostra que o risco é interrompido ao encontrar um carboneto $\mathrm{M}_{7} \mathrm{C}_{3}$. A Figura 5.10 (B) apresenta uma trinca formada pelo contato direto com o pedaço de vidro, pois a força aplicada ficou restrita a uma região muito pequena do carboneto. Por fim, a Figura 5.10 (C) mostra que na região da matriz perlítica do ferro fundido branco o mecanismo de microcorte é observado, da mesma forma que no aço AISI 52100 trefilado (Figura 5.9), o que era esperado devido à dureza da matriz dos materiais ser semelhante. $\mathrm{O}$ carboneto, por ser mais duro que o vidro, foi eficiente para interromper a atuação de microcorte na matriz. As trincas nos carbonetos não foram suficientes para removê-los, garantindo a sua eficiência ao longo do período de ensaio com lixas de vidro.

Efeitos semelhantes aos observados na Tabela 5.5, que relatam o aumentam da severidade do ensaio mediante o aumento da dureza do abrasivo, podem ser observados na Tabela 5.6 (ALBERTIN; SINATORA, 2001). Nesta, a maior severidade de ensaio se deveu a elevação simultânea da dureza do abrasivo, do seu tamanho de grão e da força aplicada. Verifica-se em ambas as Tabelas que nos sistemas de maior severidade de desgaste, o efeito da dureza dos carbonetos é menos efetivo que nos sistemas de menor severidade. 
Tabela 5.6 - Fatores de desgaste $\left(\times 10^{-6}\right)$ de aço matriz e ferro fundido branco eutético, ambos martensíticos, em ensaios pino contra lixa. Abrasivos: SiC grana \#80 e alumina grana \#400 (ALBERTIN; SINATORA, 2001).

\begin{tabular}{ccc}
\hline Material & $\mathrm{SiC} \# 80$ com 19,65 N & $\mathrm{Al}_{2} \mathrm{O}_{3} \# 400$ com 9,85 N \\
\hline Aço matriz (0\% carbonetos) & 9,41 & 3,63 \\
Ferro fundido branco eutético & 9,25 & 1,54 \\
\hline
\end{tabular}

A Tabela 5.7 apresenta as taxas de desgaste para o aço AISI 52100 na condição bruto de têmpera, com e sem tratamento sub-zero, utilizando alumina como abrasivo.

Tabela 5.7 - Taxas de desgaste [mg/m] do aço AISI 52100 nas condições bruto de têmpera, com e sem tratamento sub-zero. Abrasivo: alumina grana \#220.

\begin{tabular}{ccc}
\hline Condição metalúrgica & Dureza de engenharia $[\mathrm{MPa}]$ & Taxa de desgaste $[\mathrm{mg} / \mathrm{m}]$ \\
\hline Após sub-zero & 9.500 & $0,98 \pm 0,03$ \\
Sem sub-zero & 8.400 & $1,00 \pm 0,03$ \\
\hline
\end{tabular}

Os resultados da Tabela 5.7 mostram que as taxas de desgaste não foram afetadas pelo tratamento sub-zero para o aço AISI 52100 na condição bruto de têmpera, embora existam indicações na literatura de que o ensaio pino contra lixa é sensível à presença de austenita retida, podendo esta fase contribuir para um melhor desempenho quanto ao desgaste neste sistema, como mostram os resultados de ALBERTIN; SINATORA (2001) apresentados na Tabela 5.8.

Tabela 5.8 - Fatores de desgaste de ferro fundido branco com $30 \%$ de carbonetos $\mathrm{M}_{7} \mathrm{C}_{3}$ em ensaios pino contra lixa, utilizando 9,8 N. Abrasivo: alumina grana \#400 (ALBERTIN; SINATORA, 2001).

\begin{tabular}{cc}
\hline Matriz & Fator de desgaste $\times 10^{-6}$ \\
\hline Austenítica & 1,64 \\
Martensítica & 1,80 \\
\hline
\end{tabular}


O efeito da austenita retida em outros sistemas de desgaste, tais como moinho de bolas, é o oposto do que indicam os resultados da Tabela 5.8, ou seja, maiores teores deste microconstituinte implicam em maiores taxas de desgaste (ALBERTIN; SINATORA, 2001). Este é o motivo pelo qual a avaliação de desempenho de materiais no ensaio pino contra lixa fica comprometida na presença de austenita retida.

Os resultados obtidos nas Tabelas 5.5 e 5.7 permitem comparar o desempenho do ferro fundido branco de alto cromo com um aço na condição bruta de têmpera, como apresenta a Tabela 5.9.

Tabela 5.9 - Taxas de desgaste [mg/m] do aço AISI 52100 na condição bruto de têmpera com tratamento sub-zero e do ferro fundido branco de alto cromo. Abrasivo: alumina grana \#220.

\begin{tabular}{ccc}
\hline Material & Dureza de engenharia $[\mathrm{MPa}]$ & Taxa de desgaste $[\mathrm{mg} / \mathrm{m}]$ \\
\hline Aço AISI 52100 & 9.500 & $0,98 \pm 0,03$ \\
Ferro fundido branco & 4.600 & $1,02 \pm 0,03$ \\
\hline
\end{tabular}

A Tabela 5.9 mostra que o ferro fundido branco perlítico apresentou a mesma taxa de desgaste que a do aço AISI 52100 bruto de têmpera, mesmo tendo dureza de engenharia menor. Este tipo de resultado foi reportado por GUNDLACH; PARKS (1977), em ensaios com lixa de SiC $80 \mu \mathrm{m}$. Estes pesquisadores verificaram que um aço AISI 1090 temperado e revenido com $735 \mathrm{HV}_{30}$ teve uma resistência ao desgaste apenas $3 \%$ superior a de um ferro fundido branco de alto cromo perlítico com $398 \mathrm{HV}_{30}$. Nestes casos, o efeito da dureza dos carbonetos $\mathrm{M}_{7} \mathrm{C}_{3}$ é suficiente para tornar o desempenho equivalente ao de aços de alto teor de carbono tratados termicamente. É possível fazer uma extensão dos resultados da Tabela 5.9 para uma aplicação prática, como a moagem. Corpos moedores com geometria de cylpebs 
são usualmente fabricados em ferro-gusa, um material em estado bruto com elevada fração volumétrica de carbonetos $\mathrm{M}_{3} \mathrm{C}$ e com matriz perlítica, microestrutura semelhante a do ferro fundido branco estudado neste trabalho. Esta microestrutura talvez explique porque os cylpebs possuem desempenho equivalente ao de bolas temperadas de aço forjado.

Este Item teve como principal objetivo mostrar os casos em que o efeito da microestrutura de alguns dos materiais estudados nas taxas de desgaste é mais relevante que a dureza.

O resumo do efeito da microestrutura dos materiais estudados nas taxas de desgaste é:

- a dureza dos carbonetos $\mathrm{M}_{7} \mathrm{C}_{3}$ modifica a atuação de um abrasivo como o vidro, diminuindo a ação do mecanismo de microcorte e;

- a dureza dos carbonetos $\mathrm{M}_{7} \mathrm{C}_{3}$ leva a um desempenho do ferro fundido branco de alto cromo de matriz perlítica semelhante à de um aço com alto teor de carbono tratado termicamente para uma dureza elevada.

\subsubsection{Valores médios das taxas de desgaste dos aços AISI 1006 e AISI 52100}

A Tabela 5.10 mostra os valores médios de taxas de desgaste, relativas ao regime permanente. 
Tabela 5.10 - Taxas de desgaste [mg/m] dos aços AISI 1006 e AISI 52100. Abrasivo: vidro.

\begin{tabular}{ccc}
\hline Material & Lixa grana \#80 & Lixa grana \#240 \\
\hline AISI 1006 & $2,2 \pm 0,1$ & $0,67 \pm 0,03$ \\
AISI 52100 recozido & $1,13 \pm 0,03$ & $0,35 \pm 0,02$ \\
AISI 52100 trefilado & $1,13 \pm 0,05$ & $0,38 \pm 0,02$ \\
AISI 52100 temperado e revenido 1 & $0,53 \pm 0,03$ & $0,057 \pm 0,002$ \\
AISI 52100 temperado e revenido 2 & $0,16 \pm 0,01$ & $\mathrm{~N}$ \\
AISI 52100 bruto de têmpera & $\mathrm{N}$ & $\mathrm{N}$ \\
\hline
\end{tabular}

$\mathrm{N}$ : considerada nula

As condições de ensaio em que as taxas de desgaste foram consideradas nulas são aquelas nas quais não se obteve diferença de $1 \mathrm{mg}$ entre a massa inicial e a massa final, mesmo após 10 lixas terem sido utilizadas. Estes resultados são um forte indicativo que o aço AISI 52100 bruto de têmpera e temperado e revenido $2\left(500{ }^{\circ} \mathrm{C} / 90\right.$ min) estavam sob regime moderado de desgaste.

Este tipo de resultado também foi reportado por RICHARDSON (1968), em ensaios de pino contra lixas de vidro, para materiais com determinados níveis de dureza. Por exemplo, RICHARDSON não conseguiu determinar a taxa de desgaste do aço AISI 1074 com 650 HV, ensaiado com lixa de vidro grana \#180.

Uma análise detalhada dos resultados apresentados na Tabela 5.10 será apresentada a seguir, considerando-se que o aço AISI 1006 é um material de referência. 


\subsubsection{Análise dos mecanismos de desgaste dos aços AISI 1006 e AISI 52100}

As taxas de desgaste apresentadas na Tabela 5.10 foram calculadas em função da taxa de desgaste do aço AISI 1006, denominando-se este valor resistência ao desgaste relativa. Por exemplo, a resistência ao desgaste relativa do aço AISI 52100 trefilado ensaiado com a lixa grana \#80 é $2,2 \mathrm{mg} / \mathrm{m}$ (taxa do aço AISI 1006) dividido por $1,13 \mathrm{mg} / \mathrm{m}$, resultando em 1,91. Em todos os casos, a resistência ao desgaste relativa do aço AISI 1006 é igual a 1.

A Tabela 5.11 apresenta os valores de resistência ao desgaste relativa do aço AISI 52100 para os ensaios com as lixas de vidro granas \#80 e \#240.

Tabela 5.11 - Resistência ao desgaste relativa e dureza de engenharia do aço AISI 52100 [MPa]. Abrasivo: vidro.

\begin{tabular}{cccc}
\hline Material & Dureza de engenharia [MPa] & Lixa \#80 & Lixa \#240 \\
\hline Recozido & 1.930 & 1,91 & 1,90 \\
Trefilado & 3.160 & 1,91 & 1,74 \\
Temperado e revenido 1 & 4.070 & 4,06 & 11,76 \\
Temperado e revenido 2 & 4.900 & 13,68 & Indeterminada \\
\hline
\end{tabular}

A Figura 5.11, construída com os valores da Tabela 5.11, apresenta a variação da resistência ao desgaste relativa do aço AISI 52100 com a dureza de engenharia. 


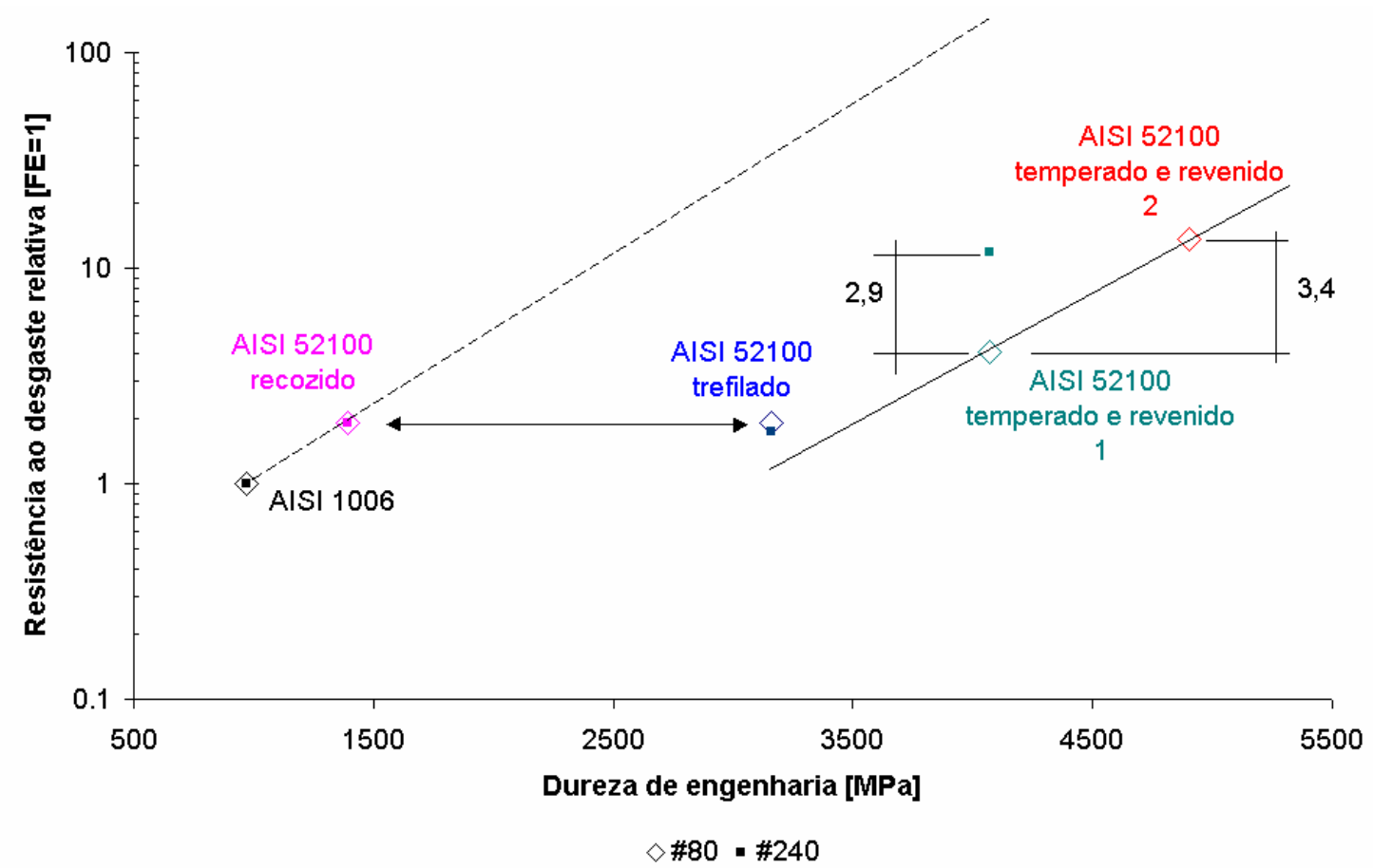

Figura 5.11. Variação da resistência ao desgaste relativa (AISI $1006=1$ ) com a dureza de engenharia [MPa].

Na Figura 5.11 serão comparados os seguintes materiais:

- aço AISI 1006 e aço AISI 52100 recozido;

- aço AISI 52100 nas condições recozido e trefilado;

- aço AISI 52100 temperado e revenido nos ensaios com a lixa de vidro grana \#80 e;

- aço AISI 52100 temperado e revenido $1\left(500{ }^{\circ} \mathrm{C} / 24 \mathrm{~h}\right)$ nos ensaios com as lixas de vidro grana \#80 e grana \#240.

A linha de tendência tracejada na Figura 5.11 representa um comportamento que abrange os aços AISI 1006 e AISI 52100 recozido. Estes materiais representam uma classe de materiais descrita pela literatura (KRUSCHOV, 1957 e RICHARDSON, 
1968) como um grupo de "metais puros e aços recozidos", os quais a resistência ao desgaste abrasivo obedece à equação de Archard, ou seja, a resistência ao desgaste varia de forma linear com a dureza. É possível perceber para este grupo de materiais que a resistência ao desgaste relativa independe do tamanho do abrasivo.

Os resultados da Figura 5.11 indicam que a resistência ao desgaste relativa observada para o aço AISI 52100 recozido é semelhante à observada para o aço AISI 52100 trefilado, apesar da diferença de dureza entre estes materiais. Para ambos a resistência ao desgaste independe do tamanho do abrasivo. Este resultado também é reportado na literatura (KRUSCHOV, 1957 e SIN e colaboradores, 1979) e explicado pelo encruamento, uma vez que a dureza da superfície após o desgaste é a mesma para um material recozido é a mesma que a atingida por um material previamente deformado (SIN e colaboradores, 1979).

Uma outra linha de tendência apresentada na Figura 5.11 representa o grupo "aços temperados e revenidos", neste o tamanho do abrasivo afetou a resistência ao desgaste relativa, diferentemente do observado até então. Na Figura 5.11 estão indicadas duas comparações entre valores de resistência ao desgaste relativa. A primeira se refere aos ensaios com a lixa de vidro grana \#80, que é de 3,4 vezes entre o aço AISI 52100 temperado e revenido 1 e o mesmo aço na condição 'temperado e revenido 2'. Esta diferença é surpreendente, tendo em vista que a diferença entre a dureza destes materiais não é tão acentuada, em torno de $20 \%$. Além disso, a diferença de dureza entre as condições temperado e revenido 1 e recozido, que foi de $50 \%$, levou a diferenças de 50 \% na resistência ao desgaste.

A Figura 5.12 apresenta imagens da superfície desgastada do aço AISI 52100 temperado e revenido $1\left(500{ }^{\circ} \mathrm{C} / 24 \mathrm{~h}\right)$, após os ensaios com a lixa de vidro grana \#80. 


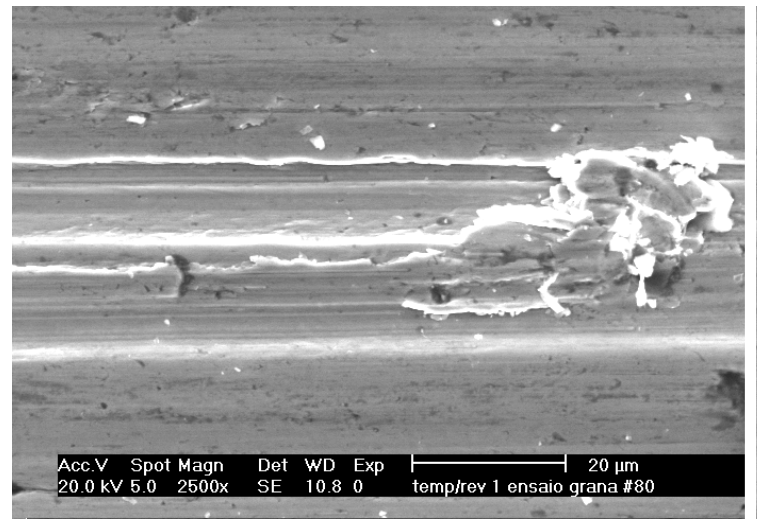

(A)

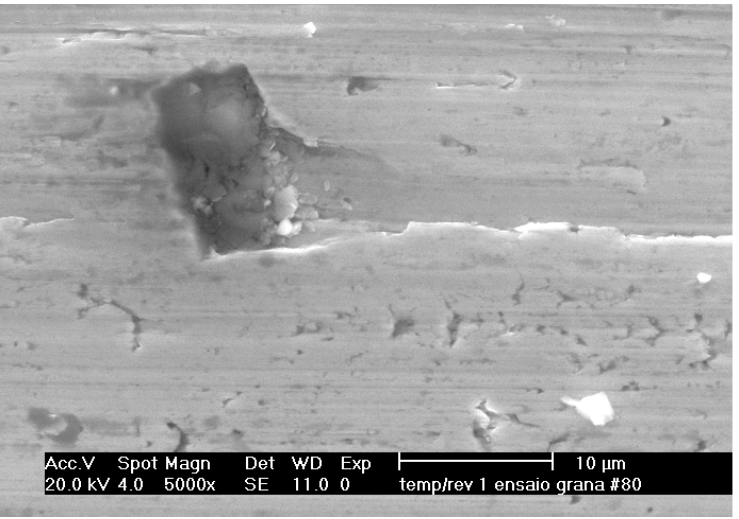

(B)

Figura 5.12. Superfície desgastada de aço AISI 52100 temperado e revenido a $500{ }^{\circ} \mathrm{C}$ por 24 h, observada em microscopia eletrônica de varredura, após ensaio com a lixa de vidro grana \#80: (A) microssulcamento e (B) vazio deixado por partícula abrasiva.

A Figura 5.12 (A) mostra um sulco formado por um grão de vidro com um acúmulo de material na frente deste sulco. Na Figura 5.12 (B) observa-se o vazio deixado por um grão de vidro na superfície do aço, após este grão ter gerado um sulco de desgaste e ser incrustado e arrancado da superfície. Nesta Figura observa-se também a formação de pequenas trincas laterais à região do sulco.

O afloramento de trincas em materiais dúcteis como observado na Figura 5.12 (B) caracteriza o mecanismo de delaminação. A ocorrência deste mecanismo em sistemas abrasivos foi associado por LARSSEN-BASSE (1983) à transição para o regime moderado de desgaste, situação na qual a dureza do abrasivo passa a não ser suficientemente alta para penetrar na superfície a ser desgastada.

A Figura 5.13 apresenta imagens da superfície desgastada do aço AISI 52100 temperado e revenido $2\left(500{ }^{\circ} \mathrm{C} / 90 \mathrm{~min}\right)$, após os ensaios com a lixa de vidro grana \#80. 


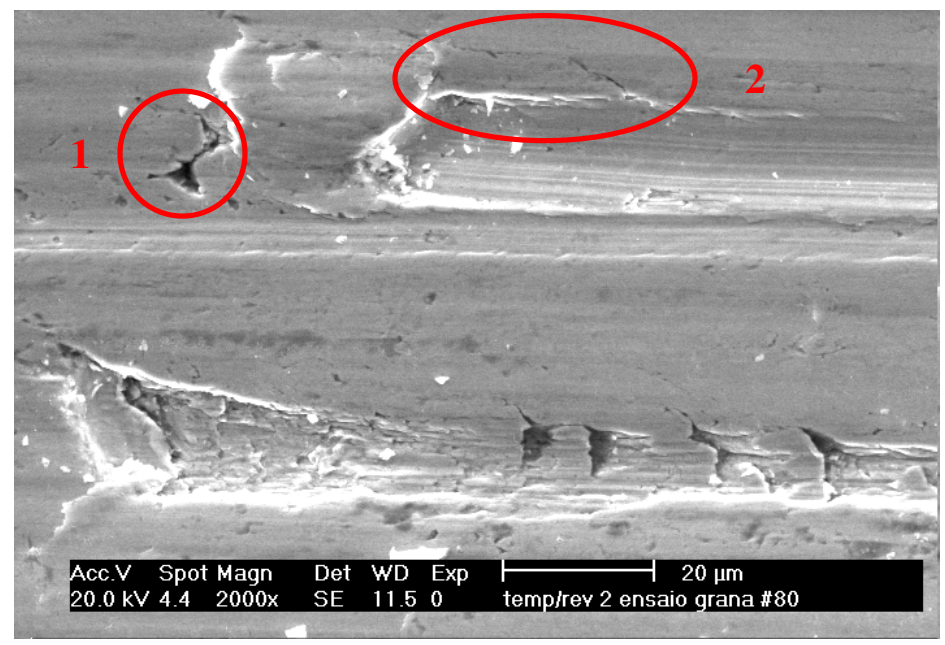

Figura 5.13. Superfície desgastada de aço AISI 52100 temperado e revenido a $500{ }^{\circ} \mathrm{C}$ por 90 min, observada em microscopia eletrônica de varredura, após ensaio com a lixa de vidro grana $\# \mathbf{8 0}$.

Na parte superior da Figura 5.13 observa-se que há material acumulado na frente de um sulco, como observado na Figura 5.12 (A). Entretanto, há diferenças marcantes entre esta Figura e o que foi observado para o aço AISI 52100 temperado e revenido 2 $\left(500{ }^{\circ} \mathrm{C} / 24 \mathrm{~h}\right)$, tais como:

- há uma trinca formada na frente do material acumulado com dimensões maiores (1) e;

- há uma trinca crescendo lateralmente à região do sulco, indicando a possibilidade de arrancamento posterior de material desta região (2).

Na parte inferior da Figura 5.13 as trincas estão em maior número e possuem maiores dimensões que as observadas na Figura 5.12 (B). O afloramento de trincas em regiões fora da região de contato foi observado por MEDEIROS (2002) em aço AISI M2 temperado e revenido, após ensaios de fadiga de contato na configuração disco contra disco, como apresentado na Figura 5.14. 


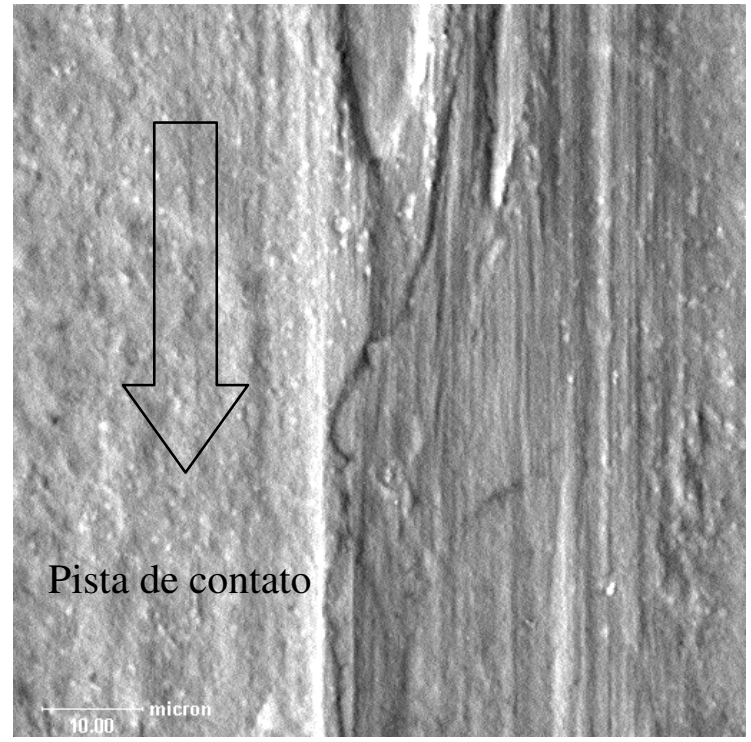

Figura 5.14. Superfície desgastada de aço AISI 52100 temperado e revenido, observada em microscopia eletrônica de varredura, após 4,4 megaciclos em ensaio disco contra disco com pressão máxima de contato de 2,41 GPa (MEDEIROS, 2002).

É possível associar os mecanismos de deformação plástica observados nas Figuras 5.13 e 5.14, embora se tratem de sistemas mecânicos distintos. Os danos na região de contato ocorrem preferencialmente na subsuperfície, enquanto na região fora do contato ocorrem danos superficiais devido à deformação plástica, como previsto pela teoria de delaminação, proposta por SUH em 1973. Portanto, o mecanismo de delaminação fica evidenciado de forma mais clara para o aço AISI 52100 temperado e revenido 2 (500 $\left.{ }^{\circ} \mathrm{C} / 90 \mathrm{~min}\right)$. Sendo assim, a diferença nas taxas de desgaste do aço AISI 52100 'temperado e revenido 1' e do aço 'temperado e revenido 2' se deve à diferença de intensidade na formação de trincas. Nestes casos, pequenas mudanças na dureza dos materiais causam grandes alterações nas taxas de desgaste.

A outra diferença significativa entre os valores de resistência ao desgaste relativa, indicada na Figura 5.11, é o caso em que a lixa de vidro grana \#80 desgasta o aço AISI 52100 temperado e revenido $1\left(500{ }^{\circ} \mathrm{C} / 24 \mathrm{~h}\right) 2,9$ vezes mais que a lixa grana 
\#240. A Figura 5.15 apresenta imagens da superfície desgastada deste material, após os ensaios com a lixa de vidro grana \#240.

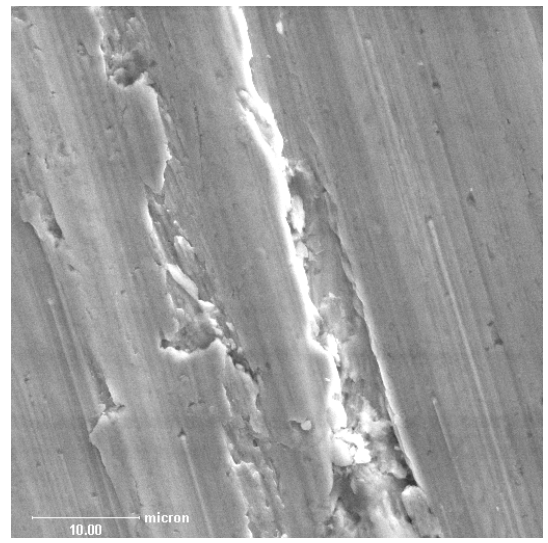

(A)

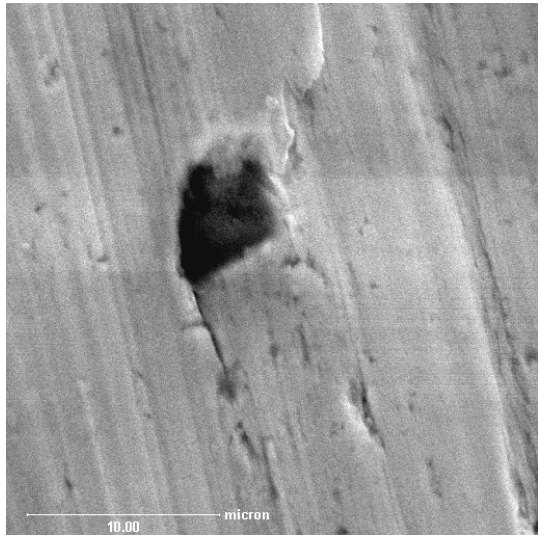

(B)

Figura 5.15. Superfície desgastada de aço AISI 52100 temperado e revenido a $500{ }^{\circ} \mathrm{C}$ por 24 h, observada em microscopia eletrônica de varredura, após ensaio com a lixa de vidro grana \#240: (A) microssulcamento e (B) vazio deixado por partícula abrasiva.

A Figura 5.15 mostra que os mecanismos de desgaste são semelhantes aos observados na Figura 5.12, ou seja, percebe-se o microssulcamento associado com deformação plástica (Figura 5.15 A) e a incrustação e arrancamento de abrasivos na superfície desgastada (Figura 5.15 B). Entretanto, em outras regiões da superfície desgastada observou-se uma grande incidência de pequenas trincas superficiais, como apresenta a Figura 5.16. 


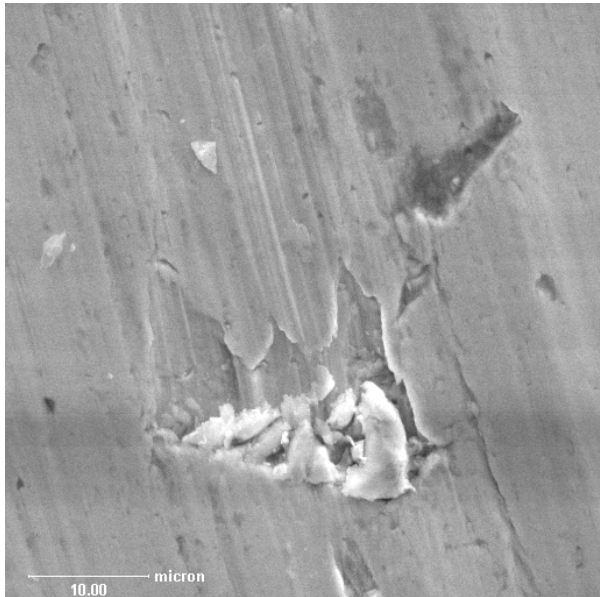

(A)

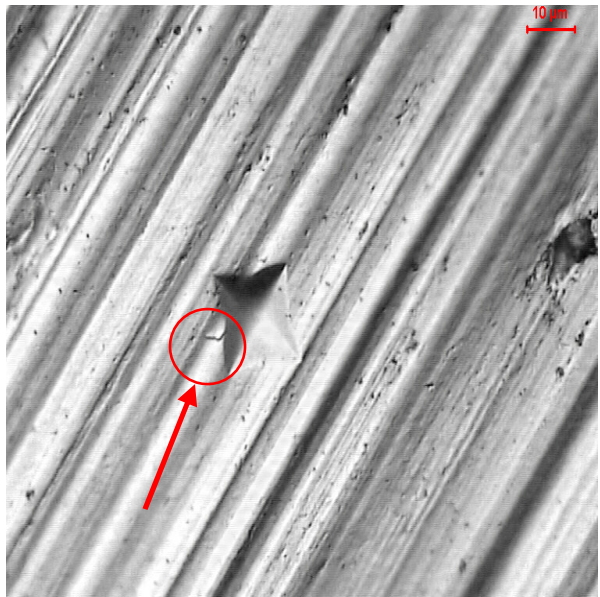

(B)

Figura 5.16. (A) Superfície desgastada de aço AISI 52100 temperado e revenido a $500{ }^{\circ} \mathrm{C}$ por $24 \mathrm{~h}$, observada em microscopia eletrônica de varredura, após ensaios com a lixa de vidro grana \#240. (B) Mesma superfície, observada em microscopia óptica. Nota-se uma trinca ao lado de uma impressão de dureza.

A Figura 5.16 (A) mostra que a superfície desgastada possui uma camada encruada de pequena espessura, que pode ser arrancada com a sucessão dos contatos entre os grãos de vidro e a superfície desgastada, como se estivesse ocorrendo uma "escamação". A imagem da Figura 5.16 (B) corrobora esta possibilidade, pois se observa uma pequena trinca que se forma lateralmente a uma impressão de dureza feita sobre a superfície desgastada. Este tipo de trincamento não foi observado no caso dos ensaios deste material com a lixa de vidro grana \#80. Este tipo de mecanismo foi observado por JANHAMIR e colaboradores (1974) para cobre 99,96\% de pureza, após ensaios de deslizamento na configuração cilindro contra cilindro, como apresentado na Figura 5.17. 


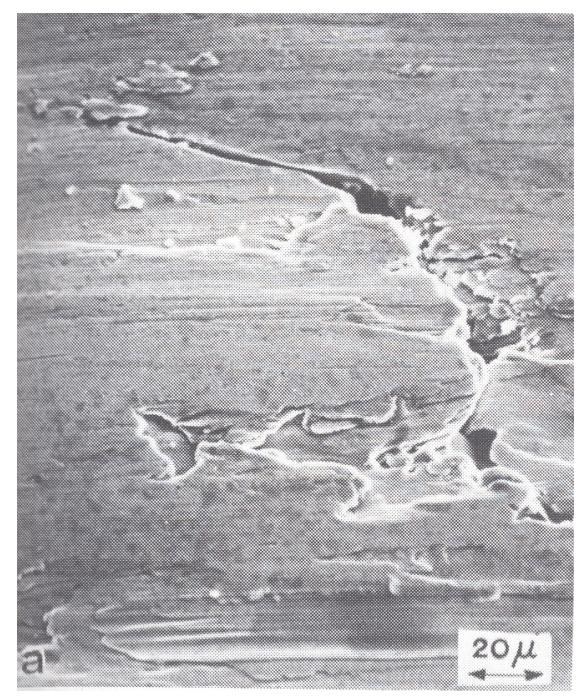

Figura 5.17. Superfície desgastada de cobre $99,96 \%$ de pureza, após ensaios de desgaste por deslizamento em dispositivo cilindro contra cilindro (JAHANMIR e colaboradores, 1974).

MISRA; FINNIE (1981) observaram um comportamento quanto ao desgaste abrasivo para o tungstênio que desviava da linearidade entre resistência ao desgaste e dureza de metais puros, quando este material foi ensaiado com abrasivos de tamanho pequeno. Estes pesquisadores sugeriram a possibilidade da existência de uma transição entre comportamento dúctil e frágil para este material, à medida que o mesmo fosse ensaiado com tamanhos de abrasivo maiores. Os mecanismos de desgaste apresentados para o aço AISI 52100 temperado e revenido $1\left(500{ }^{\circ} \mathrm{C} / 24 \mathrm{~h}\right)$ não corroboram a hipótese de MISRA; FINNIE, mas indicam que a mudança de mecanismo se dá entre os controlados por deformação plástica, como microssulcamento e delaminação com o aumento do tamanho de abrasivo.

Os valores de resistência ao desgaste apresentados na Figura 5.11 podem ser comparados com os obtidos por RICHARDSON (1968), que estão apresentados na Figura 5.18, porque este pesquisador utilizou ferro comercialmente puro como material de referência com dureza semelhante à do aço AISI 1006. 
Na Figura 5.18 estão indicadas três linhas de tendência de comportamento, relativas aos seguintes grupos de materiais:

- 'metais puros/aços recozidos' e;

- 'aços temperados e revenidos'.

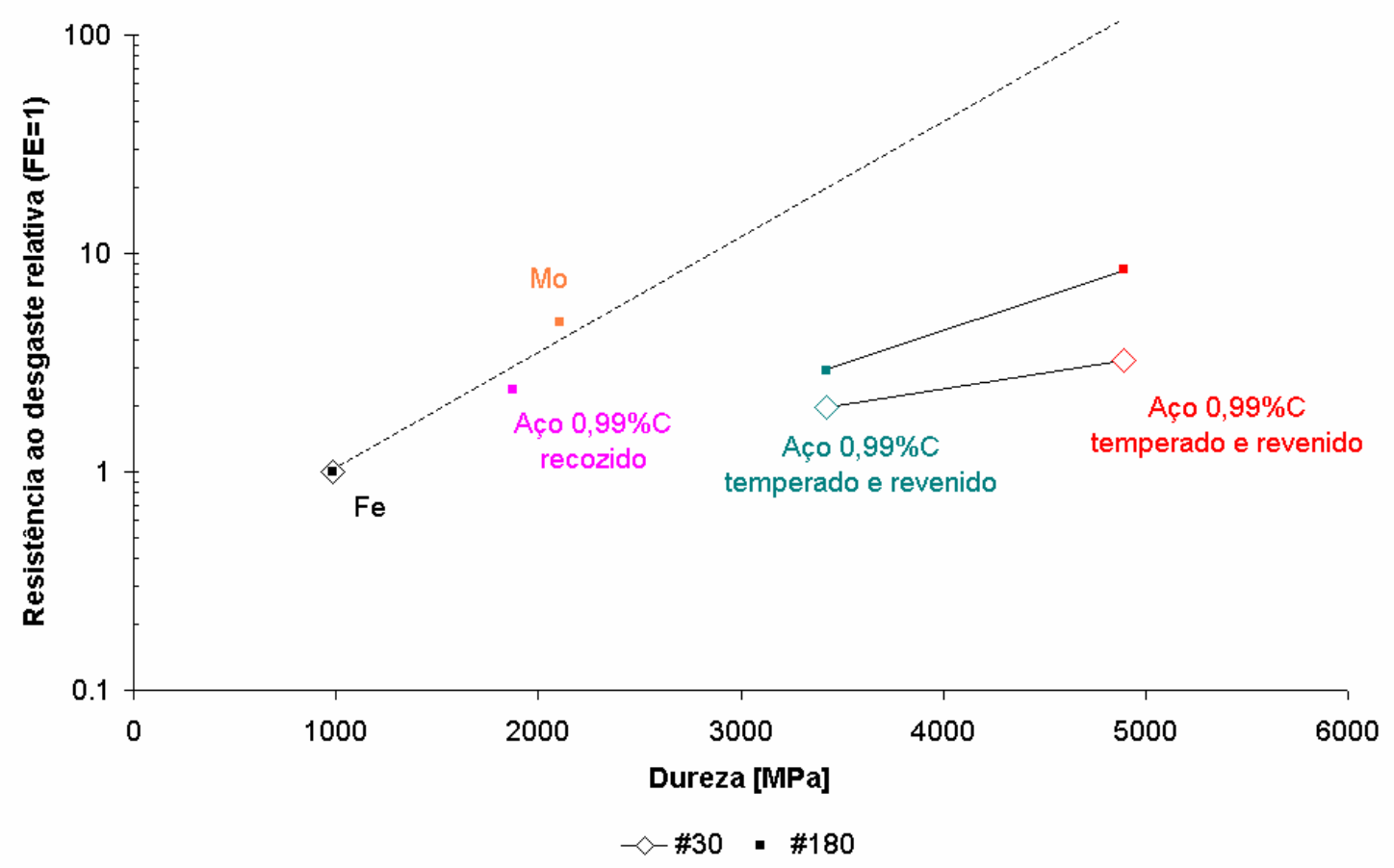

Figura 5.18. Variação da resistência ao desgaste relativa $(\mathrm{Fe}=1)$ com a dureza dos materiais. Abrasivo: vidro (RICHARDSON, 1968).

Estes grupos haviam sido identificados na Figura 5.11, bem como a análise de que o tamanho do abrasivo afeta os valores de resistência ao desgaste dos aços temperados e revenidos, mas não afeta no caso dos metais puros e aços recozidos. Além disso, os resultados obtidos por RICHARDSON (1968) permitem concluir que, quanto maior a dureza do aço temperado e revenido, maior é o efeito que o tamanho do abrasivo exerce sobre a resistência ao desgaste relativa. Este tipo de análise não foi possível de ser feita para os resultados da Figura 5.11 porque o aço AISI 52100 
temperado e revenido 2 não apresentou taxa de desgaste suficiente para ser quantificada nos ensaios com a lixa de vidro grana \#240.

\subsubsection{Coeficiente de atrito}

\subsubsection{Evolução do coeficiente de atrito com o tempo de ensaio}

Verificou-se que a evolução do coeficiente de atrito com o tempo de ensaio apresentou dois tipos de comportamentos, que serão descritos em detalhe para o aço AISI 1006 e para o aço AISI 52100 bruto de têmpera.

A Figura 5.19 apresenta a evolução do coeficiente de atrito com o tempo para o aço AISI 1006.

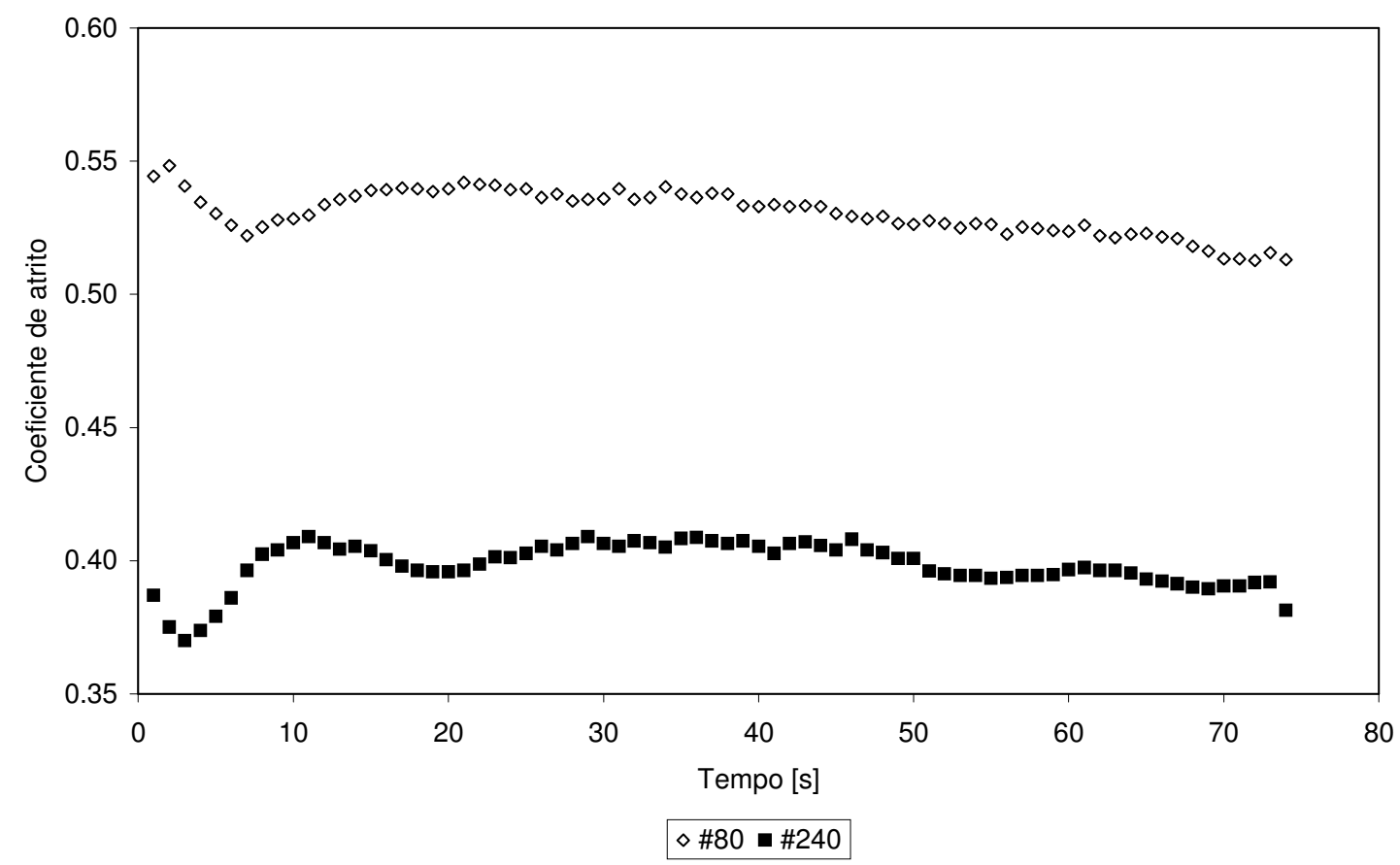

Figura 5.19. Evolução do coeficiente de atrito com o tempo de ensaio [s] para o aço AISI 1006.

A Figura 5.19 mostra que os valores de coeficiente de atrito apresentam uma maior dispersão no estágio inicial do ensaio, relacionada com a estabilização da 
velocidade tangencial. Além disso, esta Figura mostra que os valores de coeficiente de atrito no ensaio com a lixa grana \#80 são maiores.

A Figura 5.20 mostra a evolução do coeficiente de atrito com o tempo para o aço AISI 52100 bruto de têmpera.

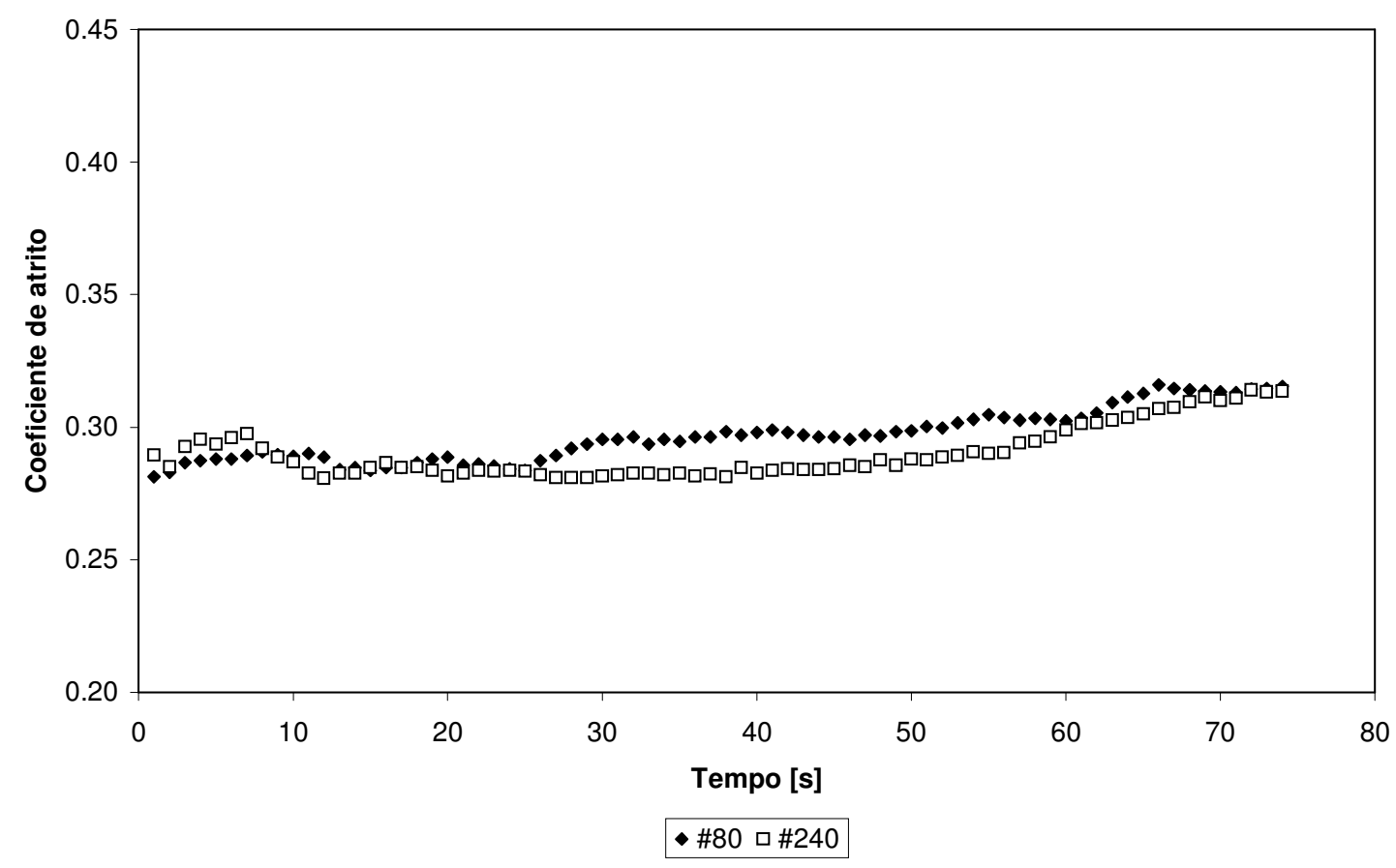

Figura 5.20. Evolução do coeficiente de atrito com o tempo de ensaio [s] para o aço AISI 52100 bruto de têmpera.

O comportamento do aço AISI 52100 bruto de têmpera difere do observado para o aço AISI 1006, pois o tamanho dos grãos abrasivos não afetou significativamente os valores de coeficiente de atrito.

As curvas de evolução do coeficiente de atrito com o tempo de ensaio para os demais materiais ensaiados estão apresentadas no Anexo C.

\subsubsection{Valores médios de coeficiente de atrito}

A Tabela 5.12 apresenta os valores médios de coeficiente de atrito. 
Tabela 5.12 - Valores médios de coeficiente de atrito. Abrasivo: vidro.

\begin{tabular}{ccc}
\hline Material & Lixa grana \#80 & Lixa grana \#240 \\
\hline AISI 1006 & $0,531 \pm 0,008$ & $0,398 \pm 0,009$ \\
AISI 52100 recozido & $0,45 \pm 0,02$ & $0,348 \pm 0,008$ \\
AISI 52100 trefilado & $0,44 \pm 0,01$ & $0,330 \pm 0,006$ \\
AISI 52100 temperado e revenido 1 & $0,33 \pm 0,01$ & $0,24 \pm 0,02$ \\
AISI 52100 temperado e revenido 2 & $0,277 \pm 0,007$ & $0,281 \pm 0,009$ \\
Ferro fundido branco de alto cromo & $0,324 \pm 0,005$ & $0,30 \pm 0,01$ \\
AISI 52100 bruto de têmpera & $0,30 \pm 0,01$ & $0,29 \pm 0,01$ \\
\hline
\end{tabular}

A Tabela 5.12 mostra que a variação do coeficiente de atrito com o tamanho de partícula abrasiva, para um determinado conjunto de materiais, segue o comportamento verificado por GODDARD; WILMAN (1962), ou seja, quanto maior o tamanho médio de partícula maior é o coeficiente de atrito. De um modo geral, os ensaios com lixa grana \#80 resultaram em coeficientes de atrito 25\% maiores para o aço AISI 1006 e para o aço AISI 52100 nas condições recozido, trefilado e temperado e revenido 1, que os valores dos ensaios com lixa grana \#240.

Por outro lado, para o aço AISI 52100 nas condições temperado e revenido 2 e bruto de têmpera e para o ferro fundido branco de alto cromo a variação do tamanho do abrasivo não afetou os valores de coeficiente de atrito.

\subsubsection{Comportamento dos materiais quanto ao coeficiente de atrito}

A Figura 5.21 apresenta a variação do coeficiente de atrito médio com a dureza de engenharia dos materiais. 


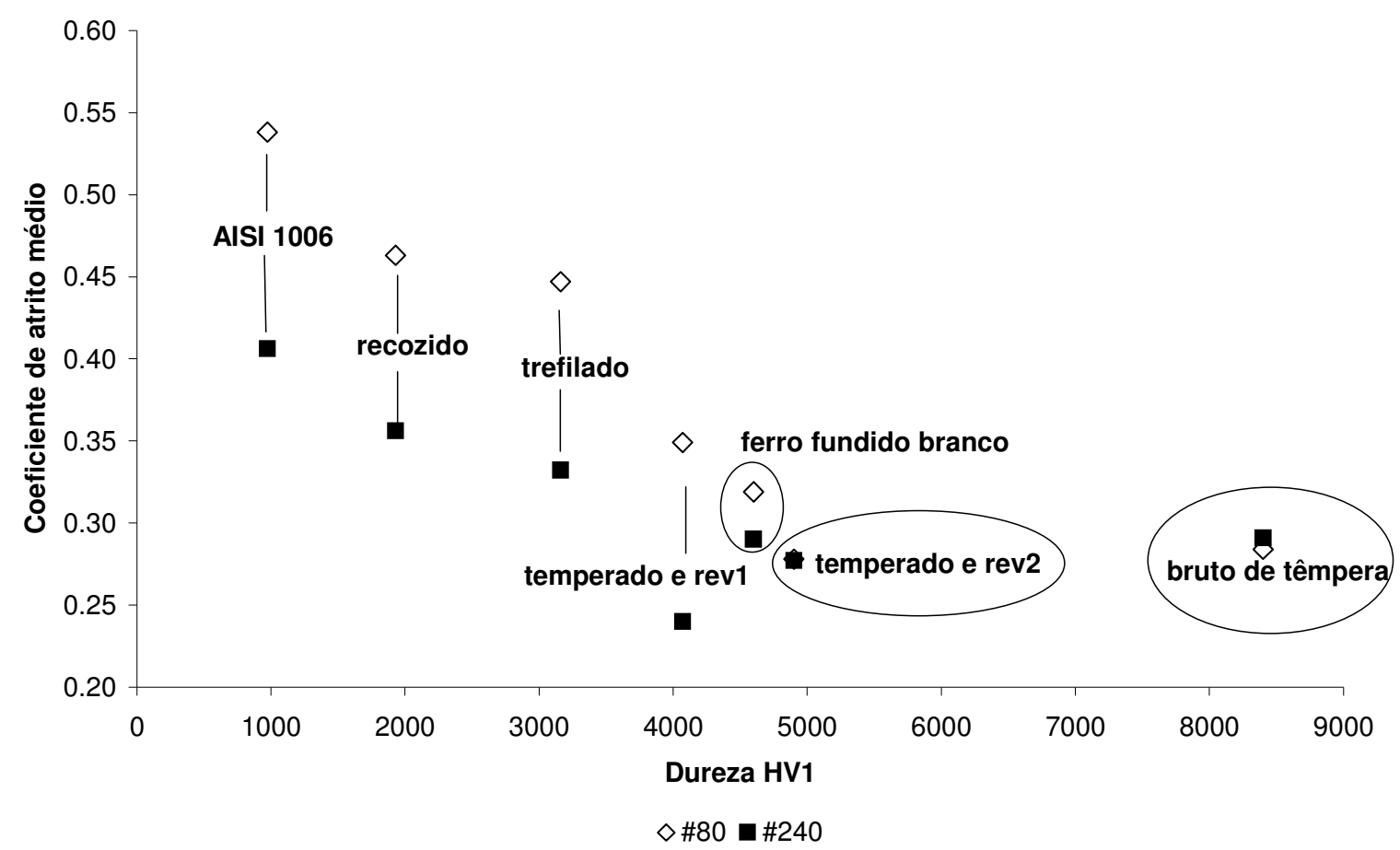

Figura 5.21. Variação do coeficiente de atrito médio com a dureza de engenharia dos materiais [MPa].

Nota-se na Figura 5.21 que há uma tendência de queda nos valores de coeficiente de atrito à medida que a dureza dos materiais aumenta. Este tipo de comportamento foi verificado também por GODDARD; WILMAN (1962) para metais puros.

Esta variação foi investigada com base em duas análises, para os aços AISI 1006 e AISI 52100 bruto de têmpera, por serem os materiais que representam os extremos em valores de dureza, mediante:

- determinação da dureza superficial após processo de desgaste e;

- análise da superfície das lixas de vidro após os ensaios de desgaste. 
A força empregada para os ensaios de dureza foi diferente para cada um dos aços estudados, como se explica a seguir. Considerando que o tamanho da impressão é proporcional à dureza do material e à força aplicada, inicialmente foi investigada qual a força seria a mais adequada para cada uma das condições de ensaio, como mostra a Figura 5.22.

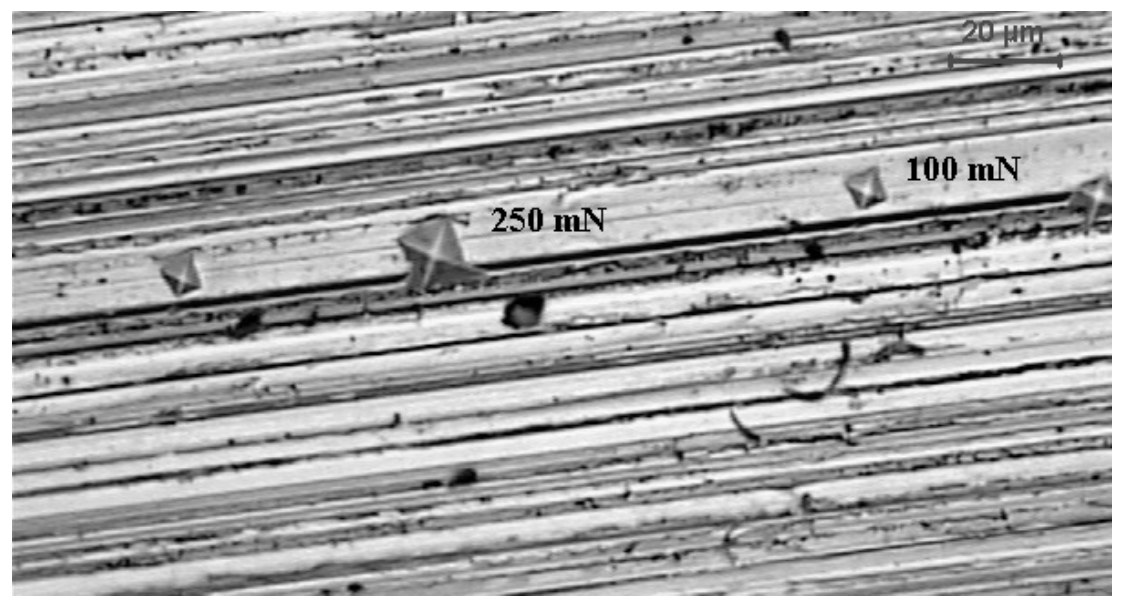

Figura 5.22. Superfície desgastada do aço AISI 1006, após o nivelamento com a lixa de alumina grana \#600, ilustrando as medidas de dureza.

Na Figura 5.22 estão mostradas as impressões feitas com $0,1 \mathrm{~N}$ e $0,25 \mathrm{~N}$ para o aço AISI 1006. Observa-se que, para 0,1 N, a impressão fica restrita à área interna dos sulcos, permitindo a avaliação do encruamento sofrido pelo material.

Esta técnica foi utilizada por PINTAÚDE; SINATORA (1998) e difere da metodologia aplicada por RICHARDSON (1967) para estimar o encruamento superficial. A Figura 5.23 mostra impressões de dureza em superfícies desgastadas, segundo as técnicas utilizadas em cada um destes trabalhos. 


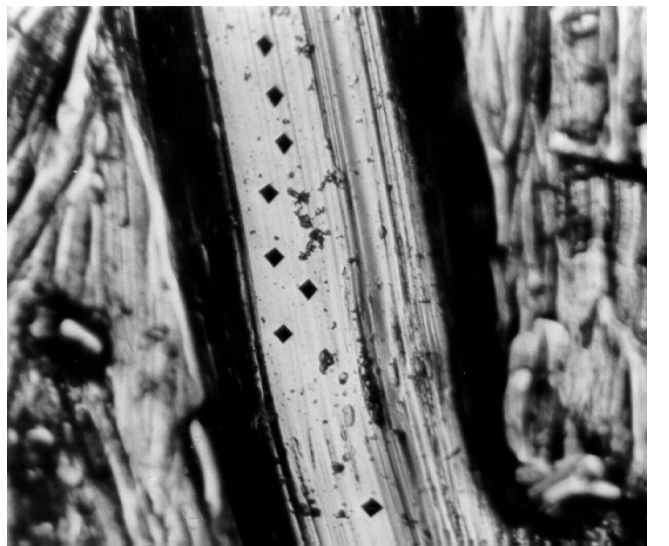

(A)

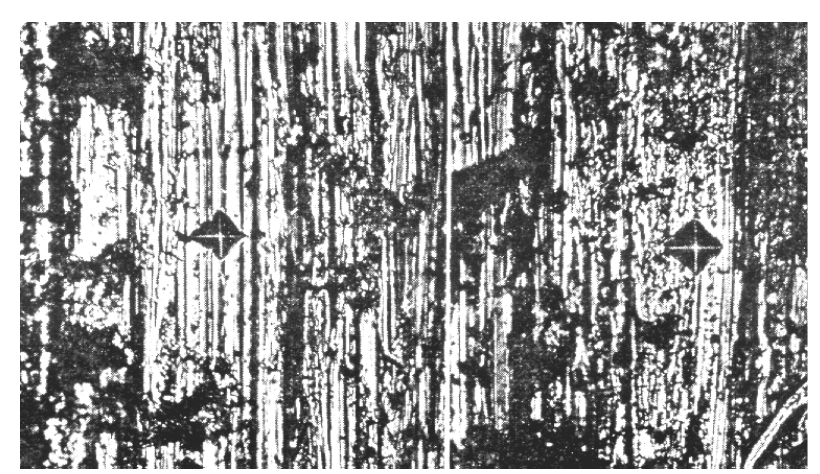

(B)

Figura 5.23. (A) Impressões de dureza Vickers em aço Cr-Si temperado, após ensaio em britador de mandíbulas (PINTAÚDE; SINATORA, 1998). (B) Impressões de dureza Vickers em Mo puro, após ensaio pino contra lixa de SiC grana \#180 (RICHARDSON, 1967).

A Figura 5.23 mostra que a força empregada por RICHARDSON (1967) não foi adequada ao tamanho dos sulcos, o que gera uma influência da rugosidade superficial nos valores de dureza. Os resultados da Tabela 5.13 sugerem que a técnica empregada por RICHARDSON subestima os valores de dureza após o desgaste.

Tabela 5.13 - Variação na dureza Vickers [MPa] de aços martensíticos após ensaios de desgaste empregando técnicas de determinação diferentes.

\begin{tabular}{cccc}
\hline Material & Dureza inicial & Dureza após desgaste & Referência \\
\hline AISI 4340 & 6.140 & 6.660 & Richardson \\
Aço 2Cr-1,6Si-0,5Mo & 7.550 & 10.300 & Pintaúde; Sinatora \\
\hline
\end{tabular}

A Tabela 5.14 mostra os resultados de dureza $\mathrm{H}_{\mathrm{IT}}$ ("indentation hardness") dos aços AISI 1006 e AISI 52100 bruto de têmpera, após as diferentes etapas dos ensaios de desgaste (nivelamento com lixa de alumina \#600). 
Tabela 5.14 - Dureza $\mathrm{H}_{\mathrm{IT}}$ ("indentation hardness") [MPa] dos aços AISI $1006 \mathrm{e}$ AISI 52100 bruto de têmpera, após diferentes etapas de ensaio de desgaste.

\begin{tabular}{ccc}
\hline Condição superficial & $\begin{array}{c}\text { AISI 1006 } \\
(0,1 \mathrm{~N})\end{array}$ & $\begin{array}{c}\text { AISI 52100 bruto de } \\
\text { têmpera }(0,25 \mathrm{~N})\end{array}$ \\
\hline Polido (referência) & $1.800 \pm 40$ & $11.000 \pm 200$ \\
Lixa alumina \#600 (nivelamento) & $2.150 \pm 90$ & $13.200 \pm 300$ \\
Lixa vidro \#240 & $2.600 \pm 200$ & $14.000 \pm 200$ \\
Lixa vidro \#80 & $3.700 \pm 200$ & $14.100 \pm 300$ \\
\hline
\end{tabular}

Os resultados da Tabela 5.14 mostram que a etapa de nivelamento da superfície com a lixa de alumina grana \#600, realizada previamente às determinações de massa ao longo dos ensaios, promove um encruamento significativo em relação à dureza das superfícies polidas metalograficamente.

Os valores de dureza atingidos após os ensaios com a lixa de vidro grana \#80 são semelhantes aos obtidos por RICHARDSON (1967), após trepanação para materiais de mesma classe, como mostra a Tabela 5.15. RICHARDSON considerou que a dureza avaliada após a trepanação é a máxima que a superfície de um material pode atingir quando submetido a um processo de abrasão.

Tabela 5.15 - Dureza $\mathrm{H}_{\mathrm{IT}}$ dos aços [MPa] AISI 1006 e AISI 52100 bruto de têmpera, após ensaio com lixa de vidro grana \#80 e dureza Vickers HV [MPa] de materiais de classes equivalentes, após ensaio de trepanação (RICHARDSON, 1967).

\begin{tabular}{ccc}
\hline Material & Tabela 5.14 $\left(\mathrm{H}_{\mathrm{IT}}\right)$ & Após trepanação $(\mathrm{HV})$ \\
\hline Aço AISI 1006 & $3.700 \pm 200$ & 3.930 \\
Fe comercialmente puro & & \\
\hline AISI 52100 bruto de têmpera & $14.100 \pm 300$ & 13.350 \\
AISI 1074 bruto de têmpera & & \\
\hline
\end{tabular}


Os valores da Tabela 5.15 mostram que a técnica utilizada para determinação da dureza da superfície desgastada (Figura 5.22) é adequada para determinar a máxima dureza atingida em um processo de desgaste.

A intensa deformação plástica do aço AISI 1006 após ensaios com a lixa de vidro grana \#80 pode ser vista na Figura 5.24.

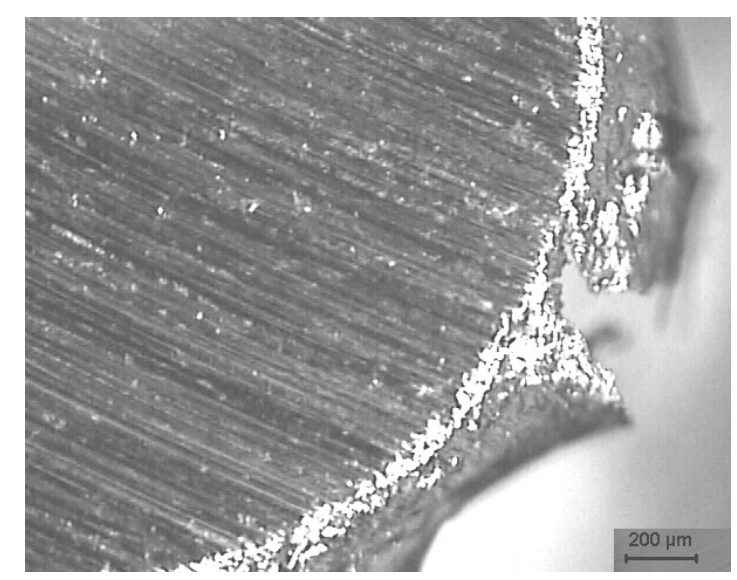

Figura 5.24. Imagem em microscopia óptica da superfície desgastada do aço AISI 1006, após ensaios com a lixa de vidro grana \#80. Nota-se a intensa deformação plástica do material.

No caso dos ensaios com a lixa de vidro grana \#240, a dureza superficial atingida pelo aço AISI 1006 foi $2.600 \pm 200 \mathrm{MPa}$, que não corresponde a máxima dureza, segundo os resultados de RICHARDSON (1967). Esta diferença na deformação plástica imposta pelo sistema possui efeito significativo nos valores de coeficiente de atrito.

Conforme proposto por SUNDARARAJAN (1987), no seu modelo matemático para desgaste abrasivo, o coeficiente de atrito pode ser avaliado por meio do encruamento superficial, conforme mostra a Equação 5.1: 


$$
\mu \propto \mathrm{H}_{\mathrm{S}} / \mathrm{H}_{0}
$$

Equação 5.1

onde;

$\mathrm{H}_{\mathrm{S}}$ é a dureza após processo abrasivo [MPa] e;

$\mathrm{H}_{0}$ é a dureza inicial $[\mathrm{MPa}]$.

Considerando como a dureza inicial os valores obtidos após o nivelamento com a lixa de alumina grana \#600, a aplicação da equação 5.1 mostra que os valores de dureza após os ensaios correlacionam-se com os valores de coeficiente de atrito, ou seja, quanto maiores são os valores da razão $\mathrm{H}_{S} / \mathrm{H}_{0}$, maiores são os coeficientes de atrito, como apresentado na Figura 5.25.

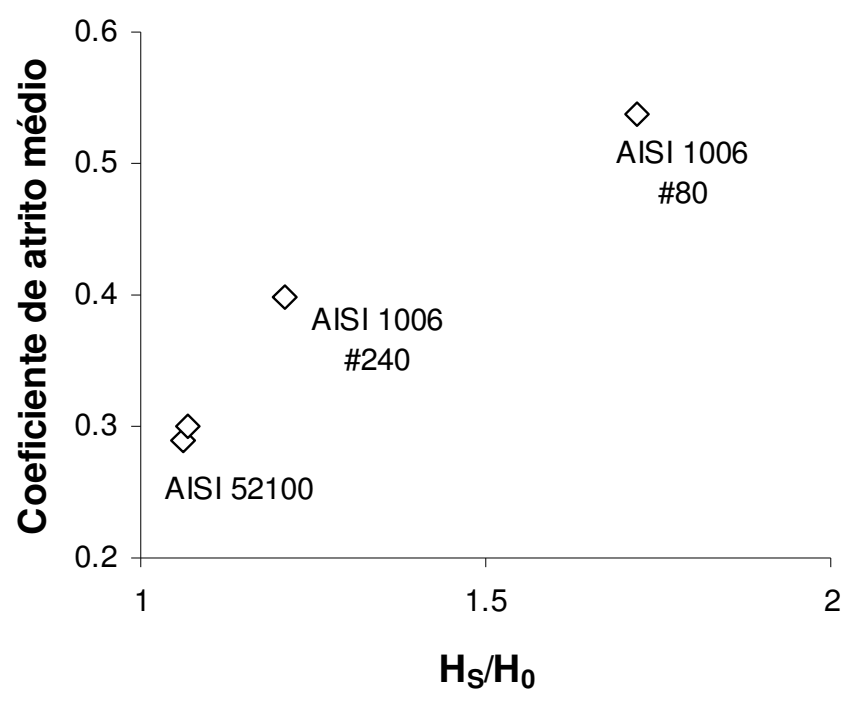

Figura 5.25. Relação entre a razão $H_{S} / H_{0}$ (equação 5.1) e o coeficiente de atrito dos aços AISI 1006 e AISI 52100 bruto de têmpera.

Considerando o modelo de SUNDARARAJAN (1987) e o conceito de máxima dureza da superfície, proposto por RICHARDSON (1967), a dureza do aço AISI 52100 bruto de têmpera, atingida na etapa de nivelamento, já está próxima da máxima dureza. Esta condição fez com que as lixas de vidro grana \#80 e grana \#240 não sejam capazes 
de causar níveis de deformação plástica diferentes e, consequentemente, os valores de coeficiente de atrito não foram afetados pelo tamanho do abrasivo.

$\mathrm{O}$ aspecto da superfície desgastada do aço AISI 52100 bruto de têmpera, após ensaios com a lixa de vidro grana \#80 pode ser vista na Figura 5.26.

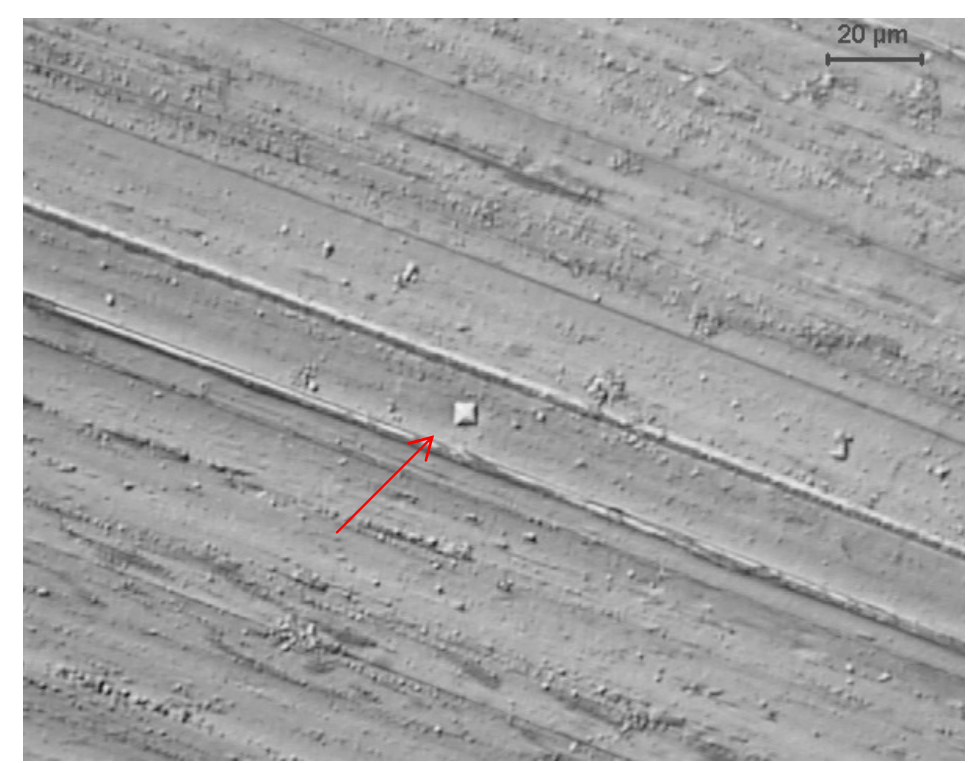

Figura 5.26. Imagem em microscopia óptica da superfície desgastada do aço AISI 52100 bruto de têmpera após ensaio com lixa de vidro grana \#80. Nota-se uma impressão de dureza com $0,25 \mathrm{~N}$.

A Figura 5.26 mostra que, diferentemente do observado na Figura 5.24, após o processo de desgaste, o aço AISI 52100 bruto de têmpera apresentou pouca deformação plástica e que a rugosidade da superfície é menor que a do aço AISI 1006.

A análise das superfícies da lixa grana \#240 após processo de desgaste, como mostram as Figuras 5.27 e 5.29 para o aço AISI 1006, corroboram a análise feita por meio das medidas de dureza da superfície desgastada destes materiais. 


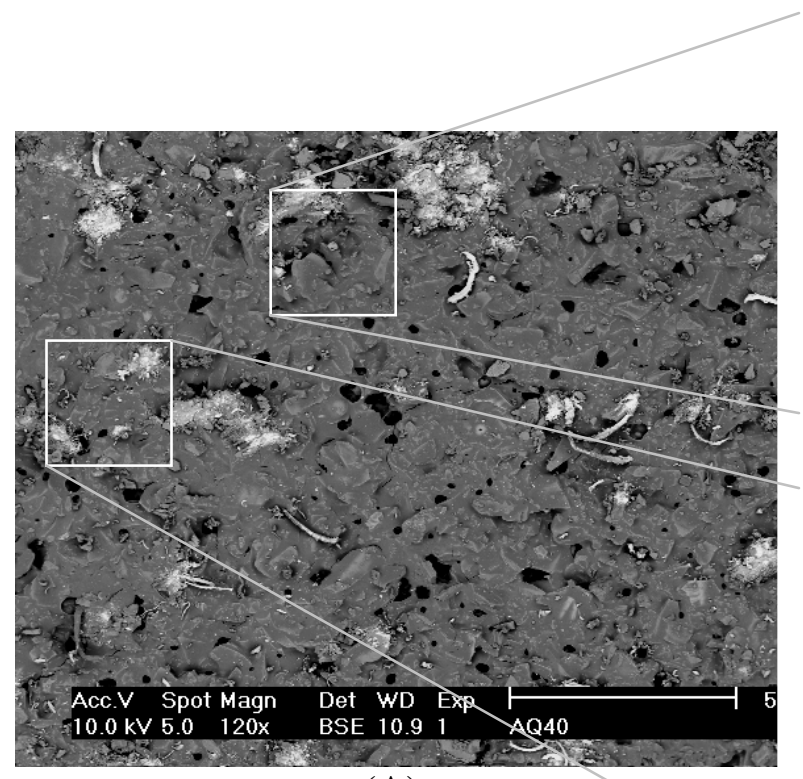

(A)

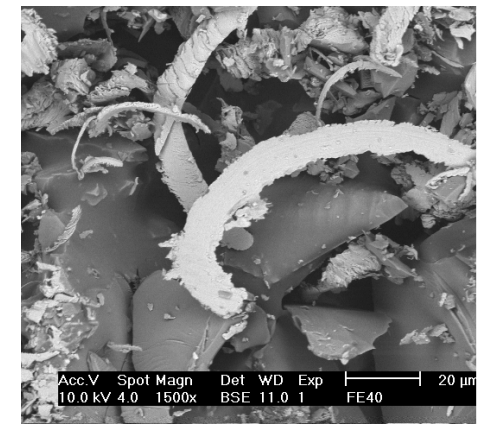

(B)

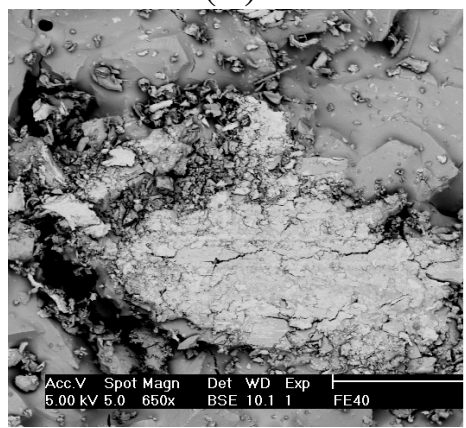

(C)

Figura 5.27. Superfície da lixa de vidro grana \#240 observada em microscopia eletrônica de varredura, após os ensaios com o aço AISI 1006.

A Figura 5.27 (A) mostra um aspecto geral da lixa de vidro grana \#240 após ensaio do aço AISI 1006. Pode-se perceber nesta imagem a diferença na intensidade de brilho em determinadas regiões, que são apresentadas em detalhe nas Figuras 5.27 (B) e (C).

A Figura 5.27 (B) mostra que um cavaco do aço AISI 1006 permanece na região de contato entre a lixa e o pino, estando alojado nos espaços existentes entre os grãos de vidro. A seqüência dos contatos entre pino e lixa promove um "esmagamento" destes cavacos, como mostra a Figura 5.27 (C). Nesta Figura, o material metálico apresenta algumas trincas, evidenciando o alto grau de deformação imposta. $\mathrm{O}$ fenômeno descrito de interposição dos cavacos nos espaços existentes de lixas abrasivas é usualmente denominado por obstrução ("clogging") (GODDARD; WILMAN, 1962). GAHLIN; JACOBSON (1999) verificaram que nos casos onde esta obstrução ocorre, o 
coeficiente de atrito varia com o tamanho dos abrasivos e a Figura 5.28 apresenta o mecanismo de obstrução observado por estes pesquisadores, podendo ser notada a semelhança com a Figura $5.27(\mathrm{C})$.

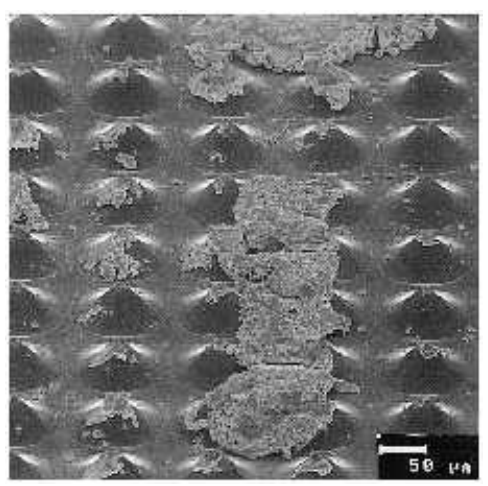

Figura 5.28. Superfície da lixa de "waffers" de silício, após desgastarem pinos de chumbo (GAHLIN; JACOBSON, 1999).

A Figura 5.29 apresenta a superfície da lixa de vidro grana \#80 após os ensaios com o aço AISI 1006.

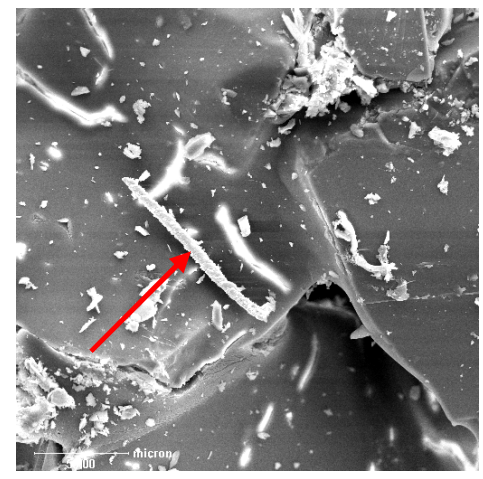

$50 \mu \mathrm{m}$

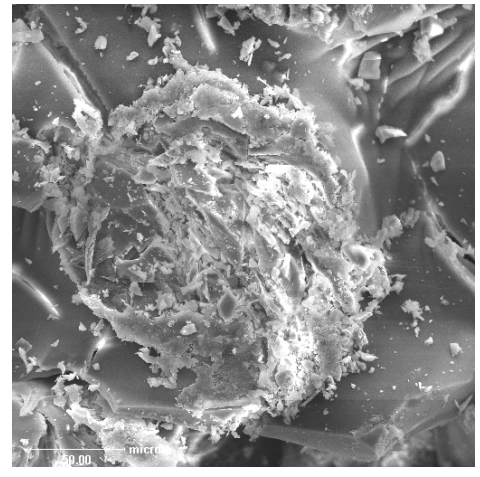

$50 \mu \mathrm{m}$

(A)

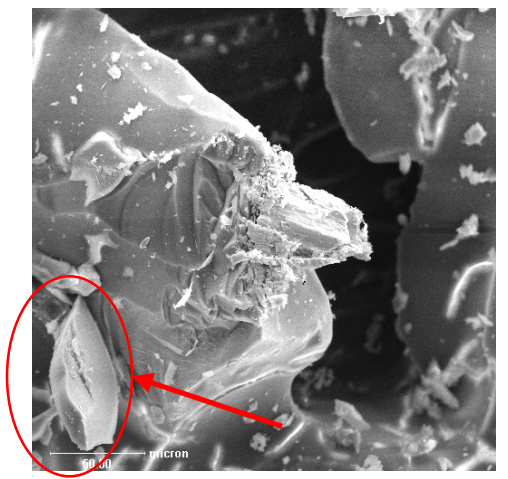

$\overline{50 \mu \mathrm{m}}$

(B)

(C)

Figura 5.29. Superfície da lixa de vidro grana \#80 observada em microscopia eletrônica de varredura, após os ensaios com o aço AISI 1006.

Na Figura 5.29 não está evidenciado o mecanismo de obstrução, como observado na Figura 5.27. A Figura 5.29 (A) mostra que os cavacos formados permanecem sobre os grãos e não nos interstícios dos mesmos. Além disso, observa-se 
que há uma grande aderência dos resíduos de desgaste aos grãos (Figura 5.29 B), que podem sofrer lascamento, gerando pequenos fragmentos (Figura 5.29 C). A diferença entre os mecanismos de contato dos resíduos de desgaste do aço AISI 1006 com as lixas abrasivas, observados nas Figuras 5.27 e 5.29, colabora para afirmar que a obstrução contribui para que o coeficiente de atrito seja afetado pelo tamanho do abrasivo, como sugerido por GODDARD; WILMAN (1962) e por GAHLIN; JACOBSSON (1999).

A Figura 5.30 apresenta a superfície da lixa de vidro grana \#240, após os ensaios com o aço AISI 52100 bruto de têmpera.

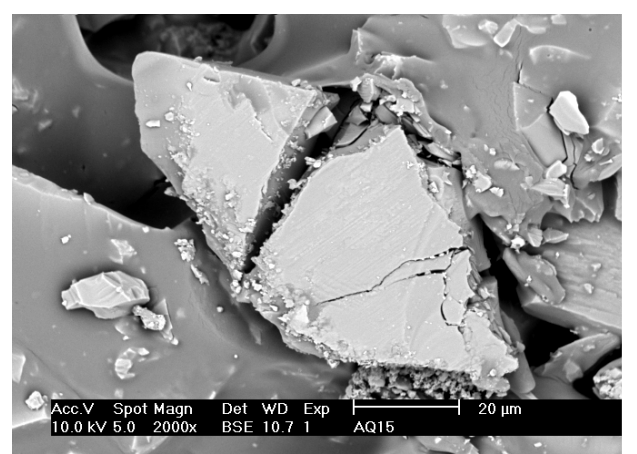

(A)

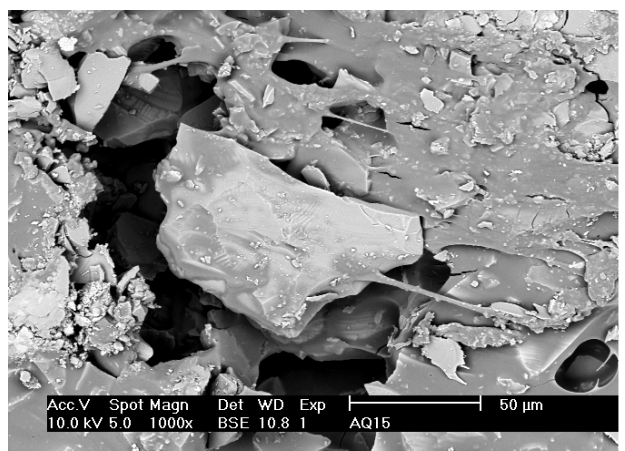

(B)

Figura 5.30. Superfície da lixa de vidro grana \#240 observada em microscopia eletrônica de varredura, após os ensaios com o aço AISI 52100 bruto de têmpera.

A Figura 5.30 (A) mostra que os grãos de vidro são fragmentados à medida que o contato entre o pino e a lixa ocorre. Outros danos à estrutura da lixa também são verificados, como mostra a Figura 5.30 (B). No caso do aço AISI 52100 bruto de têmpera, ao invés do abrasivo estar penetrando na superfície, a energia disponível ao sistema está sendo desperdiçada para promover danos às partículas, e com isso, é provável que o mecanismo de adesão esteja sendo majoritário no valor do coeficiente de atrito nestes casos. 
SIN e colaboradores (1979) apresentaram uma teoria para explicar este efeito, na qual supõe que abrasivos de pequeno tamanho são "naturalmente rombudos", ou seja, à medida que o tamanho de um abrasivo diminui, esta partícula passa a ter ângulos de ataque insuficientes para operar o mecanismo de microcorte. Resultados obtidos por GAHLIN; JACOBSON (1999) corroboraram esta teoria. Estes pesquisadores selecionaram uma metodologia de ensaio na qual foi possível controlar a angulosidade dos abrasivos e a disposição dos mesmos em uma lixa.

A Figura 5.31 mostra de forma quantitativa o modelo proposto por SIN e colaboradores (1979).

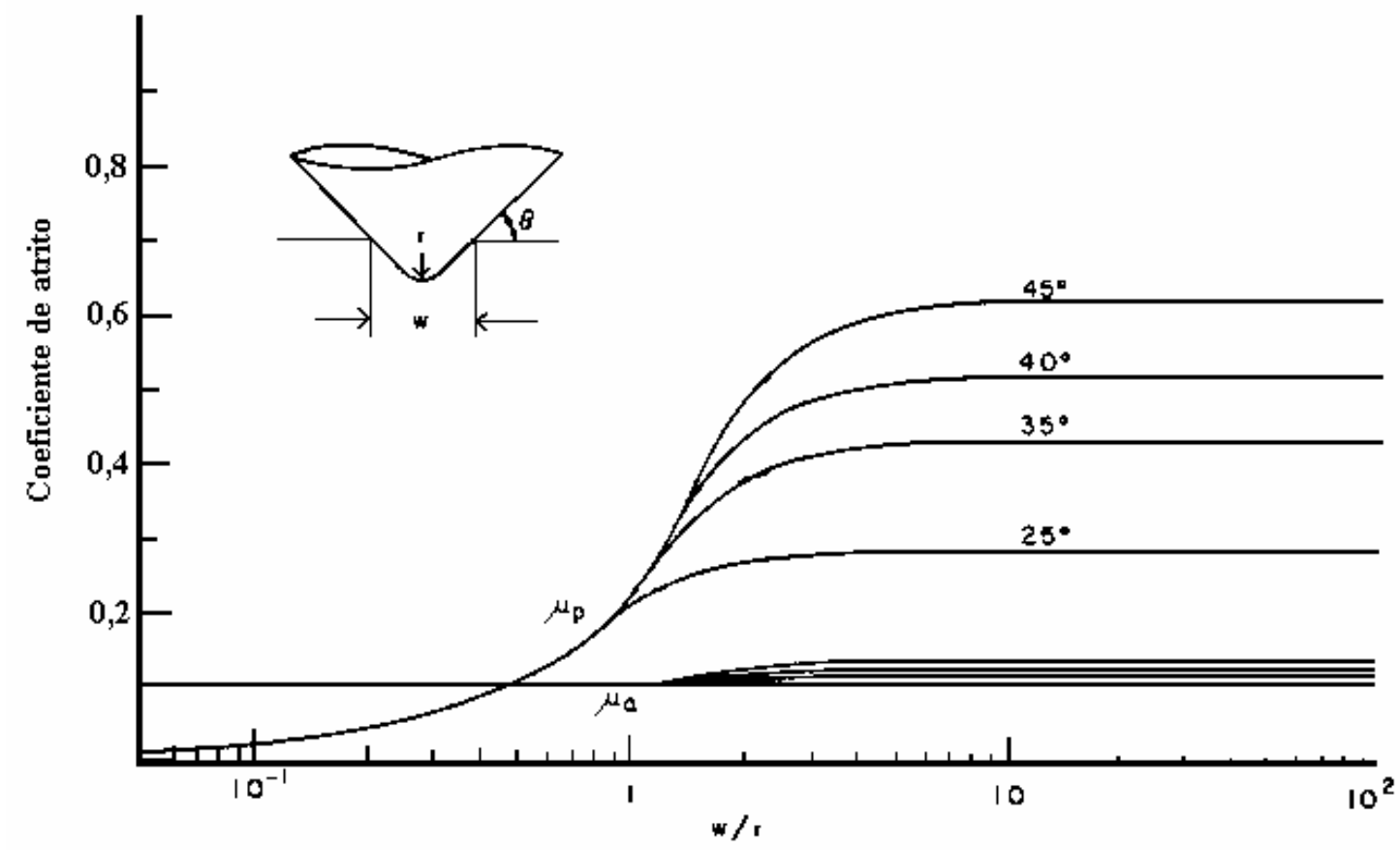

Figura 5.31. Variação do coeficiente de atrito com a razão w/r (largura do sulco/raio do abrasivo), segundo modelo de SIN e colaboradores (1979) para abrasivos cônicos com ponta esférica.

A Figura 5.31 mostra que a partir de um determinado tamanho de abrasivo, a componente de deformação do coeficiente de atrito, $\mu_{\mathrm{p}}$, que é bastante afetada pela angulosidade, passa a ser menor que a componente de adesão, $\mu_{\mathrm{a}}$, que praticamente não 
é afetada pela angulosidade. Segundo BLAU (2001), a angulosidade de uma partícula determina o nível de penetração da mesma, que afeta a magnitude da componente de deformação do coeficiente de atrito. Com os dados da Figura 5.31, pode-se afirmar que esta dependência da componente de deformação com a angulosidade é válida apenas para valores de w/r maiores que 1.

TABOR (1954) estudou a transição dos valores de força tangencial em esclerometria linear, variando o ângulo de ataque da ferramenta de corte e a dureza ao longo do comprimento da peça a ser desgastada, com a configuração apresentada na Figura 5.32 (A). Os resultados obtidos por este pesquisador estão apresentados na Figura $5.32(\mathrm{~B})$.

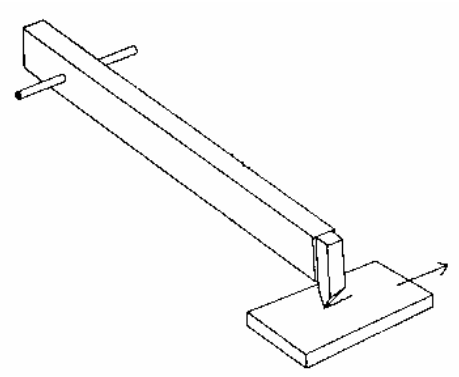

(A)

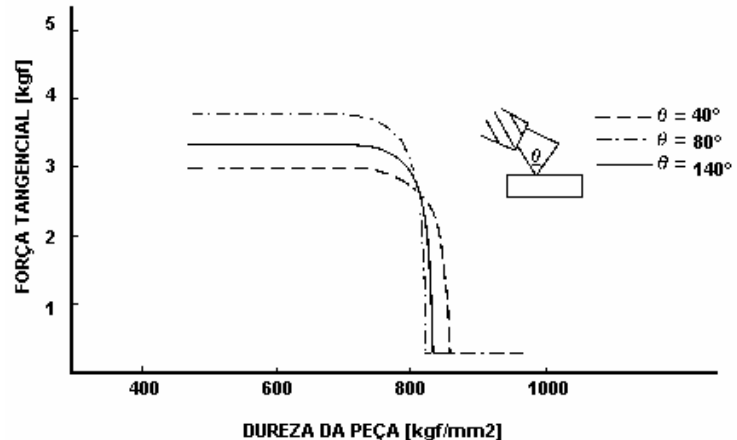

(B)

Figura 5.32. (A) Aparato experimental utilizado por TABOR (1954). (B) Variação da força tangencial [kgf] com três ângulos $\alpha$, utilizando ferramenta de dureza $940 \mathrm{kgf} / \mathrm{mm}^{2}$, força normal de 4,2 kgf e ângulo $\beta$ de $75^{\circ}$.

Os resultados obtidos por TABOR (1954) mostram que o ângulo de ataque afeta os resultados de força tangencial e, portanto, de coeficiente de atrito, apenas enquanto a dureza da ferramenta é maior que a dureza do corpo-de-prova, ou seja, em regime severo de desgaste. 
A teoria de SIN e colaboradores (1979) sobre o efeito do tamanho do abrasivo no coeficiente de atrito possibilita a unificação dos resultados da Figura 5.32 (B) (TABOR, 1954) com os resultados obtidos nesta Tese: o efeito do tamanho do abrasivo (e da sua angulosidade) é significativo para os valores de coeficiente de atrito apenas nos casos em que há regime severo de desgaste, situações que correspondem aos casos em que a dureza do abrasivo é suficientemente maior que a dureza da superfície desgastada.

Um sumário da análise feita para os aços AISI 1006 e AISI 52100 bruto de têmpera é apresentada a seguir:

\section{$\underline{\text { Para o aço AISI 1006, desgastado em regime severo: }}$}

- os valores de coeficiente de atrito são dependentes do tamanho de partícula do abrasivo;

- a obstrução da lixa abrasiva é mais intensa para os ensaios com menor tamanho de grão (grana \#240);

- nos ensaios com a lixa de vidro grana \#80 a dureza da superfície desgastada é similar à dureza máxima possível descrita por RICHARDSON (1967) e;

- o tamanho de partícula determina a intensidade de encruamento da superfície desgastada.

$\underline{\text { Para o aço AISI } 52100 \text { bruto de têmpera, desgastado em regime moderado: }}$

- os valores de coeficiente de atrito são independentes do tamanho do abrasivo; 
- observa-se a fragmentação dos grãos de vidro e a deterioração da estrutura da lixa abrasiva;

- a dureza da superfície desgastada do aço AISI 52100 bruto de têmpera é próxima dos valores de máxima dureza descrita por RICHARDSON (1967) e;

- o tamanho do abrasivo não determina a intensidade do encruamento da superfície desgastada.

Esta análise pode ser estendida para os demais materiais estudados, com base na Figura 5.21, que apresenta a variação do coeficiente de atrito com a dureza, sendo:

$\underline{\text { Análise feita para o aço AISI 1006, desgastado em regime severo: }}$

- Válida para o aço AISI 52100 nas condições recozido, trefilado e temperado e revenido $500{ }^{\circ} \mathrm{C} / 24 \mathrm{~h}$.

Análise feita para o aço AISI 52100 bruto de têmpera, desgastado em regime moderado:

- Válida para o aço AISI 52100 na condição temperado e revenido $500{ }^{\circ} \mathrm{C} / 90 \mathrm{~min}$ e para o ferro fundido branco de alto cromo. 


\subsection{RUGOSIDADE DAS SUPERFÍCIES DESGASTADAS}

A Tabela 5.16 apresenta os valores dos parâmetros Ra, Rz e Sm para cada uma das condições de ensaios de desgaste (nivelamento e lixas de vidro grana \#80 e \#240).

Tabela 5.16 - Valores em micrometros dos parâmetros de rugosidade Ra, Rz e Sm das superfícies desgastadas.

\begin{tabular}{|c|c|c|c|c|}
\hline \multirow{3}{*}{} & Lixa $\mathbf{A l}_{2} \mathbf{O}_{\mathbf{3}} \# \mathbf{6 0 0}$ & $\mathrm{Ra}$ & $\mathrm{Rz}$ & $\mathrm{Sm}$ \\
\cline { 2 - 5 } & AISI1006 & $0,25 \pm 0,04$ & $1,6 \pm 0,1$ & $12 \pm 1$ \\
\cline { 2 - 5 } & Recozido & $0,16 \pm 0,02$ & $0,9 \pm 0,1$ & $9,9 \pm 0,7$ \\
\cline { 2 - 5 } & Trefilado & $0,18 \pm 0,01$ & $1,0 \pm 0,1$ & $10,7 \pm 0,8$ \\
\cline { 2 - 5 } & Temperado e rev1 & $0,17 \pm 0,02$ & $0,89 \pm 0,07$ & $12 \pm 1$ \\
\cline { 2 - 5 } & Temperado e rev2 & $0,13 \pm 0,01$ & $0,7 \pm 0,1$ & $10 \pm 1$ \\
\cline { 2 - 5 } & Bruto de têmpera & $0,13 \pm 0,01$ & $0,71 \pm 0,09$ & $11 \pm 2$ \\
\cline { 2 - 5 } & Ferro fundido & $0,12 \pm 0,02$ & $0,66 \pm 0,05$ & $12 \pm 2$ \\
\hline
\end{tabular}

\begin{tabular}{|c|c|c|c|c|}
\hline & Lixa vidro \#240 & $\mathrm{Ra}$ & $\mathrm{Rz}$ & $\mathrm{Sm}$ \\
\cline { 2 - 5 } & AISI1006 & $0,5 \pm 0,1$ & $2,1 \pm 0,4$ & $15 \pm 2$ \\
\cline { 2 - 5 } & Recozido & $0,34 \pm 0,02$ & $1,56 \pm 0,07$ & $18 \pm 2$ \\
\cline { 2 - 5 } & Trefilado & $0,30 \pm 0,06$ & $1,4 \pm 0,2$ & $26 \pm 7$ \\
\cline { 2 - 5 } \\
\cline { 2 - 5 } & Temperado e rev1 & $0,32 \pm 0,03$ & $1,4 \pm 0,2$ & $30 \pm 3$ \\
\cline { 2 - 5 } & Temperado e rev2 & $0,08 \pm 0,01$ & $0,38 \pm 0,02$ & $16 \pm 2$ \\
\cline { 2 - 5 } & Bruto de têmpera & $0,07 \pm 0,01$ & $0,34 \pm 0,05$ & $16 \pm 2$ \\
\cline { 2 - 5 } & Ferro fundido & $0,08 \pm 0,01$ & $0,34 \pm 0,03$ & $29 \pm 6$ \\
\hline
\end{tabular}

\begin{tabular}{|c|c|c|c|c|}
\hline \multirow{8}{*}{ 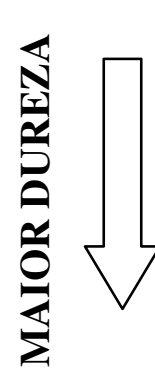 } & Lixa vidro \#80 & $\mathrm{Ra}$ & $\mathrm{Rz}$ & $\mathrm{Sm}$ \\
\hline & AISI1006 & $0,71 \pm 0,07$ & $2,6 \pm 0,4$ & $26 \pm 3$ \\
\hline & Recozido & $0,8 \pm 0,2$ & $2,9 \pm 0,6$ & $26 \pm 7$ \\
\hline & Trefilado & $0,8 \pm 0,1$ & $2,9 \pm 0,5$ & $33 \pm 5$ \\
\hline & Temperado e rev1 & $1,0 \pm 0,2$ & $3,3 \pm 0,4$ & $50 \pm 10$ \\
\hline & Temperado e rev2 & $0,6 \pm 0,1$ & $2,2 \pm 0,3$ & $44 \pm 5$ \\
\hline & Bruto de têmpera & $0,10 \pm 0,02$ & $0,52 \pm 0,06$ & $15 \pm 2$ \\
\hline & Ferro fundido & $0,5 \pm 0,1$ & $1,7 \pm 0,5$ & $44 \pm 8$ \\
\hline
\end{tabular}

Para a etapa de nivelamento com a lixa de alumina grana \#600, o parâmetro Sm foi independente da dureza de engenharia, sendo os valores estatisticamente semelhantes. No caso dos parâmetros $\mathrm{Ra}$ e $\mathrm{Rz}$, é possível distinguir 3 grupos de materiais: o primeiro relativo ao aço AISI 1006, um segundo grupo que compreende o 
aço AISI 52100 nas condições recozido, trefilado e temperado e revenido 1 $\left(500{ }^{\circ} \mathrm{C} / 24 \mathrm{~h}\right)$ e o último que compreende os materiais com maior dureza: aço AISI 52100 nas condições temperado e revenido $2\left(500{ }^{\circ} \mathrm{C} / 90 \mathrm{~min}\right)$ e bruto de têmpera; e o ferro fundido branco.

Para os ensaios com a lixa de vidro grana \#240, considerando-se os parâmetros $\mathrm{Ra}$ e Rz, os 3 grupos de materiais indicados no caso da etapa de nivelamento se repetem. Entretanto, há uma mudança significativa nos valores de Sm, que independiam da dureza do material após a etapa de nivelamento. Há um aumento gradativo nos valores de Sm com a dureza de engenharia dos materiais para as condições nas quais foram possíveis ser determinadas as taxas de desgaste, o que ocorreu para os aços AISI 1006 e AISI 52100 nas condições recozido, trefilado e temperado e revenido 1. Para o aço AISI 52100 bruto de têmpera e temperado e revenido 2, os valores de Sm são inferiores e constantes com o aumento da dureza. O valor de $\mathrm{Sm}$ do ferro fundido branco é semelhante ao do aço AISI 52100 temperado e revenido 1.

Para os ensaios com a lixa grana \#80, o grupo de materiais que foi distinguido por meio dos parâmetros Ra e Rz, no caso das lixas de alumina e de vidro grana \#240, deixam de existir. Há apenas um único grupo que corresponde aos aços AISI 1006 e AISI 52100 nas condições recozido, trefilado e temperado e revenido $500{ }^{\circ} \mathrm{C} / 90 \mathrm{~min}$, todos com valores $\mathrm{Ra}$ e $\mathrm{Rz}$ estatisticamente semelhantes. Para os materiais de maior dureza, os valores de Ra e Rz tendem a cair à medida que a dureza aumenta. No caso do parâmetro Sm, há uma tendência de aumento com a dureza até um determinado valor, correspondente à dureza do aço AISI 52100 temperado e revenido 1.

Os resultados de rugosidade corroboram a análise feita para a variação do coeficiente de atrito com o tamanho da partícula abrasiva, no caso dos aços AISI 1006 e 
AISI 52100 bruto de têmpera. Como exemplo, a Figura 5.33 apresenta os valores de Sm para cada uma das etapas de ensaio.

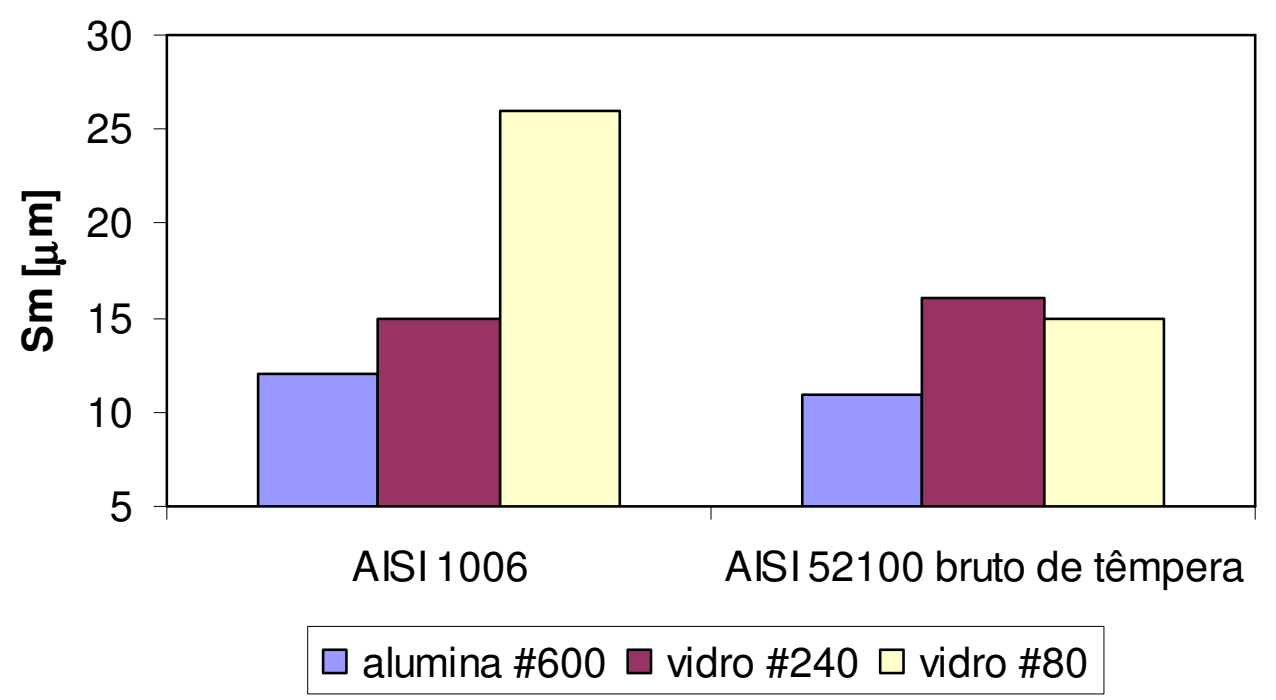

Figura 5.33. Variação do parâmetro Sm dos aços AISI 1006 e AISI 52100 bruto de têmpera com as diferentes etapas de ensaio.

A Figura 5.33 mostra que a diferença entre os valores Sm do aço AISI 1006, considerando-se os ensaios com as lixas de vidro grana \#80 e \#240, é significativa, enquanto que, para o aço AISI 52100 bruto de têmpera, os valores de Sm praticamente não variam a partir da condição de nivelamento com a lixa de alumina grana \#600. Estes resultados mostram que, quando o desgaste é severo, o aumento do tamanho do abrasivo eleva os valores de Sm, da mesma forma que elevava os valores de coeficiente de atrito. Em ensaios no regime moderado, esta variação não ocorre.

A interpretação que se dará ao parâmetro Rz é que o mesmo pode representar a máxima profundidade de penetração que a partícula abrasiva causa na superfície desgastada. A Figura 5.34 apresenta a definição do parâmetro Rz. 


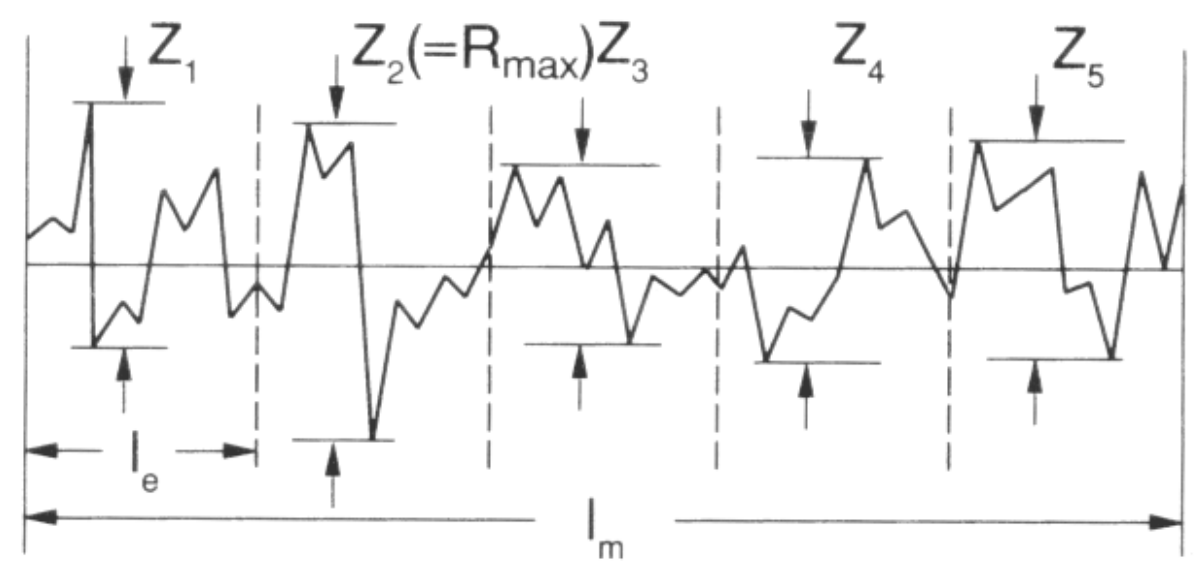

Figura 5.34. Definição de Rz. Legenda: $l_{m}=$ segmento de cálculo (cut-off); $l_{e}=$ segmento de medida $\left(=\mathrm{l}_{\mathrm{m}} / \mathbf{5}\right) ; \mathrm{Zn}$ = valores unitários para o cálculo de $\mathrm{Rz}$; e $\mathbf{R}_{\max }=$ máximo valor unitário de Rz.

A Figura 5.34 mostra de forma esquemática a definição de Rz, que corresponde às maiores distâncias entre picos e vales de rugosidade, dentro de cada uma das 5 divisões em que um segmento de cálculo (cut-off) é dividido. Rz é uma média destes 5 valores. Esta Figura apresenta também o parâmetro $R_{\max }$, que é o máximo valor de $\mathrm{Rz}$ dentre os 5 utilizados no cálculo.

A Figura 5.35 apresenta um típico perfil real de superfície desgastada após ensaio de esclerometria linear, indicando a profundidade máxima de penetração $\mathrm{h}_{\text {máx }}$ (BUTTERY; ARCHARD, 1970/71). 


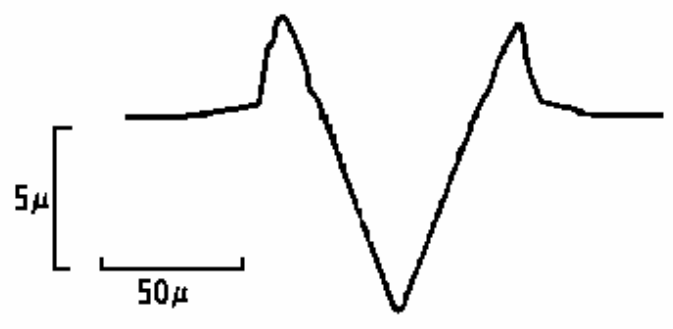

(a)

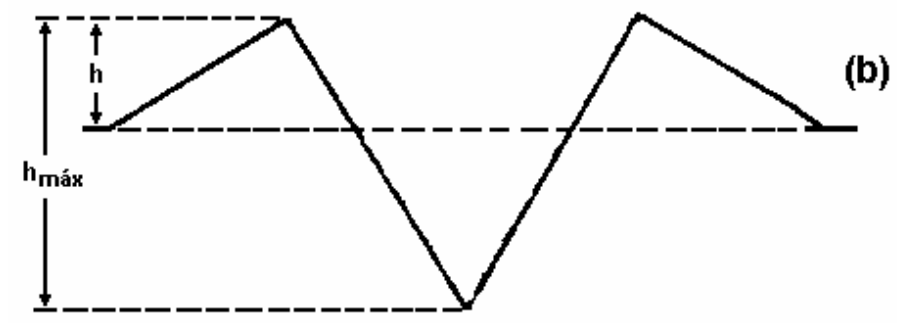

Figura 5.35. (a) Exemplo de perfil real de liga de cobalto (Stellite) após ensaio de esclerometria linear e (b) Esquema ilustrativo de referência para indicação da profundidade máxima $h_{\text {máx }}$ (BUTTERY; ARCHARD, 1970/71).

A Figura 5.35 mostra que a profundidade máxima de penetração que uma partícula abrasiva gera sobre uma superfície, no que diz respeito ao conceito físico, se assemelha à definição do parâmetro Rz.

Alguns exemplos da literatura serão apresentados para confirmar a hipótese que o parâmetro $\mathrm{Rz}$ pode representar de forma adequada a profundidade máxima de penetração. A Figura 5.36 mostra resultados de profundidades máximas determinadas por MULHEARN; SAMUELS (1962) para um aço baixo carbono, após ensaio pino contra lixa de SiC grana \#220, com tensão nominal 0,022 MPa. 


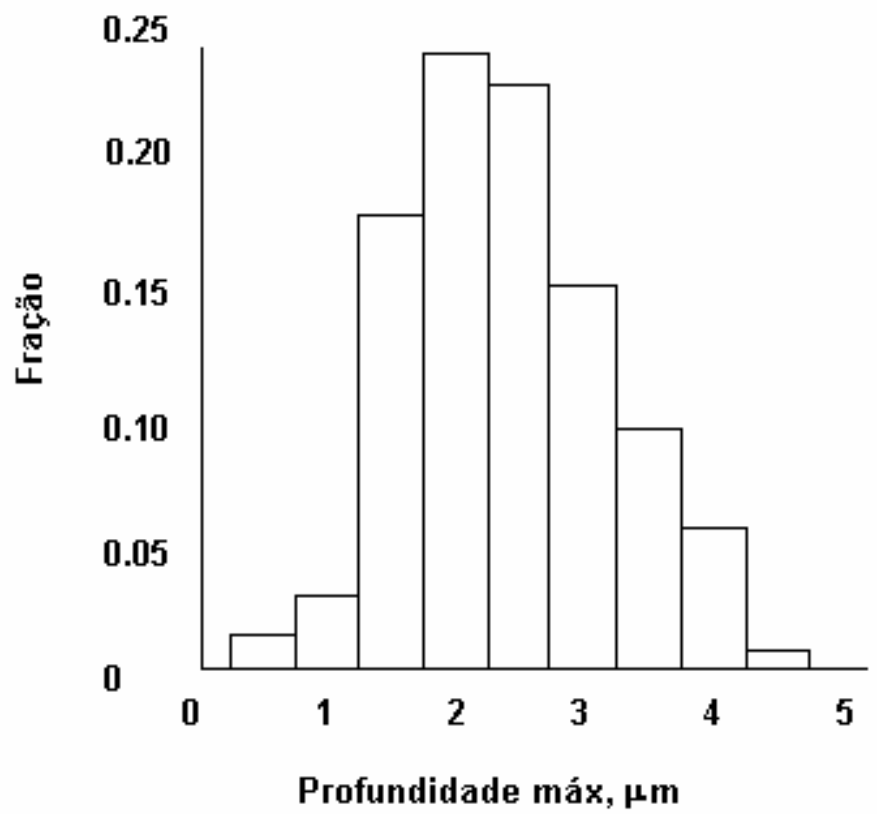

Figura 5.36. Freqüência de valores de profundidade máxima de sulcos $[\mu \mathrm{m}]$ produzidos por lixa de $\mathrm{SiC}$ grana \#220 em aço baixo carbono (MULHEARN; SAMUELS, 1962).

A Tabela 5.17 apresenta valores de profundidade máxima obtidos por MOORE (1980) para um compósito cobre-prata, após ensaios pino contra lixa de SiC, com tensão nominal de contato $0,97 \mathrm{MPa}$.

Tabela 5.17 - Valores de profundidade máxima [ $\mu \mathrm{m}]$ de compósito cobre-prata (MOORE, 1980).

\begin{tabular}{cc}
\hline Grana da lixa $\mathrm{SiC}$ & Profundidade máxima $[\mu \mathrm{m}]$ \\
\hline$\# 320$ & 3,0 \\
$\# 180$ & 4,7 \\
\hline
\end{tabular}

Os resultados obtidos por MULHEARN; SAMUELS (1962) e por MOORE (1980) podem ser comparados com o valor $\mathrm{Rz}$ obtido para o par 'aço AISI 1006/lixa de vidro grana \#240', que é a condição mais próxima em dureza e em tamanho de abrasivo em relação às condições apresentadas na Figura 5.36 e na Tabela 5.17. O valor $\mathrm{Rz}$ para a condição de ensaio citada foi $2,1 \mu \mathrm{m}$, muito próximo dos 
obtidos por MULHERN; SAMUELS (1962) e da mesma ordem de grandeza que os apresentados na Tabela 5.17.

Portanto, conclui-se que o parâmetro $\mathrm{Rz}$ pode representar a profundidade máxima de penetração de uma superfície desgastada por partículas abrasivas. Esta hipótese é a base para a concepção de uma metodologia de cálculo da força atuante em cada grão abrasivo que será denominada força de penetração, utilizada para definir a metodologia de medida de dureza neste trabalho.

\subsection{ENSAIOS INSTRUMENTADOS DE DUREZA}

Serão apresentados a seguir os resultados obtidos em ensaios instrumentados de dureza, realizados com base nos resultados de rugosidade das superfícies desgastadas. Com estes ensaios foram obtidos 5 tipos de dureza, além do módulo elástico dos materiais. Em uma das formas de cálculo de dureza, foi incorporado um fator para prever o tipo de morfologia de impressão, formação de bordas ou retração. Com este conceito, a extensão da zona plástica formada durante a penetração de dureza (ou durante o processo abrasivo) foi considerada no cálculo de dureza.

\subsubsection{Força de penetração}

A força de penetração exercida por uma partícula abrasiva, em uma primeira abordagem, é dependente do tamanho da partícula e da dureza do material desgastado (MOORE, 1980; BULSARA e colaboradores, 1998). O conhecimento desta força permite a adequação das medidas de dureza ao sistema de desgaste, no sentido de utilizar forças no ensaio de dureza que sejam compatíveis com as forças atuantes em cada abrasivo. A metodologia aplicada aproveita a possibilidade do equipamento instrumentado de dureza realizar o ensaio indicando a profundidade máxima de 
penetração, ao invés da força máxima. Como resultado, a força máxima é uma função da profundidade selecionada. Estas profundidades foram selecionadas a partir dos valores do parâmetro Rz.

A Tabela 5.18 apresenta os resultados das profundidades máximas selecionadas e de força de penetração obtidos. Os resultados de Rz são novamente apresentados para efeito de comparação.

Tabela 5.18 - Força de penetração $F_{\text {máx }}[N]$, profundidades máxima de penetração $h_{\max }[\mu \mathrm{m}]$ e $R z[\mu \mathrm{m}]$ das condições de ensaio de desgaste nas quais se observaram perdas de massa.

\begin{tabular}{|c|c|c|c|}
\hline \multirow{2}{*}{ Material } & \multicolumn{3}{|c|}{ Ensaios lixa grana \#80 } \\
& $\mathrm{F}_{\text {máx }}[\mathrm{N}]$ & $\mathrm{h}_{\text {máx }}[\mu \mathrm{m}]$ & $\mathrm{Rz}[\mu \mathrm{m}]$ \\
\hline AISI 1006 & $0,33 \pm 0,01$ & $3,2 \pm 0,02$ & $2,6 \pm 0,4$ \\
AISI 52100 recozido & $0,53 \pm 0,02$ & $3,02 \pm 0,01$ & $2,9 \pm 0,6$ \\
AISI 52100 trefilado & $0,743 \pm 0,006$ & $3,004 \pm 0,005$ & $2,9 \pm 0,5$ \\
AISI 52100 temp. e rev.1 & $0,94 \pm 0,02$ & $3,04 \pm 0,02$ & $3,3 \pm 0,4$ \\
AISI 52100 temp e rev.2 & $0,655 \pm 0,005$ & $2,33 \pm 0,01$ & $2,2 \pm 0,3$ \\
Ferro fundido branco & $0,25 \pm 0,02$ & $1,49 \pm 0,02$ & $1,7 \pm 0,5$ \\
\hline \multirow{2}{*}{ AISI 1006 } & $0,159 \pm 0,005$ & $2,11 \pm 0,02$ & $2,1 \pm 0,4$ \\
AISI 52100 recozido & $0,166 \pm 0,007$ & $1,607 \pm 0,009$ & $1,56 \pm 0,07$ \\
AISI 52100 trefilado & $0,207 \pm 0,003$ & $1,473 \pm 0,006$ & $1,4 \pm 0,2$ \\
AISI 52100 temp e rev.1 & $0,238 \pm 0,005$ & $1,50 \pm 0,01$ & $1,4 \pm 0,2$ \\
\hline
\end{tabular}


A comparação entre os resultados de profundidade máxima de penetração e os valores $\mathrm{Rz}$ apresentados na Tabela 5.18 mostra que a seleção destas profundidades foi adequada, resultando em valores semelhantes aos do parâmetro Rz. Esta semelhança é uma condição básica para que se possa utilizar os valores de força máxima como sendo a força de penetração dos abrasivos, considerando ainda o fato que a geometria do penetrador de dureza Vickers é uma simplificação em relação às possíveis geometrias que os grãos de vidro das lixas possam apresentar.

A Tabela 5.18 mostra que os valores de força variaram entre 0,15 e $1 \mathrm{~N}$. Disto decorre que os fenômenos de desgaste estudados ficaram restritos à escala micrométrica, segundo a definição da ISO 14577-1 (ISO, 2002) para esta escala, que inicia na profundidade de $0,2 \mu \mathrm{m}$ e vai até a força de $2 \mathrm{~N}$. De acordo com esta Norma, é possível calcular a dureza Martens dos materiais para cada uma das condições de ensaio, que estão apresentadas na Tabela 5.19.

Tabela 5.19 - Dureza Martens HM [MPa] dos materiais que apresentaram perda de massa.

\begin{tabular}{|c|cc|cc|}
\hline \multirow{2}{*}{ Material } & \multicolumn{2}{|c|}{$\mathrm{F}_{\text {máx }}[\mathrm{N}]$} & HM $\left(=0,0378 . \mathrm{F}_{\text {máx }} / \mathrm{h}_{\text {máx }}{ }^{2}\right)$ \\
\cline { 2 - 5 } & Lixa \#80 & Lixa \#240 & Lixa \#80 & Lixa \#240 \\
\hline AISI 1006 & $0,33 \pm 0,01$ & $0,161 \pm 0,006$ & $1.230 \pm 60$ & $1.370 \pm 70$ \\
AISI 52100 recozido & $0,53 \pm 0,02$ & $0,166 \pm 0,007$ & $2.200 \pm 60$ & $2.400 \pm 100$ \\
AISI 52100 trefilado & $0,743 \pm 0,006$ & $0,207 \pm 0,003$ & $3.110 \pm 20$ & $3.610 \pm 60$ \\
AISI 52100 temp. e rev.1 & $0,94 \pm 0,02$ & $0,238 \pm 0,005$ & $3.830 \pm 30$ & $4.010 \pm 30$ \\
AISI 52100 temp. e rev.2 & $0,655 \pm 0,005$ & & $4.560 \pm 20$ & \\
Ferro fundido branco & $0,25 \pm 0,02$ & & $4.200 \pm 200$ & \\
\hline
\end{tabular}


Com base nos dados da Tabela 5.19 é possível construir a Figura 5.37, que apresenta a variação da força de penetração com a dureza Martens para os aços AISI 1006, AISI 52100 recozido, AISI 52100 trefilado e AISI 52100 temperado e revenido $1\left(500{ }^{\circ} \mathrm{C} / 24 \mathrm{~h}\right)$.

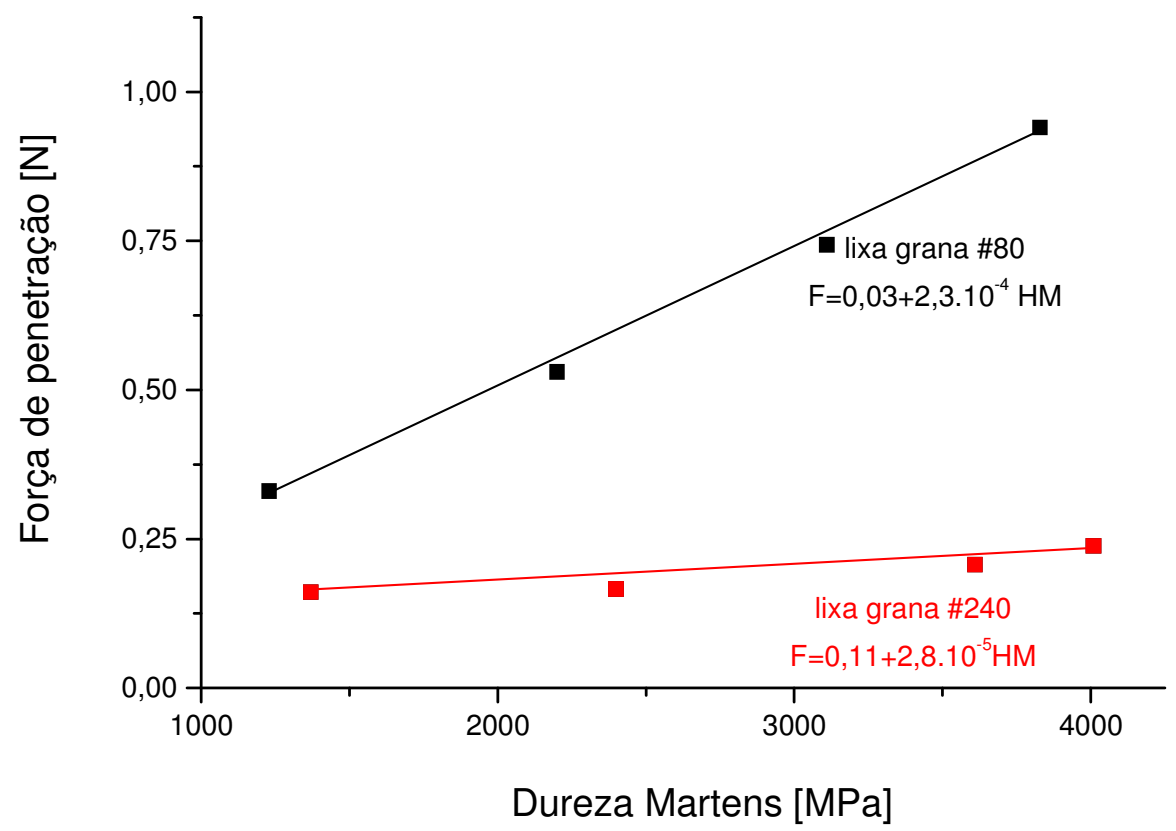

Figura 5.37. Variação da força de penetração [N] com a dureza Martens HM [MPa] dos aços AISI 1006, AISI 52100 recozido, AISI 52100 trefilado e AISI 52100 temperado e revenido a $500{ }^{\circ} \mathrm{C}$ por $24 \mathrm{~h}$, nas condições relativas aos ensaios com as lixas de vidro grana \#80 e grana \#240.

A Figura 5.37 mostra que a força de penetração $\left(\mathrm{F}_{\text {máx }}\right)$ aumenta com a dureza dos materiais, para os dois tamanhos de abrasivo. Além disso, aumenta a diferença na força de penetração na superfície de desgaste produzida pelos abrasivos de diferentes tamanhos à medida que a dureza se eleva.

O aumento da força de penetração com a dureza não foi verificada para o aço AISI 52100 temperado e revenido $2\left(500{ }^{\circ} \mathrm{C}\right.$ por $\left.90 \mathrm{~min}\right)$ e para o ferro fundido branco de alto cromo, no caso dos ensaios com a lixa grana $\# 80$ como mostra a Figura 5.38. 


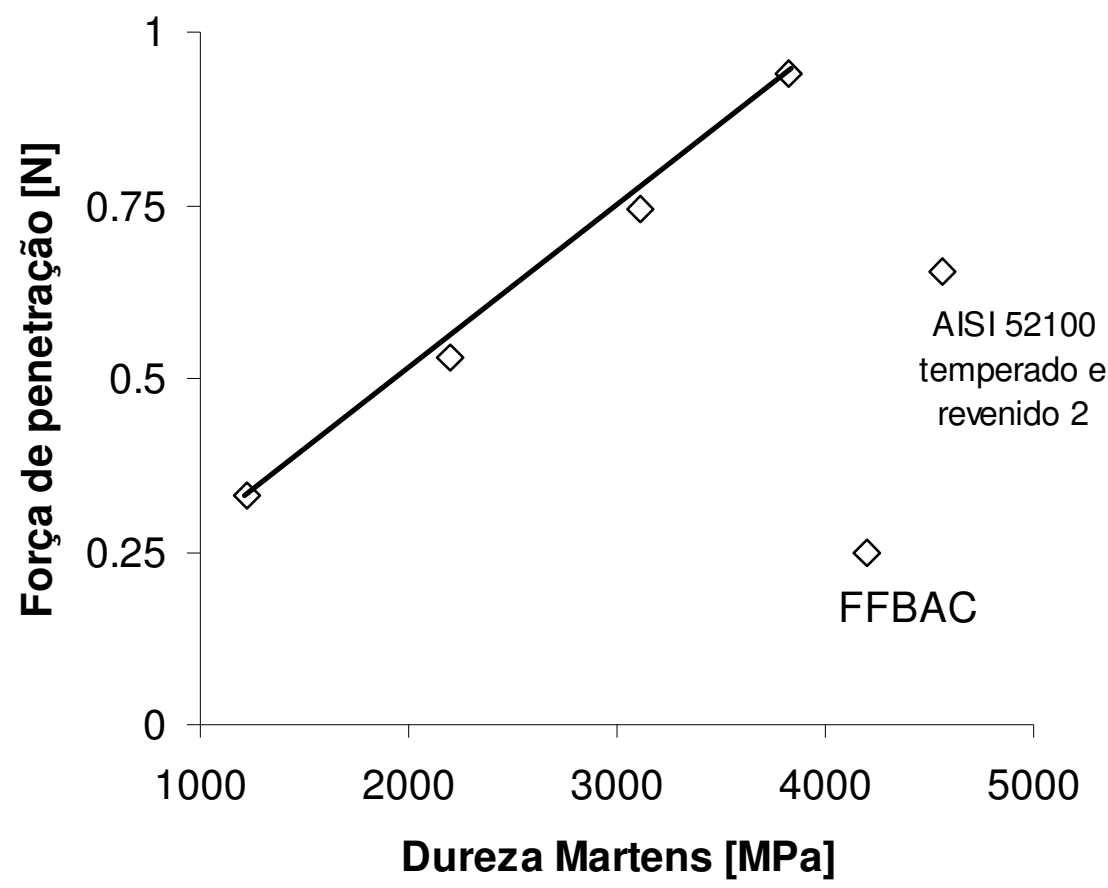

Figura 5.38. Variação da força de penetração [N] com a dureza Martens [MPa] dos materiais estudados, na condição relativa ao ensaio com a lixa de vidro grana \#80.

O resultado esperado para a Figura 5.38 era que a força de penetração fosse proporcional à dureza em toda a faixa estudada, como obtido por BULSARA e colaboradores (1998). Um possível motivo para que isto deixasse de ocorrer é a fragmentação dos grãos abrasivos, descrita na análise do desgaste e do coeficiente de atrito. Quando o grão é fragmentado em grandes proporções, o tamanho que causará a penetração na superfície de desgaste é menor e, portanto, a força de penetração diminui.

No caso do aço temperado e revenido na condição 2, é possível estimar a força de penetração, proporcional à dureza deste material, caso não houvesse a fragmentação do abrasivo. Utilizando o valor da dureza HM deste material na regressão linear indicada na Figura 5.37 chega-se ao valor de 1,079 N (que não seria possível 
determinar, pois a força máxima possível do equipamento instrumentado é $1 \mathrm{~N}$ ). A diferença entre este valor e a força de penetração apresentada na Tabela 5.18 é 0,424 N. Esta força é parcela de uma energia, utilizada em parte na fragmentação dos grãos abrasivos.

Esta análise é corroborada pelas imagens da superfície desgastada do ferro fundido branco de alto cromo apresentada na Figura 5.39.

A Figura 5.39 (A) mostra que há uma grande quantidade de grãos de vidro incrustados na superfície do ferro fundido branco de alto cromo, que deve ocorrer nas regiões de matriz perlítica. O tamanho destes grãos é muito menor que o tamanho original dos grãos de vidro da lixa grana \#80 (0,2 $\mathrm{mm})$, indicando que houve fragmentação destes grãos anteriormente à penetração. A análise química por EDS (Figura 5.39 B) mostra os principais elementos de liga do ferro fundido branco (cromo e manganês) junto com os principais elementos do vidro (silício e cálcio). Dois fatores contribuíram para a queda na força de penetração dos grãos abrasivos no caso do ferro fundido branco: a fragmentação dos grãos de vidro, devido à incapacidade dos mesmos de penetrar nas regiões dos carbonetos eutéticos, que possuem elevada dureza e, posteriormente, a incrustação destes grãos na superfície desgastada. Isto faz com que o abrasivo vidro encontre uma superfície de vidro sobre o corpo-de-prova, resultando em uma relação de durezas igual a 1 , maior do que a relação entre a dureza do vidro e da matriz perlítica e, portanto, menor desgaste. 


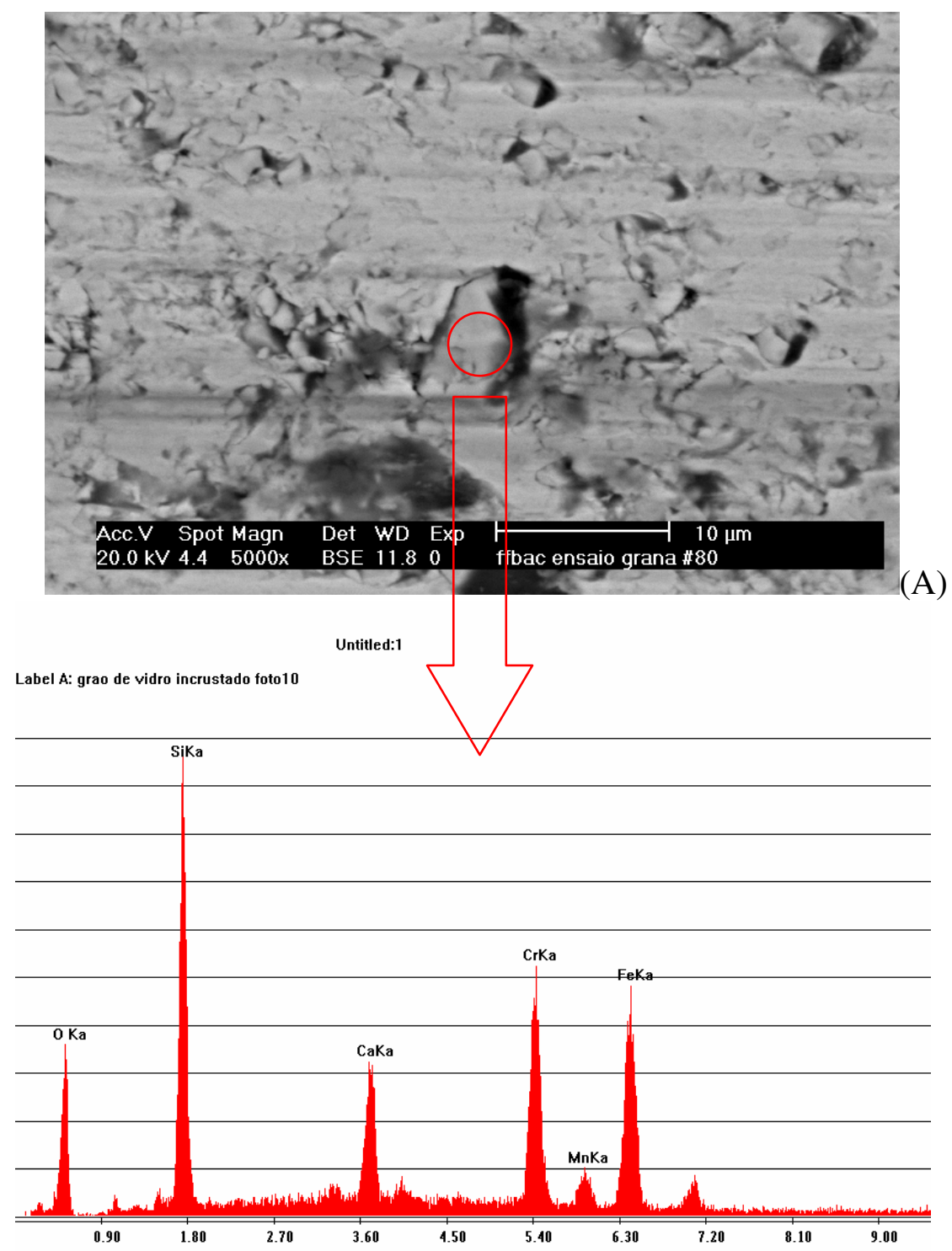

(B)

Figura 5.39. (A) Imagem da superfície desgastada do ferro fundido branco de alto cromo em microscopia eletrônica de varredura, após ensaio com a lixa de vidro grana \#80. Nota-se uma elevada incidência de incrustação de abrasivos na superfície. (B) Análise química por espectrometria de energia dispersiva (EDS) da região indicada com seta vermelha na imagem $A$.

A fragmentação dos grãos abrasivos em ensaios de desgaste é usualmente verificada nas situações de regime moderado (MOORE; KING, 1980 e BOZZI; DE MELLO, 1999), ou seja, aquelas situações nas quais a razão entre a dureza do abrasivo $\left(\mathrm{H}_{\mathrm{A}}\right)$ e a dureza do material desgastado $(\mathrm{H})$ é menor que 1,2 ; valor mais utilizado pela literatura (HUTCHINGS, 1992) para caracterizar a mudança de regime. 
Portanto, os resultados da Figura 5.38 são mais um indicativo da mudança no mecanismo de desgaste que ocorre para o aço AISI 52100 temperado e revenido 2 (500 $\left.{ }^{\circ} \mathrm{C} / 90 \mathrm{~min}\right)$.

\subsubsection{Propriedades mecânicas dos materiais metálicos}

\subsubsection{Fator $\alpha$ (morfologia de impressão de dureza) e dureza}

A Tabela 5.20 apresenta os valores do fator $\alpha$, calculado segundo o modelo de ZENG e claboradores (1996), e a razão entre profundidade final e profundidade máxima de penetração $\left(h_{P} / h_{\text {máx }}\right)$, fator sugerido por SURESH; GIANNAKOPOULOS (1999) para a previsão da morfologia de impressão de dureza.

Tabela 5.20 - Fator $\alpha$ e razão $h_{P} / h_{\text {máx }}$ dos materiais estudados, sob as condições nas quais se observou perda de massa.

\begin{tabular}{|c|cc|cc|}
\hline \multirow{2}{*}{ Material } & \multicolumn{2}{|c|}{$\alpha\left(=45,423 \mathrm{~h}_{\text {máx }}{ }^{2} / \mathrm{d}^{2}\right)$} & \multicolumn{2}{|c|}{$\mathrm{h}_{\mathrm{P}} / \mathrm{h}_{\text {máx }}$} \\
\cline { 2 - 5 } & Lixa \#80 & Lixa \#240 & Lixa \#80 & Lixa \#240 \\
\hline AISI 1006 & 0,86 & 0,83 & 0,95 & 0,95 \\
AISI 52100 recozido & 0,90 & 0,87 & 0,88 & 0,88 \\
AISI 52100 trefilado & 0,95 & 0,86 & 0,81 & 0,82 \\
AISI 52100 temp. e rev.1 & 0,92 & 0,87 & 0,80 & 0,80 \\
AISI 52100 temp. e rev.2 & 0,93 & & 0,77 & \\
Ferro fundido branco & 0,93 & 0,83 & \\
\hline
\end{tabular}

A Tabela 5.20 mostra que os valores de $\alpha$ foram menores que 1 para todos os materiais. Segundo a proposta de ZENG e colaboradores (1996), isto significa que os materiais estudados apresentaram formação de bordas, o que foi confirmado por meio de imagens das impressões de dureza obtidas em microscopia óptica e em 
interferometria laser, como apresentado na Figura 5.40 para o aço AISI 52100 trefilado, o material para o qual foi obtido o maior valor do fator $\alpha$.

Os valores da razão $h_{P} / h_{\text {máx }}$ apresentados na Tabela 5.20, para a maioria dos casos estudados, foi menor que 0,875 , o que corresponderia à morfologia de retração, segundo a proposta de SURESH; GIANNAKOPOULOS (1999). Esta morfologia não foi verificada em nenhuma das impressões de dureza, e, portanto, a proposta de SURESH; GIANNAKOPOULOS não se aplica às condições estudadas.

A Tabela 5.21 apresenta os valores de dureza Vickers convencional e os valores de dureza verdadeira $\mathrm{H}_{\mathrm{IP}}$. Esta última propriedade foi determinada considerando-se o valor de $\alpha$, o que incorpora o efeito da morfologia de impressão.

Tabela 5.21 - Dureza Vickers convencional HV [MPa] e dureza verdadeira $\mathrm{H}_{\text {IP }}$ [MPa] dos materiais estudados, sob as condições nas quais se observou perda de massa.

\begin{tabular}{|c|cc|cc|}
\hline \multirow{2}{*}{ Material } & \multicolumn{2}{|c|}{$\mathrm{HV}\left(=1,854 . \mathrm{F}_{\text {máx }} / \mathrm{d}^{2}\right)$} & \multicolumn{2}{c|}{$\mathrm{H}_{\mathrm{IP}}\left(=\alpha^{2} . \mathrm{F}_{\text {máx }} / 24,5 . \mathrm{h}_{\text {máx }}{ }^{2}\right)$} \\
\cline { 2 - 5 } & Lixa \#80 & Lixa \#240 & Lixa \#80 & Lixa \#240 \\
\hline AISI 1006 & $1.150 \pm 60$ & $1.230 \pm 60$ & $990 \pm 50$ & $1.020 \pm 50$ \\
AISI 52100 recozido & $2.150 \pm 80$ & $2.200 \pm 100$ & $1.930 \pm 50$ & $1.940 \pm 80$ \\
AISI 52100 trefilado & $3.200 \pm 50$ & $3.350 \pm 80$ & $3.060 \pm 20$ & $2.890 \pm 60$ \\
AISI 52100 temp. e rev.1 & $3.800 \pm 100$ & $3.800 \pm 200$ & $3.530 \pm 30$ & $3.310 \pm 20$ \\
AISI 52100 temp. e rev.2 & $4.550 \pm 70$ & & $4.210 \pm 20$ & \\
Ferro fundido branco & $4.300 \pm 200$ & & $4.100 \pm 200$ & \\
\hline
\end{tabular}




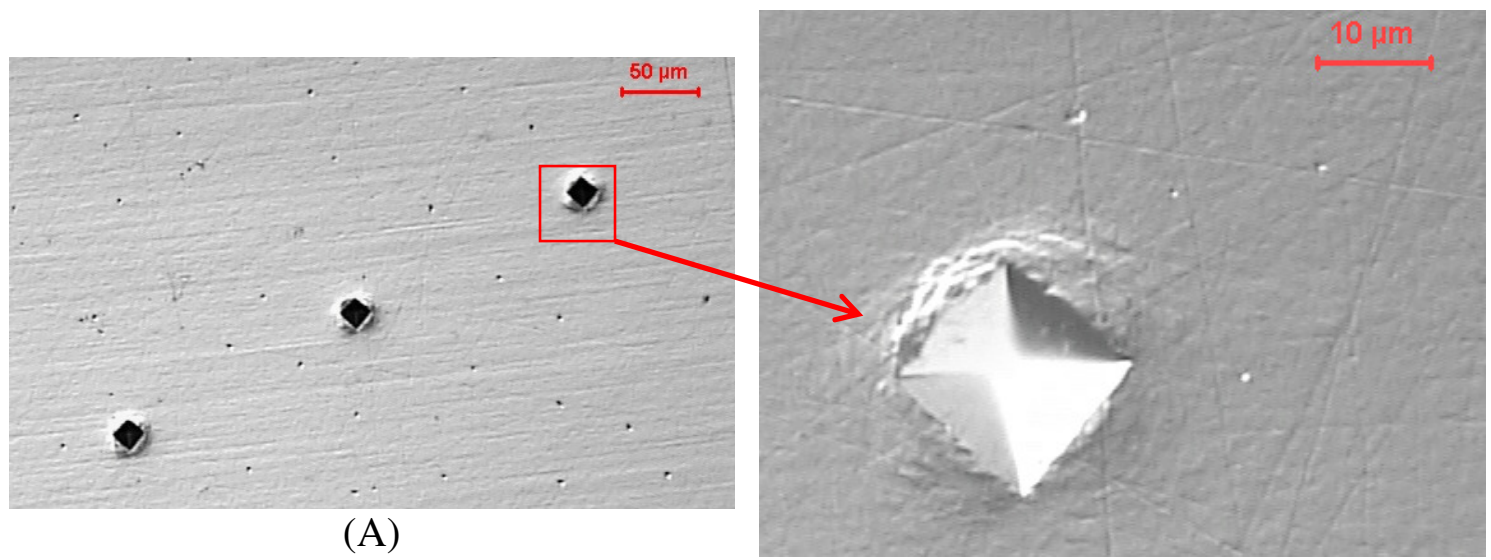

(B)

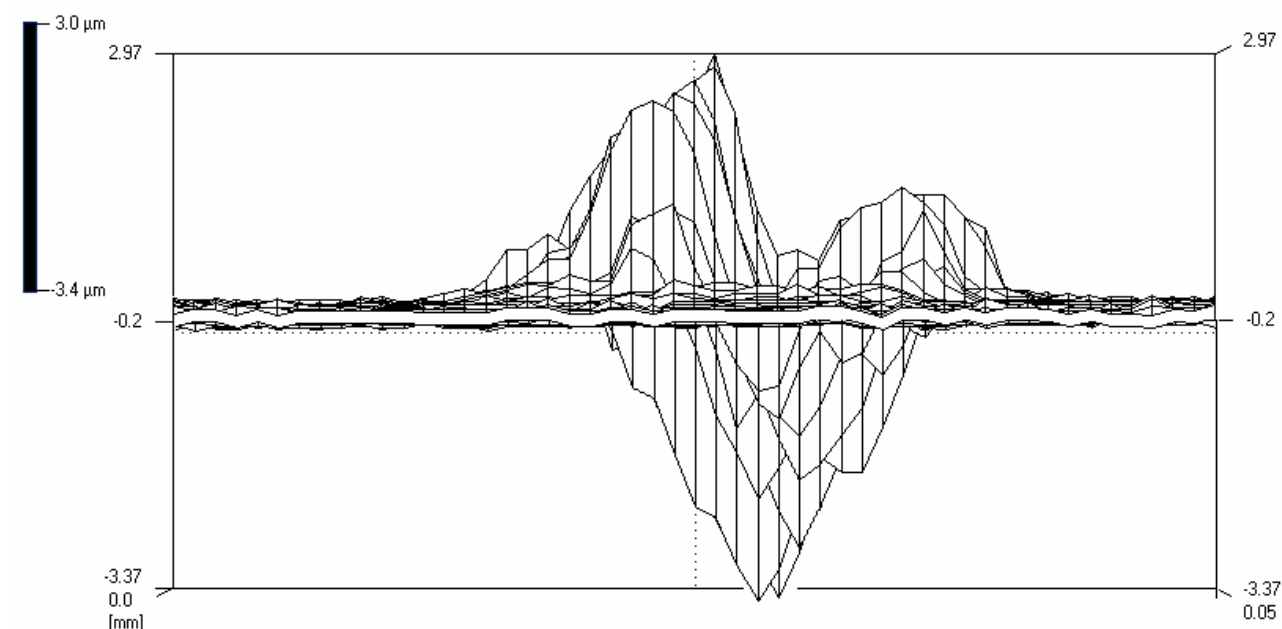

(C)

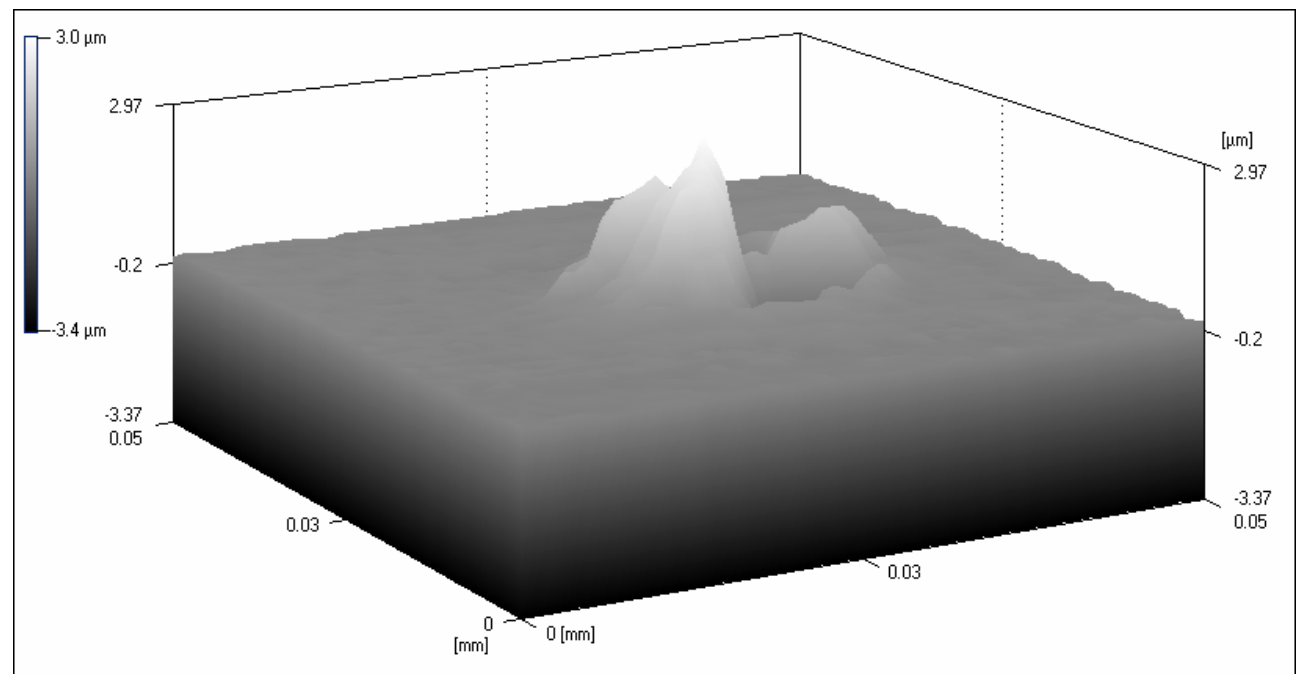

(D)

Figura 5.40. Impressões de dureza com profundidade máxima de penetração de $3,0 \mu \mathrm{m}$ em aço AISI 52100 trefilado: (A) e (B) imagens em microscopia óptica; (C) e (D) imagens em interferometria laser. Nota-se a formação de bordas. 
A Tabela 5.21 mostra que os valores de dureza Vickers convencional e de dureza $\mathrm{H}_{\mathrm{IP}}$ são pouco afetados pela diferença da profundidade de penetração (relativas às condições de ensaio com as lixas grana \#80 e grana \#240), sendo estatisticamente semelhantes para o aço AISI 1006 e para o aço AISI 52100.

A comparação entre os valores de dureza Martens (Tabela 5.19), dureza $\mathrm{H}_{\mathrm{IP}}$ e dureza Vickers convencional (Tabela 5.21) para a condição de ensaio relativa à lixa de vidro grana \#80 está apresentada na Figura 5.41.

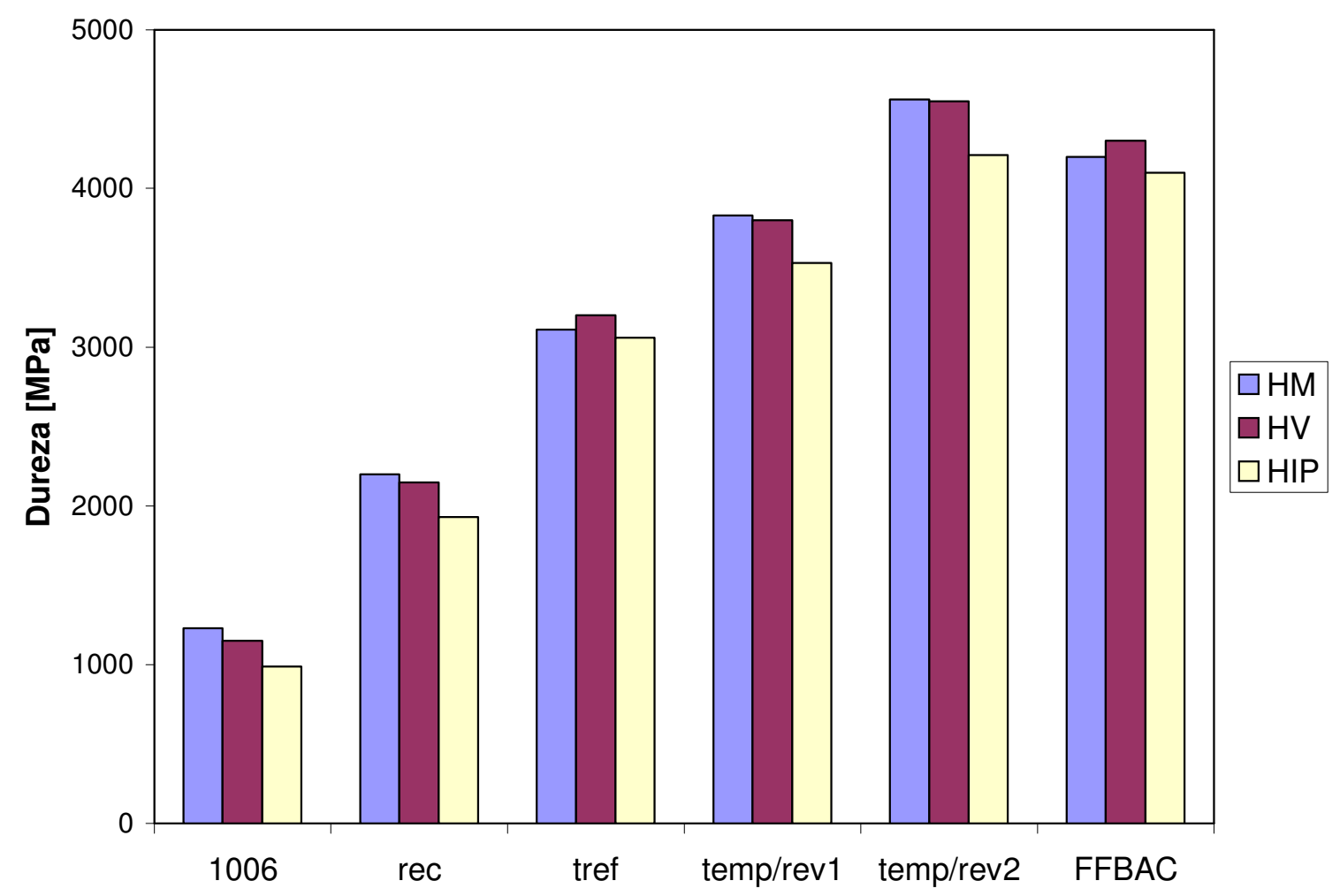

Figura 5.41. Valores de dureza HM, HV e $\mathrm{H}_{\text {IP }}$ [MPa] dos aços AISI 1006 e AISI 52100 e do ferro fundido branco de alto cromo (FFBAC), para a condição de ensaio relativa à lixa de vidro grana \#80.

A Figura 5.41 mostra que os valores da dureza $\mathrm{H}_{\mathrm{IP}}$ são menores que os valores das outras escalas. Isto era esperado, pois a área que suporta a força aplicada é maior quando se considera o efeito da formação de bordas, uma morfologia de impressão que 
está associada com um aumento da extensão da zona plástica. Esta Figura mostra também que os valores de dureza Martens e dureza Vickers convencional são semelhantes. Disto conclui-se que a diagonal de impressão, deixada pelo penetrador no material após a remoção da força, continua refletindo a geometria do penetrador, dado que a recuperação elástica nas diagonais de impressão é praticamente nula e também muito pequena no sentido da profundidade de penetração.

A comparação entre os valores de dureza Martens (Tabela 5.21), dureza verdadeira e dureza Vickers convencional para a condição de ensaio relativa à lixa de vidro grana \#240 está apresentada na Figura 5.42.

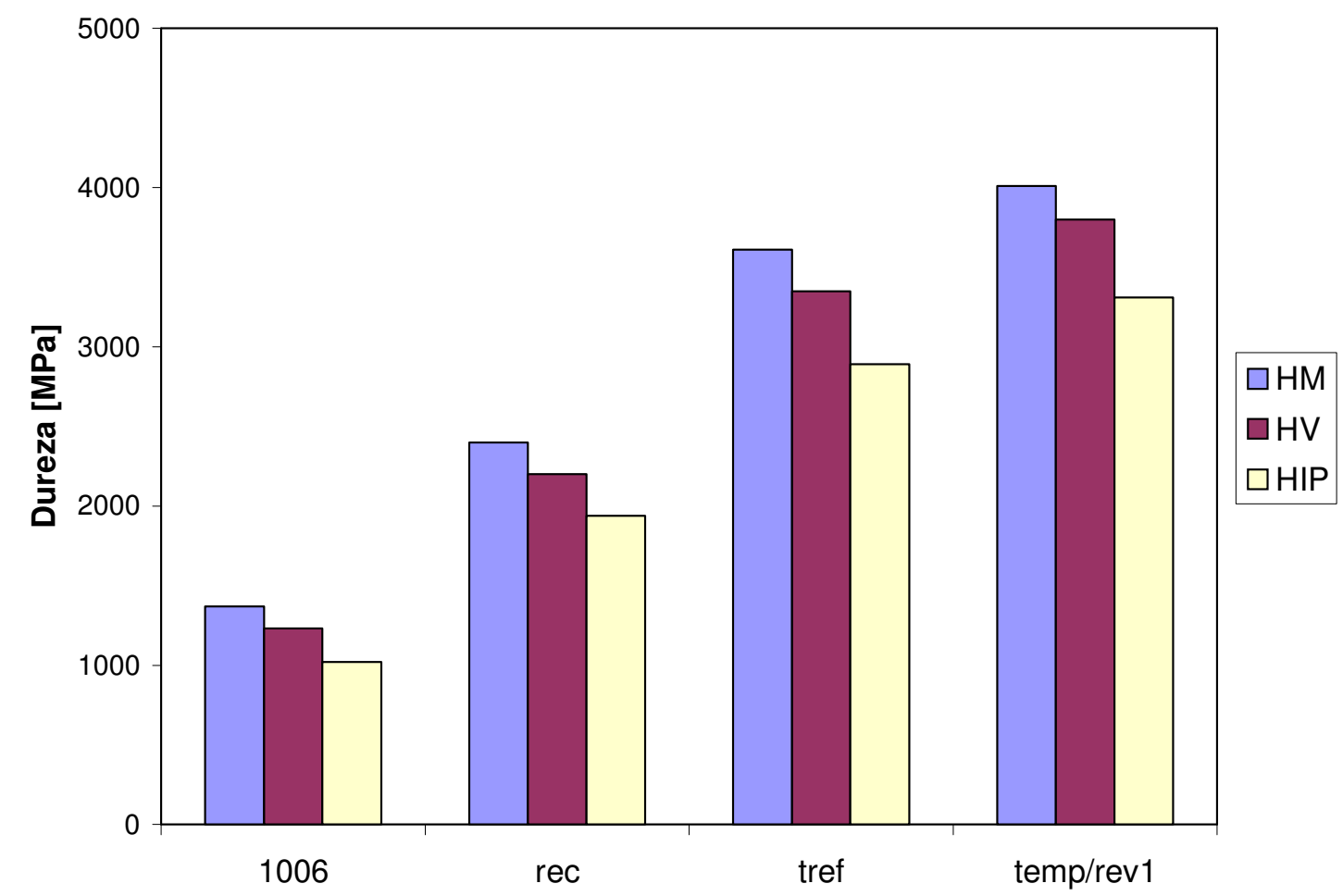

Figura 5.42. Valores de dureza HM, HV e $\mathrm{H}_{\text {IP }}$ [MPa] dos aços AISI 1006 e AISI 52100, para a condição de ensaio relativa à lixa de vidro grana \#240. 
As considerações feitas para a Figura 5.41 continuam sendo válidas no caso da Figura 5.42, com a ressalva de que neste caso os valores de dureza Martens são um pouco maiores que os valores de dureza convencional para todos os materiais.

\subsubsection{Rigidez de contato e módulo elástico reduzido}

A Tabela 5.22 apresenta os valores de rigidez de contato e de módulo elástico reduzido.

Tabela 5.22 - Rigidez de contato $S$ [MN/m] e módulo elástico reduzido $E_{r}$ [GPa] dos materiais estudados, sob as condições nas quais se observou perda de massa.

\begin{tabular}{|c|rr|cc|}
\hline \multirow{2}{*}{ Material } & \multicolumn{3}{|c|}{$\mathrm{S}$} & \multicolumn{2}{c|}{$\mathrm{E}_{\mathrm{r}}\left[=(\alpha . S) /\left(5,65 . \mathrm{h}_{\text {máx }}\right)\right]$} \\
\cline { 2 - 5 } & Lixa \#80 & Lixa \#240 & Lixa \#80 & Lixa \#240 \\
\hline AISI1006 & $3,3 \pm 0,2$ & $2,2 \pm 0,2$ & $160 \pm 10$ & $150 \pm 10$ \\
AISI 52100 recozido & $2,99 \pm 0,03$ & $1,80 \pm 0,07$ & $158 \pm 2$ & $172 \pm 7$ \\
AISI 52100 trefilado & $2,24 \pm 0,07$ & $1,40 \pm 0,04$ & $125 \pm 4$ & $145 \pm 3$ \\
AISI 52100 temp. e rev.1 & $2,86 \pm 0,04$ & $1,42 \pm 0,04$ & $153 \pm 3$ & $146 \pm 3$ \\
AISI 52100 temp. e rev.2 & $2,68 \pm 0,03$ & & $189 \pm 2$ & \\
Ferro fundido branco & $1,75 \pm 0,08$ & & $190 \pm 10$ & \\
\hline
\end{tabular}

Os valores de rigidez de contato $\mathrm{S}$ são bastante afetados pela profundidade de penetração selecionada. Apesar disso, os valores de módulo elástico reduzido são razoavelmente constantes, o que se verifica mediante a comparação dos valores médios de módulo elástico para os aços ensaiados com lixa de vidro grana \#80 (157 GPa) e os ensaiados com lixa de vidro grana \#240 (153 GPa). 
A Figura 5.43 apresenta o aspecto dos grãos de vidro utilizados nos ensaios de dureza.

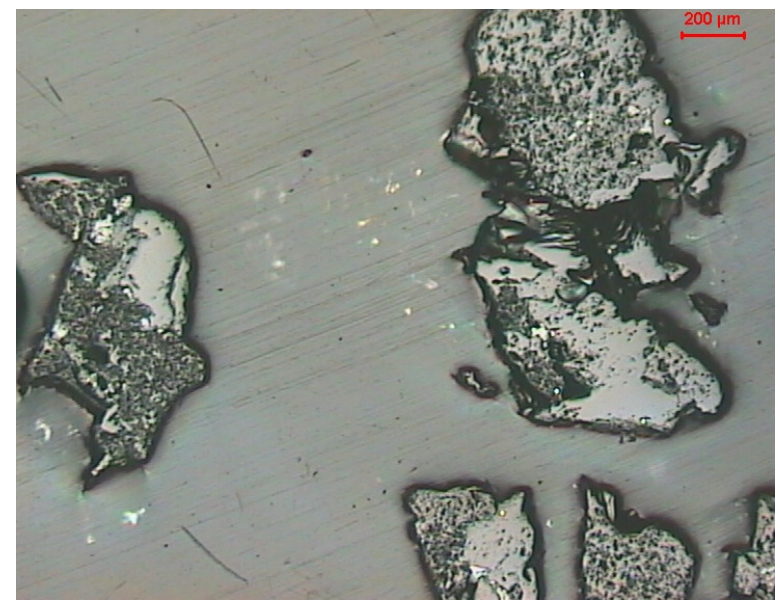

Figura 5.43. Aspecto dos grãos de vidro grana \#36 embutidos em resina a frio para os ensaios de dureza.

A Tabela 5.23 apresenta os resultados de dureza e de módulo elástico obtidos para o vidro.

Tabela 5.23 - Dureza Martens [MPa], dureza sob carregamento [MPa], dureza Vickers convencional [MPa], "indentation hardness" [MPa], dureza verdadeira [MPa], fator $\alpha$ e módulo elástico reduzido [GPa] obtidos para o vidro.

\begin{tabular}{|c|c|}
\hline Dureza Martens $(\mathrm{HM})$ & $3.250 \pm 150$ \\
\hline Dureza sob carregamento $\left(\mathrm{HM}_{\mathrm{S}}\right)$ & $2.000 \pm 100$ \\
\hline Dureza Vickers convencional $(\mathrm{HV}) *$ & $5.500 \pm 100$ \\
\hline "Indentation hardness" $\left(\mathrm{H}_{\mathrm{IT}}\right)$ & $6.100 \pm 100$ \\
\hline Fator $\alpha *$ & 1,57 \\
\hline $\mathrm{h}_{\mathrm{P}} / \mathrm{h}_{\text {máx }}$ & 0,45 \\
\hline Dureza verdadeira $\left(\mathrm{H}_{\mathrm{IP}}\right)$ & $8.600 \pm 400$ \\
\hline Módulo elástico reduzido & $59 \pm 4$ \\
\hline
\end{tabular}

*valores calculados com correção da diagonal de impressão determinada no equipamento MICROMET 2103 com 0,98 N, em função da diferença com a medida da diagonal de impressão gerada no equipamento FISCHERSCOPE H100V com $1 \mathrm{~N}$. 
A Tabela 5.23 apresenta um valor de $\alpha$ maior que 1, o que segundo ZENG e colaboradores (1996) evidencia a retração do volume de impressão de dureza, como verificado pela literatura para o vidro (COOK; PHARR, 1990). Além disso, a razão $\left(h_{P} / h_{\text {máx }}\right)$ foi menor que 0,875 , o que está de acordo com o postulado por SURESH; GIANNAKOPOULOS (1999) para esta morfologia de impressão.

A comparação entre os valores de dureza $\mathrm{HM}$, dureza $\mathrm{H}_{\mathrm{IP}}$ e dureza $\mathrm{HV}$ para o vidro está apresentada na Figura 5.44.

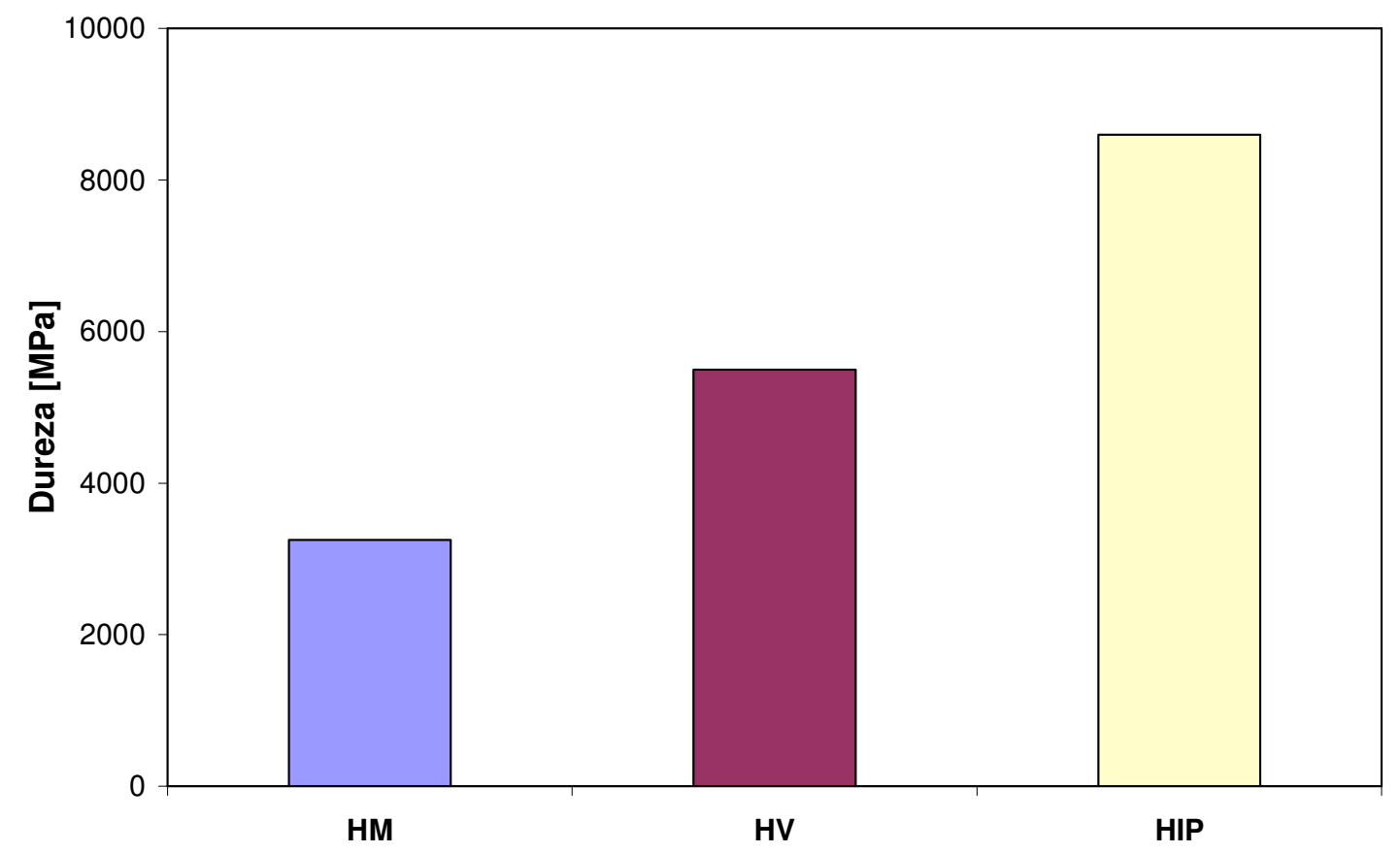

Figura 5.44. Valores de dureza HM, HV e $\mathrm{H}_{I P}[\mathrm{MPa}]$ do vidro.

A Figura 5.44 mostra que o valor de dureza $\mathrm{H}_{\mathrm{IP}}$ do vidro foi significativamente maior que os valores de dureza nas escalas Vickers convencional e Martens. Este resultado decorre da extensão da zona plástica ser reduzida nos casos em que há retração do volume de impressão de dureza, o que ocorre para materiais como o vidro. 
Além disso, diferentemente do observado para os aços (Figuras 5.41 e 5.42), o valor de dureza Martens foi bem inferior ao de dureza convencional. Isto significa que, após a retirada da força, a impressão de dureza no material deixou de refletir a geometria do penetrador Vickers, devido a grande recuperação elástica na profundidade de penetração (parcela de trabalho elástico de $63 \pm 1 \%$ ).

\subsubsection{Conseqüências dos resultados de dureza para a análise dos regimes de desgaste abrasivo}

\subsubsection{Ensaios com lixa de vidro grana \#80}

Os resultados experimentais de resistência ao desgaste, coeficiente de atrito e força de penetração dos grãos abrasivos mostraram, por exemplo, que o aço AISI 1006 desgastou sob regime severo e que o ferro fundido branco desgastou sob regime moderado. Por sua vez, o aço AISI 52100 temperado e revenido a $500{ }^{\circ} \mathrm{C}$ por $90 \mathrm{~min}$ está num regime de transição entre os regimes moderado e severo. As evidências experimentais para o aço AISI 52100 temperado e revenido a $500{ }^{\circ} \mathrm{C}$ por 90 min foram:

- a resistência ao desgaste relativa 3,4 vezes maior que a do material de dureza de engenharia apenas $20 \%$ menor (AISI 52100 temperado e revenido $500{ }^{\circ} \mathrm{C} / 24 \mathrm{~h}$ );

- o mecanismo de desgaste por delaminação, relacionado com a nucleação e com a propagação de trincas subsuperficiais, em um processo que se assemelha com a fadiga de baixo ciclo, ou seja, com o acúmulo de danos na superfície. Este tipo de mecanismo está associado com o regime de transição e com baixas razões entre a dureza do abrasivo e a dureza do material desgastado $\left(\mathrm{H}_{\mathrm{A}} / \mathrm{H}\right)$ (LARSSENBASSE, 1983); 
- o tamanho do abrasivo não afetou os valores de coeficiente de atrito, o que foi verificado para o aço AISI 52100 bruto de têmpera, material que foi claramente desgastado em regime moderado e;

- a força de penetração deixou de crescer com o aumento da dureza, a partir do valor relativo deste material, o que também ocorreu para o ferro fundido branco de alto cromo, que possui carbonetos com elevada dureza.

Portanto, serão apresentadas as razões entre a dureza do vidro $\left(\mathrm{H}_{\mathrm{A}}\right)$, determinadas sob 5 diferentes formas, com a dureza do aço AISI 52100 temperado e revenido a $500{ }^{\circ} \mathrm{C}$ por $90 \min (\mathrm{H})$, considerando que esta razão corresponda ao início do regime severo de desgaste ( $\mathrm{K}_{2}$, segundo Figura 1.2; KRUSCHOV, 1957). Estas razões estão apresentadas na Tabela 5.24.

Tabela 5.24 - Razões entre a dureza do abrasivo (vidro, $\mathrm{H}_{\mathrm{A}}$ ) e a dureza do material ensaiado (H, aço AISI 52100 temperado e revenido $500^{\circ} \mathrm{C} / 90 \mathrm{~min}$ ), considerando as durezas: Martens $(\mathrm{HM})$, sob carregamento $\left(\mathrm{HM}_{\mathbf{S}}\right)$, Vickers convencional $(\mathrm{HV})$, "indentation hardness" $\left(\mathrm{H}_{\mathrm{IT}}\right)$ e verdadeira $\left(\mathrm{H}_{\mathrm{IP}}\right)$.

\begin{tabular}{cc}
\hline Dureza & Razão $\mathbf{H}_{\mathbf{A}} / \mathbf{H}$ \\
\hline Sob carregamento $\left(\mathrm{HM}_{\mathrm{S}}\right)$ & $2.000 / 3.000=0,67$ \\
Martens $(\mathrm{HM})$ & $3.250 / 4.560=0,71$ \\
Vickers convencional $(\mathrm{HV})$ & $5.500 / 4.550=1,21$ \\
"Indentation hardness" $\left(\mathrm{H}_{\mathrm{IT}}\right)$ & $6.100 / 4.810=1,27$ \\
Verdadeira $\left(\mathrm{H}_{\mathrm{IP}}\right)$ & $8.600 / 4.210=2,04$ \\
\hline
\end{tabular}


A Tabela 5.24 mostra que a razão $\mathrm{H}_{\mathrm{A}} / \mathrm{H}$ foi 1,21 quando considerada a dureza Vickers convencional. Este valor é o usual reportado pela literatura para a transição entre regimes de desgaste (RICHARDSON, 1968 e HUTCHINGS, 1992). Embora este valor possa ser utilizado para a previsão da transição entre regimes moderado e severo de desgaste, não está incorporado o tipo de comportamento mecânico dos materiais quando submetidos a ensaios de dureza, expresso pela morfologia de impressão. Portanto, o significado físico deste tipo de dureza não é claro suficiente para que seja estendido aos fenômenos que ocorrem durante um processo de desgaste abrasivo.

A dureza denominada "indentation hardness", $\mathrm{H}_{\mathrm{IT}}$, calculada a partir da metodologia proposta por OLIVER; PHARR (1992) e adotada pela ISO/FDIS 14577-1 (ISO, 2002), mostra uma razão $\mathrm{H}_{\mathrm{A}} / \mathrm{H}$ próxima do valor obtido com a dureza convencional. O conceito físico utilizado para o cálculo esta dureza semelhante ao da dureza convencional, desprezando os efeitos da morfologia de impressão, o que justifica os valores de $\mathrm{H}_{\mathrm{A}} / \mathrm{H}$ terem sido semelhantes. A dureza $\mathrm{H}_{\mathrm{IT}}$ expressa bem apenas os casos em que se verifica retração do volume de impressão de dureza, o que dificilmente é verificado no desgaste abrasivo controlado por deformação plástica.

As razões $\mathrm{H}_{\mathrm{A}} / \mathrm{H}$ obtidas com a dureza Martens e com a dureza $\mathrm{HM}_{\mathrm{S}}$ ficaram em torno de 0,7 . Estes tipos de dureza consideram a parcela elástica envolvida durante a aplicação da força, que é consideravelmente maior no caso do vidro do que no caso do aço, fazendo com que a razão $\mathrm{H}_{\mathrm{A}} / \mathrm{H}$ se torne menor que 1,2. Embora a dureza Martens seja mais adequada que a dureza convencional nos casos de formação de bordas, o mesmo não pode se dizer no caso de retração, pois a área de contato utilizada neste caso será maior do que a extensão da zona plástica, justificando a grande diferença entre os valores de dureza $\mathrm{H}_{M}$ e $\mathrm{H}_{\mathrm{IP}}$ para o vidro, conforme apresentado na Figura 5.44. Estes 
motivos fazem com que este tipo de dureza não consiga expressar o comportamento do abrasivo durante o ensaio de dureza e também durante o processo de desgaste.

Por fim, a razão $\mathrm{H}_{\mathrm{A}} / \mathrm{H}$ considerando-se as durezas $\mathrm{H}_{\mathrm{IP}}$ dos materiais desgastados e do abrasivo vidro, ou seja, aquela na qual estão incorporados os efeitos da morfologia de impressão, é aproximadamente 2, valor maior que o usual para prever a transição entre os regimes de desgaste abrasivo. Esta metodologia para o cálculo da dureza permite visualizar de forma mais adequada a transição entre os regimes moderado e severo de desgaste abrasivo. A razão para isto é que este método de cálculo de dureza possibilita uma menor discrepância entre a área de contato 'penetrador / material ensaiado' e a área correspondente à zona plástica, que as demais formas de dureza abordadas neste trabalho.

Um possível refinamento do valor da razão $\mathrm{H}_{\mathrm{A}} / \mathrm{H}$ correspondente à transição entre regimes de desgaste, calculada com a dureza $H_{I P}$, pode ser conseguido ao se incorporar a extensão de zona plástica, c/a, ou seja, o contorno elasto-plástico formado durante o contato entre o penetrador de dureza (ou o abrasivo) e o material ensaiado.

Supondo-se que esta extensão seja proporcional à área de contato que suporta a força, pode-se entender que uma estimativa desta área seja por meio da razão (c/a $)^{2}$. Além disso, esta razão pode ser estimada por meio de uma combinação entre a dureza $\mathrm{H}_{\mathrm{IP}}$ e o módulo elástico reduzido, conforme proposto por LAWN e colaboradores (1980). Os resultados experimentais obtidos por estes pesquisadores mostraram que a razão c/a é proporcional à (E/H) $)^{0,41}$ (Figura 2.27). 
A razão $H_{\mathrm{A}} / \mathrm{H}$, incorporando a extensão da zona plástica, pode ser calculada por meio da seguinte relação:

$$
\frac{H_{A}}{H} \propto\left[\frac{(c / a)_{\text {aço }}^{2}}{(c / a)_{\text {vidro }}^{2}}\right] \propto\left[\frac{(E / H)_{\text {aço }}^{0,82}}{(E / H)_{\text {vidro }} 0,82}\right]=\left[\frac{E_{\text {aço }}}{E_{\text {vidro }}} \frac{H_{\text {vidro }}}{H_{\text {aço }}}\right]^{0,82}
$$

O valor de módulo elástico reduzido a ser aplicado será o conceito aqui introduzido de módulo elástico reduzido de desgaste, $\mathrm{E}_{\mathrm{rd}}$, que é uma combinação entre o módulo reduzido do abrasivo e o módulo reduzido do material desgastado, como mostra a equação 5.3:

$$
\frac{1}{E_{r d}}=\left(\frac{1}{E_{r}{ }^{\text {vidro }}}+\frac{1}{E_{r}^{a c ̧ o}}\right)-2 \frac{\left(1-v_{i}^{2}\right)}{E_{i}}
$$

onde,

$\mathrm{E}_{\mathrm{rd}}$ é o módulo elástico reduzido do sistema de desgaste [GPa];

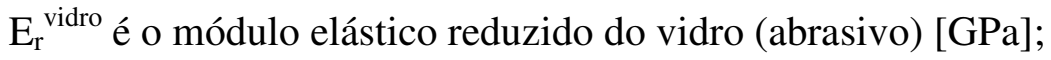

$\mathrm{E}_{\mathrm{r}}^{\text {aço }}$ é o módulo elástico reduzido do aço (material a ser desgastado) [GPa]; e

Ei é o módulo do penetrador de diamante $\left[11,4\right.$ x $\left.10^{7} \mathrm{GPa}\right]$.

Considerando a equação 5.3 e os valores de módulo elástico reduzido apresentados nas Tabelas 5.22 e 5.23, os valores de módulo reduzido de desgaste para a condição de ensaio relativa à lixa grana \#80 estão apresentados na Tabela 5.25. 
Tabela 5.25 - Módulo elástico reduzido de desgaste $\left(\mathbf{E}_{\mathrm{rd}}\right)[\mathrm{GPa}]$ para a condição de ensaio relativa à lixa grana $\# 80$.

\begin{tabular}{cc}
\hline Material & $\mathrm{E}_{\mathrm{rd}}$ \\
\hline AISI 1006 & 43 \\
AISI 52100 recozido & 43 \\
AISI 52100 trefilado & 40 \\
AISI 52100 temperado e revenido 1 & 43 \\
AISI 52100 temperado e revenido 2 & 45 \\
Ferro fundido branco & 45 \\
\hline
\end{tabular}

A Tabela 5.25 mostra que os valores do módulo elástico reduzido de desgaste são semelhantes para todos os materiais ensaiados, ou seja, o valor de módulo reduzido do abrasivo é determinante para o valor desta propriedade de sistema, o que justifica a pouca dependência dos valores com a dureza dos materiais. Dessa forma, os valores de $E_{\text {aço }}$ e $E_{\text {vidro }}$ a serem aplicados na equação 5.2 são os mesmos, ou seja, o valor do módulo elástico reduzido do sistema de desgaste. Isto faz com que a equação 5.2 passe a ser escrita como a equação 5.4:

$\frac{H_{A}}{H} \propto\left[\frac{H_{\text {vidro }}}{H_{\text {aço }}}\right]^{0,82}$

Equação 5.4

A simplificação da equação 5.2, representada pela equação 5.4, pode não ocorrer dependendo dos pares do sistema tribológico.

A aplicação da equação 5.4 ao valor $\mathrm{H}_{\mathrm{A}} / \mathrm{H}$ apresentado na Tabela 5.24, calculado com a dureza $\mathrm{H}_{\mathrm{IP}}$, resulta em um valor de 1,8. Em resumo, este valor decorre dos seguintes conceitos: 
- a dureza verdadeira $H_{I P}$, que considera os efeitos de morfologia de impressão de dureza, formação de bordas e retração;

- o módulo elástico reduzido do sistema de desgaste, que considera a interação elástica entre abrasivo e material desgastado, isolando o efeito do penetrador de dureza de diamante, por ter propriedades muito diferentes das do abrasivo e;

- a extensão da zona plástica formada corresponder à área de contato entre abrasivo e material desgastado que suporta a força;

possibilitando obter um valor de razão $\mathrm{H}_{\mathrm{A}} / \mathrm{H}$ com significado físico, expressando o comportamento mecânico dos materiais durante o estado de tensões e de deformações existentes em um ensaio de dureza e em um sistema abrasivo.

\subsubsection{Ensaios com lixa de vidro grana \#240}

Os resultados de taxas e mecanismos de desgaste apresentados no item 5.2.1.4 mostraram que o tamanho do abrasivo exerce um efeito significativo na transição entre os regimes de desgaste moderado e severo. Considerando que a condição de ensaio relativa ao aço AISI 52100 temperado e revenido $500{ }^{\circ} \mathrm{C} / 24 \mathrm{~h}$ ensaiado com a lixa de vidro grana \#240 representa uma transição entre os mecanismos de desgaste, a Tabela 5.26 apresenta as razões $\mathrm{H}_{\mathrm{A}} / \mathrm{H}$ calculadas para esta condição, segundo três métodos de determinação de dureza. 
Tabela 5.26 - Razões entre a dureza do abrasivo (vidro, $\mathrm{H}_{\mathrm{A}}$ ) e a dureza do material ensaiado (H, aço AISI 52100 temperado e revenido $500{ }^{\circ} \mathrm{C} / 24 \mathrm{~h}$ ), considerando as durezas Vickers convencional $(\mathrm{HV})$ e verdadeira $\left(\mathrm{H}_{\mathrm{IP}}\right)$.

\begin{tabular}{cc}
\hline Dureza & Razão $\mathbf{H}_{\mathbf{A}} / \mathbf{H}$ \\
\hline Vickers convencional $(\mathrm{HV})$ & $5.500 / 3.800=1,45$ \\
Verdadeira $\left(\mathrm{H}_{\mathrm{IP}}\right)$ & $8.600 / 3.310=2,6$ \\
Verdadeira $\left(\mathrm{H}_{\mathrm{IP}}\right)^{0,82}$ & $(2,6)^{0,82}=2,2$ \\
\hline
\end{tabular}

A comparação entre os valores da Tabela 5.26 com os apresentados na Tabela 5.24 mostra que as razões $\mathrm{H}_{\mathrm{A}} / \mathrm{H}$ que indicam o início da transição entre os mecanismos são maiores para sistemas com abrasivos menores, para todos os tipos de dureza apresentados. Este resultado era esperado, pois as taxas de desgaste são reduzidas à medida que o tamanho dos abrasivos diminui, provavelmente em intensidades diferentes dependendo do regime e, portanto, a transição entre os mecanismos de desgaste deve ocorrer em torno de um valor $\mathrm{H}_{\mathrm{A}} / \mathrm{H}$ diferente do que ocorre em sistemas com abrasivos maiores. Esta situação foi prevista por PINTAÚDE e colaboradores (2001), que obtiveram os resultados apresentados na Figura 5.45.

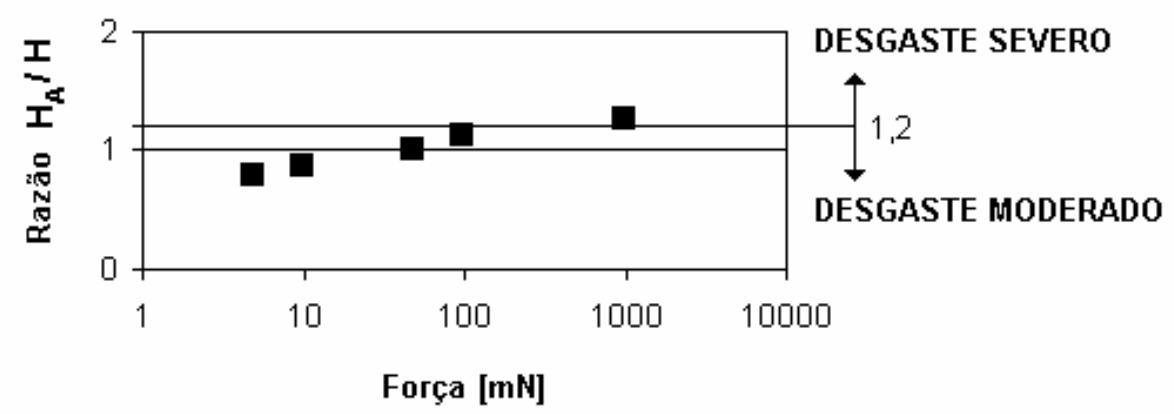

$H_{A}=$ dureza do vidro
$H=$ dureza do aço carbono baixa lig̣a

Figura 5.45. Variação da razão $H_{\Lambda} / H$, calculada segundo a dureza $H_{I T}$, com a força de ensaio de dureza (PINTAÚDE e colaboradores, 2001). 
A Figura 5.45 mostra que para um mesmo par 'abrasivo / material desgastado' existe mais de um valor para a razão $\mathrm{H}_{\mathrm{A}} / \mathrm{H}$, ou ainda, considerando o valor 1,2 como aquele que descreve a transição entre os regimes de desgaste (apresentado para a dureza $\mathrm{H}_{\mathrm{IT}}$ na Tabela 5.24), um mesmo par poderia ora estar sob regime moderado, ora sob regime severo, o que seria devido ao tamanho do abrasivo, expresso pela força aplicada no ensaio de dureza. 


\section{CONCLUSÕES}

As principais conclusões deste trabalho são:

$\underline{\text { Sobre o regime severo de desgaste abrasivo: }}$

1. A resistência ao desgaste variou proporcionalmente com a dureza para os aços AISI 1006 e AISI 52100 recozido.

2. Observa-se a predominância do mecanismo de microcorte.

3. Os valores de resistência ao desgaste relativa não dependem do tamanho do abrasivo.

4. Os valores de coeficiente de atrito diminuem com o aumento da dureza.

5. Os valores de coeficiente de atrito são dependentes do tamanho do abrasivo.

6. O encruamento da superfície afeta os valores de coeficiente de atrito.

7. A força de penetração dos abrasivos aumenta com a dureza dos materiais, de forma mais intensa para as superfícies desgastadas pelo abrasivo de maior tamanho.

$\underline{\text { Sobre o regime moderado de desgaste abrasivo: }}$ 
1. As taxas de desgaste não puderam ser quantificadas, sendo consideradas nulas para o aço AISI 52100 nas condições bruto de têmpera e 'temperado e revenido a $500{ }^{\circ} \mathrm{C}$ por 90 min' e para o ferro fundido branco de alto cromo.

2. Os valores de coeficiente de atrito são pouco afetados pela dureza dos materiais.

3. Os valores de coeficiente de atrito são independentes do tamanho do abrasivo.

4. O tamanho do abrasivo não determina a intensidade do encruamento da superfície desgastada.

5. Observa-se a fragmentação dos grãos de vidro e a deterioração da estrutura da lixa abrasiva.

6. A força de penetração dos abrasivos não aumenta com a dureza dos materiais.

\section{$\underline{\text { Sobre o regime de transição de desgaste abrasivo: }}$}

1. A resistência ao desgaste relativa não varia de forma proporcional com a dureza, por exemplo, aumenta 3,4 vezes para uma variação de dureza de apenas $20 \%$.

2. Observam-se os mecanismos de microssulcamento e de delaminação.

3. Os valores de resistência ao desgaste relativa dependem do tamanho do abrasivo, podendo ser complementados pelos resultados de RICHARDSON (1968), nos quais se verifica que esta dependência se acentua à medida que a dureza dos materiais aumenta.

4. O tamanho do abrasivo modifica a relação entre dureza do abrasivo e a dureza do material desgastado que indica o início da transição entre regimes moderado e severo de desgaste. 
$\underline{\text { Sobre o efeito de segunda fase dura nos mecanismos e nas taxas de desgaste: }}$

1. A dureza dos carbonetos eutéticos $\mathrm{M}_{7} \mathrm{C}_{3}$ modifica a atuação de um abrasivo como o vidro, diminuindo a ação do mecanismo de microcorte.

2. Pode-se observar o microtrincamento dos carbonetos eutéticos $M_{7} C_{3}$, embora este mecanismo não foi determinante para os valores de taxa de desgaste.

3. A dureza dos carbonetos eutéticos $\mathrm{M}_{7} \mathrm{C}_{3}$ leva a um desempenho do ferro fundido branco de alto cromo de matriz perlítica semelhante à de um aço com alto teor de carbono tratado termicamente para uma dureza elevada.

A Figura 6.1 apresenta um resumo das principais conclusões desta Tese, considerando a variação da perda volumétrica com a razão $\mathrm{H}_{\mathrm{A}} / \mathrm{H}$, proposta por KRUSCHOV (1957). 


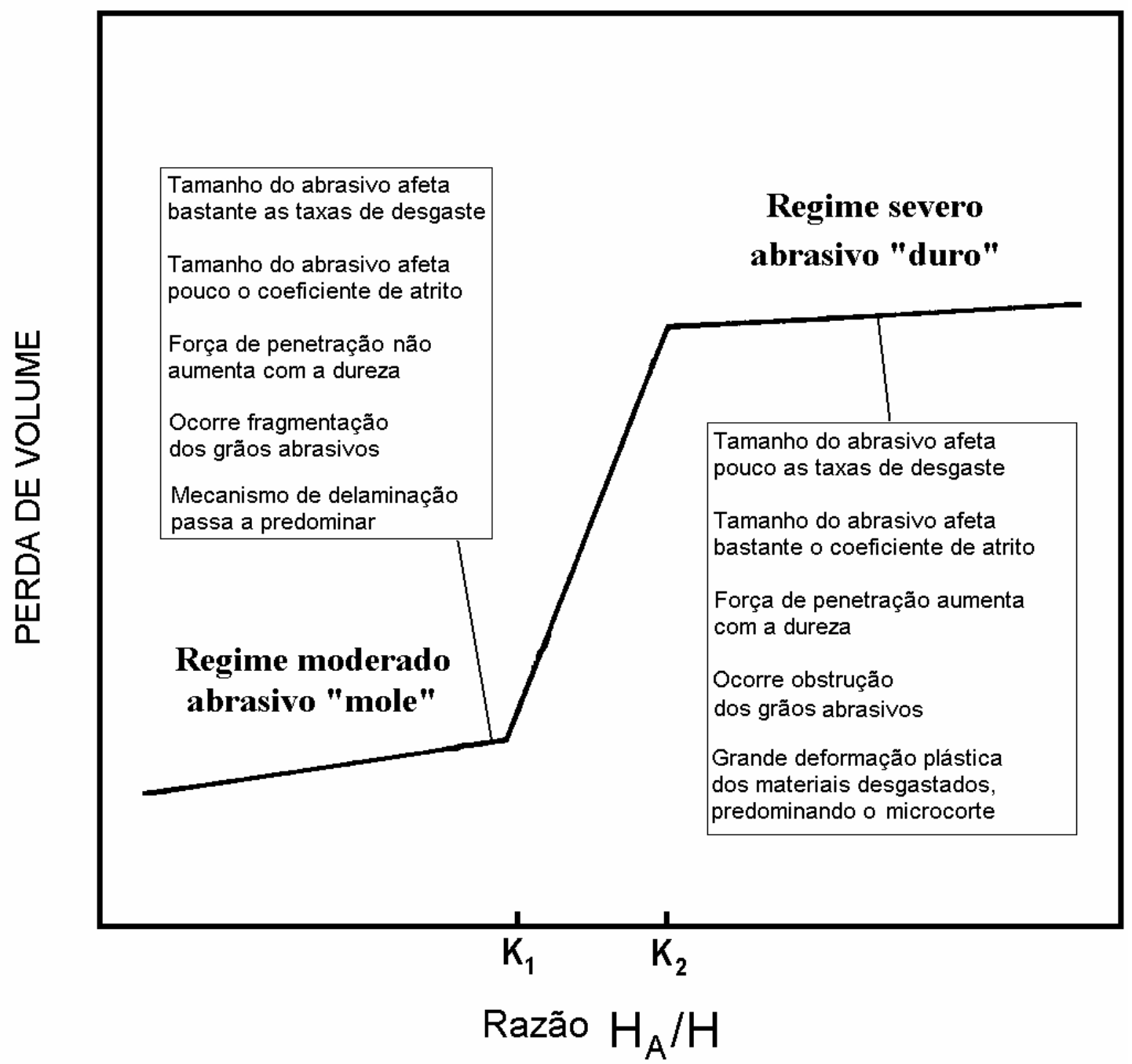

Figura 6.1. Quadro resumo das conclusões da Tese, considerando os regimes moderado e severo de desgaste abrasivo, segundo o modelo de KRUSCHOV (1957).

A partir do estudo do comportamento mecânico dos materiais submetidos a ensaios de dureza, concluiu-se que:

$\underline{\text { Sobre o fator } \alpha \text { para a previsão da morfologia de impressão de dureza: }}$

1. A proposta de ZENG e colaboradores (1996) para a previsão das morfologias de impressão de dureza se aplicou tanto aos materiais que apresentaram formação de bordas 
( $\alpha>1$, materiais metálicos) quanto para os materiais que apresentaram retração $(\alpha<1$, vidro).

2. A proposta de SURESH; GIANNAKOPOULOS (1999) para a previsão das morfologias de impressão de dureza não se aplica aos materiais que apresentaram formação de bordas.

$\underline{\text { Sobre as formas de cálculo de dureza para geometria Vickers: }}$

1. Foi proposta uma metodologia de cálculo para a dureza, incorporando os efeitos da morfologia de impressão, formação de bordas ou retração, por meio do fator $\alpha$, proposto por ZENG e colaboradores (1996).

2. Para os materiais desgastados: $\mathrm{HM} \geq \mathrm{HV}>\mathrm{H}_{\mathrm{IP}}$, demonstrando que a área que suporta a força aplicada aumenta devido à formação de bordas.

3. Para o abrasivo vidro: $\mathrm{HM}<\mathrm{HV}<\mathrm{H}_{\mathrm{IP}}$, demonstrando que a área que suporta a força aplicada diminui devido à retração.

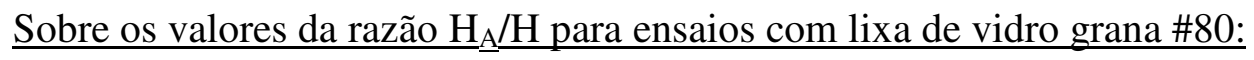

1. Mostrou-se que empregar a dureza Vickers convencional HV para indicar a transição entre os regimes de desgaste abrasivo despreza em grande parte o efeito da morfologia de impressão de dureza.

2. Os valores de dureza $\mathrm{HM}$ e $\mathrm{HM}_{\mathrm{S}}$ não expressam o comportamento mecânico do abrasivo vidro nos ensaios. 
3. Os valores de dureza $\mathrm{HV}$ e $\mathrm{H}_{\mathrm{IT}}$ não expressam o comportamento mecânico dos materiais desgastados nos ensaios.

4. Os valores de dureza $H_{I P}$ expressam o comportamento mecânico do abrasivo e dos materiais desgastados, por incorporar os efeitos da morfologia de impressão de dureza e, segundo esta dureza, o valor da razão $\mathrm{H}_{\mathrm{A}} / \mathrm{H}$ que indica a transição entre os regimes moderado e severo de desgaste abrasivo é 2.

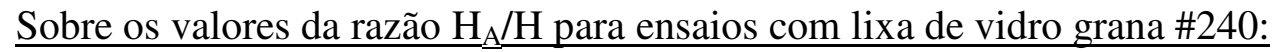

1. Os valores da razão $\mathrm{H}_{\mathrm{A}} / \mathrm{H}$ foram maiores que para os ensaios com a lixa de vidro grana \#80, para qualquer tipo de dureza, demonstrando que o tamanho do abrasivo afeta o regime de transição. 


\title{
7 SUGESTÕES PARA TRABALHOS FUTUROS
}

\author{
"From W'ear to where? The future of wear \\ research." (Painel de discussão do13th International \\ Conference on Wear of Materials, Vancouver, 24 de \\ abril de 2001)
}

1) Estudar a relação entre o nível de encruamento das superfícies desgastadas e a evolução das taxas de desgaste com o tempo de ensaio.

2) Investigar qual dureza de matriz, em materiais com segunda fase dura, impede a ocorrência do mecanismo de microtrincamento da segunda fase.

3) Estudar o efeito do tamanho do abrasivo nas taxas de desgaste e nos valores de coeficiente de atrito em outros sistemas de desgaste abrasivo, como em ensaios a três corpos, considerando os regimes moderado e severo de desgaste.

4) Estudar o efeito da lubrificação ou da presença de um lubrificante sólido nas taxas de desgaste e no coeficiente de atrito em cada um dos regimes de desgaste abrasivo, moderado e severo.

5) Verificar a aplicação do modelo para cálculo de dureza 'verdadeira' como indicador da transição entre regimes de desgaste abrasivo, estudando pares tribológicos diferentes, em especial materiais com módulo elástico distintos.

6) Estudar as morfologias de impressão de dureza com a variação dos parâmetros de ensaio de dureza para diferentes microconstituintes dos materiais.

7) Estudar a relação entre propriedades mecânicas obtidas a partir de ensaios instrumentados de dureza com as obtidas em ensaios mecânicos convencionais, como tração. 


\section{ANEXO A - Caracterização das lixas abrasivas}

Para as caracterizações realizadas nos grãos abrasivos das lixas utilizadas nos ensaios de desgaste, inicialmente se procedeu a separação dos grãos dos costados das lixas. Esta etapa foi executada pela empresa Saint-Gobain Abrasivos Industriais. Com os grãos soltos, caracterizou-se o tamanho e a composição química dos mesmos.

A caracterização de tamanho de grão das lixas abrasivas utilizadas nos ensaios de desgaste abrasivo foi realizada no equipamento Mastersize Microplus 2.19, situado no Laboratório de Caracterização Tecnológica do Departamento de Engenharia Mineral da Escola Politécnica da USP.

A composição química dos grãos foi analisada de forma qualitativa em microscopia eletrônica de varredura, após metalização com ouro, utilizando EDS, após recobrimento com carbono.

\section{A.1. TAMANHO DE GRÃO}

A Figura A.1 mostra resultados de análise de tamanho de grão da lixa grana \#80. 


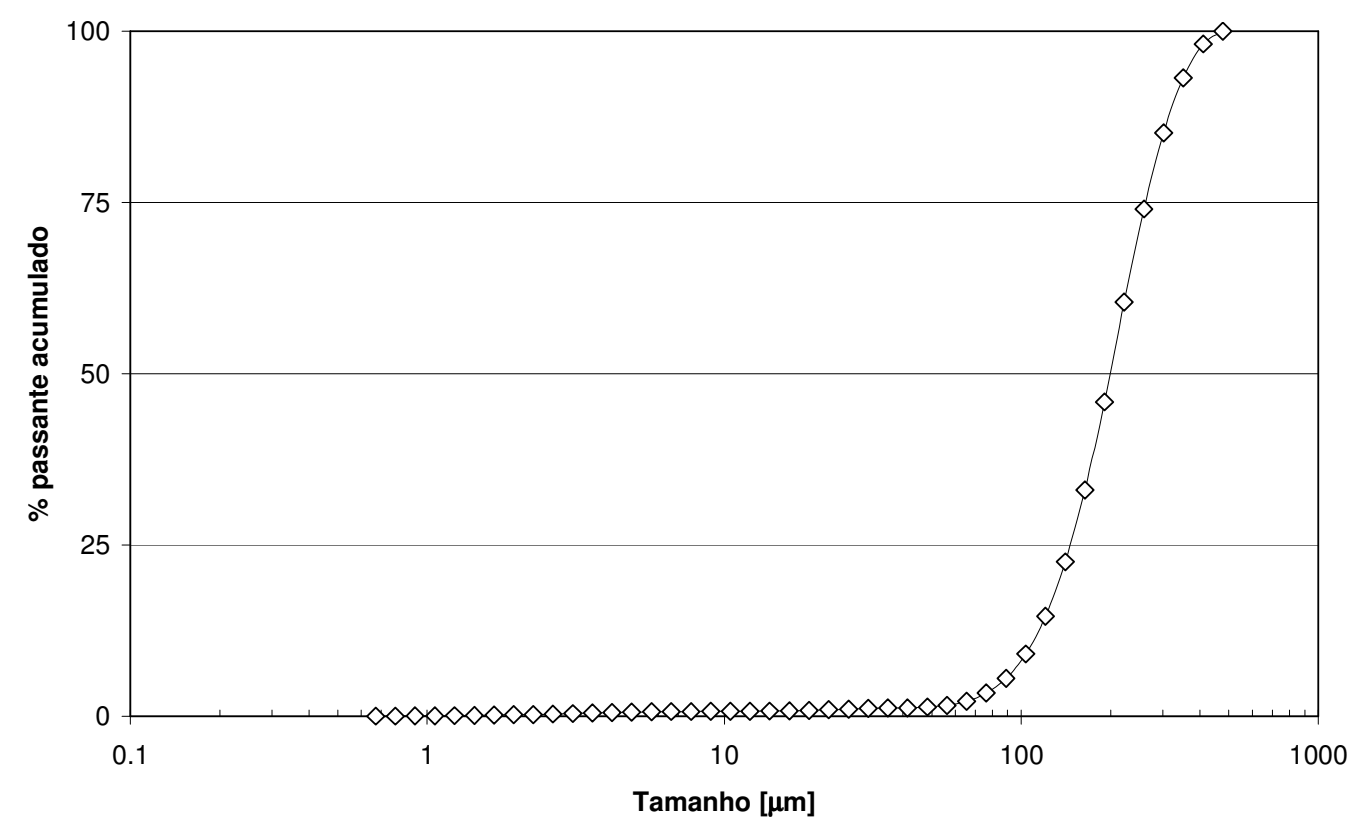

Figura A.1. \% do material passante acumulado em função do tamanho de grão da lixa grana \#80.

Um índice bastante utilizado para caracterizar tamanho médio de grão é o tamanho relativo que corresponde a $50 \%$ do total do material passante, denominado $\mathrm{d}_{50}$. Com base na Figura A.1, este índice é de aproximadamente $200 \mu \mathrm{m}$ para a lixa de grana \#80. Segundo a FEPA 43-GB-1984 R1993 ${ }^{24}$, este índice para grana \#80 deve ser de $201 \mu \mathrm{m}$, o que coincide com o valor obtido na Figura A.1.

Interessante observar as indicações do fabricante e do importador da lixa abrasiva para esta grana, como mostram as Figuras A.2 e A.3, respectivamente.

\footnotetext{
${ }^{24}$ Informações obtidas na página www.fepa-abrasives.org/public-e.htm
} 


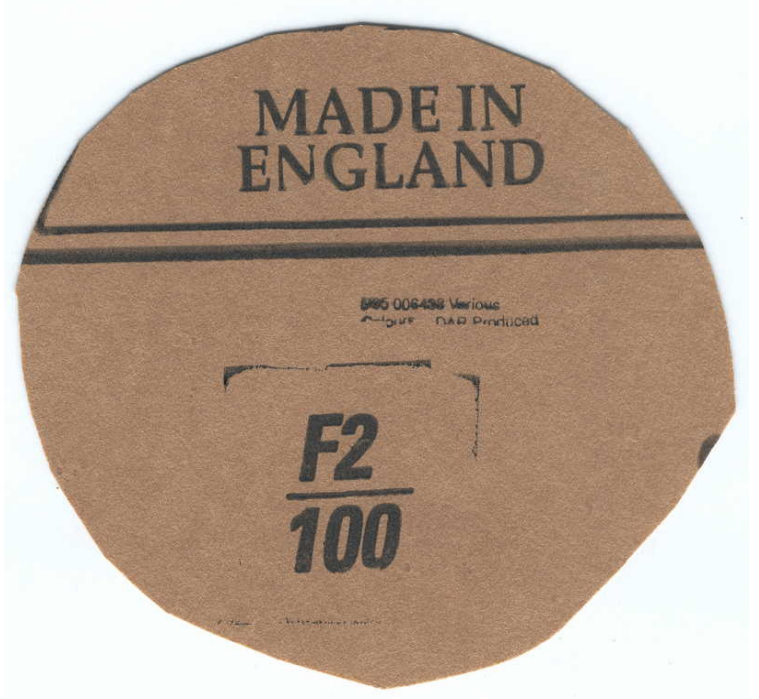

Figura A.2. Costado da lixa de grana \#80 utilizada nos ensaios de desgaste abrasivo, indicando grana segundo fabricante.

A Figura A.2 mostra o costado de papel de uma lixa já recortada para $100 \mathrm{~mm}$ de diâmetro para ensaio de desgaste abrasivo. As inscrições F2/100 indicam o código utilizado para uma grana supostamente \#100, o que foi verificado não ser verdadeiro.

A Figura A.3 mostra a etiqueta da embalagem das lixas. Segundo o importador, as mesmas correspondem a uma grana \#80, confirmada pelos resultados apresentados na Figura A.1.

\section{3-062}

1 Glass Paper $230 \times 280$

Grade F2 (80 grit)

Made in UK

||||||||||||||||

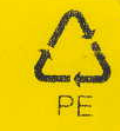

$P E$ 
Figura A.3. Etiqueta de embalagem do importador da lixa GlassPaper Premium para lixa de grana \#80.

A Figura A.4 mostra resultados de análise de tamanho de grão da lixa grana \#240.

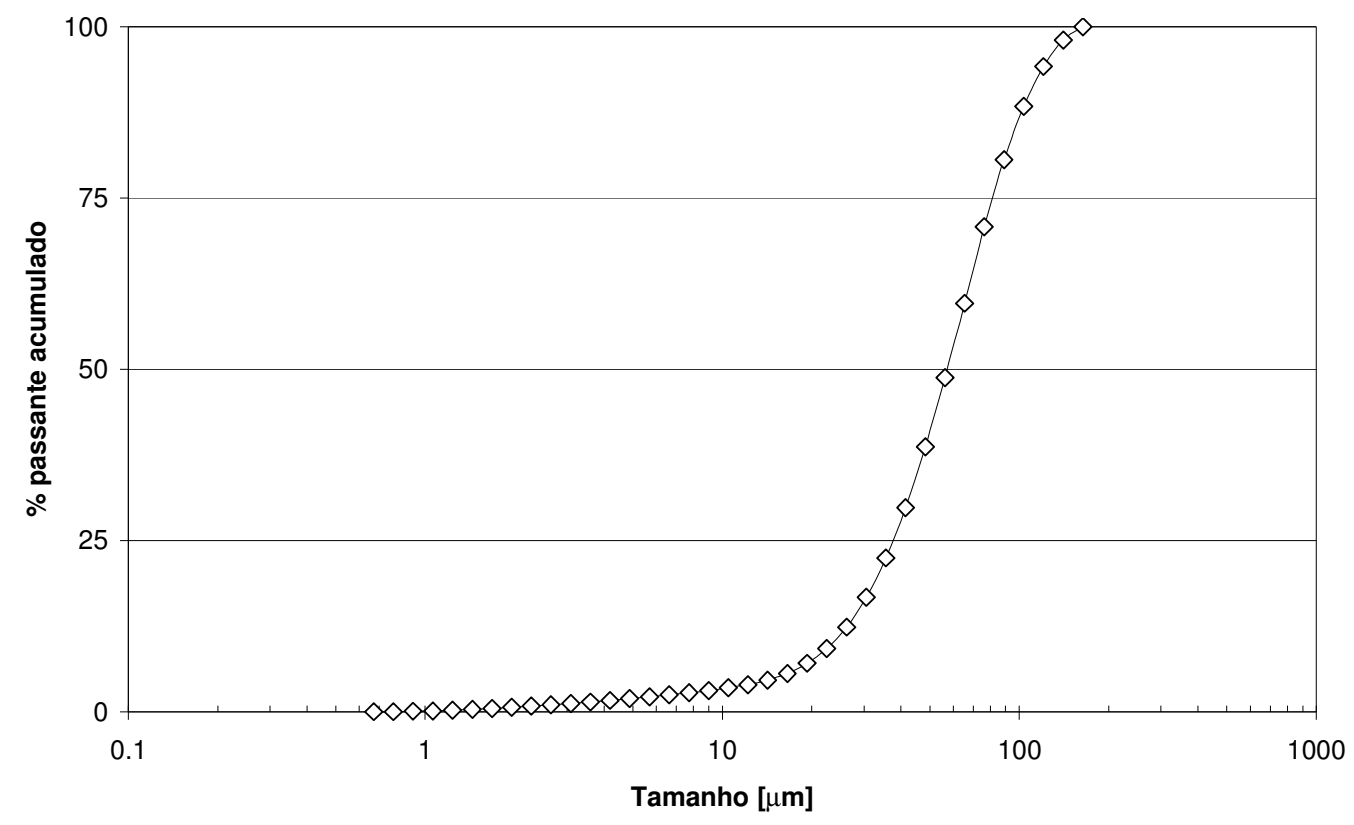

Figura A.4. \% do material passante acumulado em função do tamanho de grão da lixa grana \#240.

Com base na Figura A.4, o valor de $\mathrm{d}_{50}$ é de aproximadamente $60 \mu \mathrm{m}$ para a lixa de grana \#240. Segundo a FEPA 43-GB-1984 R1993, este índice para grana \#240 deve ser de 58,5 $\pm 2,0 \mu \mathrm{m}$, o que coincide com o valor obtido na Figura A.4. Segundo esta mesma norma, grãos classificados abaixo da grana \#220 são denominados microgrãos, e devem ser classificados não mais por peneiramento, mas sim por sedimentação, por isso indica os valores de tamanho de grão médio associado com desvio-padrão. 
Novamente é interessante observar as indicações do fabricante e do importador da lixa abrasiva para esta grana, apresentadas nas Figuras A.5 e A.6.

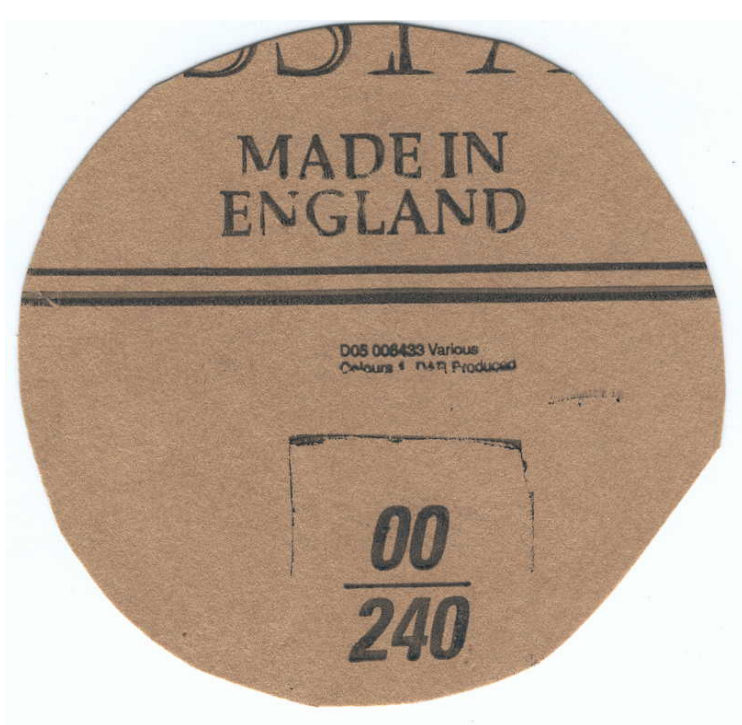

Figura A.5. Costado da lixa de grana \#240 utilizada nos ensaios de desgaste abrasivo, indicando grana segundo fabricante.

Como analisado na Figura A.5, para esta grana o fabricante indica inscrições 00/240, o que coincide com os resultados apresentados na Figura A.4.

A Figura A.6 mostra que a indicação do importador para a lixa de grana \#240 seria P180, o que remete à norma FEPA já comentada. Para esta granulometria, o tamanho médio de grão seria de $82 \mu \mathrm{m}$, muito diferente dos resultados apresentados na Figura A.4. 


\section{$762-534$}

1 Glass sheets $230 \times 280$

Grade 00 (P180)

Made in UK

'..WIII

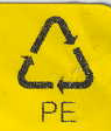

$P E$

Figura A.6. Etiqueta de embalagem do importador da lixa GlassPaper Premium para lixa de grana $\# 240$.

Um resultado foi "importado" diretamente do programa que comanda as funções relativas à determinação de tamanhos por volume, mostrando os resultados obtidos na forma de malhas de peneiras padronizadas. Com este resultado, será possível discutir, com base na Norma Brasileira NBR 11094 (ABNT, 1990) que regula a fabricação de lixas abrasivas, a adequação do material analisado às restrições impostas para a confecção de uma lixa.

A Norma Brasileira NBR 11094 foi elaborada prevendo aplicações com os abrasivos óxido de alumínio, carbureto de silício, quartzo e granada. Lixas compostas por abrasivos de quartzo ainda são fabricadas no Brasil em escala muito reduzida e lixas compostas de granada não se encontram mais no mercado nacional, bem como lixas compostas de grãos de vidro, como as que estão sendo analisadas.

A análise de tamanho de grão com relação a malhas padronizadas de peneiras está apresentada na Figura A.7. 
Result: Sieve ASTM E11:61 Table

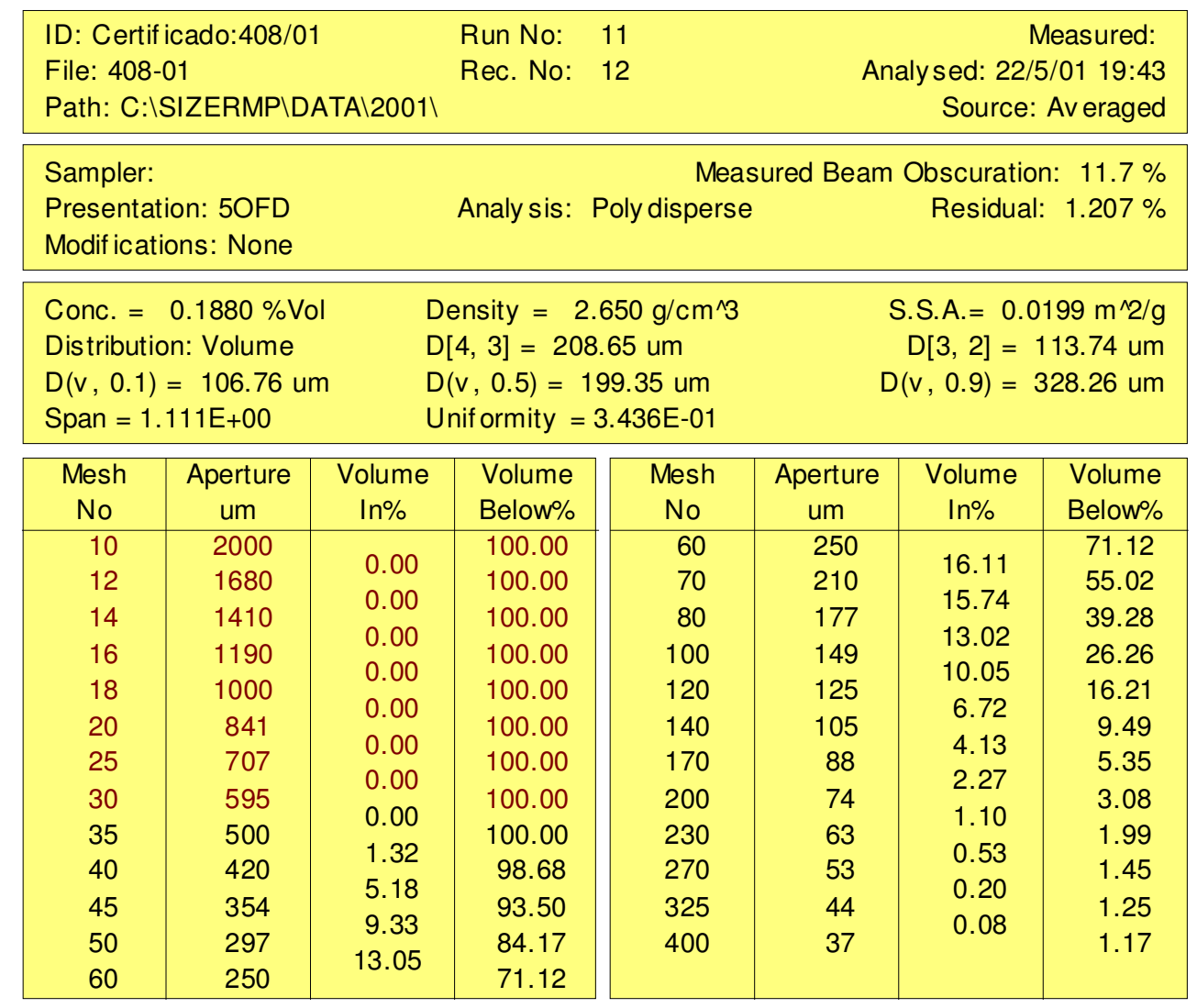

Figura A.7. Análise do tamanho de grão do vidro de grana \#80 com relação a malhas de peneiras padronizadas.

Segundo a Norma Brasileira NBR 11094 (ABNT, 1990) os grãos soltos de lixas abrasivas até grana \#220 (macrogrãos) devem ser classificados segundo 4 critérios. Os dois primeiros critérios tratam da grossura máxima dos grãos, que é avaliada por meio de peneiras através das quais 100 e $99,5 \%$ do material deve passar. O terceiro critério está relacionado com uma peneira de controle, com faixas máximas e mínimas para percentagem de material retido na mesma. Por fim, o último critério está relacionado com uma "peneira de finos", na qual há uma percentagem mínima e máxima para o material ser retido. Segundo a Norma, este último critério não é aplicado à grana \#80. 
Como os critérios citados da NBR 11094 são aplicados para macrogrãos, não é possível realizar este tipo de análise para a lixa de vidro grana \#240.

A Tabela A.1 mostra o quadro que resume as restrições para a análise da grana \#80, bem como os resultados com base na Figura A.7.

Tabela A.1 - Aplicação dos critérios da Norma NBR 11094 (ABNT, 1990) à lixa abrasiva de vidro grana \#80.

\begin{tabular}{cccc}
\hline Abertura $(\mu \mathrm{m})$ & 421 & 336 & 241 \\
\hline Restrição & $100 \%$ devem passar & $99,5 \%$ devem passar & Retido 8,4 e 14,4\% \\
Resultado & $98,68 \%$ & $93,5 \%($ com 345 $\mu \mathrm{m})$ & $13,05 \%($ com $250 \mu \mathrm{m})$ \\
\hline
\end{tabular}

Os resultados apresentados na Tabela A.1 mostram uma adequação razoável da lixa de vidro às exigências da NBR 11094, segundo os 3 critérios necessários, mesmo que o material vidro não esteja previsto como material a ser analisado segundo esta Norma. O único critério que não satisfez foi o segundo, sendo que a diferença foi de 6 pontos percentuais, utilizando uma abertura $9 \mu \mathrm{m}$ maior do que a exigida pela norma.

\section{A.2. COMPOSIÇÃO QUÍMICA}

A Figura A.8 mostra o espectro de intensidades após análise de espectrometria por dispersão de energia em microscopia eletrônica de varredura. 


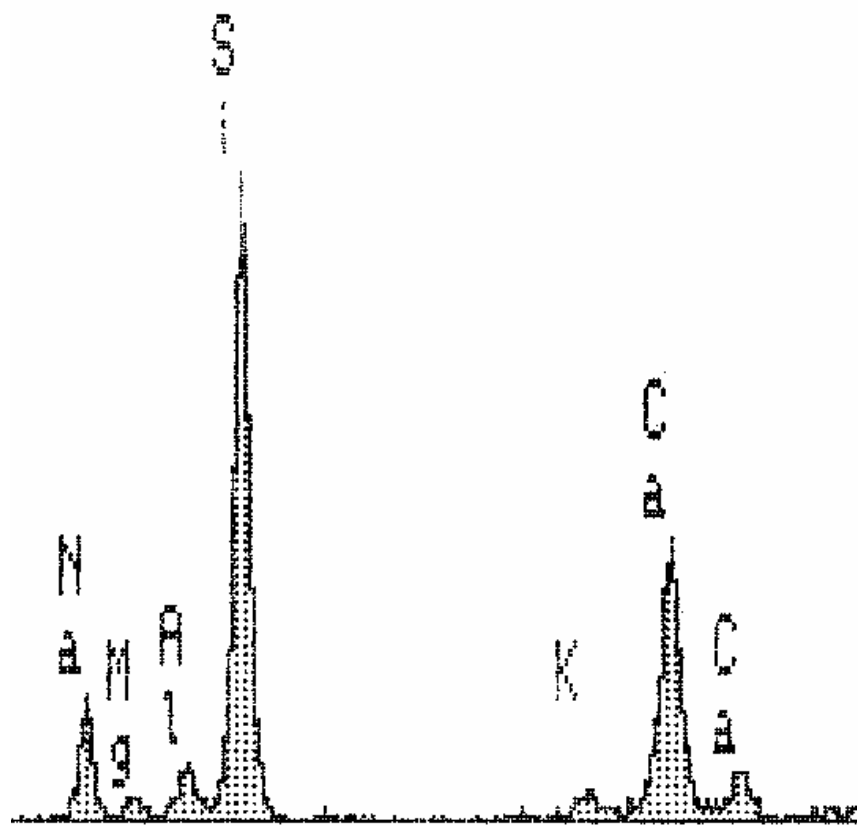

Figura A.8. Espectro de EDS dos grãos de vidro.

É possível verificar, embora de forma qualitativa, que os elementos presentes na análise são os mesmo encontrados no tipo de vidro calco-sódico, comum para aplicações como vidros de janelas. A Tabela A.2 mostra alguns exemplos de composição química usuais de vidros comerciais (VAN VLACK, 1973).

Tabela A.2 - Exemplos de composição química usuais de vidros comerciais (VAN VLACK, 1973).

Principais componentes, $\%$ em massa.

\begin{tabular}{cccccc} 
& $\mathrm{SiO}_{2}$ & $\mathrm{Al}_{2} \mathrm{O}_{3}$ & $\mathrm{CaO}$ & $\mathrm{Na}_{2} \mathrm{O}$ & $\mathrm{MgO}$ \\
\hline Pratos & 73 & 1 & 13 & 13 & - \\
Vidro de janelas & 72 & 1 & 10 & 14 & 2 \\
Bulbo de lâmpadas & 74 & 1 & 5 & 16 & 4 \\
\hline
\end{tabular}




\section{ANEXO B - Resultados individuais de perda de massa}

As Tabelas B.1 a B.10 apresentam os valores de perda de massa individuais sob regime permanente de desgaste para as condições de ensaio nas quais foi possível determinar esta perda de massa considerando a sensibilidade da balança eletrônica utilizada. Com exceção dos casos indicados, todos as medidas referem-se a determinação de perda de massa após 1 lixa ter sido utilizada.

Nos ensaios utilizando vidro como abrasivo serão encontradas determinações que correspendem a um número maior de lixas, para os seguintes materiais:

- aço AISI 52100 temperado e revenido $500{ }^{\circ} \mathrm{C} / 24 \mathrm{~h}$,

- aço AISI 52100 temperado e revenido $500{ }^{\circ} \mathrm{C} / 90 \mathrm{~min}$ e;

- ferro fundido branco de alto cromo. 
Tabela B.1 - Valores de perda de massa individuais [mg] para o aço AISI 1006, em ensaios utilizando vidro como material abrasivo.

\begin{tabular}{|c|c|c|}
\hline \multirow{2}{*}{ Medida } & \multicolumn{2}{|c|}{ Perda de massa [mg] } \\
\hline & Lixa grana \#80 & Lixa grana \#240 \\
\hline 1 & 13,7 & 3,5 \\
\hline 2 & 11,9 & 4,1 \\
\hline 3 & 12,1 & 3,9 \\
\hline 4 & 12,7 & 4,4 \\
\hline 5 & 13,3 & 4,3 \\
\hline 6 & 13,2 & 4,1 \\
\hline 7 & 13,5 & 3,8 \\
\hline 8 & 13,3 & 3,8 \\
\hline 9 & 11,7 & 4,0 \\
\hline 10 & 12,3 & 4,3 \\
\hline 11 & 13,0 & 4,0 \\
\hline 12 & 12,6 & 4,1 \\
\hline 13 & 14,3 & 3,8 \\
\hline 14 & 12,6 & \\
\hline 15 & 12,3 & \\
\hline 16 & 14,2 & \\
\hline 17 & 13,5 & \\
\hline 18 & 13,3 & \\
\hline 19 & 14,2 & \\
\hline Média & $13,0 \pm 0,8$ & $4,0 \pm 0,2$ \\
\hline
\end{tabular}

Tabela B.2 - Valores de perda de massa individuais [mg] para o aço AISI 52100 recozido, em ensaios utilizando vidro como material abrasivo.

\begin{tabular}{|c|c|c|}
\hline \multirow{2}{*}{ Medida } & \multicolumn{2}{|c|}{ Perda de massa [mg] } \\
\cline { 2 - 3 } & Lixa grana \#80 & Lixa grana \#240 \\
\hline 1 & 7,0 & 2,1 \\
\hline 2 & 6,8 & 2,1 \\
\hline 3 & 6,7 & 2,2 \\
\hline 4 & 6,7 & 2,3 \\
\hline 5 & 6,8 & 2,2 \\
\hline 6 & 6,7 & 2,0 \\
\hline 7 & 6,5 & 2,2 \\
\hline 8 & & 2,2 \\
\hline Média & $6,8 \pm 0,2$ & $2,1 \pm 0,1$ \\
\hline
\end{tabular}


Tabela B.3 - Valores de perda de massa individuais [mg] para o aço AISI

52100 trefilado, em ensaios utilizando vidro como material abrasivo.

\begin{tabular}{|c|c|c|}
\hline \multirow{2}{*}{ Medida } & \multicolumn{2}{|c|}{ Perda de massa [mg] } \\
\cline { 2 - 3 } & Lixa grana \#80 & Lixa grana \#240 \\
\hline 1 & 6,4 & 1,7 \\
\hline 2 & 7,1 & 1,7 \\
\hline 3 & 6,8 & 1,9 \\
\hline 4 & 7,0 & 1,7 \\
\hline 5 & 6,7 & 2,0 \\
\hline 6 & 6,6 & 1,9 \\
\hline 7 & 6,9 & 1,7 \\
\hline 8 & 6,7 & 2,0 \\
\hline 9 & 6,3 & 2,0 \\
\hline 10 & 6,3 & 1,7 \\
\hline 11 & 7,3 & 1,7 \\
\hline 12 & 7,2 & 1,8 \\
\hline 13 & 7,3 & 1,9 \\
\hline 14 & 6,7 & 1,7 \\
\hline 15 & 6,5 & 2,0 \\
\hline 16 & 6,8 & 1,9 \\
\hline 17 & & 1,7 \\
\hline 18 & & 2,0 \\
\hline 19 & & 2,0 \\
\hline 20 & & $1,8 \pm 0,1$ \\
\hline Média & & \\
\hline & & \\
\hline & & \\
\hline & & \\
\hline
\end{tabular}

Tabela B.4 - Valores de perda de massa individuais [mg] para o aço AISI 52100 trefilado, em ensaios utilizando alumina como material abrasivo.

\begin{tabular}{|c|c|}
\hline Medida & $\begin{array}{c}\text { Perda de massa [mg] } \\
\text { Lixa grana \#220 }\end{array}$ \\
\hline 1 & 8,7 \\
\hline 2 & 8,6 \\
\hline 3 & 8,7 \\
\hline 4 & 8,6 \\
\hline 5 & 8,5 \\
\hline 6 & 8,5 \\
\hline 7 & 9,0 \\
\hline Média & $8,6 \pm 0,2$ \\
\hline
\end{tabular}


Tabela B.5 - Valores de perda de massa individuais [mg] para o aço AISI 52100 temperado e revenido $500{ }^{\circ} \mathrm{C} / 24 \mathrm{~h}$, em ensaios utilizando vidro como material abrasivo.

\begin{tabular}{|c|c|c|}
\hline \multirow{2}{*}{ Medida } & \multicolumn{2}{|c|}{ Perda de massa [mg] } \\
\cline { 2 - 3 } & Lixa grana \#80 & Lixa grana \#240 (4 lixas) \\
\hline 1 & 2,2 & 0,33 \\
\hline 2 & 2,5 & 0,33 \\
\hline 3 & 2,9 & 0,33 \\
\hline 4 & 2,5 & 0,35 \\
\hline 5 & 2,4 & 0,35 \\
\hline 6 & 3,0 & 0,35 \\
\hline 7 & 3,1 & 0,35 \\
\hline 8 & 3,2 & \\
\hline 9 & 3,4 & \\
\hline 10 & 3,0 & \\
\hline 11 & 3,3 & \\
\hline 12 & 3,3 & $0,34 \pm 0,01$ \\
\hline Média & $2,9 \pm 0,4$ & \\
\hline
\end{tabular}

Tabela B.6 - Valores de perda de massa individuais [mg] para o aço AISI 52100 temperado e revenido $500{ }^{\circ} \mathrm{C} / 90 \mathrm{~min}$, em ensaios utilizando vidro como material abrasivo.

\begin{tabular}{|c|c|}
\hline Medida (2 lixas) & $\begin{array}{c}\text { Perda de massa [mg] } \\
\text { Lixa grana \#80 }\end{array}$ \\
\hline 1 & 1,00 \\
\hline 2 & 0,90 \\
\hline 3 & 0,95 \\
\hline 4 & 0,95 \\
\hline 5 & 0,90 \\
\hline 6 & 1,00 \\
\hline 7 & 0,95 \\
\hline Média & $0,95 \pm 0,04$ \\
\hline
\end{tabular}


Tabela B.7 - Valores de perda de massa individuais [mg] para o ferro fundido branco de alto cromo, em ensaios utilizando vidro como material abrasivo.

\begin{tabular}{|c|c|}
\hline Medida (=5 lixas) & $\begin{array}{c}\text { Perda de massa }[\mathrm{mg}] \\
\text { Lixa grana } \# 80\end{array}$ \\
\hline 1 & 0,23 \\
\hline 2 & 0,23 \\
\hline 3 & 0,23 \\
\hline 4 & 0,21 \\
\hline 5 & 0,21 \\
\hline 6 & 0,22 \\
\hline 7 & 0,22 \\
\hline 8 & 0,21 \\
\hline 9 & 0,21 \\
\hline 10 & 0,22 \\
\hline 11 & 0,22 \\
\hline 12 & 0,23 \\
\hline Média & $0,22 \pm 0,01$ \\
\hline
\end{tabular}

Tabela B.8 - Valores de perda de massa individuais [mg] para o ferro fundido branco de alto cromo, em ensaios utilizando alumina como material abrasivo.

\begin{tabular}{|c|c|}
\hline Medida & $\begin{array}{c}\text { Perda de massa }[\mathrm{mg}] \\
\text { Lixa grana \#220 }\end{array}$ \\
\hline 1 & 13,6 \\
\hline 2 & 13,0 \\
\hline 3 & 12,4 \\
\hline 4 & 12,2 \\
\hline 5 & 12,3 \\
\hline 6 & 12,1 \\
\hline 7 & 13,3 \\
\hline 8 & 11,8 \\
\hline 9 & 12,6 \\
\hline 10 & 13,5 \\
\hline 11 & 12,6 \\
\hline 12 & 13,0 \\
\hline 13 & 12,9 \\
\hline 14 & 13,5 \\
\hline 15 & 13,6 \\
\hline Média & $12,8 \pm 0,6$ \\
\hline
\end{tabular}


Tabela B.9 - Valores de perda de massa individuais [mg] para o aço AISI 52100 bruto de têmpera, em ensaios utilizando alumina como material abrasivo.

\begin{tabular}{|c|c|}
\hline Medida & $\begin{array}{c}\text { Perda de massa }[\mathrm{mg}] \\
\text { Lixa grana \#220 }\end{array}$ \\
\hline 1 & 6,4 \\
\hline 2 & 6,1 \\
\hline 3 & 6,1 \\
\hline 4 & 6,1 \\
\hline 5 & 6,0 \\
\hline 6 & 5,7 \\
\hline 7 & 5,9 \\
\hline 8 & 6,2 \\
\hline 9 & 5,7 \\
\hline Média & $6,0 \pm 0,2$ \\
\hline
\end{tabular}

Tabela B.10 - Valores de perda de massa individuais [mg] para o aço AISI 52100 bruto de têmpera seguido de tratamento sub-zero, em ensaios utilizando alumina como material abrasivo.

\begin{tabular}{|c|c|}
\hline Medida & $\begin{array}{c}\text { Perda de massa [mg] } \\
\text { Lixa grana \#220 }\end{array}$ \\
\hline 1 & 5,7 \\
\hline 2 & 5,8 \\
\hline 3 & 6,1 \\
\hline 4 & 5,9 \\
\hline 5 & 5,8 \\
\hline 6 & 5,7 \\
\hline 7 & 6,3 \\
\hline Média & $5,9 \pm 0,2$ \\
\hline
\end{tabular}




\section{ANEXO C - Curvas dos valores médios de coeficiente de atrito}

As Figuras C.1 a C.4 apresentam a evolução do coeficiente de atrito com o tempo de ensaio para o aço AISI 52100 nas condições recozido, trefilado, temperado e revenido a $500{ }^{\circ} \mathrm{C} / 24 \mathrm{~h}$ e temperado e revenido a $500{ }^{\circ} \mathrm{C} / 90 \mathrm{~min}$, respectivamente. Todas as curvas foram construídas considerando a média de 3 ensaios.

A Figura C.5 mostra a evolução do coeficiente de atrito para o ferro fundido.

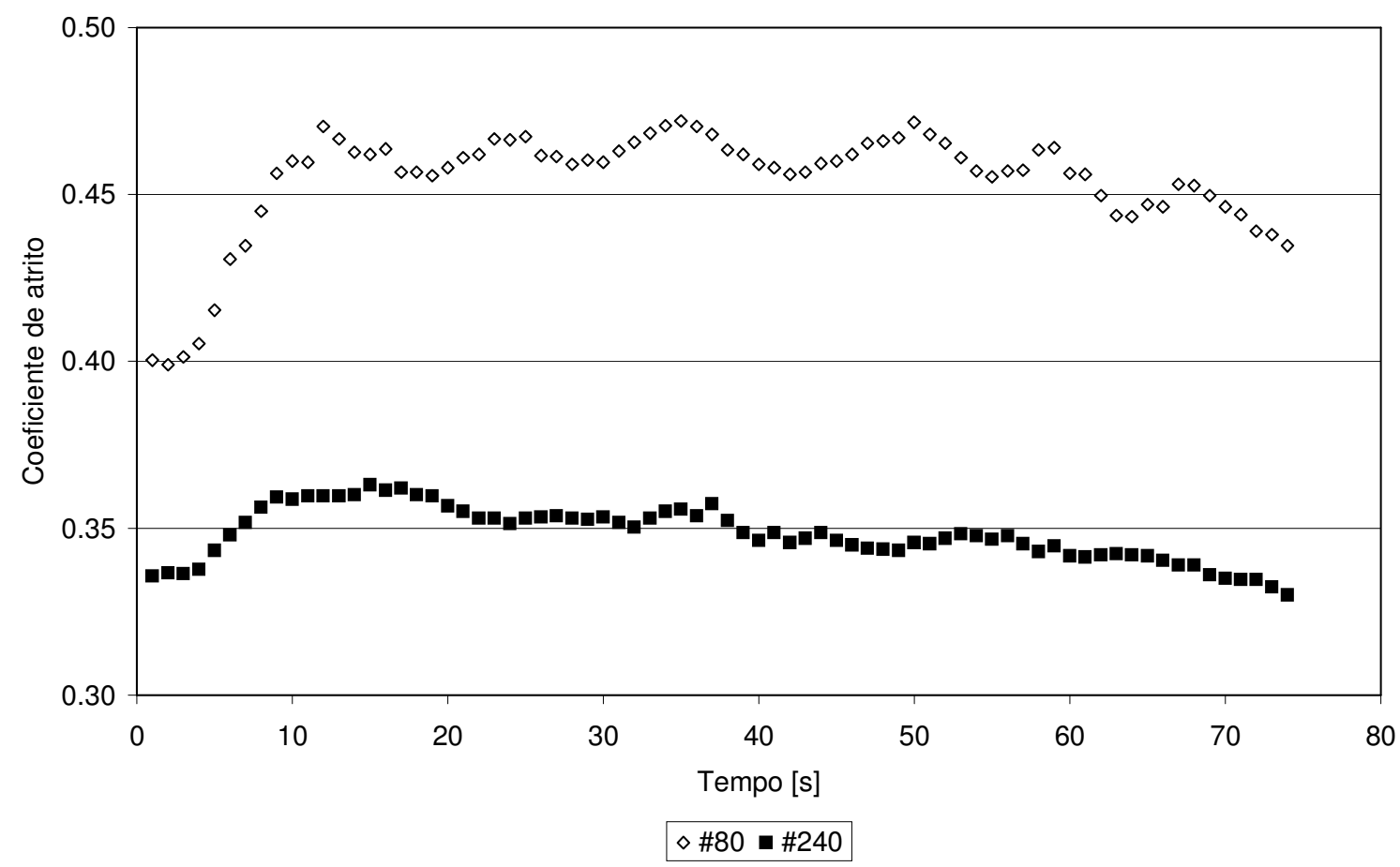

Figura C.1. Evolução do coeficiente de atrito com o tempo de ensaio [s] para o aço AISI 52100 recozido. 


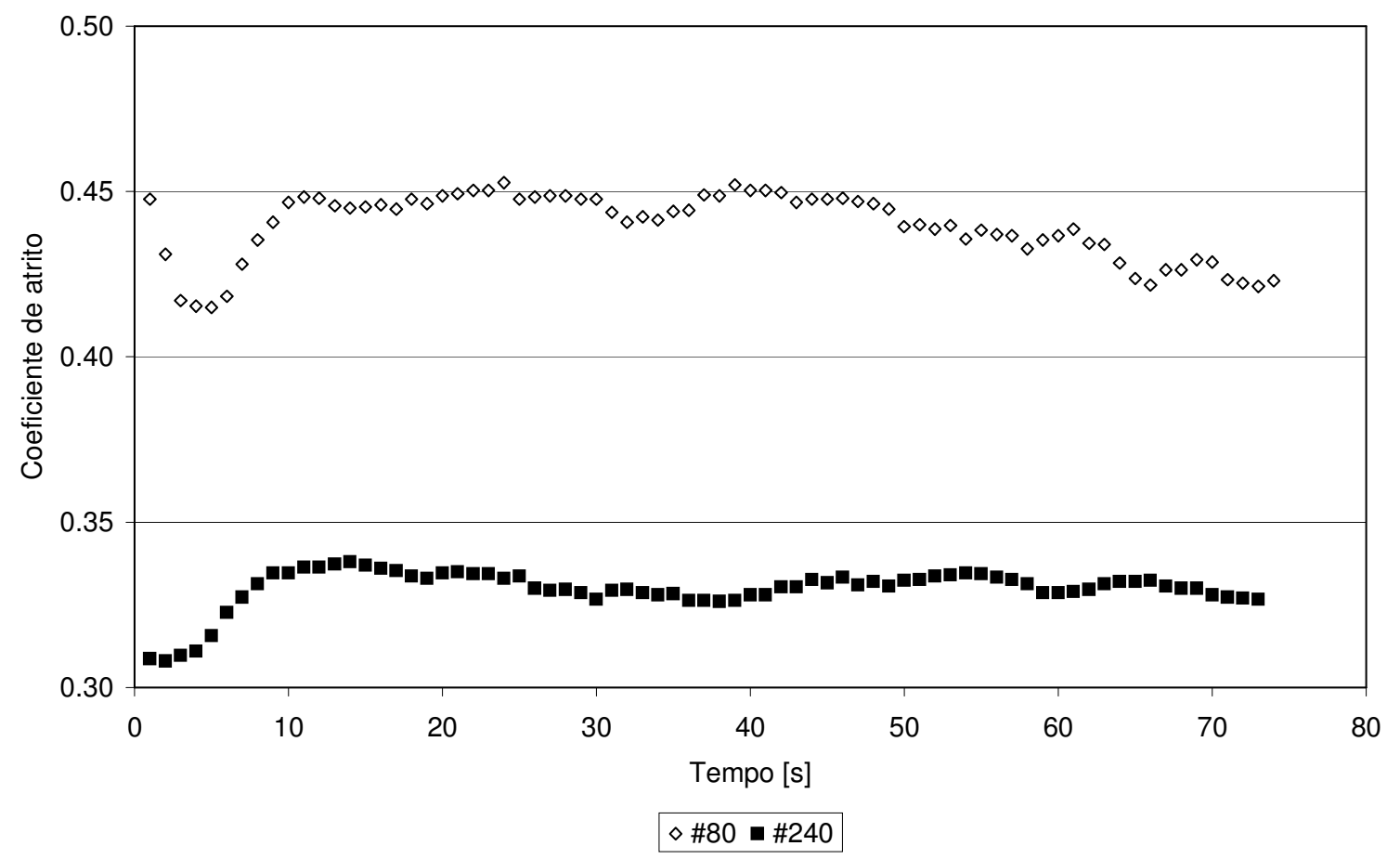

Figura C.2. Evolução do coeficiente de atrito com o tempo de ensaio [s] para o aço AISI 52100 trefilado.

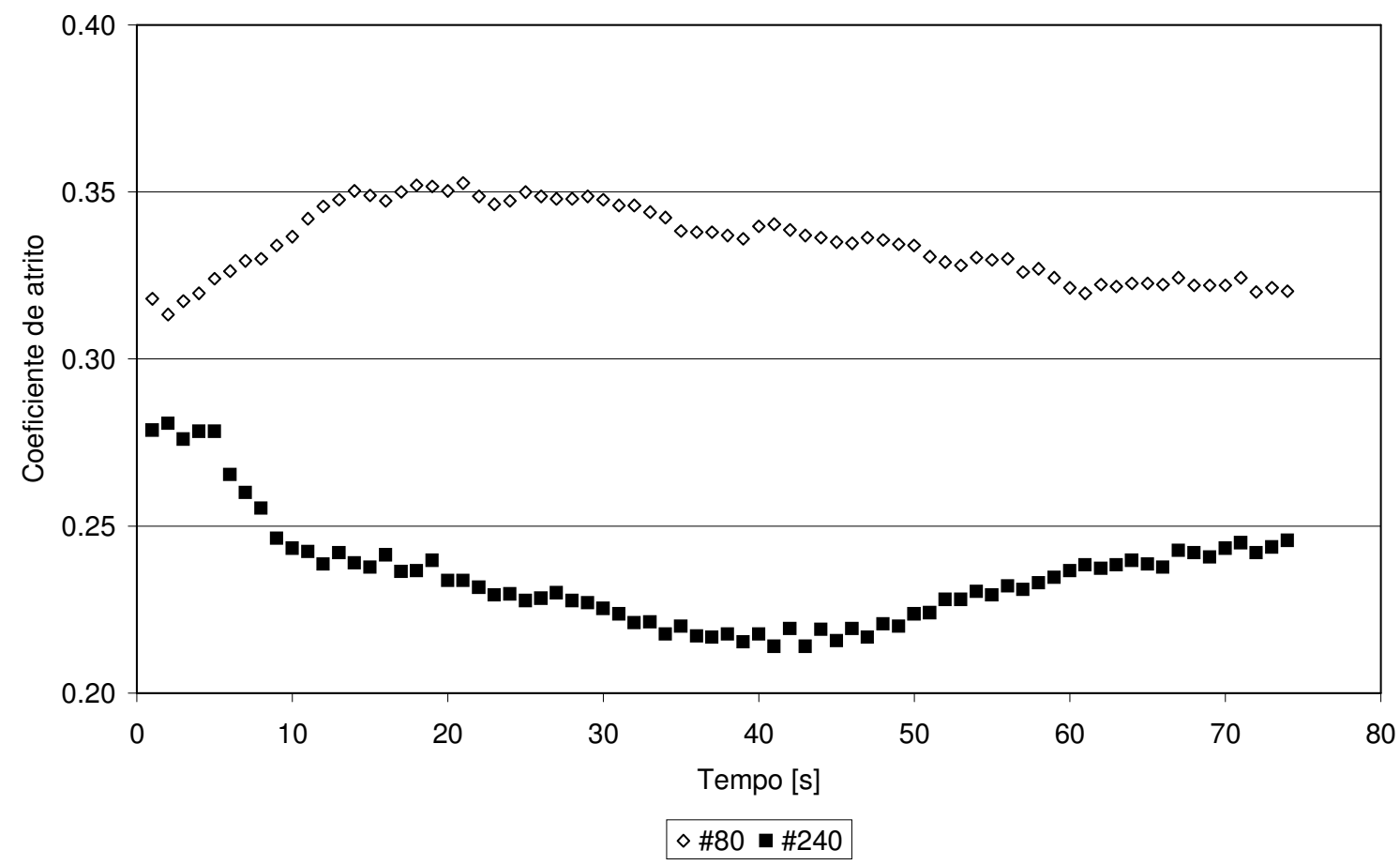

Figura C.3. Evolução do coeficiente de atrito com o tempo de ensaio [s] para o aço AISI 52100 temperado e revenido $500{ }^{\circ} \mathrm{C} / 24 \mathrm{~h}$. 


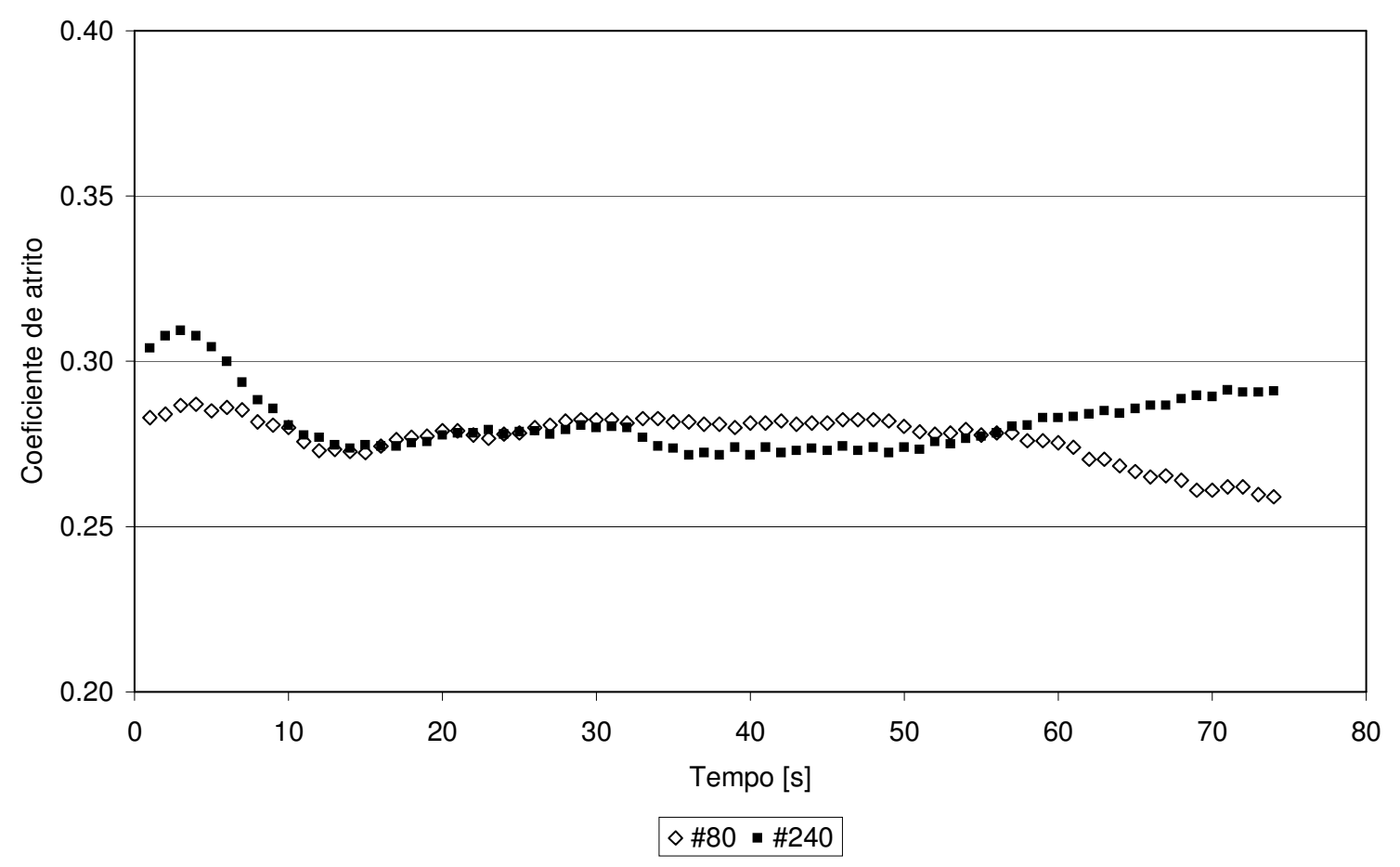

Figura C.4. Evolução do coeficiente de atrito com o tempo de ensaio [s] para o aço AISI 52100 temperado e revenido $500{ }^{\circ} \mathrm{C} / 90 \mathrm{~min}$.

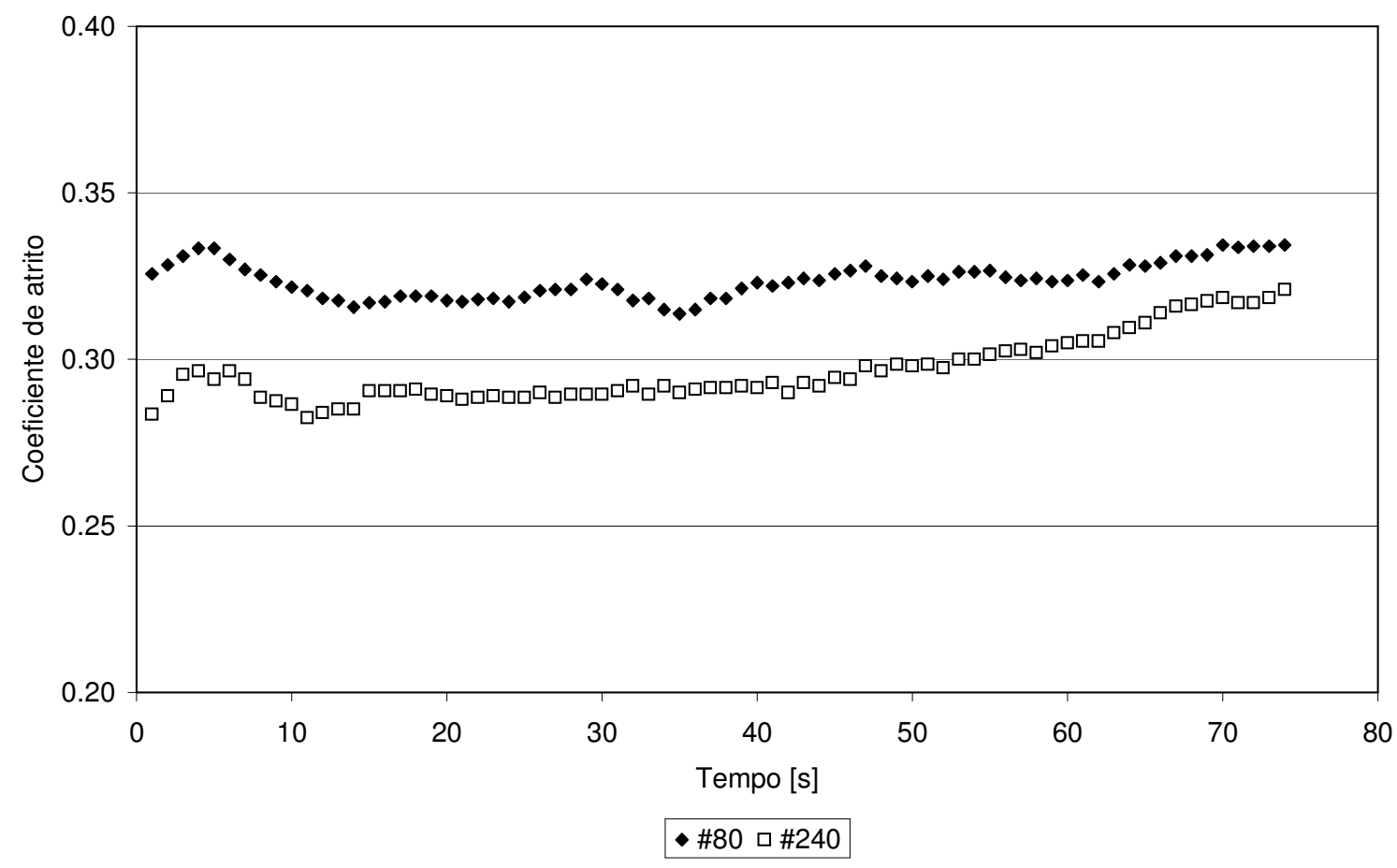

Figura C.5. Evolução do coeficiente de atrito com o tempo de ensaio [s] para o ferro fundido branco de alto cromo. 


\section{REFERÊNCIAS BIBLIOGRÁFICAS}

ABRAHÃO, A.; LÉPORE NETO, F.P.; DE MELLO, J.D.B. Automatização de ensaios esclerométricos, In: IV Seminário de Desgaste (Desgaste e Proteção), São Paulo, 1998, Anais, ABM, São Paulo, 1998, p. 539-53.

ALBERTIN, E.; SINATORA, A. Effect of carbide fraction and matrix microstructure on the wear of cast ion balls tested in a laboratory ball mill, Wear, v. 250, p. 492-501, 2001.

ALCALÁ, J.; BARONE, A. C.; ANGLADA, M. The influence of plastic hardening on surface deformation modes around Vickers and spherical indents, Acta Materialia, v. 48, p. 3451-64, 2000.

ABNT - Associação Brasileira de Normas Técnicas. NBR 11094 - Grãos abrasivos aplicados em lixas - Ensaios. Rio de Janeiro, Brasil, 1990.

ABNT - Associação Brasileira de Normas Técnicas. NBR 13818 - Placas cerâmicas para revestimento - Especificação e métodos de ensaios. Rio de Janeiro, Brasil, 1997.

ASTM - American Standard for Testing Materials. E384-99e1 Standard Test Method for Microindentation Hardness of Materials. Annual Book of ASTM Standards Volume 03.01: Metals--Mechanical Testing; Elevated and LowTemperature Tests; Metallography. Philadelphia, USA, 2001.

ASTM - American Standard for Testing Materials. G40-01 - Standard Terminology Relating to Wear and Erosion. Annual Book of Standards Volume 03.02: Wear and Erosion; Metal Corrosion. Philadelphia, USA, 2001.

ASTM - American Standard for Testing Materials. G65-00e1 - Test Method for Measuring Abrasion using the Dry Sand/Rubber Wheel Apparatus. Annual Book of Standards Volume 03.02: Wear and Erosion; Metal Corrosion. Philadelphia, USA, 2001.

ASTM - American Standard for Testing Materials. G81-97a - Standard Test Method for Jaw Crusher Gouging Abrasion Test. Annual Book of Standards Volume 03.02: Wear and Erosion; Metal Corrosion. Philadelphia, USA, 2001.

ASTM - American Standard for Testing Materials. G99-95a(2000)e1 Standard Test Method for Wear Testing with a Pin-on-Disk Apparatus. Annual Book of Standards Volume 03.02: Wear and Erosion; Metal Corrosion. Philadelphia, USA, 2001. 
ASTM - American Standard for Testing Materials. G132-96 Standard Test Method for Pin Abrasion Testing. Annual Book of Standards Volume 03.02: Wear and Erosion; Metal Corrosion. Philadelphia, USA, 2001.

ATKINS, A.G. Toughness in wear and grinding, Wear, v. 61, p. 183-190, 1980.

AVERY, H. S. Work hardening in relation to abrasion resistance, In: Materials for the Mining Industry, Vail, Colorado, 1974. Proceedings. Barr, R. Q., ed. Climax Molybdenum, pp. 43-77.

BATISTA, J.C.A.; JOSEPH, M.C.; GODOY, C.; MATTHEWS, A. Micro-abrasion wear testing of PVD TiN coatings on untreated and plasma nitrided AISI H13 steel, Wear, v. 249, p. 971-979, 2002.

BERNS, H. Comparison of wear resistant MMC and white cast iron, In: XIV Congresso Brasileiro de Engenharia Mecânica, COBEM 2001, Uberlândia; Anais (CD). ABCM, 2001.

BERNS, H.; WEWERS, B. Development of an abrasion resistant steel composite with in situ TiC particles, Wear, v. 251, p. 1386-95, 2001.

BERNS, H.; FRANCO, S.D. Effect of coarse hard particles on high-temperature sliding abrasion of new metal matrix composites, Wear, v. 203-204, p. 608-614, 1997.

BHATTACHARYA, A. K.; NIX, W. D. Analysis of elastic and plastic deformation associated with indentation testing of thin films on substrates, Int. J. of Solids Structures, v. 24, p. 1287-98, 1988.

BISHOP, R.F.; HILL, R.; MOTT, N. F. The theory of indentation and hardness tests, The Proc. of the Physical Soc., v. 57, p. 147-159, 1945.

BLAU, P.J. The significance and use of the friction coefficient, Tribology Int., v.34, p. 585-91, 2001.

BLAU, P.J. Microhardness indentation testing, In: ASM Handbook v. 18. Friction, Lubrication and Wear Technology, 1992. ASM International, p. 414-8.

BLICKENSDERFER, R.; MADSEN, B.W.; TYLZAC, J.H. Comparison of several types of abrasive wear tests. In: In: Wear of Materials Conference, 1985, Proceedings, Ludema, K. C., ed., ASME p.313-23.

BORIK, F., SCHOLZ, W. G. Gouging abrasion test for materials used in ore and rock crushing, Part II - Effect of metallurgical variables on gouging wear. J. of Materials, v. 6, p. 591-605, 1971.

BOZZI, A. C.; SANTANA, S. A.; DE MELLO, J.D.B. Comparação da performance de recobrimentos de WC-12\%Co depositados por "spray" térmico e a de ferros fundidos brancos de alto cromo em ensaios de abrasão a três corpos, In: IV Seminário de Desgaste (Desgaste e Proteção), Anais, ABM, São Paulo, 1998, p. 1-13. 
BOZZI, A. C.; DE MELLO, J.D.B. Wear resistance and wear mechanisms of WC$12 \%$ Co thermal sprayed coatings in three-body abrasion, Wear, v. 233-235, p. 575-87, 1999.

BÜCKLE, H. Progress in microhardness testing, Metallurgical Review, v. 4, p. 49-100, 1959.

BULSARA, V.H. et al. Mechanics of polishing, J. Applied Mechanics, v. 65, p. 410-6, 1998.

BUTTERY, T.C.; ARCHARD, J.F. Grinding and abrasive wear, Proc. Inst. Mech. Eng., v. 185, p. 537-51, 1970/71.

CHAUDHRI, M.M.; WINTER, M. The load-bearing area of a hardness indentation, J. Phys. D: Applied Phys., v. 21, p. 370-4, 1988.

CHAWLA, K.K. Ceramic matrix composites, Chapman \& Hall, New York, 1993.

CHIANG, S. S.; MARSHAL, D.B.; EVANS, A.G. The response of solids to elastic/plastic indentation: I. Stresses and residual stresses, J. Applied Phys., v. 53, p. 298-311, 1982.

COOK, R.F.; PHARR, G. M. Direct observation and analysis of indentation cracking in glasses and ceramics, J. of American Ceramic Soc., v. 73, p. 787-817, 1990.

CSM INSTRUMENTS, Nanoindentation Reference Manual, Switzerland, 36 p., 2002.

DA SILVA, C.H.; TANAKA, D.K.; SINATORA, A. The effect of load and relative humidity on friction coefficient between high density polyethylene on galvanized steel - preliminary results, Wear, v. 225-229, Part 1, p. 339-42, 1999.

DIETER, G. Mechanical Metallurgy, McGraw-Hill, New York, 1976.

DOERNER, M.F.; NIX, W. D. A method for interpreting the data from depth-sensing indentation instruments, J. Mater. Research, v. 1, p. 601-9, 1986.

EVANS, A.G.; WILSHAW, T.R. Quasi-static solid particle damage in brittle solids - I. Observations, analysis and implications, Acta Metallurgica, v. 24, p. 939-56, 1976.

EVANS, J. T.; BUDD, S. M. A model of the effect of abrasion on the strength of glass, Glass Technology, v. 35, p. 48-52, 1994.

FARIAS; M.C.M; SINATORA, A. Desgaste por deslizamento de aços inoxidáveis austeníticos, Boletim Técnico da Escola Politécnica da USP, v. BT/PMC/151, 1999. 
FERREIRA, V.; DA SILVA, C.H.; BRESSIANI, J.C.; SINATORA, A. A influência da umidade relativa no coeficiente de atrito da alumina e do compósito $\mathrm{Al}_{2} \mathrm{O}_{3^{-}}$ YAG-NbC, In: XIV Congresso Brasileiro de Engenharia Mecânica, COBEM 2001, Uberlândia; Anais (CD). ABCM, 2001.

FINKIN, E. F. Examination of abrasion resistance criteria for some ductile metals, J. Lubrication Technology, v. 96, p.210-4, 1974.

FRANCO, S.D.; PÉLIZER, M.C.; SOARES, A.B. Desenvolvimento e construção de um microesclerômetro/microdurômetro totalmente informatizado para altas temperaturas, In: XIV Congresso Brasileiro de Engenharia Mecânica, COBEM 2001, Uberlândia; Anais (CD). ABCM, 2001.

FRANCO, S.D.; SINATORA, A. Determinação da tenacidade à fratura de carbonetos $\mathrm{M}_{7} \mathrm{C}_{3}$ usando o método da indentação, In: XI Congresso Brasileiro de Engenharia e Ciência dos Materiais, Águas de São Pedro, 1994, Anais, p. 24750 .

FRÖLICH, F.; GRAU, P.; GRELLMANN, W. Performance and analysis of recording microhardness tests, Physica Status Solidi A, v. 42, p. 79-89, 1977.

GAHLIN, R.; JACOBSON, S. The particle size effect in abrasion studied by controlled abrasive surfaces, Wear, v. 224, p. 118-125, 1999.

GATES, J.D. Two-body and three-body abrasion: a critical discussion, Wear, 214, p. 139-146, 1998.

GIANNAKOPULOS, A. E.; SURESH, S. Determination of elastoplastic properties by instrumented sharp indentation, Scripta Materialia, v. 40, p. 1191-8, 1999.

GODDARD, J.; WILMAN, H. A theory of friction and wear during the abrasion of metals, Wear, v. 5, p. 114-35, 1962.

GONÇALVES, R. A. et al. Determination of Mohs hardness of glazed tiles by scratching tests, In: Qualicer 2000, 2000, Proceedings, Castellon, Spain.

GREENWOOD, J. A.; WILLIAMSON, J. B. P. Contact of nominally flat rough surfaces, Proc. Royal Soc. London A, v. 295, p. 300-319, 1966.

GUNDLACH, R.B.; PARKS, J.L. Influence of abrasive hardness on wear resistance of high-chromium irons, In: Wear of Materials Conference, 1977, Proceedings, Glaeser, W.A.; Ludema, K.C.; Rhee, S.K., eds., ASME, p. 211-6.

HIBBS, M.K.; SINCLAIR, R. Room-temperature deformation mechanims and the defect structure of tungsten carbide, Acta Metallurgica, v. 29, p. 1645-54, 1981.

HILL, R.; LEE, E.H.; TUPPER, S.J. The theory of wedge indentation of ductile metals, Proc. Royal Soc. London A, v. 188, p. 273-89, 1947. 
HIRAO, K.; TOMOZAWA, M. Microhardness of $\mathrm{SiO}_{2}$ glass in various enviroments, J. of American Ceramic Soc., v. 70, p. 497-502, 1987.

HIRST, W.; HOWSE, M.G.J.W. The indentation of materials by wedges, Proc. Royal Soc. London A, v. 311, p. 429-44, 1969.

HOKKIRIGAWA, K.; KATO, K.; LI, Z.Z. The effect of hardness on the transition of the abrasive wear mechanism of steels, Wear, v. 123, p. 241-51, 1987.

HUTCHINGS, I.M. Tribology - Friction and Wear of Engineering Materials, London, Edward Arnold, 1992.

ION, R. H.; POLLOCK, H. M.; ROQUES-CARMES, C. Micron-scale indentation of amorphous and drawn P.E.T. surfaces, J. Mater. Science, v. 25, p. 1444-54, 1990.

ISO - International Organization for Standardization. ISO 6506-1 - Metallic materials Brinell hardness test - Part 1: Test method. Geneva, Switzerland, 1999.

ISO - International Organization for Standardization. ISO 6507-1 - Metallic materials Vickers hardness test - Part 1: Test method. Geneva, Switzerland, 1997.

ISO - International Organization for Standardization. ISO 6508-1 - Metallic materials Rockwell hardness test - Part 1: Test method (scales A, B, C, D, E, F, G, H, K, N, T). Geneva, Switzerland, 2002.

ISO - International Organization for Standardization. ISO/FDIS 14577-1 - Metallic materials - Instrumented indentation test for hardness and material parameter - Part 1: Test method. Geneva, Switzerland, 2002.

JACOBSSON, S.; OLSSON, M.; HEDENQVIST, P.; VINGSBO, O. Scratch Testing, In: ASM Handbook v. 18. Friction, Lubrication and Wear Technology, 1992. ASM International, p. 430-7.

JAHANMIR, S.; SUH, N. P.; ABRAHAMSON, E. P. Microscopic observations of the wear sheet formation by delamination, Wear, v. 28, p. 235-49, 1974.

JAYARAM, V. et al. Plastic deformation of WC-Co at high confining pressure, Scripta Metallurgica, v. 20, p. 701-5, 1986.

JOHNSON, K. L. The correlation of indentation experiments, J. Mech. Physics Solids, v. 18 , p. 115-26, 1970.

JOHNSON, W.; SOWERBY, R.; HADDOW, J. B. Plane-strain slip-line fields: theory and bibliography, London, Edward Arnold Ltd., 1970.

KAYABA, T.; HOKKIRIGAWA, K.; KATO, K. Analysis of the abrasive wear mechanism by sucessive observations of wear processes in a scanning electron microscope, Wear, v. 110, p. 419-30, 1986. 
KING, R. B. Elastic analysis of some punch problems for a layered medium, Int. J. of Solids Structures, v. 23, p. 1657-64, 1987.

KRUSCHOV, M.M. Resistance of metals to wear by abrasion as related to hardness, In: Conference on Lubrication and Wear, London, 1957, Proceedings, Institution of Mechanical Engineering, p. 655-9.

JOSLIN, D.L.; OLIVER, W.C. A new method for analyzing data from continuous depth-sensing microindentation tests, J. Mater. Research, v. 5, p. 123-6, 1990.

LARSEN-BASSE, J. The abrasion resistance of some hardened and tempered carbon steels, Trans. of AIME, v. 236, p.1461-6, 1966.

LARSEN-BASSE, J. Abrasion mechanism - delamination to machining, In: Conference on Fundamentals of Tribology; Massachusetts, 1978. Proceedings. Suh, N.P., Saka, N., eds., 1983, p. 679-89.

LARSEN-BASSE, J. Success and failure of simple models for abrasive wear, In: ASTM STP 1105 - Tribological modeling for mechanical designers, Proceedings, Ludema, K.C.; Bayer, R.G., eds., ASTM, 1991, p. 51-62.

LARSEN-BASSE, J.; KOYANAGI, E.T.; Abrasion of WC-Co alloys by quartz, J. Lubrication Technology, v. 101, p. 208-211, 1979.

LARSEN-BASSE, J.; PREMARATNE, B. Effect of relative hardness on transitions in abrasive wear mechanisms, In: Wear of Materials Conference, 1983, Proceedings, Ludema, K.C., ed., ASME, 1983, p. 161-6.

LAWN, B.R.; EVANS, A.G.; MARSHALL, D.B. Elastic/plastic indentation damage in ceramics: the median/radial crack system, J. of American Ceramic Soc., v. 63, p. $574-81,1980$.

LAWN, B. R.; MARSHALL, D.B. Hardness, toughness and brittleness: an indentation analysis, J. of American Ceramic Soc., v. 62, p. 347-350, 1979.

LAWN, B. R.; SWAIN, M. V. Microfracture beneath point indentations in brittle solids, J. Mat. Science, v. 10, p. 2016-24, 1975.

LEYLAND, A.; MATTHEWS, A. On the significance of the H/E ratio in wear control: a nanocomposite coating approach to optimised tribological behaviour, Wear, v. 246, 2000, p. 1-11.

LI, H.; GHOSH, A.; HAN, Y.H.; BRADT, R.C. The frictional component of the indentation size effect in low load microhardness testing, J. Mater. Research, v. 8, p. 1028-32, 1993.

MARSH, D. M. Plastic flow in glass, Proc. Royal Soc. of London A, v. 279, p. 420-35, 1964. 
MARSHALL, D.B.; NOMA, T.; EVANS, A.G. A simple method for determining elastic-modulus-to-hardness ratios using Knoop indentation measurements, J. of American Ceramic Soc., v. 65, p. C-175 e C-176, 1982.

MATSUBARA, Y.; ALBERTIN, E., BOCCALINI Jr., M. Multi-component white cast iron for hot working roll, In: $49^{\circ}$ Congresso Anual da ABM, São Paulo, 1994, Anais, ABM, p. 1-10.

MCCOLM, I.J. Ceramic Hardness, Plenum Press, New York, 1990.

MEDEIROS, J. T. N. Fadiga de contato de discos metálicos não-conformes submetidos a ensaios a seco de rolamento cíclico. São Paulo, 2002. 501 p. Tese (Doutorado) - Escola Politécnica, Universidade de São Paulo.

MEYERS, M. A.; CHAWLA, K.K. Mechanical Behavior of Materials, Prentice-Hall, New Jersey, 1999.

MISRA, A.; FINNIE, I. A classification of three-body abrasive wear and design of a new tester, Wear, 60, p. 111-21, 1980.

MISRA, A.; FINNIE, I. Some observations on two-body abrasive wear, Wear, 68, p. 41-56, 1981.

MOORE, M. A. Abrasive wear, In: Fundamentals of Friction and Wear of Materials, Pittsburgh, PA, 1980, Proceedings. Rigney, D. A., ed., ASM, p. 73-118.

MOORE, M. A.; KING, F. S. Abrasive wear of brittle solids, Wear, v. 60, p. 123-40, 1980.

MOROZ, P.J. The effects of matrix hardness and microstructure on the wear of steel grinding balls during wet iron ore (magnetite) grinding; In: Intermountain Minerals Symposium, Vail, Colorado, 1982, Proceedings. Barr, R.Q., Doane, D.V. e Miska, K.H.; eds, pp. 63-78.

MULHEARN, T.O.; SAMUELS, L.E. The abrasion of metals: a model of the process, Wear, v. 5, p. 478-98, 1962.

MURRAY, M. J.; MUTTON, P. J., WATSON, J. D. Abrasive wear mechanisms in steels, J. Lubrication Technology, v. 104, p. 9-16, 1982.

MUSCARA, J.; SINNOTT, M. J. Construction and evaluation of a versatile abrasive wear testing apparatus, Metals Eng. Quartely, v. 12, p. 21-32, 1972.

MUTTON, P. J., WATSON, J. D. Some effects of microstructure on the abrasion resistance of metals, Wear, v. 48, p. 385-98, 1978.

NORBURY, A. L.; SAMUEL, T. The recovery and sinking-in or piling-up of material in the Brinell test, and the effects of these factors on the correlation of the Brinell with certain other hardness tests, J. of the Iron and Steel Institute, v. p. $673-87,1928$. 
OHMURA, T.; TSUZAKI, K.; MATSUOKA, S. Nanohardness measurement of highpurity Fe-C martensite, Scripta Materialia, v. 45, p. 889-894, 2001.

OLIVER, W.C., PHARR, G.M. An improved technique for determining hardness and elastic modulus using load and displacement sensing indentation experiments, J. Mater. Res., v. 7, p. 1564-83, 1992.

PINTAÚDE, G., FARIAS, M.C.M., KOHNLEIN, M., TANAKA, D.K., SINATORA, A., Desgaste abrasivo de ferramentas de corte na indústria madeireira - Estudo de caso, In: CONEM2000 - Congresso Nacional de Engenharia Mecânica, 07 a 11 de agosto de 2000, Natal - RN, Anais (CD).

PINTAÚDE, G.; SINATORA, A. Estudo do regime transiente em desgaste abrasivo Ensaios em britador de mandíbulas, Boletim Técnico da Escola Politécnica da USP, v. BT/PMC/125, 1998.

PINTAÚDE, G., TANAKA, D.K., SINATORA, A. Considerações sobre modelagem matemática em desgaste abrasivo controlado por deformação plástica, In: $2^{\circ}$ Congresso Internacional de Metalurgia e Materiais, ABM, São Paulo - SP, 12 a 17 de outubro de 1997, São Paulo - SP, Anais (CD).

PINTAÚDE, G., TANAKA, D.K., SINATORA, A. Effect of indentation size and microhardness calculation on abrasive wear severity, Scripta Materialia, v. 44, p. 659-63, 2001.

PINTAÚDE, G.; TSCHIPTSCHIN, A. P.; TANAKA, D.K.; SINATORA, A. The particle size effect on abrasive wear of high-chromium white cast iron mill balls, Wear, v. 250, p. 66-70, 2001.

RABINOWICZ, E.; DUNN, L. A.; RUSSEL, P.G. A study of abrasive wear under three-body conditions, Wear, v. 4, p. 345-55, 1961.

RICHARDSON, R.C.D. The maximum hardness of strained surfaces and the abrasive wear of metals and alloys, Wear, v. 10, p. 353-82, 1967.

RICHARDSON, R.C.D. The wear of metals by relatively soft abrasives, Wear, v. 11, p. 245-75, 1968.

RUTHERFORD, K.L.; HUTCHINGS, I. M. Theory and application of a micro-scale abrasive wear test, J. of Testing and Evaluation, v. 25, p. 250-60, 1997.

SARE, I.R., ARNOLD, B. K. Gouging abrasion of wear-resistant alloy white cast irons, Wear, v.131, p. 15-38, 1989.

SARGENT, P.M. Indentation size effect and strain-hardening, J. Mater. Sci. Letters, v. 8, p. 1139-40, 1989.

SILVA, W. G.; CUMINO, R. S.; GOLDENSTEIN, H. Obtenção de teores controlados de austenita retida em aço DIN $100 \mathrm{Cr} 6$ e seu efeito num ensaio de desgaste. In: $51^{\circ}$ Congresso Anual da ABM, Porto Alegre - RS, 5 a 9 de agosto de 1996. Anais, p. 459-476, v. 5. 
SIN, H.; SAKA, N.; SUH, N. P. Abrasive wear mechanisms and the grit size effect, Wear, v. 55, p. 163-190, 1979.

SINATORA, A.; BOCCALINI Jr, M., coord., Desafios e experiências em moldes para conformação de plásticos: materiais, processos e transformação. Anais, São Paulo: EPUSP, 1999, 142 p.

SINATORA, A.; BOCCALINI Jr, M., coord., Moldes para conformação de plásticos: projeto, construção, desempenho. Anais, São Paulo: EPUSP/IPT, 2000, 92 p.

SOUZA, S.A. Ensaios Mecânicos de Materiais Metálicos, Editora Edgard Blücher Ltda., São Paulo, 1982.

STELMASHENKO, N. A.; WALLS, M. G.; BROWN, L. M.; MILMAN, Y.V. Microindentations on W and Mo oriented single crystals: an STM study, Acta Metall. Materialia, v. 41, p. 2855-65, 1993.

STILWELL, N. A., TABOR, D. Elastic recovery of conical indentations, Proc. Phys. Soc. London, v. 78, p.169-79, 1961.

STEVENSON, A. N. J.; HUTCHINGS, I. M. Development of the dry sand / rubber wheel abrasion test, Wear, v. 195, p. 233-43, 1996.

STRANGE, D. J.; VARSHNEYA, A. K. Finite element simulation of microindentation on aluminum, J. of Materials Science, v. 36, p. 1943-9, 2001.

STROUD, M.F.; WILMAN, H. The proportion of the groove volume removed as wear in abrasion of metals, British J. of Applied Physics, v. 13, p. 173-7, 1962.

SUH, N. P. The delamination theory of wear, Wear, v. 25, p. 111-124, 1973.

SUNDARARAJAN, G. A new model for two-body abrasive wear based on the localization of plastic deformation, Wear, v. 117, p. 1-35, 1987.

SUSZYNSKA, M.; GRAU, P.; SZIMDA, M.; NOWAK-WOZNY, D. Correlated studies of Vickers hardness and the yield stress of $\mathrm{NaCl}$ crystals doped with $\mathrm{Ni2}+, \mathrm{Ca} 2+$ and $\mathrm{Eu} 2+$, Materials Science and Engineering A, v. 234-236, p. 747-50, 1997.

TABOR, D. The hardness and strength of metals, J. Inst. Metals, v. 79, p. 1-18, 1951.

TABOR, D. Moh's hardness scale - A physical interpretation, Proc. Phys. Soc. London B, v. 67, p. 249-57, 1954.

TABOR, D. The physical meaning of indentation and scratch hardness, British J. of Applied Physics, v. 7, p. 159-165, 1956.

TATE, D. R. A comparison of microhardness indentation tests, Trans. of the A.S.M., v. 35, p.374-83, 1945.

TAYLOR, J. L. Dicionário Metalúrgico, São Paulo, ABM, 1994. 
TORRANCE, A. A. The correlation of abrasive wear tests, Wear, v. 63, p. 359-70, 1980.

TREZONA, R.I.; ALLSOPP, D.N.; HUTCHINGS, I.M. Transitions between two-body and three-body abrasive wear: influence of test conditions in the microscale abrasive wear test, Wear, v. 225-229, p. 205-214, 1999.

VAN VLACK, L.H. Propriedades dos Materiais Cerâmicos, São Paulo, Editora Edgard Blücher Ltda., 1973.

WEILER, W. Hardness testing - a new method for economical and physically meaningful microhardness testing, The British J. of Non-Destructive Testing, v. 31, p.253-8, 1989.

WILDE, H-R.; WEHRSTEDT, A. Introduction of Martens Hardness HM, Materialprüfung, v. 42, p. 468-470, 2001.

XUAN, J.L.; HONG, I.T.; FITCH, E.C. Hardness effect on three-body abrasive wear under fluid film lubrication, J. of Tribology, v. 111, p. 35-40, 1989.

ZENG, K.; SÖDERLUNG, F.; GIANNAKOPOULOS, A. E.; ROWCLIFFE, D. J. Controlled indentation: a general approach to determine mechanical properties of brittle materials, Acta Materialia, v. 44, p. 1127-41, 1996.

ZUM GAHR, K.H. Microstructure and Wear of Materials - Tribology Series v. 10, Elsevier, Amsdertã, 1987. 